\title{
A CoMPREHENSIVE METABOLITE PROFILING OF ISATIS TINCTORIA LEAF EXTRACTS
}

\author{
Inauguraldissertation
}

\author{
Zur \\ Erlangung der Würde eines Doktors der Philosphie \\ vorgelegt der \\ Philosophisch-Naturwissenschaftlichen Fakultät \\ der Universität Basel
}

von

Tobias Mohn

aus IImenau

DEUTSCHLAND

Basel, 2009 
Genehmigt von der Philosophisch-Naturwissenschaftlichen Fakultät der Universität Basel auf Auftrag von:

Herrn Prof. Dr. Matthias Hamburger

Herrn Prof. Dr. Jean-Luc Wolfender (Korreferent)

Basel, den 24. März 2009

Prof. Dr. Eberhard Parlow

Dekan 
Meinen Eltern und Birgit in Liebe und Dankbarkeit gewidmet 



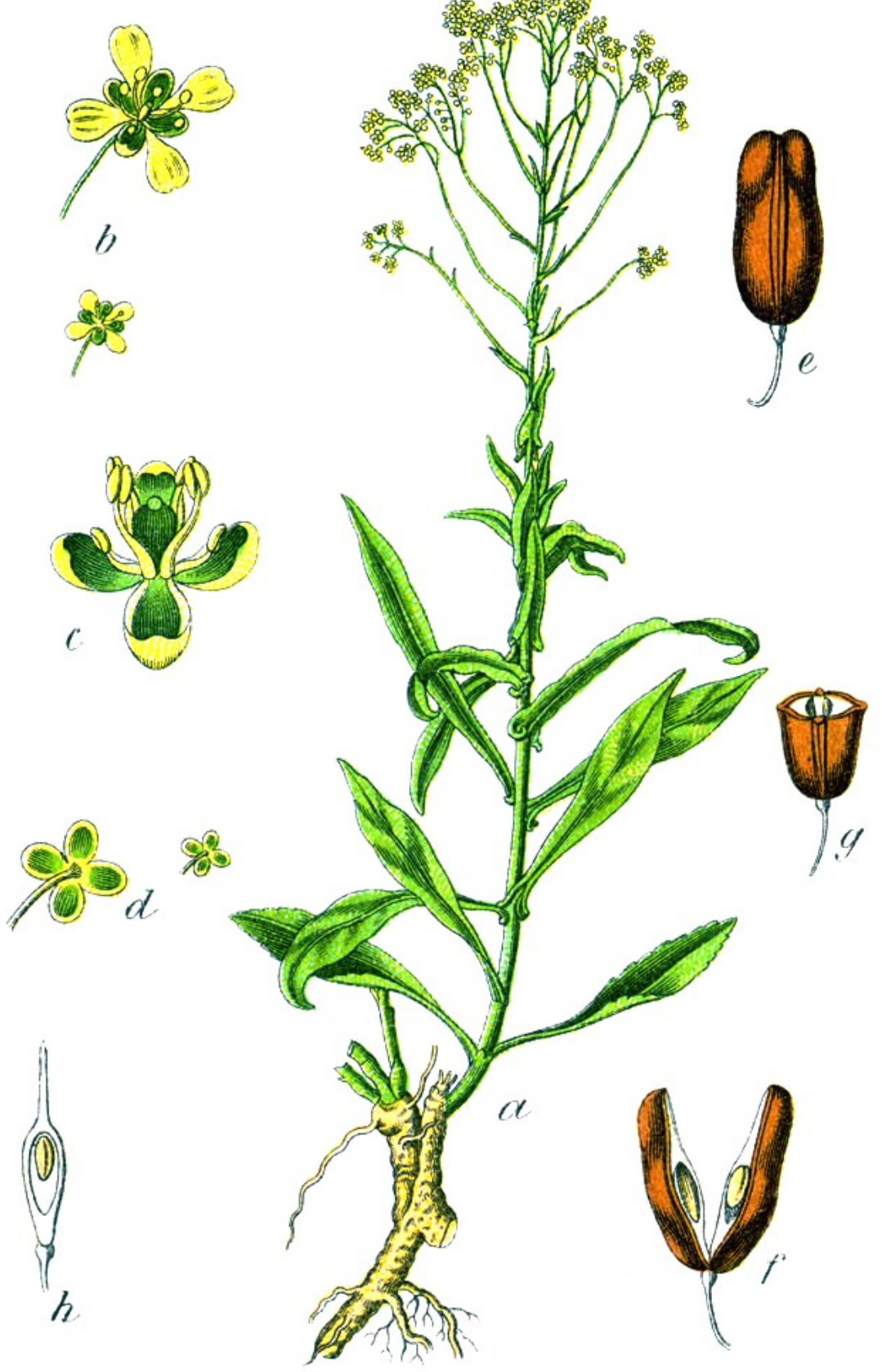

Isatis tinctoria L., Brassicaceae 


\section{Danksagung}

An erster Stelle danke ich meinem Doktorvater Herrn Prof. Dr. Matthias Hamburger für die engagierte Betreuung von den allerersten Anfängen der Dissertation bis zu deren Fertigstellung, für seinen Optimismus, seine Ideen und für die Freiheit, die er mir stets gewährte. Obwohl er durch Lehre und Forschung stark beansprucht war, fand ich stets eine offene Tür und die Bereitschaft für ein Gespräch.

Herrn Dr. Olivier Potterat und Herrn Dr. Michael Adams danke herzlich ich für die wertvollen Hinweise beim Überarbeiten des Manuskriptes und für das Korrekturlesen der einzelnen Artikel.

I would like to express my gratitude to Prof. Dr. Jean-Luc Wolfender who accepted to be co-referee of my thesis. His review as an expert in instrumental analysis of natural products was a great honor for me. Ebenso bin ich Herrn Prof. Dr. Alex Odermatt sehr verbunden, da er sich trotz Termindruck bereit erklärt hat den Vorsitz bei meiner Dissertationsprüfung zu übernehmen.

Allen Mitarbeitern des Instituts für Pharmazeutischen Biologie danke ich für die vielen kreativen Inputs, ihre Unterstützung und das tolle Arbeitsklima. Katrin Suter, Natalie Sedlacek und Carlos Basalo gebührt ein besonderer Dank für ihren unermüdlichen Einsatz im Rahmen ihrer Masterarbeit und das mir entgegengebrachte Vertrauen als Betreuer. Für die angenehme Zusammenarbeit in den Praktika danke ich insbesondere Herrn Dr. Olivier Potterat, Frau Dr. Karin Berger-Büter, Herrn Dr. Michael Adams, Frau Anna Koryakina und Frau Janine Zaugg.

Für die Hilfe bei etlichen NMR-Messungen und bei der Strukturaufklärung einiger Verbindungen bin ich Frau Dr. Inken Plitzko sehr dankbar. Die quantitativen ${ }^{1} \mathrm{H}-\mathrm{NMR}$ Messungen für die Reinheitsbestimmung der Referenzsubstanzen wurde in Kooperation mit dem Institut für Molekulare Pharmazie der Universität Basel durchgeführt, da zu diesem Zeitpunkt noch kein NMR Spektrometer in unserem Institut verfügbar war. Ein grosses Merci diesbezüglich an Herrn Dr. Brian Cutting für die Ausführung der Messungen.

Frau Biertümpfel und Herrn Dr. Vetter, Thüringische Landesanstalt für Landwirtschaft Dornburg, danke ich für die Bereitstellung der Waidproben (Anbau und Ernte der Waidherkünfte). Ebenso danke ich Herrn Prof. Dr. Y. Ye, Shanghai Institute of Materia Medica, Shanghai für die Beschaffung und Zusendung der I. indigotica Samen aus China.

Vielen lieben Dank an die Basler Naturstofffreunde für die lustigen Sitzungen und die "Siedler" Abende. Ich bin mir sicher, dass Ihr bald einen guten Nachfolger für das frei werdende Präsidentenamt in eurem "Gschaftlhuberverein" finden werdet. 
Auch meinen Freunden insbesondere Christine, meiner Vorgängerin auf dem "Isatisprojekt", sowie meinen langjährigen Weggefährten Katja und Martin sei gedankt für die vielen nützlichen Ratschläge und die schöne Zeit.

Ein ganz grosses Dankeschön geht an meine Birgit, die während des Studiums und der Dissertation immer für mich da war und ein offenes Ohr für meine Sorgen hatte. Gerade als es mal nicht voranzugehen schien, hat sie mir mit sehr viel Geduld und Liebe neue Kraft gegeben.

Und ich danke meinen Eltern für ihre Liebe, das Vertrauen und dafür, dass sie mir mit grosser Selbstverständlichkeit alle Wege ermöglichten und mir stets die freie Wahl liessen. 


\section{Table of Contents}

Summary / Zusammenfassung 11

1. Aim of the work 17

2. Introduction 21

2.1 Woad (Isatis tinctoria L.) $\quad 22$

Historical background of woad as source of indigo 22

Medicinal uses, phytochemistry and biological activities of woad 22

2.2 Interaction and synergy in phytomedicines 26

Synergistic interactions between plant constituents 26

Interaction by solubility enhancement 28

Solubility enhancing effects observed in Isatis 29

Negative aspects of compound interaction in plant extracts 29

2.3 The role of plant extracts in the pharmacopoeia, and aspects of quality control 31

Definitions by the European Pharmacopoeia 31

Example: the refined Ginkgo biloba extract EGb 761

Example: the Petasites hybidus extract Ze 339

Drawbacks of current methods $\quad 35$

2.4 Metabolite profiling and quality control of medicinal plants 37

Terminology and definitions $\quad 37$

Analytical platforms utilized for metabolic profiling - general considerations 38

Mass spectrometric approaches for metabolite profiling 40

Nuclear magnetic resonance spectroscopy approaches for metabolite profiling $\quad 47$

HPLC coupling to mass spectrometry and NMR techniques: some examples 54

Other technology platforms in metabolite profiling 55

$\begin{array}{ll}\text { Cited literature } & 57\end{array}$ 
3.1 Quantification of active principles and pigments in leaf extracts of Isatis tinctoria by HPLC/UV/MS

3.2 A comprehensive metabolite profiling of Isatis tinctoria leaf extracts

3.3 Extraction and analysis of intact glucosinolates - A validated pressurized liquid extraction/liquid chromatography - mass spectrometry protocol for Isatis tinctoria, and qualitative analysis of other cruciferous plants

3.4 Seasonal changes and effect of harvest on glucosinolates in Isatis leaves 131

3.5 Glucosinolate pattern in Isatis tinctoria and I. indigotica seeds

4. Conclusion and outlook 



\section{Summary}

Woad (Isatis tinctoria L., Brassicaceae) is an ancient indigo dye and anti-inflammatory medicinal plant, which has been used and cultivated in Europe since antiquity. The antiinflammatory potential of lipophilic leaf extracts was recently confirmed in a broad-based pharmacological profiling, in various animal models and in a clinical pilot study. Tryptanthrin, an indolin-2-one derivative, and $\gamma$-linoleic acid were identified as pharmacologically active compounds inhibiting cyclooxygenase-2 (COX-2), 5-lipoxygenase (5-LOX), the expression of the inducible nitric oxide synthase (iNOS), human neutrophil elastase, and the release of histamine from mast cells. Indirubin inhibits inflammatory reactions in delayed-type hypersensitivity and is a potent inhibitor of cyclin-dependent kinase 5 (CDK5) and glycogen synthase kinase $3 \beta$ (GSK3B).

In view of a development of this lipophilic woad extract towards a new anti-inflammatory herbal medicine, analytical tools were developed to address various issues related to quality control. This study was conducted as part of the development process and had the purpose to characterise the pharmacologically active leaf extracts of $I$. tinctoria and the closely related species I. indigotica Fort. As a first step, a gradient LC-PDA-MS method for the quantitative determination of pharmacologically relevant constituents and the dye indigo was developed and validated. The assay enabled quality assessment in the development of phytomedicinal preparations based on woad extracts.

A comprehensive phytochemical profiling of the pharmacologically active dichloromethane extract from I. tinctoria leaves was carried out. The polar constituents of $I$. tinctoria (MeOH extract) and the taxonomically closely related TCM plant I. indigotica were also profiled for comparative purposes. PDA, ELSD, APCI- and ESIMS, and ESI-TOF-MS detectors were used in parallel to ensure a wide coverage of secondary metabolites with highly diverging structural properties. Off-line microprobe NMR after peak purification by semi-preparative HPLC enabled the structure elucidation of some minor constituents. More than 75 compounds belonging to various structural 
classes such as alkaloids, flavonoids, fatty acids, porphyrins, lignans, carotenoids, glucosinolates and cyclohexenones were unambiguously identified, and tentative structures were proposed for additional compounds. Numerous compounds were identified for the first time in the genus Isatis, and a new indole alkaloid was discovered.

The content of indole glucosinolates in woad, and their possible role as precursors of the alkaloid tryptanthrin was investigated. At first, a robust HPLC-MS method for the quantitative determination of glucosinolates was developed and validated. Direct analysis of glucosinolates was rendered possible by the use of a volatile ion-pairing reagent. Extraction via pressurised liquid extraction was optimized, and purity assessment of reference compounds was carried out with quantitative ${ }^{1} \mathrm{H}-\mathrm{NMR}$.

Seasonal fluctuations of glucosinolates in the leaf material of five defined $I$. tinctoria and one I. indigotica accessions were assessed. Significant qualitative and quantitative differences in the glucosinolate patterns were observed when comparing the two species, while differences among the various I. tinctoria accessions were much smaller. Repeated harvesting during the growth season did not have a major effect on glucosinolate concentrations of newly grown leaves.

We investigated the influence of the drying procedure on the glucosinolate content. In contrast to shock frozen samples, none of the glucosinolates could be detected in plant material that had been dried at ambient temperature or at $40{ }^{\circ} \mathrm{C}$. However, none of the known breakdown products of indole glucosinolates could be detected.

The glucosinolate patterns in seeds of the five $I$. tinctoria and two I. indigotica accessions were also investigated. The glucosinolate patterns of the seeds showed characteristic differences compared to leaves. Qualitative and quantitative differences in glucosinolate patterns between both /satis species were found, enabling a differentiation of the two species at the level of seed material. 


\section{Zusammenfassung}

Färberwaid (Isatis tinctoria L.) ist eine historische Indigofärberpflanze mit enzündungshemmenden Eigenschaften und wird bereits seit der Antike in Europa kultiviert und angewendet. Die entzündungshemmende Wirkung der lipophilen Blattextrakte wurde kürzlich in einem breit angelegten, pharmakologischen Screeningprogramm sowie in zahlreichen Tierversuchen und einer klinischen Pilotstudie bestätigt.

Tryptanthrin, ein Indolin-2-on-derivat und $\gamma$-Linolensäure wurden als pharmakologisch wirksame Verbindungen identifiziert und es konnte gezeigt werden, dass diese Stoffe in der Lage sind Targets wie Cyclooxygenase-2 (COX-2), 5-Lipoxygenase (5-LOX), die humane, neutrophile Elastase, die Expression der induzierbaren NO Synthase (iNOS) sowie die Freisetzung von Histamin aus Mastzellen zu hemmen. Indirubin stoppt die Entzündung bei Überempfindlichkeitsreaktionen vom Spättyp und ist ein wirksamer Inhibitor der cyclin-abhängigen Kinase 5 (CDK5) und der Glycogensynthase Kinase $3 \beta$ (GSK3B).

Für die Weiterentwicklung dieses entzündungshemmenden, lipophilen Waidextraktes zu einem Phytopharmakon wurden analytische Methoden für verschiedene Fragestellungen in der Qualitätskontrolle erarbeitet. Diese Arbeit ist als Teil dieses Entwicklungsprozesses einzuordnen und hat den Zweck die pharmakologisch aktiven Blattextrakte von I. tinctoria und der nahe verwandten Art I. indigotica Fort. zu charakterisieren. In einem ersten Schritt wurde eine LC-PDA-MS Methode entwickelt und validiert, die eine quantitative Bestimmung der pharmakologisch relevanten Inhaltsstoffe sowie des Indigofarbstoffs ermöglicht. Diese Methode kann zur Qualitätsprüfung bei der Entwicklung eines pflanzlichen Arzneimittels aus Färberwaidextrakten eingesetzt werden.

Ein umfangreiches, phytochemisches Profiling des pharmakologisch aktiven Isatis tinctoria Dichlormethanextraktes wurde durchgeführt. Die polaren Verbindungen in 
I. tinctoria (MeOH Extrakt) und die taxonomisch nah verwandte TCM Pflanze I. indigotica wurden für Vergleichszwecke ebenfalls untersucht. Verschiedene Detektoren wie PDA, ELSD, APCI- and ESI-MS und ESI-TOF-MS wurden dabei parallel eingesetzt um eine möglichst große Auswahl von strukturell unterschiedlichen Sekundärmetaboliten abzudecken. Ausserdem kam eine neuartige NMR Technologie mit Mikroprobenkopf zum Einsatz, die die Strukturaufklärung einiger Minorverbindungen nach semi-preparativer Auftrennung ermöglichte. Die Strukturen von mehr als 75 Verbindungen aus zahlreichen Strukturklassen wie bespielsweise Alkaloiden, Flavonoiden, Fettsäuren, Porphyrinen, Lignanen, Carotinoiden, Glucosinolaten und Cyclohexenonen wurden zweifelsfrei aufgeklärt und für einige weitere Verbindungen konnten Strukturvorschläge getroffen werden. Neben zahlreichen in der Gattung Isatis bisher unbekannten Stoffen wurde dabei auch ein neues Indolalkaloid entdeckt.

Der Gehalt an Indolglucosinolaten in Waid und deren mögliche Rolle als Vorstufe für das Alkaloid Tryptanthrin wurde untersucht. Zuerst wurde eine HPLC-MS Methode für die quantitative Bestimmung der Glucosinolate entwickelt und validiert. Der Einsatz eines flüchtigen lonenpaarreagenzes ermöglichte die Direktbestimmung der Glucosinolate. Die Extraktion mittels Hochdruckflüssigextraktion wurde optimiert und die Reinheit der Referenzsubstanzen wurde mit Hilfe einer quantitativen ${ }^{1} \mathrm{H}-\mathrm{NMR}$ Methode bestimmt.

Saisonale Schwankungen des Glucosinolatgehaltes in Blättern von fünf definierten I. tinctoria Kulturen sowie einer I. indigotica Varietät wurden untersucht. Beim direkten Vergleich beider Arten waren signifikante qualitative und quantitative Veränderungen der Glucosinolatmuster festzustellen, während die Unterschiede innerhalb der verschiedenen I. tinctoria Stämme deutlich kleiner waren. Die Wiederholung der Ernte während der Wachstumsperiode hatte keine deutliche Auswirkung auf den Gehalt der Glucosinolate in nachwachsenden Blättern. 
Wir untersuchten den Einfluss des Trocknungsverfahrens auf den Glucosinolatgehalt.

Im Gegensatz zu den schockgefrorenen Proben konnten wir keine Glucosinolate in Pflanzenmaterial finden, das zuvor bei Raumtemperatur oder bei $40{ }^{\circ} \mathrm{C}$ getrocknet wurde. Allerdings konnten auch keine bekannten Abbauprodukte der Indolglucosinolate identifiziert werden.

Die Glucosinolatmuster in Samen von fünf definierten I. tinctoria und zwei I. indigotica Kulturen wurden ebenfalls untersucht. Dabei wurden in den Samen deutliche Unterschiede im Vergleich zu den Blättern festgestellt. Qualitative und quantitative Unterschiede zwischen beiden Isatis Arten wurden entdeckt, was eine Unterscheidung beider Arten bereits auf Ebene des Saatgutes ermöglicht. 

1. AIM OF THE WORK 
The potential of woad (Isatis tinctoria L., Brassicaceae) extracts as new active ingredient for anti-inflammatory phytopharmaceuticals was explored during the last years and is still ongoing. Tryptanthrin, $\gamma$-linolenic acid and an indolin-2-one derivative were shown to be active principles inhibiting cyclooxygenase-2 (COX-2), 5-lipoxygenase (5-LOX), the expression of inducible nitric oxide synthase (iNOS), human neurophil elastase, and the release of histamine from mast cells. Indirubin inhibits inflammatory reactions in delayed-type hypersensitivity and is a potent inhibitor of cyclin-dependent kinase 5 (CDK5) and glycogen synthase kinase $3 \beta$ (GSK3B), whereas indigo is a side product of indirubin formation from indigo precursors during the drying of woad.

In contrast to the numerous pharmacological studies on woad and its constituents, comparably few analytical work had been performed. A range of suitable analytical tools are, however, needed for the quality control and optimization of breeding, post-harvest treatment etc. As a first step, a suitable HPLC method for the quantification of the pharmacologically active constituents and indigo should be developed and validated, to be used in quality control for herbal extract preparations based on woad.

Besides the quantity of active compounds, the overall composition (fingerprint) of an extract is important in quality control of phytopharmaceuticals, since legal authorities consider the extract in its entirety as active ingredient even if specific activities can be attributed to single compounds. A second aim was, therefore, to analyse the spectrum of extracted metabolites as comprehensively as reasonably possible, for the pharmacologically active lipophilic leaf extract of. I. tinctoria. This profiling study should be complemented with an analysis of polar metabolites, and a profiling of the closely related I. indigotica Fort. A detailed knowledge of the chemical composition of the active extract should provide some clues on the nature of the compounds responsible for the solubility enhancing effects observed in a previous microdialysis study. 
Oberthür et al. (2004) observed that the phytochemical profile of woad underwent profound changes during post-harvest treatment. Indigo precursors largely disappeared, whereas the pharmacologically active tryptanthrin and indirubin were formed only during the drying process. The precursor molecules of tryptanthrin and indirubin remained, however, unknown. A systematic investigation of possible candidates is crucial to optimise cultivation and harvesting conditions in the development of a new herbal drug. Indole glucosinolates occur in rather high concentrations in fresh woad leaves and are thus possible precursors of these indole alkaloids. The second part of the metabolite profiling study should, therefore, focus on the indole glucosinolates in Isatis, and their role as putative precursors of tryptanthrin and other indole alkaloids.

First, a robust method should be developed for the quantitative determination of glucosinolates. Relevant parameters for sample preparation, extraction and analysis should be optimised and validated. Required reference compounds, which are not commercially available, should be isolated and their purity should be determined with a suitable procedure.

The developed method should then be used to investigate seasonal fluctuations of glucosinolate patterns in leaves of defined Isatis accessions. Furthermore, the effects of repeated harvesting during the growth season and the influence of the drying procedure on the glucosinolate content should be examined. The glucosinolate patterns in seeds of defined I. tinctoria and $I$. indigotica strains should be analysed for comparative purposes. 

2. INTRODUCTION 


\subsection{Woad (Isatis tinctoria L.)}

\section{Historical background of woad as source of indigo}

Woad (Isatis tinctoria L., Brassicaceae) has a long and well documented history as an indigo dye plant and as a medicinal herb. This biennial herbaceous plant has been known in Central Europe for centuries. From the Middle Ages up to the $18^{\text {th }}$ century, the cultivation of woad played an important economical role in certain parts of Europe.

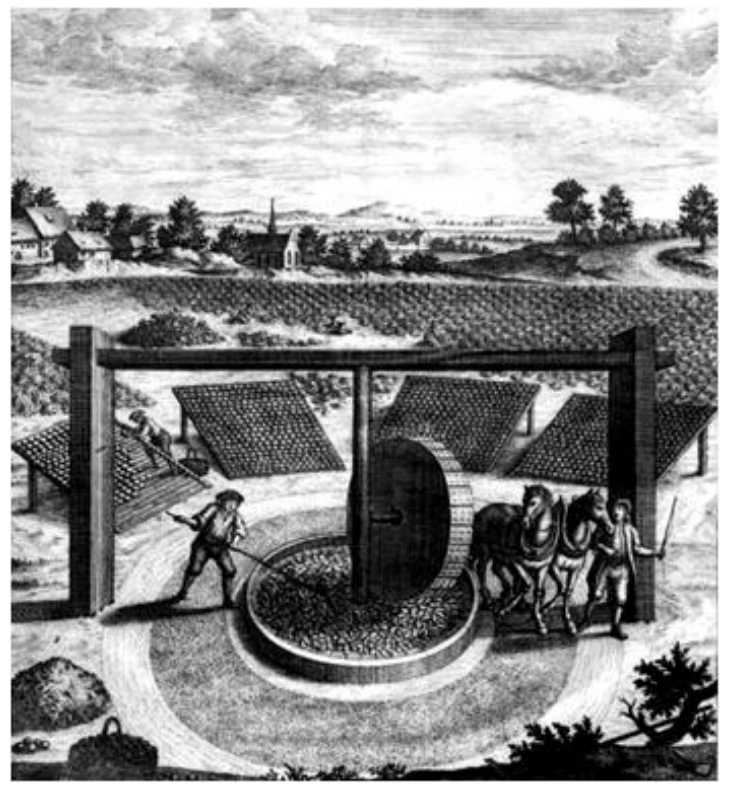
Centres of indigo production were located in Germany (especially in Thuringia) as well as in France (Normandy, Languedoc, Somme), England (Somerset, Lincolnshire) and Italy (Piedmont, Tuscany). The import of cheaper indigo from Indigofera suffruticosa initiated the decline of the woad industry in the late $17^{\text {th }}$ century and woad cultures disappeared completely with the production of synthetic indigo in the late 1890's ${ }^{1,2}$

Figure 1. Traditional woad mill in Thuringia.

(Illustration: $17^{\text {th }}$ century) Source: Hurry ${ }^{2}$

\section{Medicinal uses, phytochemistry and biological activities of woad}

The medicinal properties of the plant were esteemed in Europe and in Traditional Chinese Medicine (TCM) for centuries. The application of woad for the treatment of wounds, ulcers and haemorrhoids was described by Hippokrates (460 B.C.), Galen (129-216 A.D.) and Pliny (23-79 A.D.). During the late Middle Ages Isatis was used to 
treat snake bites, wounds and other inflammatory ailments. Its curative properties fell into oblivion after woad lost its importance as source of indigo for dying in Europe ${ }^{2}$. In China, Banlangen (Isatis root) and Daqingye (Isatis leaf) from the taxonomically closely related Isatis indigotica Fort. are still important and popular herbal drugs in Traditional Chinese Medicine (TCM) used for the treatment of inflammation, fever or swelling and are official drugs of the Chinese Pharmacopoeia up to the present time. Antibacterial and antiviral properties have also been described ${ }^{3}$.

A considerable number of phytochemical, biological and pharmacological investigations have been carried out, mostly over the last 4 decades. More than 100 secondary metabolites have been identified from $I$. tinctoria and $I$. indigotica. They include numerous indole derivatives like tryptanthrin ${ }^{4}(1)$, indirubin $^{5}(2)$, indigo ${ }^{5,6}(3)$, indolinone ${ }^{7}$ (4), deoxivasicinone ${ }^{8}(5)$, or the indigo precursors isatan $A(6)$ and isatan $B^{9}(7)$, but also aliphatic and indolic glucosinolates ${ }^{10-13}$, aromatic and aliphatic carboxylic acids ${ }^{14,15}$, aliphatic alcohols, esters, ethers, aldehydes, hydrocarbons, nitriles and furans ${ }^{15,16}$, lignans $^{17}$, various glycosides ${ }^{18,19}$, amino acids $^{20,21}$, isoprenoids ${ }^{15,18}$, flavonoids ${ }^{8,22,23}$, sphingolipids $^{24}$ and anthranoids ${ }^{8}$ (Figure 2).<smiles>O=C1c2ccccc2-n2c1nc1ccccc1c2=O</smiles><smiles>O=C1Nc2ccccc2/C1=C1\Nc2ccccc2C1=O</smiles><smiles>O=C1/C(=C2\Nc3ccccc3C2=O)Nc2ccccc21</smiles><smiles>COc1cc(/C=C2\C(=O)Nc3ccccc32)cc(OC)c1O</smiles><smiles>O=c1c2ccccc2nc2n1CCC2</smiles>

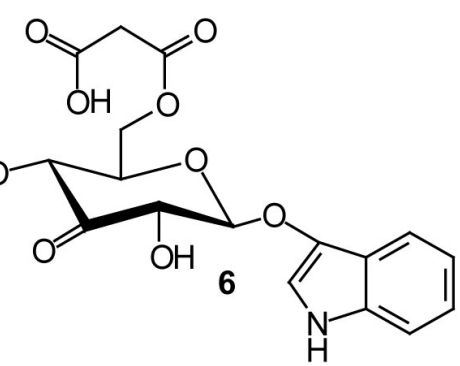

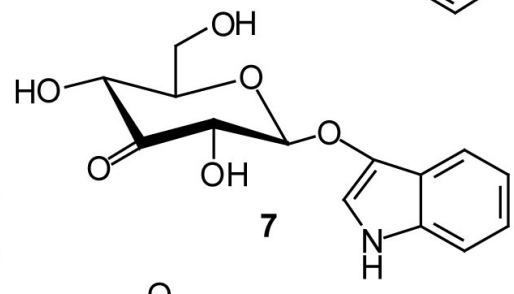

5<smiles>CC/C=C/C/C=C/C/C=C/CCCCCCCC(=O)O</smiles>

Figure 2: Structures of compounds 1-8. 
Tryptanthrin (1) was originally isolated by Honda et al. ${ }^{4}$ as an anti-dermatophytic compound. High antimycobacterial activity of the compound and some derivatives was observed against Mycobacterium smegmatis in several in vitro studies ${ }^{25-27}$ but a notable in vivo efficacy was lacking ${ }^{28}$. An aqueous extract of woad was tested in a chronic pulmonary infection model in rats. The observed effect was positive and was deemed promising for human studies ${ }^{29}$. Furthermore, its applicability was investigated in the context of the development of wood protecting varnishes. Fermented woad juice inhibited wood rotting fungi ${ }^{30}$ and weak insecticidal activity was found for tryptanthrin $^{31}(1)$.

Isatis extracts and selected constituents were screened for antiviral, antifungal, antibacterial and cytoinhibitory activities. However, its potential as an anti-inflammatory was not discovered at that time. Some years ago, a broad-based pharmacological screening was initiated and tryptanthrin (1), $\gamma$-linoleic acid (8) and (E)-3-(3',5'-dimethoxy4'-hydroxy-benzylidene)-2-indolinone (4) were shown to inhibit cyclooxygenase-2 (COX2), 5-lipoxygenase (5-LOX), expression of inducible nitric oxide synthase (iNOS), human neutrophil elastase and the release of histamine from mast cells ${ }^{32-36}$.

Leclerc et al. ${ }^{37}$ found that indirubin (2) inhibits inflammatory reactions in delayed type hypersensitivity and is a potent inhibitor of cyclin-dependent kinase 5 (CDK5) and glycogen kinase $3 \beta$ (GSK3B). These findings were corroborated by pharmacological studies on tryptanthrin (1) and indirubin (2) performed by other groups ${ }^{4,38-40}$. A clinical pilot study in experimentally induced skin erythema ${ }^{41}$ and in vivo studies in models of acute and chronic inflammation, contact allergy, and rheumatoid arthritis confirmed the anti-inflammatory activity of lipophilic Isatis tinctoria extracts ${ }^{42,43}$.

Parallel to these pharmacological investigations, advanced phytochemical and analytical studies of the plant have been carried out. Oberthür et al. identified the correct structures of the major indigo precursors (6 and 7) in woad and observed profound post-harvest changes in metabolite patterns during the drying of Isatis leaves ${ }^{9}$. 
Indigo precursors largely disappear, whereas pharmacologically active compounds such as tryptanthrin (1) were formed during the drying process ${ }^{44}$. However, the precursor molecules of tryptanthrin (1) or indirubin (2) are so far unknown and a systematic investigation of possible candidates is essential to optimise cultivation and harvesting conditions in order to establish a new herbal drug.

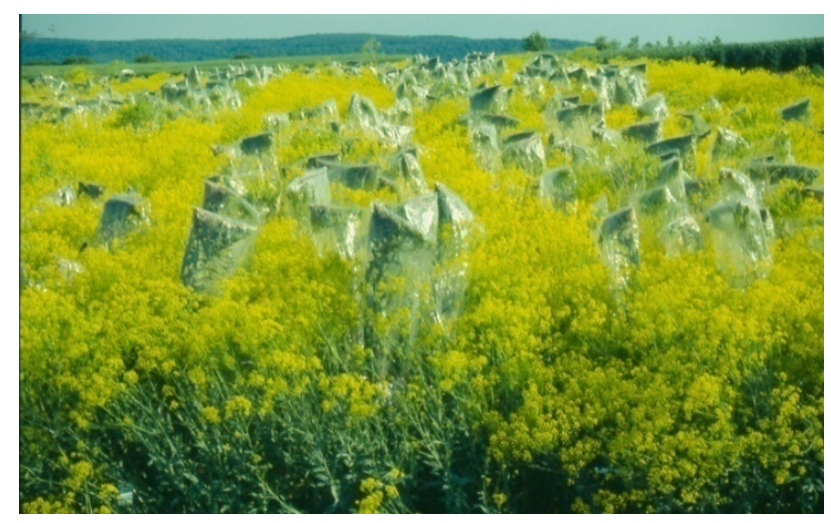

Figure 3. Experimental research plots with Isatis plants at the Agricultural research station of Thuringia, Dornburg.

The clinical efficacy of Isatis extracts can not be explained solely by the presence of individual active compounds like tryptanthrin (1), indirubin (2) and (E)-3-(3',5'dimethoxy-4'-hydroxy-benzylidene)-2-indolinone (4) because these compounds occur in too low amounts. Synergistic effects between extract constituents seem to play a central role and/or compounds in the complex extract matrix presumably increase the solubility of these poorly soluble alkaloids. 


\subsection{Interaction and synergy in phytomedicines}

Commonly, plant extracts are very complex mixtures, whose individual constituents are known only to a limited extent. The extracted compounds can be divided into main active substances and concomitant compounds. Pharmacologically active main compounds are responsible for the therapeutic effect of the extract, while concomitant compounds can change physico-chemical properties and therefore influence biopharmaceutical parameters like solubility and bioavailability of the main active substances.

Several factors like conditions of cultivation, harvest, drying or storage, but also the selection of an appropriate extraction method, particle size, solvent and extraction duration have a major impact on composition and concentration of active compounds in an extract. As a general rule, the extract yield increases with the polarity of the solvent or solvent mixture used. This results in a lower drug-to-extract ratio ${ }^{45-47}$.

The pharmacological activity of plant extracts is often not attributable to a single compound, and interactions between the extracts constituents have to be expected. In fact, proponents of phytotherapy consider the occurrence of synergistic effects in herbal extracts as a major advantage of this type of medicines. However, surprisingly few studies have been carried out to understand synergistic effects and interactions between plant constituents.

\section{Synergistic interactions between plant constituents}

Synergistic interactions have been described for constituents from an extract of a single plant, as well as for those from different plants in a multi-herbal formulation. The general understanding of synergy is that an effect of a combination of substances is greater than what can be expected from the sum of their individual contributions ${ }^{48,49}$. For 
example, Wagner et al. found that isolated ginkgolides A and B from Ginkgo biloba L. were pharmacologically less effective as anti-inflammatory agents in vitro than a mixture of the two compounds ${ }^{50}$. Another case of synergistic interactions was described for Piper methysticum G. Forst (Kava-Kava), where the anticonvulsant activity of the kava lactones yangonin and desmethoxyyangonin was found to be much higher in combination with other kava constituents ${ }^{51}$. Keledjian et al. investigated the absorption of the kava lactones dihydrokavain, kavain, desmethoxyyangonin and yangonin in mice. The authors found higher concentrations of yangonin and kavain in the brain after administration of an extract compared to the equivalent amount of pure compounds ${ }^{52}$. Similar observations were described by Nahrstedt for kavain. After oral administration of pure kavain to mice the plasma concentration was more than $50 \%$ lower compared than that found after administration of the same amount of kavain in a refined Piper methysticum extract ${ }^{53}$.

Flavonoids are present in many phytomedicines but their role as synergistic compounds is still not clear. Philippson observed that the activity of artemisinin in an in vitro antimalarial test was enhanced in the presence of the flavonoids artemetin and casticin ${ }^{54}$. Flavonoids were also involved in synergistic effects observed in a clinical trial with willow bark (Salix alba L.) for the treatment of ostheo-arthritis. According to the work of Schmidt et al., the applied amount of salicin (240 mg daily) was too low to explain the observed activity. Interestingly, gastrointestinal side effects associated with non-steroidal anti-inflammatory drugs such as acetylsalicylic acid were not observed, although it is known that the salicylalcohol derivative salicin is transformed in the liver into salicylic acid $^{55}$.

Butterweck et al. investigated the mode of action of St. Johns Wort (Hypericum perforatum L.) which is used for the treatment of mild forms of depression. Several compounds were isolated from the plant and used for an in vitro screening on several receptors, transporters and ion channels. Synergistic interactions between different 
compounds were observed, and the authors concluded that this effect is responsible for the antidepressant activity in St. Johns wort ${ }^{56}$.

\section{Interaction by solubility enhancement}

Solubility enhancing properties have been described for saponins. It is known, for example, that saponins from Ginseng lead to a pronounced enhancement of the solubility of saikosaponins in water ${ }^{57}$. Kimata et al. found a considerable solubility enhancement of saikosaponin A, (a triterpene saponin of Bupleuri radix) by the Ginseng saponin chikusetsusaponin $\mathrm{V}$ (a bidesmoside of the oleanolic acid type $)^{58}$. The solubility of saikosaponin $A$ in water can also be enhanced by glycyrrhizin and glycyrrhizin $30-\beta$ glucoside ester and glycyrrhizin-30- $\beta$-glucuronide ester ${ }^{59}$. Zhou et al. showed that the significant solubility enhancement of saicosaponin $B$ in water in the presence of a ginseng-saponin mixture is caused by malonyl-ginsenosides. No solubility enhancing effects were observed with neutral ginseng-saponins of the dammarane type. In contrast, solubility enhancing effects of malonyl-saponins were increased in the presence of dammarane saponins ${ }^{60}$.

Schöpke and Bartlakowski studied solubility enhancing effects that single saponins or mixtures of saponins had on quercetin, which was used as a model compound with poor solubility in water. The authors found that the saponin mixture enhanced the solubility of quercetin far below the critical micelle concentration (CMC), while this effect was not observed with a single saponin ${ }^{61}$. This result indicates that solubility enhancement can not be explained completely by micellar solubilisation.

Liquorice (Glycyrrhiza glabra L.) contains a large variety of saponins and is used in many mixtures in Chinese medicine as an agent with synergistic and solubility enhancing properties. For example, it potentiates the effect of the neuromuscular blocking agent paeoniflorin ${ }^{62}$. Schindler found that adding $10 \%$ glycyrrhizinic acid, the 
major saponin in Glycyrrhiza glabra, to am aqueous medium can enhance the solubility of the sapogenin isoliquiritigenin by a factor of $570^{63}$.

However, a further systematic investigation of solubility enhancing effects of saponins has not been carried out so far.

\section{Solubility enhancing effects observed in Isatis}

Solubility enhancing effects were also found for Isatis tinctoria. The skin penetration of pharmacologically active tryptanthrin (1) from solutions of pure compound and lipophilic Isatis leaf extracts was investigated with a microdialysis study using an ex vivo pig foreleg model ${ }^{64}$. Tryptanthrin concentrations in the dialysates increased faster when the alkaloid was applied in the extract matrix. When applied in pure solutions the alkaloid crystallised on the skin surface. One explanation for this was that extract constituents act as solubility enhancers and increase the cutaneous penetration of poorly soluble compounds like tryptanthrin. Also synergistic pharmacological effects from other constituents in the extract have to be taken into account when considering the in vivo activities reported.

\section{Negative aspects of compound interaction in plant extracts}

In general, synergistic effects are considered to be positive because lower doses have to be applied but also less desirable interactions have been reported ${ }^{48}$. The presence of tannins in an herbal drug, for example, can lead to lower absorption of proteins or alkaloids due to the formation of poorly soluble complexes ${ }^{65}$. In case of St. John's wort (Hypericum perforatum), the induction of the cytochrome P450 enzyme systems may accelerate the metabolism of other drugs which finally results in blood levels that are too low for a therapeutic effect ${ }^{48}$. 
Franz $^{66}$ observed that polysaccharides can generate a hydrocolloid film in the gastrointestinal tract and hereby decrease the absorption of other compounds. An absorption lowering effect has also been described for resins, gum and pektins ${ }^{67}$.

Due to the complex composition of most plant extracts, it was possible only in rare cases to unequivocally assign factors which are responsible for the solubility enhancement and higher dissolution rate of poorly soluble compounds. Several factors that influence synergistic effects may interfere with each other. So far, only a small number of examples have been investigated ${ }^{45,46,48}$, and a systematic investigation of this issue is still lacking.

These selected examples of influences of concomitant compounds on the dissolution and absorption of active compounds show, that concomitant compounds should not be regarded as worthless. It is therefore right that legal authorities consider the extract in its entirety as active ingredient, even if the specific activity can only be attributed to single compounds. Besides the quantity of active compounds also the composition of an extract is important in quality control of phytopharmaceuticals. 


\subsection{The role of plant extracts in the pharmacopoeia, and aspects of quality control}

Medicinal plants and plant-derived phytopharmaceuticals account for approx. $25 \%$ of prescribed medicines and approx. $50 \%$ of the market share in over-the-counter products in industrial countries ${ }^{68,69}$. Safety and efficacy of these products are a central issue for regulatory authorities like BfArM (Germany) or Swissmedic (Switzerland) and for manufacturers. Compulsory guidelines to guarantee the quality of medicinal products including all phytopharmaceuticals are specified in pharmacopoeias such as the European Pharmacopoeia, the British Pharmacopoeia or the US Pharmacopeia.

\section{Definitions by the European Pharmacopoeia}

If the active constituents of herbal extracts are not known, marker compounds are used for standardisation to guarantee a constant quality. The European Pharmacopoeia (PhEur 6.0) distinguishes between different types of extracts according to their type of marker compounds ${ }^{70}$.

"Standardised extracts" are adjusted to a given content of constituents with known therapeutic activity within an acceptable tolerance. The amount of active ingredient is defined in the final product but the amount of native extract varies. "Quantified extracts" are adjusted to a defined range of pharmacologically active constituents, or else, to a limited concentration of toxicologically critical compounds. Such adjustments are made by blending batches of extracts.

Production of quantified extracts is only possible in cases where toxicological or pharmacological data of marker compounds exist. Examples are Devils Claw dry 
extracts (Harpagophyti extractum siccum), standardised Horse Chestnut dry extract (Hippocastani extractum siccum normatum) or St. John's Wort dry extract (Hyperici herbae extractum siccum).

"Other extracts" are essentially defined by their production process. Factors like herbal material, extraction conditions or extraction solvents are specified. Quantification of analytically relevant markers is carried out for each individual batch and the amount of extract per dose is constant.

Often, marker compounds of pharmacological, toxicological or analytical relevance are used for quality control purposes. Examples for the selection of compounds with pharmacological activity as markers are oligomeric procyanidines in Hawthorn dry extract (Crataegi folii extractum siccum), hyperforin in St. John's Wort dry extract (Hyperici herbae extractum siccum) or ginkgolides in standardised Ginko biloba dry extracts (Ginkgo extractum siccum normatum). Aristolochic acid in Traditional Chinese Medicine (TCM) plants or pyrrolizidine alkaloids in butterbur (Petasites hybridus L. Gaertn.) dry extracts are examples of toxicologically relevant markers. Increase and decrease of marker compounds with analytical relevance give information on the identity and purity of extracts or herbal drugs.

A special kind of extract as defined by the European Pharmacopoeia is the so called "refined extract". If the active compounds are known, it is possible to obtain such extracts by several enrichment steps to remove unwanted compounds. Techniques for the separation of complex mixtures are selective extraction and partitioning methods, for example liquid-liquid-extraction, adsorption techniques and precipitation procedures in combination with filtration. Especially precipitation steps are widely used in industrial scale to remove unwanted constituents like proteins, polyphenols or waxy compounds.

Only for very few phytopharmaceuticals the global composition of the active ingredient (extract) has been analysed in a more comprehensive manner and data published. 
Notable examples include the special extracts EGb 761 (derived from Ginkgo biloba leaves) and ZE 331 (obtained from Petasites hybridus leaves). Both examples are discussed in the following sections.

\section{Example: the refined Ginkgo biloba extract EGb 761}

One example for a refined extract is the Ginkgo biloba extract EGb 761, where some compound classes are enriched and others are depleted compared to their original proportions in the plant. This is achieved in a sophisticated multi step extraction procedure (Figure 4).

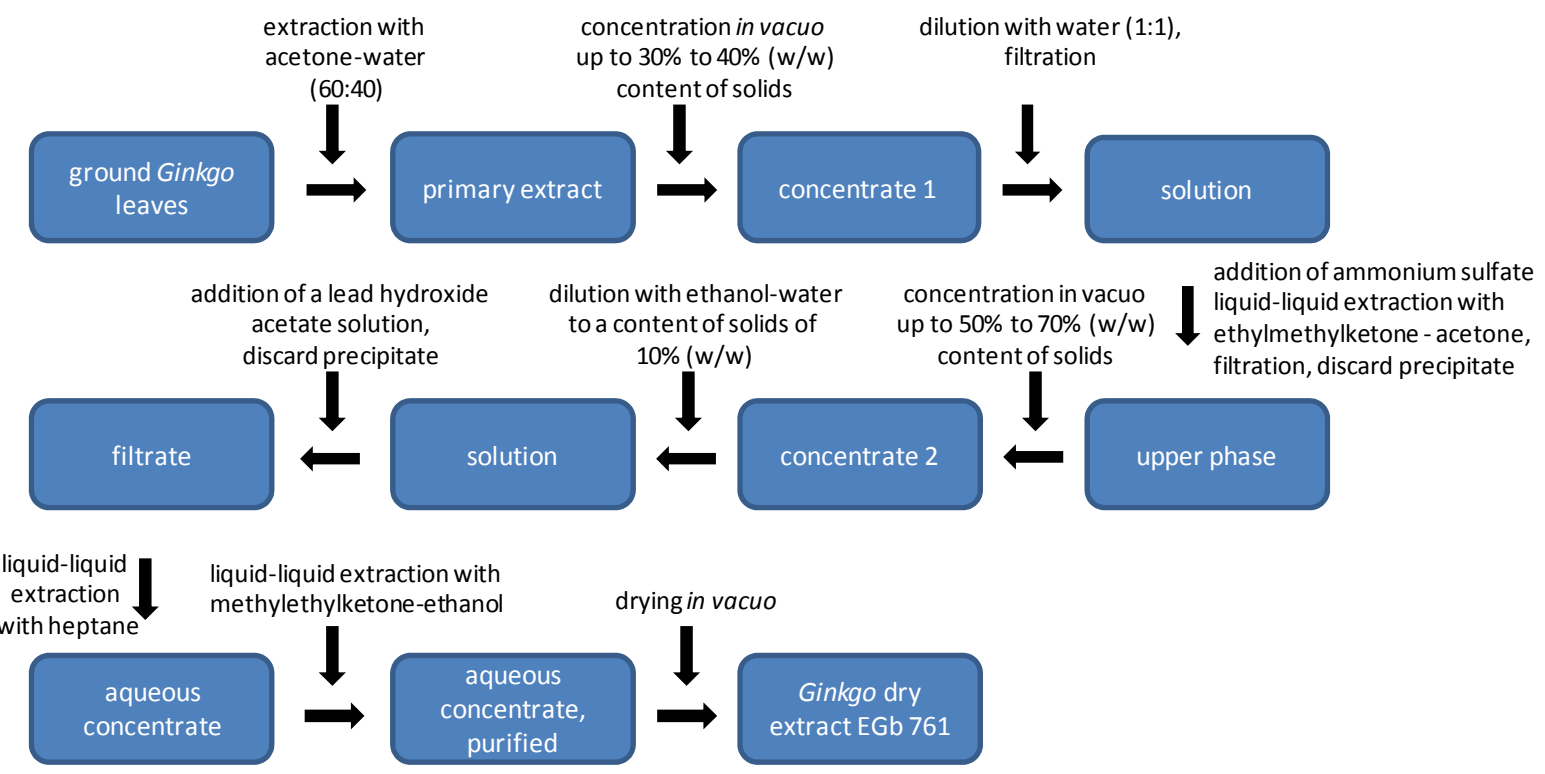

Figure 4. Simplified production scheme of the Ginkgo biloba extract EGb 761. Adapted from Hänsel and Spie $\beta^{71}$ with minor modifications.

Compounds which are responsible for allergic reactions ${ }^{72-74}$ or serious mucosal disturbances $^{75}$ such as ginkgolic acid derivatives are removed. An overview of compounds present in Ginkgo biloba leaves but not in EGb 761 is shown in Table 1. 
Compounds, which are regarded as pharmacologically active like flavonol glycosides, ginkgolides and bilobalide can be enriched by this extraction procedure. According to DeFeudis $^{76}$ about $2.5 \mathrm{~kg}$ of extract is obtained from $100 \mathrm{~kg}$ of Ginkgo leaves. The extract contains approximately $24 \%(\mathrm{w} / \mathrm{w})$ flavonoid glycosides, $3.6 \%(\mathrm{w} / \mathrm{w})$ ginkgolides, $2.9 \%(\mathrm{w} / \mathrm{w})$ bilobalide, $6.5 \%(\mathrm{w} / \mathrm{w})$ proanthocyanidins and less than $1 \mathrm{ppm}$ alkyl phenol compounds (ginkgolic acid derivatives). The final EGb 761 product is standardised to contain $24 \%$ flavonol glycosides and $6 \%$ terpene lactones (3.1\% ginkgolides, $2.9 \%$ bilobalide) which is controlled analytically to ensure the consistency of its composition.

\begin{tabular}{|l|c|}
\hline Compound class & Content [\%] \\
\hline Flavonol glycosides & 24 \\
Terpene lactones, thereof & 6 \\
$\quad$ Bilobalide & 2.9 \\
$\quad$ Ginkgolides A, B and C & 3.1 \\
Oligomeric proanthocyanidines & $5-10$ \\
Carboxylic acids & approx. 9 \\
$\quad$ (among others 6-hydroxy- & \\
$\quad$ kynurenic acid, vanllic acid, & \\
$\quad$ protocatechuic acid, p- & \\
$\quad$ hydroxybenzoic acid) & \\
Ginkgoles and ginkgolic acids & 0.0005 \\
Biflavones & 0.1 \\
\hline
\end{tabular}

Table 1. Composition of the Ginkgo biloba extract (50:1) EGb 761.

Source: Hänsel and Spie $\beta^{71}$

\section{Example: the Petasites hybidus extract Ze 339}

An other example for a well characterised extract is the butterbur (Petasites hybridus) extract Ze 339 used for the treatment of allergic rhinitis. Careful selection of plant material for cultivation, study of harvest conditions and choice of an appropriate extraction method (the manufacturer used an extraction technique with subcritical $\mathrm{CO}_{2}$ ) enable an enrichment of the pharmacologically active petasins (petasin, neo-petasin, iso-petasin, S-petasin, neo-S-petasin and iso-S-petasin), while toxic pyrrolizidine 
alkaloids (such as senecionine, integerrimine and their $\mathrm{N}$-oxides) are absent from Ze $339^{77,78}$. The composition of the respective compound classes is shown in Table 2.

\begin{tabular}{|c|c|}
\hline Compound class & $\begin{array}{l}\text { Content } \\
{[\%]}\end{array}$ \\
\hline $\begin{array}{l}\text { Sum of petasins including } \\
\text { petasin, neo-petasin, iso-petasin, S- } \\
\text { petasin, neo-S-petasin, iso-S-petasin }\end{array}$ & 20.3 \\
\hline Fatty acids (total) & 40.2 \\
\hline unsaturated cis-fatty acids & 1.1 \\
\hline poly-unsaturated cis-fatty acids & 33.8 \\
\hline unsaturated trans-fatty acids & 0.0 \\
\hline poly-unsaturated trans-fatty acids & 5.3 \\
\hline Aroma components & 7.0 \\
\hline Steroids/Phytosterols & 1.2 \\
\hline Pyrrolizidine-alkaloids & n.d. \\
\hline Remaining substances & 30 \\
\hline $\begin{array}{l}\text { apolar constituents without chromophors } \\
\text { water }\end{array}$ & 6.9 \\
\hline
\end{tabular}

\section{Drawbacks of current methods}

Special care has to be taken for the quality control of raw and final formulated products due to their complex composition. Current methods such as TLC, HPLC-UV or GC-MS provide only a limited insight into the complexity of the samples and often show limited separation and detection capabilities owing to the physicochemical properties of the analytes under investigation (e.g. poor volatility, lack of chromophores etc.). These methods are adapted to fulfil control needs of regulatory authorities and pharmaceutical manufacturers to track known adulterations but unknown adulterations can be easily overlooked. As a consequence of the lack of efficient tools in quality control, large variations of phytopharmaceuticals can be found on the market. The analysis of 14 commercially available feverfew samples showed that each batch had a characteristic 
spectra profile and two of the batches were distinctly different from the other twelve ${ }^{79}$. Since the chemical composition of a phytopharmaceutical critically depends on the plant growth environment, harvesting conditions and used preparation methods, it is essential that quality control of phytomedicines takes these factors into account. It is therefore desirable to establish analytical methods, which are able to profile plant extracts in a holistic manner and to provide a means for standardisation and quality control of phytopharmaceuticals based on their entire composition without reference to "active" molecules. 
2.4 Metabolite profiling and quality control of medicinal plants

\section{Terminology and definitions}

Several approaches like metabonomics, metabolomics or metabolomic profiling have been developed during the last years. All these techniques try to give detailed qualitative and quantitative metabolite overviews in organisms or extracts. Metabonomics is a systems oriented approach describing "the quantitative measurement of the dynamic multiparametric metabolic response of living systems to pathophysiological stimuli or genetic modification" as defined in 1999 by Nicholson et al. ${ }^{80}$ Metabolomics is defined as "a comprehensive analysis in which all the metabolites of a biological system are identified and quantified" ${ }^{\prime 1}$ while, in contrast, metabolic profiling is defined as an approach using predefined metabolites which are biogenetically closely related and limited in number ${ }^{82}$. Hence metabolic profiling has to be considered as a biased approach. An overview on strategies for metabolic analysis has been given by Dunn and Ellis ${ }^{82}$ and is shown in Table 3 . 


\begin{tabular}{|c|c|}
\hline Strategy & Description \\
\hline Metabolomics & $\begin{array}{l}\text { Non-biased identification and quantification of all metabolites in a } \\
\text { biological system. Sample preparation must not exclude metabolites, } \\
\text { and selectivity and sensitivity of the analytical technique must be high }\end{array}$ \\
\hline Metabolite profiling & $\begin{array}{l}\text { Identification and quantification of a selected number of pre-defined } \\
\text { metabolites, generally related to a specific metabolic pathway(s). } \\
\text { Sample preparation and instrumentation are employed so to isolate } \\
\text { those compounds of interest from possible matrix effects prior to } \\
\text { detection, normally with chromatographic separation prior to } \\
\text { detection with MS. In the pharmaceutical industry, this is widely used } \\
\text { to study drug candidates, drug metabolic products and the effects of } \\
\text { therapeutic treatments }\end{array}$ \\
\hline Metabolic fingerprinting & $\begin{array}{l}\text { High-throughput, rapid, global analysis of samples to provide sample } \\
\text { classification. Quantification and metabolic identification are generally } \\
\text { not employed. A screening tool to discriminate between samples of } \\
\text { different biological status or origin. Sample preparation is simple and, } \\
\text { as chromatographic separation is absent, rapid analysis times are } \\
\text { small (normally } 1 \text { min or less) }\end{array}$ \\
\hline Metabolite target analysis & $\begin{array}{l}\text { Qualitative and quantitative analysis of one or a few metabolites } \\
\text { related to a specific metabolic reaction. } \\
\text { Extensive sample preparation and separation from other metabolites } \\
\text { is required and this approach is especially employed when low limits } \\
\text { of detection are required. Generally, chromatographic separation is } \\
\text { used followed by sensitive MS or UV detection }\end{array}$ \\
\hline Metabonomics & $\begin{array}{l}\text { Evaluation of tissues and biological fluids for changes in endogenous } \\
\text { metabolite levels that result from disease or therapeutic treatments }\end{array}$ \\
\hline
\end{tabular}

Table 3. Overview on strategies for metabolic analysis. adapted from Dunn and Ellis ${ }^{82}$ with minor modifications.

\section{Analytical platforms utilized for metabolic profiling - general considerations}

These modern metabolic strategies have to cope with the enormous number of unknown compound structures. Therefore analytical techniques as HPLC-MS using $M^{n}$ and high accuracy mass spectrometric detection, offline NMR and HPLC-NMR couplings are required for structure elucidation and identification of complex metabolite structures $^{83}$.

However, some issues need to be considered when working with these hyphenated techniques. In metabolomic analysis factors such as age, type of tissues, developmental stage, environmental conditions and harvesting time greatly affect the 
metabolome obtained even from the same genotype. Therefore, the herbal material should be frozen directly after harvesting to avoid any change. The subsequent sample preparation procedure has to be carried out most carefully to avoid artefact formation.

As metabolomics aims at comprehensive fingerprinting of all metabolites, the used extraction methods should cover all possible plant metabolites. Unfortunately, there is no single extraction method to achieve this goal because the polarity of the extraction solvent limits the range of compounds that can be extracted. Thus, it is indispensible to extract the plant material under investigation with different polar and non-polar solvents to cover a wide range of metabolites and to optimise the extraction procedure to achieve an exhaustive but non-destructive extraction. In this context, a denaturation of enzymes involved in metabolite alteration should be considered, which can be achieved by drying of the plant material before extraction (for example by freeze drying), storing, grinding and extraction at low temperatures, or by the choice of a denaturating extraction solvent. A sample transformation for example by $\mathrm{pH}$ shifts has to be excluded before analysis ${ }^{82}$.

For HPLC-MS techniques, modifiers are added to the mobile phase to increase ionisation efficiency and care must be taken to keep the physicochemical characteristics of the final samples (as $\mathrm{pH}$, ion strength) constant over the whole sample set. Ion suppression effects are another well known problem in mass spectrometry of complex biological matrices. This phenomenon leads to a decreased ion yield and is not necessarily constant over a chromatographic run. Therefore, care must be taken that analyte responses are not unpredictably influenced by this effect, if compounds from different samples should be quantified and compared. Ion suppression can be minimised with a suitable sample preparation procedure, together with optimisation of chromatographic separation conditions ${ }^{84,85}$. An enhanced chromatographic resolution can be achieved for example with recent technologies as ultra performance chromatographic systems (for example the Waters UPLC' ${ }^{\text {тм }}$ system). The method is 
based on the application of very small particles $(1.7 \mu \mathrm{m})$ at elevated pressure to achieve superior theoretical plate numbers and resolution. When applied to natural product analysis, UPLC showed great advantages compared to standard HPLC ${ }^{86,87}$

For NMR based approaches, factors as the intrinsic $\mathrm{pH}$ of the extract, NMR probe temperature stability, and quality of the residual solvent suppression affect the robustness of the applied method. Imperfect sample preparation techniques might introduce inhomogeneities to NMR spectra as described by Defernez and Colquhoun ${ }^{88}$

\section{Mass spectrometric approaches for metabolite profiling}

\section{Ionisation techniques}

Gas chromatographic and liquid chromatographic techniques have gained a considerable importance for metabolic analysis. Within the past years, different methods for ion formation and ion selection have been developed. The oldest and most frequently used ionisation technique is electron impact ionisation (EI). The analytes of interest have to be vaporized prior to ionization, and this technique is therefore commonly used in GC-MS analysis. Due to the high reproducibility of El spectra, they are amenable to database searches. Extensive databases such as the NIST database are available. Over the past two decades, ionisation techniques such as electrospray ionisation (ESI), atmospheric pressure chemical ionisation (APCI), or matrix-assisted laser desorption ionisation (MALDI) have been developed for the analysis of non-volatile and thermally labile compounds. In ESI, ions are generated from a liquid by the formation of highly charged droplets and their subsequent evaporation. ESI is probably the most used ionisation technique for a wide range of biological analytes. It can be used in combination with separation techniques as HPLC or CE, and is considered to be a soft ionisation technique which does not result in extensive fragmentation of molecular ions as observed in electron impact mass spectrometers. This is the reason 
why direct metabolite identification is not possible by comparing ESI mass spectra. Also, ESI mass spectral libraries are not available as in the case for GC-MS.

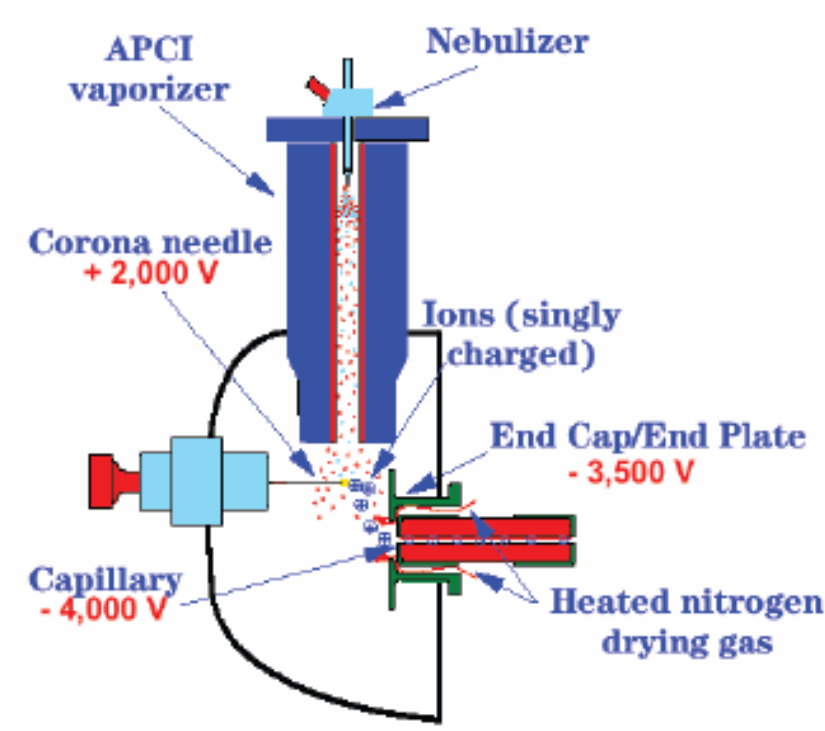

A common alternative to $\mathrm{ESI}$ is atmospheric pressure chemical ionisation (APCI). With $\mathrm{APCl}$, the HPLC eluent is heated to temperatures of about $400{ }^{\circ} \mathrm{C}$ and sprayed with nitrogen into the source. The ionisation is initiated by a corona discharge of a needle followed by a complex reaction cascade leading to an efficient ionisation of analytes (Figure 5).

Figure 5. Interface design of an APCI source. Illustration: Bruker Daltonics

Typically, the gas phase ionisation from APCI generates more fragment ions relative to the parent ion than the liquid phase ionisation technique $\mathrm{ESI}$. With $\mathrm{APCl}$ it is also possible to ionise weakly polar analytes not existing as preformed ions in solution with ESI. Thus, the two ionisation techniques are complementary.

$\mathrm{APCl}$ is known for its sensitivity, robustness and reliability but is less useful for thermally labile compounds and requires some compound volatility. In contrast to ESI, APCI has the advantage of being less susceptible to matrix interferences from salts ${ }^{85,89-92}$.

Unlike $\mathrm{ESI}$ or $\mathrm{APCI}$ in which analyte ions are produced continuously, ions in matrixassisted laser desorption ionisation (MALDI) are produced by pulsed-laser irradiation of a sample. The sample is co-crystallised with a solid matrix that can absorb a wavelength of light emitted by the laser. MALDI is the method of choice for high throughput analysis, since target plates loaded with hundreds of samples can be used. The major drawback of MALDI lies in the high degree of chemical noise as a result of 
the required matrices, especially if low molecular weight compounds have to be analysed. Therefore, a complete and reproducible MALDI of a metabolic profiling sample still remains a challenge $e^{93}$.

\section{Mass analysers}

For metabolic profiling strategies, several low resolution (single or triple quadrupole and ion trap) and high resolution (time of flight, FT-ICR-MS, orbitrap) mass analysers are utilised (Figures 6 to 8). In low resolution instruments, quadrupoles were the most commonly used mass analysers in the past, particularly in combination with El ionisation in GC-MS platforms. Their major drawback is their relatively slow scanning rate $(<4000 \mathrm{u} / \mathrm{s})$ in full scan mode, not suitable for modern high-speed separations with narrow peaks. Triple quadrupole mass spectrometers give more structural information on the target analyte by arrangement of three quadrupoles, whereas the second quadrupole is used as collision cell for a controlled ion fragmentation. This setup allows the combination of ion selection, ion reaction and ion scan processes. Another way to obtain structural information by controlled ion fragmentation (collision induced dissociation (CID)) is the application of an ion trap as mass analyser. lons are "trapped" with these devices by electrodynamic focusing and can be forced to leave the trap by putting them in unstable orbits by increasing the voltage. Ion traps enable the possibility to perform $\mathrm{MS}^{n}$ experiments, are robust and are relatively inexpensive compared to other mass spectrometric devices and are therefore widely used. Quantitative performance and dynamic range could be improved with the recently developed linear ion traps.

Time-of-flight mass analysers provide high resolution mass data by the separation of ions based on their mass-to-charge dependent velocity. All ions are formed in the ion source and accelerated through a fixed potential and consequently small mass ions 
arrive to the detector earlier than large mass ions with the same charge. A combination of a TOF mass analyser with other mass spectrometric devices such as a second TOF, an ion tap or one or two quadrupoles (Q-TOF) enable exceptionally high scan rates (up to $10^{6} \mathrm{u} / \mathrm{s}$ ) in combination with high resolving power. These hybrid mass spectrometers are used for large scale routine metabolic profiling experiments ${ }^{82,85,89-92,94}$.

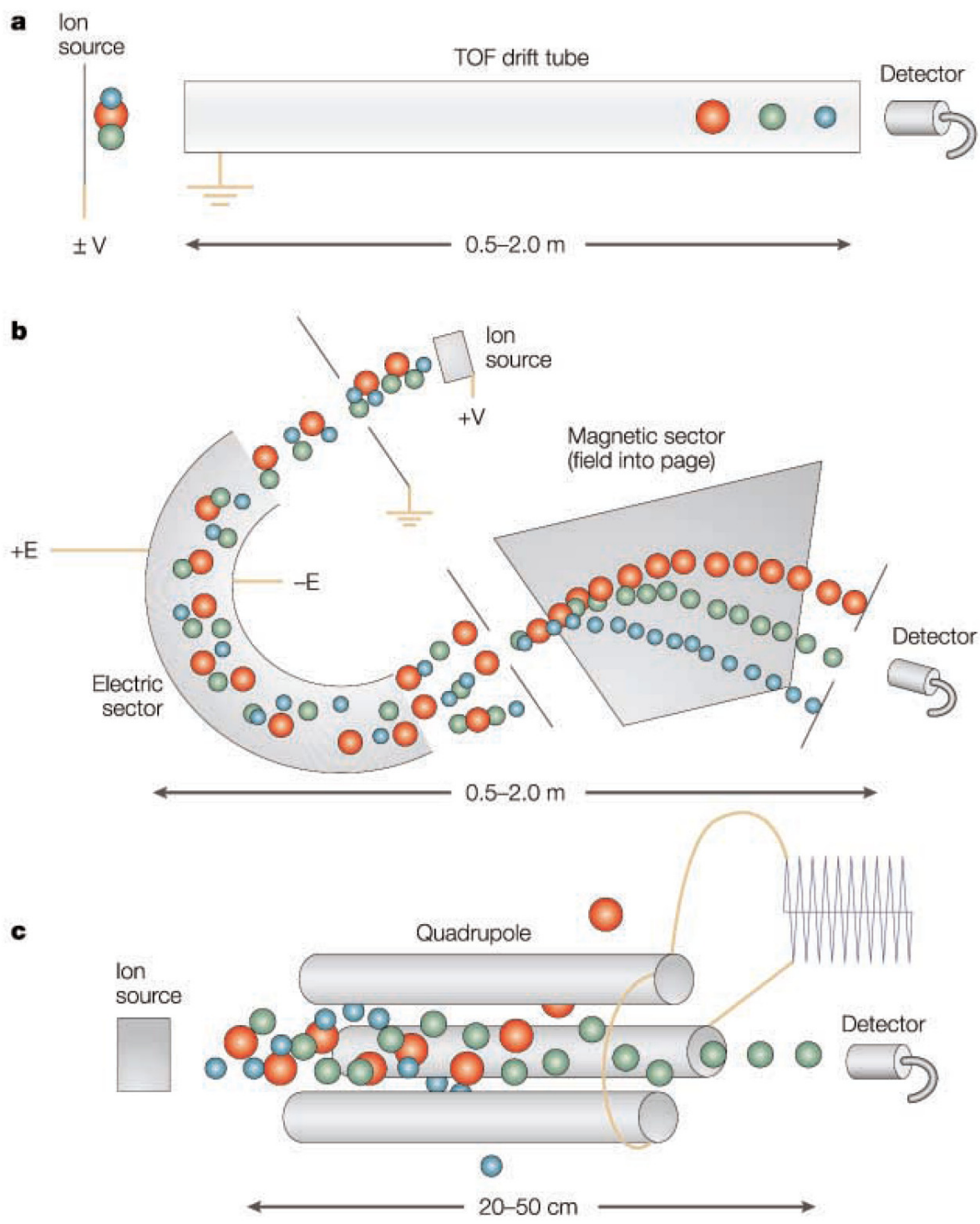

Figure 6. Pictorial diagrams of the common beam mass analysers: a single focusing time-of-flight (TOF) mass analyser b double-focusing time-of-flight analyser c quadrupole mass analyser; Illustration from Glish and Vachet ${ }^{90}$ 
A different type of mass analyser is the Fourier transform ion cyclotron mass spectrometer (FT-ICR-MS) with an unmatched resolving power. The FT-ICR-MS uses a magnetic field and the ions oscillate around the magnetic field with a cyclotron frequency that is inversely related to the $\mathrm{m} / \mathrm{z}$. Very simplified, the cyclotrone frequencies of the ions trapped in the FT-ICR are measured and converted into $\mathrm{m} / \mathrm{z}$. Today's electronic equipment is able to measure frequencies with extremely high precision and this translates to a very high mass resolution. The potential of FT-ICR-MS has been discussed in articles of Wang et al. ${ }^{95}$ or Ohta et al. ${ }^{96}$ Although the capabilities of FTICR-MS are undeniable, one has to be aware of the considerable cost and effort to operate an instrument based on a high-powered multi Tesla magnet.
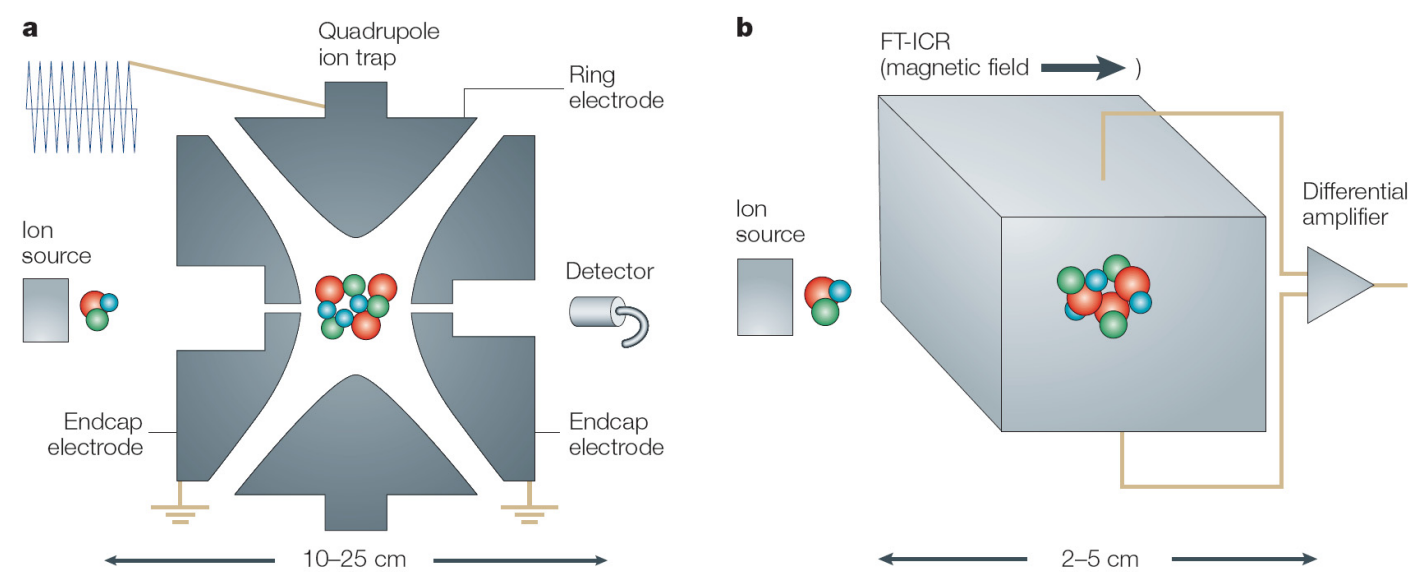

Figure 7. Pictorial diagrams of the common trapping mass analysers. a quadrupole ion trap b Fourier-transform ion-cyclotron resonance (FT-ICR) Illustration from Glish and Vachet ${ }^{90}$

The latest development, the orbitrap, was introduced on the market in 2005 as an alternative system to the FT-ICR-MS. The hybrid instrument consists of a linear ion trap which is used to selectively fill an intermediate ion storage device (C-trap) with ions of interest which are subsequently injected into the orbitrap (Figure 8). This device uses image current detection and Fourier transform similar to the FT-ICR-MS but does not 
require a superconducting magnet which significantly reduces costs and maintenance requirements ${ }^{97,98}$.

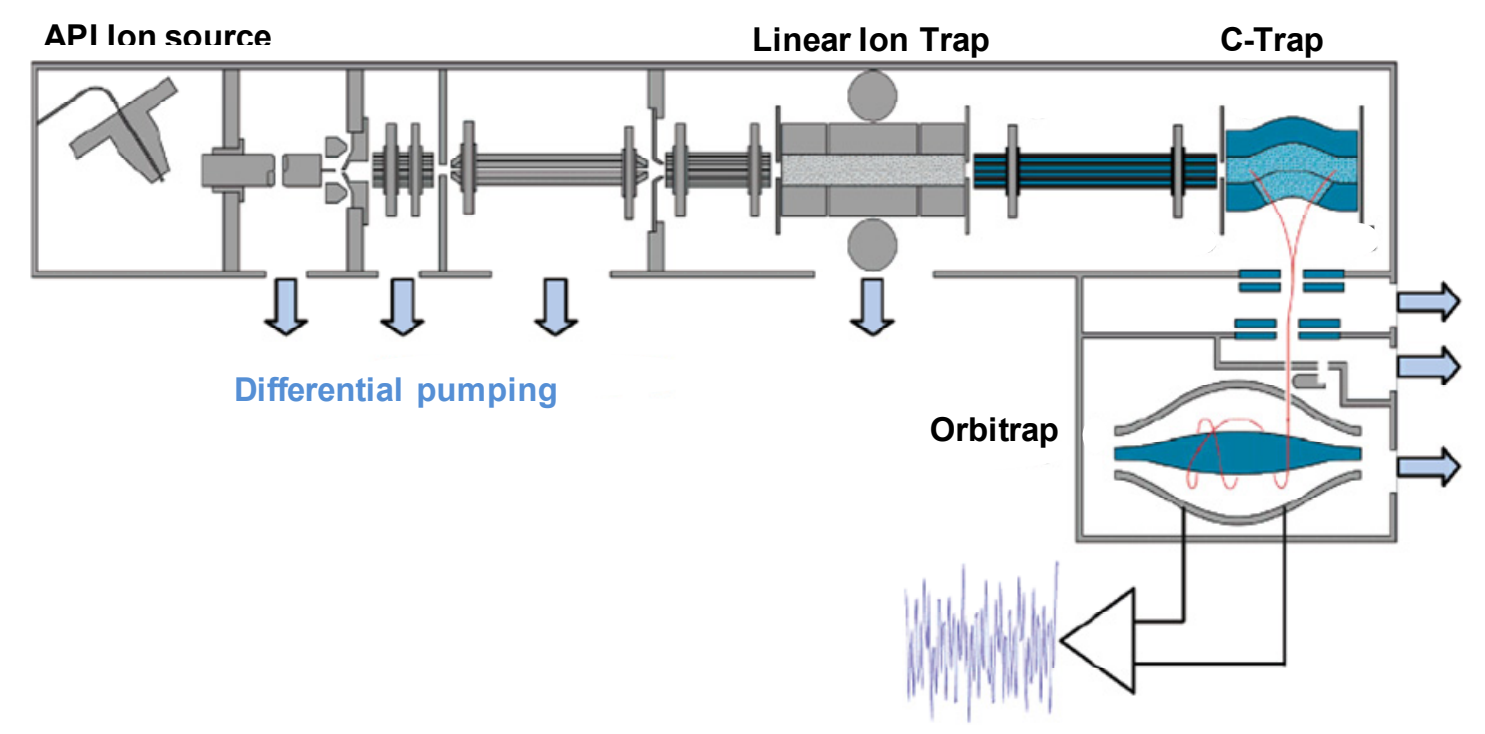

Figure 8. Pictoral diagram of a commercially available LTQ-Orbitrap instrument. Illustration from Makarov et al. ${ }^{97}$ with minor modifications.

\section{MS coupling to separation techniques}

In theory, the optimal way to obtain a mass spectrum of all metabolites in a sample in an unbiased way would be the direct application into the MS instrument without any purification or separation. However, if working with complex biogenic matrices, this approach is associated not only with an enormous instrument maintenance as cleaning of ion source and transfer optics but also with several interferences due to unspecific matrix effects and ion suppression by competitive ionisation. Therefore, commonly a chromatographic separation (for example by HPLC, UPLC or GC) of the matrix is necessary prior mass spectrometric detection. 
A complementary promising combination of a highly efficient separation technique and MS as detector is CE-MS. A wide range of analytes can be separated by capillary electrophoresis (CE) ranging from low-molecular weight compounds up to proteins ${ }^{99}$. However, the development of a robust CE-MS method is still challenging, since CE principally differs in theory and practice from HPLC and GC and only a few metabolic profiling studies have been carried out so far with this technique $e^{100-102}$.

\section{LC-MS in metabolite profiling and their application in quality control: some examples}

In recent years, significant advances in LC-based on-line mass spectroscopy opened new avenues for increasingly comprehensive analysis of plant extracts. These possibilities have been exploited in metabolite profiling studies in which plant secondary metabolism was investigated from various perspectives. However, given the enormous difficulties of a comprehensive analysis, these studies have been usually focused on a limited range of compound classes.

The metabolite profile of the model plant Arabidopsis thaliana L. Heynh. has been investigated quite intensively by LC-MS ${ }^{103-105}$.

Dan et al. investigated the metabolite profile in different plant organs of Panax notoginseng Wall. The authors identified numerous saponins in flowers, roots and rhizomes using UPLC coupled to a quadrupole time-of-flight mass spectrometer ${ }^{106}$.

Several authors developed HPLC-MS methods to investigate the composition of Ginkgo biloba preparations. For example Jensen et al. ${ }^{107}$ and Xie et al. ${ }^{108}$ used LC-APCI-MS methods to evaluate the contents of bilobalides and ginkgolides of commercial Ginkgo preparations while a capillary LC system coupled to an ion trap spectrometer was applied by Ding et al. for a fingerprinting of Ginkgo biloba preparations ${ }^{109}$.

Artemisia annua L. is a potent drug for the treatment of malaria. The activity of the plant is ascribed to the sesquiterpenelactone artemisinin, which is very effective against drug- 
resistant plasmodium species ${ }^{110}$. In view of a possible use of an herbal preparation rather than the pure artemisinin, an HPLC-MS method was proposed for the identification and quantification of artemisinin and other constituents ${ }^{111}$. An HPLCMS/MS method has been developed for a fingerprint profiling for seven different black cohosh (Cimicifuga) species and six different commercial products by Wang et al. ${ }^{112}$ The validated method was utilised for a botanical identification of Cimicifuga species according to their triterpene glycoside patterns, and for quality control of black cohosh products.

A HPLC system connected to a hybrid ion trap and time-of-flight mass spectrometer was used for the determination of flavanolignans in the hepatoprotective plant milk thristle (Silybum marianum L. Gaertn.). The authors proposed the application of this method as a general method for quality control of milk thistle products ${ }^{113}$.

\section{Nuclear magnetic resonance spectroscopy approaches for metabolite profiling}

\section{General considerations}

As a tool for metabolic profiling, NMR has some unique advantages over MS-based methods. It can provide a detailed view on the molecular composition in relatively short time while relatively simple sample preparation is required. NMR is a universal detector for all molecules with NMR-active nuclei, unlike MS where detection of analytes is dependent on ionisation conditions or UV spectrometers where only chromophore bearing compounds are detectable ${ }^{84,114}$. In proton NMR spectroscopy $\left({ }^{1} \mathrm{H}-\mathrm{NMR}\right)$ the intensity of proton signals is proportional to the concentration of the metabolite. With the application of an internal standard, the real concentration of metabolites can be easy calculated $^{115}$. Compared to modern mass spectrometry instrumentation, NMR spectroscopy is a rather insensitive analytical method but considerable effort has been conducted during the last years to overcome this issue. One major advantage of NMR 
spectroscopy compared to other analytical techniques used for metabolite profiling is its matchless reproducibility and stability. A typical day to day variation often found with MS-based approaches is uncritical for NMR-based platforms ${ }^{85,114}$.

Pattern recognition analysis in NMR fingerprinting

The information content of NMR spectra is exceeding that of mass spectrometry by far because of the fact that each proton or carbon in a molecule gives a unique signal. Therefore multivariate computer-based pattern recognition methods have been developed during the last years to reduce the complexity of ${ }^{1} \mathrm{H}-\mathrm{NMR}$ profiles of herbal extracts. In this process spectra are analysed commonly after a data reduction step where each spectrum is digitised into integrated regions over fixed spectral intervals. After removal of solvent signals the spectra are normalised to the sum of the total spectral intensity to compensate differences in the amount of plant material analysed for each sample and the obtained data can be utilised for statistical analysis ${ }^{114}$ (Figure 9). 


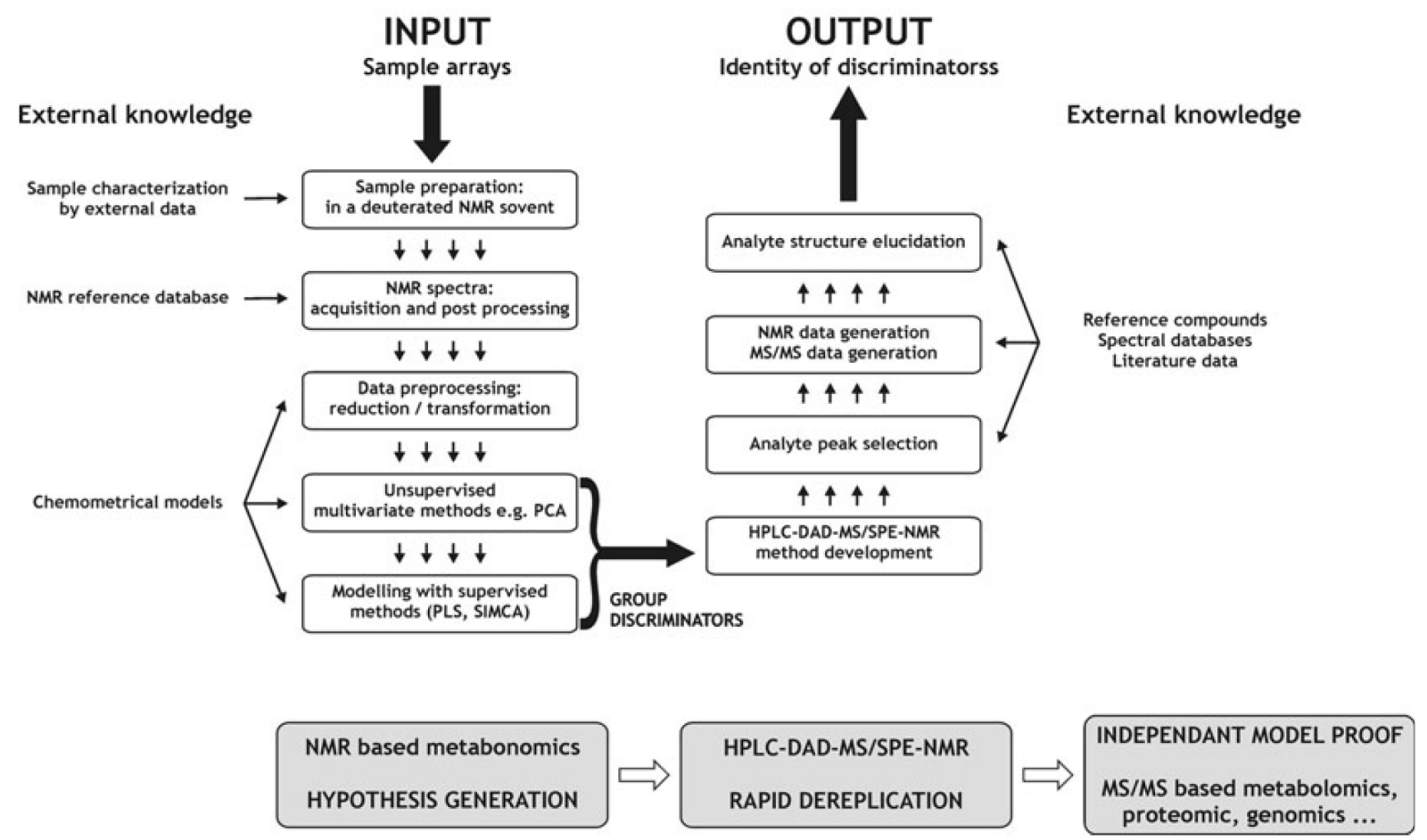

Figure 9. Schematic overview of the process of pattern recognition in complex biogenic matrices by a combination of NMR based metabonomics as discovery tool and modern hyphenated assays as analyte identification tools. Source: Holmes et al. ${ }^{114}$

The potential of this approach for a possible application in quality control of phytomedicines has been demonstrated in a recent study by Rasmussen et al. The authors investigated nine commercially available products of St. John's wort (Hypericum perforatum) by ${ }^{1} \mathrm{H}-\mathrm{NMR}$ in combination with multivariate analysis and found major variations to their global composition ${ }^{116}$. A similar study has been carried out by Seger et al. with seven crude drug lots of Hypericum perforatum. They used ${ }^{1} \mathrm{H}-\mathrm{NMR}$ fingerprinting with principal component analysis (PCA) and compared their results to those obtained by routinely used HPLC-DAD analysis and found that the discriminatory power between both methods was similar ${ }^{117}$.

Bailey et al. investigated the composition of commercially available feverfew (Tanacetum parthenium L.) samples of several different manufacturers by high resolution NMR spectroscopy in combination with pattern recognition. A considerable 
batch to batch variation was found even between products originating from the same manufacturer while a replication of experiments showed a high degree of reproducibility. They concluded that a better standardisation of these products is necessary ${ }^{79}$.

NMR-based methods have also been applied to characterise extracts and phytopharmaceutical preparations of for example Arnica montana L. ${ }^{118}$, Artemisia annua ${ }^{111,119}$, Matricaria recutita L. ${ }^{120}$, Piper methysticum ${ }^{121}$, Cannabis sativa L. ${ }^{122}$, Panax ginseng C. A. Mey. ${ }^{123}$, Angelica sp. ${ }^{124}$, Ephedra sp. ${ }^{125}$ and Ilex sp. ${ }^{126}$

\section{NMR Hyphenation: direct versus indirect techniques}

No analytical technique is suitable for the detection, identification and quantification of all metabolites in an herbal sample ${ }^{92}$. The most common strategy for structural determination is to isolate and identify metabolites, but additional options for structure elucidation have been developed in the last years. These include hyphenation of the NMR spectrometer to HPLC (as HPLC-NMR or HPLC-SPE-NMR). Such technologies employ a chromatographic work-up of the analysed mixture prior to the structural characterisation without time consuming and laborious preparative-scale isolation processes. This speeds up extract dereplication and helps to avoid re-isolation of already known extract constituents.

"Continuous flow" (on-flow) experiments with direct coupling of the NMR spectrometer to a HPLC system were the first HPLC-NMR experiments to be done and are still frequently used to gain an overview of the metabolites present in an extract. The sensitivity of continuous flow methods is, however, limited by the short residence time of analytes in the NMR flow- cell, so the method is restricted to major components and only provides preliminary information.

The "stopped-flow" NMR technique addresses this problem by stopping the flow of the HPLC pump as soon as a fraction of interest is inside the NMR flow cell. Stopped-flow 
experiments enable much longer spectra acquisitions because analytes can be kept for a longer time in the NMR flow-cell. Even the acquisition of 2D experiments is possible, which is necessary for definitive structural assignments. One major disadvantage of stopped-flow measurements is a diffusion-mediated band broadening of analytes on the HPLC column. This effect results in a substantial decrease of concentration within the elution bands and closely spaced peaks can merge. An analyte eluting as a large peak may further contaminate the following minor peaks because of the peak-broadening effect of the NMR flow cell.

In order to avoid these problems, a peak storage device for HPLC-NMR has been introduced that directs individual chromatographic peaks into capillary loops, where they are sealed and can be subsequently transferred into the NMR-flow probe. An advantage of this "loop storage" is that only minimal peak broadening occurs since the loops are made of capillaries and not of cavities like NMR flow-cells. Collected fractions can be measured in the NMR system as long as necessary and the flow cell can be washed between the transfer of individual peaks to avoid cross-contamination of analytes. Although the acquisition of NMR spectra is chronologically disconnected from the chromatographic separation, the NMR data are still obtained in the solvents used for HPLC separation. Therefore, the loop storage technique can be regarded as intermediate between direct and indirect hyphenated HPLC-NMR methods.

An alternative is the recently introduced HPLC-SPE-NMR technique, where HPLC peaks are collected on solid phase extraction (SPE) cartridges in order to remove the analyte from the HPLC mobile phase, followed by an elution with deuterated solvents. This indirect HPLC-NMR hyphenation offers numerous advantages compared to direct HPLC-NMR methods. The purified HPLC fractions typically elute in very small solvent volumes and are therefore highly concentrated. Moreover, the whole chromatography can be run with regular protic solvents, and deuterated solvents are only required for elution from the cartridge. Multiple trapping leads to an increase of analyte amounts 
available for NMR, enabling acquisition of high-quality 2D NMR data within a short time. Working with this technology also has its difficulties. A prerequisite for a successful operation of the HPLC-SPE-NMR system is that the analyte is quantitatively retained on and eluted from the SPE cartridge. Selection of the appropriate SPE material and eluting conditions can be challenging especially for unknown compounds and needs to be optimised ${ }^{127}$.

An overview on these HPLC-NMR transfer methods is given in Figure 10 and numerous examples of identified plant metabolites were discussed in recent reviews ${ }^{128-133}$

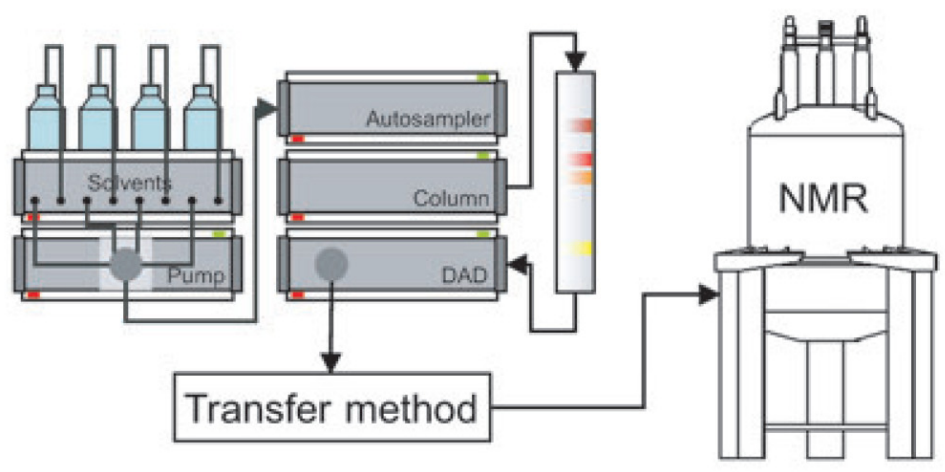

on flow:

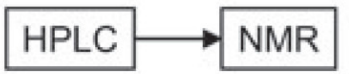

stop flow:

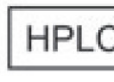

\section{Stop flow unit} NMR

loop storage:
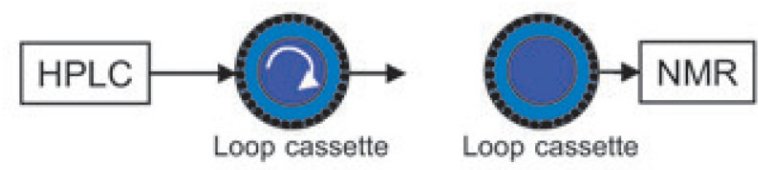

SPE:

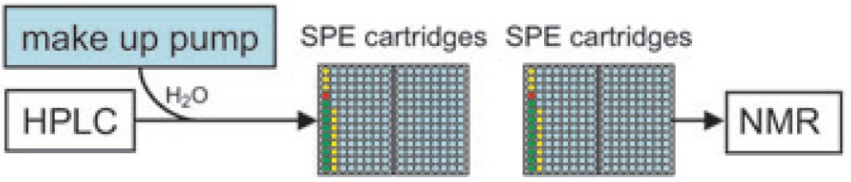

NMR is running during flow

Flow is stopped when the fraction is in the NMR cell

HPLC Fractions are collected in storage loops and then are transferred from there into the NMR

HPLC Fractions are trapped on SPE cartridges, and the carridges are dried from solvent. Fractions are then eluted from there into flow NMR or into NMR tubes

Figure 10: Various LC-NMR coupled techniques. Illustration from Bross-Walch et al. ${ }^{132}$ 
A different approach is the development of specially designed microliter NMR probes as the $1 \mathrm{~mm}$ triple resonance $(\mathrm{TXI})\left({ }^{1} \mathrm{H},{ }^{13} \mathrm{C},{ }^{15} \mathrm{~N}\right)$ probe recently introduced into the market by Bruker. This probe has been especially developed for the structural characterisation of mass and volume limited samples such as natural products and allows the measurement of $1 \mathrm{D}{ }^{1} \mathrm{H}-\mathrm{NMR}$ or $2 \mathrm{D}$ and $3 \mathrm{D}$ inverse heteronuclear NMR experiments with a few micrograms of sample. Here a single glass capillary tube for each individual sample is used in contrast to previously described directly coupled HPLC-NMR systems. NMR capillaries with microfractionated LC peaks can easily be collected and efficiently measured with the TXI probe using NMR automation and sample changing routines. This off-line approach offers some additional benefits, for example that potential dead volume effects caused by long transfer capillaries are minimised, and those caused by valve switching and fluidic problems are eliminated. LC peak dilution is

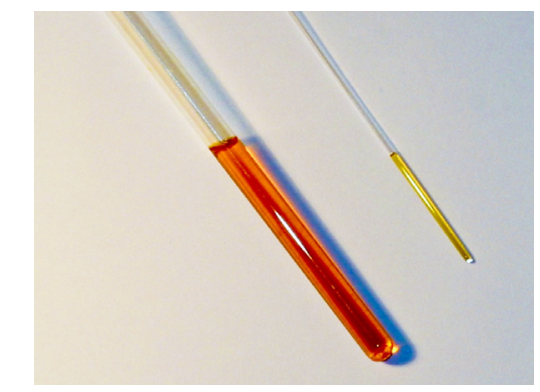
kept to an absolute minimum, which is crucial for obtaining an optimal signal-to-noise ratio of mass-limited samples. The size difference between a conventional $5 \mathrm{~mm}$ NMR tube and a $1 \mathrm{~mm}$ capillary tube is shown in Figure 11.

Figure 11: The $1 \mathrm{~mm}$ capillary tube (right) allows to identify structures from compounds in microgram range due to a higher sensitivity as result of a sample up-concentration (solvent volume approximately $5 \mu \mathrm{l}$ ). The standard NMR tube with an average sample volume of $500 \mu$ is shown on the left side.

The enormous potential of this $1 \mathrm{~mm}$ microliter probe has been demonstrated recently. Schlotterbeck et al. found an increase in mass sensitivity by a factor of five, which corresponds to a 25 fold reduction in measuring time of the same sample amount compared to a conventional $5 \mathrm{~mm}$ probe ${ }^{134}$. Furthermore, the amount of expensive deuterated solvent could be reduced by a factor of 100 . Griffin et al. used the $1 \mathrm{~mm}$ probe for a metabolic profiling of biological fluids from rats and mice. An active volume of $2 \mu \mathrm{l}$ was used to acquire ${ }^{1} \mathrm{H}-\mathrm{NMR}$ spectra of rat blood plasma and both rat and mouse cerebral spinal fluids - a volume which was easily removed without a required 
termination of the animal. Several $1 \mathrm{D}$ and 2D experiments with different solvent presaturation sequences allowed the identification of numerous compounds, which finally allowed conclusions about the distribution of metabolites between blood plasma and cerebrospinal fluids ${ }^{135}$.

\section{HPLC coupling to mass spectrometry and NMR techniques: some examples}

When considering advantages and disadvantages of NMR and MS technologies, it becomes obvious that both strategies are complementary since different analyte concentrations and analyte classes are addressed. A combination of these complementary techniques in a single setup coupled to HPLC has been described by Hostettmann et al. (Figure 12). The authors demonstrated the advantages of this powerful tool in extract screening for new antifungal agents and for the investigation of polyphenols in Gentianaceae species with monoamine-oxidase inhibitory (IMAO) properties $^{136,137}$.

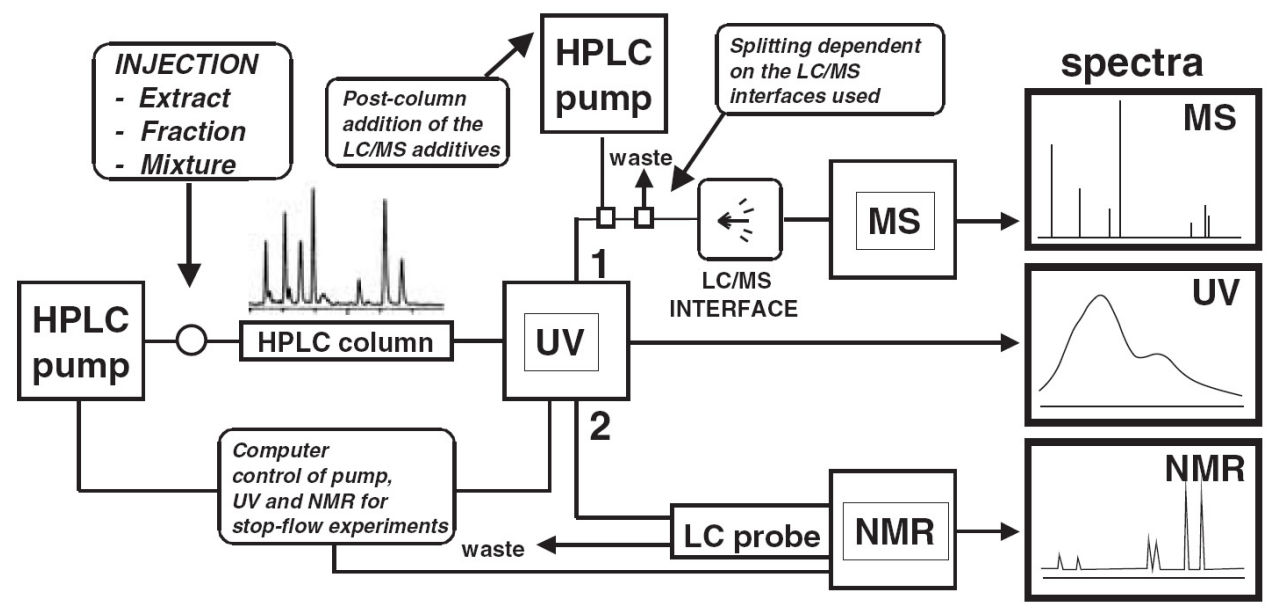

Figure 12: Schematic representation of an experimental setup used for LC-UV-MS-NMR analyses. Source: Hostettmann et al. ${ }^{137}$ 
Further studies with HPLC-MS-NMR-based methods have been carried out to identify substances from a variety of structural classes such as iridoid glycosides and phenyl propanoid glycosides from Harpagophytum procumbens Burch. DC ex. Meissn. (Devils claw) ${ }^{138,139}$, pyrrolizidine alkaloids from Senecio sp. ${ }^{140}$, iridoids from Jamesbrittenia fodina Wild O. M. Hilliard ${ }^{141,142}$, oxylipins from Arabidopsis thaliana ${ }^{143}$, carotenoids from Spinacia oleracea L. (spinach) ${ }^{144}$, furanocoumarins and quinoline alkaloids from Stauranthus perforatus Liebm. ${ }^{145}$. Various structures were identified from Hypericum perforatum $^{146,147}$, Matricaria recutita (chamomile) ${ }^{148}$, Potamogeton sp. ${ }^{149,150}$, Terminalia macroptera Guill. \& Perr. and Jasminum subtriplinerve Blume ${ }^{151}$.

Bringmann et al. showed that it is possible to elucidate the complete structure (including absolute configuration) of novel secondary plant metabolites directly from the extract matrix without a single isolation step. They used a variety of on-line spectroscopic measurements (HPLC coupled to MS, NMR and CD detection) and elucidated the structures of several naphtylisoquinoline alkaloids from from the tropical lianas Ancistrocladus griffithii Planch. ${ }^{152}$ and Habropetalum dawei (Hutch \& Dalziel) Airy Shaw $^{153}$. However, the circular dichroism (CD) detector is relatively insensitive and has so far only been applied for very few examples in natural products structure elucidation like in case of the biarylic naphtylisoqunioline alkaloids which have strong CD effects.

\section{Other technology platforms in metabolite profiling}

Some years ago, Fourier transform infrared reflectance (FT-IR) spectroscopy has been introduced as a metabolic fingerprinting technique for the analysis of plant material. This analytical technology enables a rapid, non-destructive, high-throughput analysis of a diverse range of sample types with a minimum of sample preparation. The principle of FT-IR is based on the fact that chemical bonds absorb irradiated light at a specific wavelength and vibrate in a number of ways such as stretching or bending vibrations. 
Due to its holistic nature, FT-IR is able to detect a wide range of compound classes simultaneously, but it has, however, some drawbacks. IR absorption of water in samples under investigation is very intense and can lead to signal overlapping. Moreover, sensitivity and selectivity are lower compared to previously discussed methods. Gidman et al. successfully used FT-IR to investigate global metabolites changes as a result of plant-plant interferences ${ }^{154}$ and Johnson et al. used this technology for metabolic fingerprinting of salt-stressed tomatos ${ }^{155}$. Fourier transform infrared spectroscopy has been applied to metabolomic questions far more than either raman or near infrared reflectance (NIR) spectroscopy. In NIR predominantly overtones and combination vibrations are measured while FT-IR spectra gave much more information in terms of chemical content ${ }^{156}$. NIR analysis was used by Huck et al. for a quantification of trimethoxyflavones in Primula veris L. extracts ${ }^{157}$.

A new strategy in metabolomics is to focus on a cellular level and to investigate the metabolic flux between tissues and cells. Schneider and Hölscher studied the metabolite profile in specialised cells of different Dilatris species by using laser microsection (LMS) for tissue cryosectioning in combination with NMR and compared these obtained results to those of a whole leaf extract. By the application of this technology the authors could demonstrate that some of the secondary metabolites are located only in specific cells ${ }^{158}$. A similar approach was carried out on stone cells of Norway spruce bark with a combination of LMS/NMR/MS ${ }^{159}$. 


\section{Cited Literature}

1. Hamburger, M. Isatis tinctoria - from the rediscovery of an ancient medicinal plant towards a novel anti-inflammatory phytopharmaceutical. Phytochem Rev 2003; 1, 333-344.

2. Hurry, J.B. The woad plant and its dye. Oxford University Press: London, 1930; p 8-23.

3. Tang, W., Eisenbrand, G. Chinese drugs of plant origin. In: Springer-Verlag: Berlin, 1992; pp 805-808.

4. Honda, G., Tosirisuk, V., Tabata, M. Isolation of an antidermatophytic, tryptanthrin, from the indigo plants, Polygonum tinctorium and Isatis tinctoria. Planta Med 1980; 38, 275-276.

5. Perkin, A.G., Bloxam, P. Some constituents of natural indigo. Part I. J Chem Soc 1907; 91, 279-288.

6. Perkin, A.G. Constituents of natural indigo. Part II. J Chem Soc 1907; 91, 435-440.

7. Wu, X., Liu, Y., Sheng, W., Sun, J., Qin, G. Chemical constituents of Isatis indigotica. Planta Med 1997; 63, 55-7.

8. Wu, X., Qin, G., Cheung, K.K., Cheng, K.F. New alkaloids from Isatis indigotica. Tetrahedron 1997; 53, 13323-13328.

9. Oberthür, C., Schneider, B., Graf, H., Hamburger, M. The elusive indigo precursors in woad (Isatis tinctoria L.) - identification of the major indigo precursor, isatan $\mathrm{A}$, and a structure revision of isatan B. Chem Biodiv 2004; 1, 174-182.

10. Lockwood, G.B., Belkhiri, A. Glucosinolate spectrum of some Algerian Cruciferae. Plant Syst Evol 1991; 176, 11-20.

11. Elliott, M.C., Stowe, B.B. Distribution and variation of indole glucosinolates in woad (Isatis tinctoria). Plant Physiology 1971; 48, 498-503.

12. Frechard, A., Fabre, N., Pean, C., Montaut, S., Fauvel, M.-T., Rollin, P., Fouraste, I. Novel indole-type glucosinolates from woad (Isatis tinctoria L.). Tetrahedron Letters 2001; 42, 9015-9017.

13. Goetz, J.K., Schraudolf, H. Two natural indole glucosinolates from Brassicaceae. Phytochemistry 1983; 22, 905-907.

14. Hartleb, I., Seifert, K. Acid constituents from Isatis tinctoria. Planta Med 1995; 61, 95-96.

15. Condurso, C., Verzera, A., Romeo, V., Ziino, M., Trozzi, A., Ragusa, S. The leaf volatile constituents of Isatis tinctoria by solid-phase microextraction and gas chromatography/mass spectrometry. Planta Med 2006; 72, 924-928.

16. Miyazawa, M., Kawata, J. Identification of the key aroma compounds in dried roots of Isatis tinctoria. J Essent Oil Res 2006; 18, 508-510. 
17. Peng, J., Fan, G., Wu, Y. Isolation and purification of clemastanin B and indigoticoside A from Radix Isatidis by high-speed counter-current chromatography. J Chromatogr A 2005; 1091, 89-93.

18. Hartleb, I., Seifert, K. A novel anthranilic acid derivative from Isatis tinctoria. Planta Med $1994 ; 60,578-579$.

19. Hartleb, I. Inhaltsstoffe von Isatis tinctoria L. und Verbascum songaricum Schrenk. PhD thesis, University of Bayreuth; Germany, 1994.

20. Zhu, Y.P. Chinese Materia Medica. Harwood Academic: Amsterdam, 1998.

21. Wan, S., Yang, H., Geng, X. Determination of amino acids in Isatis indigotica Fort by reversed-phase high performance liquid chromatography with pre-column derivatization. Sepu 2005; 23, 408-410.

22. Raynaud, J., Prum, N. Occurrence of isoscoparine in the seed of Isatis tinctoria L. Pharmazie 1980; 35, 712-713.

23. Cheng, Y., Schneider, B., Oberthuer, C., Graf, H., Adler, S., Hamburger, M. Flavone Cglycosides from Isatis tinctoria leaves. Heterocycles 2005; 65, 1655-1661.

24. Li, X., Sun, D.-D., Chen, J.-W., He, L.-W., Zhang, H.-Q., Xu, H.-Q. New sphingolipids from the root of Isatis indigotica and their cytotoxic activity. Fitoterapia 2007; 78, 490-495.

25. Mitscher, L.A., Baker, W. Tuberculosis: a search for novel therapy starting with natural products. Med Res Rev 1998; 18, 363-374.

26. Klutman, N.E., Bartholomew, D.W., Mitscher, L.A. Tryptanthrin, an experimental antimycobacterial drug, minimum inhibitory concentrations against multiple strains as determined by Bactec 460. Pharmacother 1997; 17, 189.

27. Klutman, N.E., Knoer, S.A., Bartholomew, W.R., Mitscher, L.A. Minimum inhibitory concentration of the 2-aza analogue and synergy of the experimental parent drug tryptanthrin against multi-drug resistant Mycobacterium tuberculosis as determined by Bactec 460. Pharmacother 1998; 18, 432.

28. Mitscher, L.A., Baker, W. A search for novel chemotherapy against tuberculosis amongst natural products. Pure Appl Chem 1998; 70, 365-371.

29. Song, Z., Johansen, H.K., Moser, C., Hoiby, N. Effects of Chinese medicinal herbs on a rat model of chronic Pseudomonas aeruginosa lung infection. APMIS 1996; 104, 350-354.

30. Bugge, G., Heiner, C. Untersuchungen zur Wirksamkeit von Färberwaid (Isatis tinctoria L.) gegenüber holzzerstörenden Pilzen. Forst Holz 1995; 50, 353-354.

31. Seifert, K., Unger, W. Insecticidal and fungicidal compounds from Isatis tinctoria. Z Naturforsch C 1994; 49, 44-49. 
32. Danz, H., Stoyanova, S., Wippich, P., Brattström, A., Hamburger, M. Identification and isolation of the cyclooxygenase-2 inhibitory principle in Isatis tinctoria. Planta Med 2001; $67,411-416$.

33. Danz, H., Stoyanova, S., Thomet, O.A.R., Simon, H.-U., Dannhardt, G., Ulbrich, H., Hamburger, M. Inhibitory activity of tryptanthrin on prostaglandin and leukotriene synthesis. Planta Med 2002; 68, 875-880.

34. Hamburger, M.M. HPLC based activity profiling for inhibitors of human neutrophil elastase in Isatis tinctoria leaf extracts. Nat Prod Commun 2006; 1, 1107-1110.

35. Oberthür, C., Jaeggi, R., Hamburger, M. HPLC based activity profiling for 5-lipoxygenase inhibitory activity in Isatis tinctoria leaf extracts. Fitoterapia 2005; 76, 324-332.

36. Rüster, G.U., Hoffmann, B., Hamburger, M. Inhibitory activity of indolin-2-one derivatives on compound 48/80-induced histamine release from mast cells. Pharmazie 2004; 59, $236-$ 237.

37. Leclerc, S. Indirubins inhibit glycogen synthase kinase-3 $\beta$ and CDK5/P25, two protein kinases involved in abnormal tau phosphorylation in Alzheimer's disease. A property common to most cyclin-dependent kinase inhibitors? J Biol Chem 2001; 276, 251-260.

38. Hoessel, R., Leclerc, S., Endicott, J.A., Nobel, M.E., Lawrie, A., Tunnah, P., Leost, M., Damiens, E., Marie, D., Marko, D., Niederberger, E., Tang, W., Eisenbrand, G., Meijer, L. Indirubin, the active constituent of a Chinese antileukaemia medicine, inhibits cyclindependent kinases. Nat Cell Biol 1999; 1, 60-67.

39. Ishihara, T., Kohno, K., Ushio, S., Iwaki, K., Ikeda, M., Kurimoto, M. Tryptanthrin inhibits nitric oxide and prostaglandin $\mathrm{E}(2)$ synthesis by murine macrophages. Eur J Pharmacol 2000; 407, 197-204.

40. Kimoto, T., Yamamoto, Y., Hino, K., Koya, S., Aga, H., Hshimoto, T., Hanaya, T., Arai, S., Ikeda, M., Fukuda, S., Kurimoto, M. Cytotoxic effects of substances in indigo plant (Polygonum tinctorium Lour.) on malignant tumor cells. Natural Med 1999; 53, 72-79.

41. Heinemann, C., Schliemann-Willers, S., Oberthür, C., Hamburger, M., Elsner, P. Prevention of experimentally induced irritant contact dermatitis by extracts of Isatis tinctoria compared to pure tryptanthrin and its impact on UVB-induced erythema. Planta Med 2004; 70, 385-90.

42. Recio, M.-C., Cerda-Nicolas, M., Potterat, O., Hamburger, M., Rios, J.-L. Anti-inflammatory and antiallergic activity in vivo of lipophilic Isatis tinctoria extracts and tryptanthrin. Planta Med 2006; 72, 539-546.

43. Recio, M.-C., Cerda-Nicolas, M., Hamburger, M., Rios, J.-L. Anti-arthritic activity of a lipophilic woad (Isatis tinctoria) extract. Planta Med 2006; 72, 715-720.

44. Oberthür, C., Graf, H., Hamburger, M. The content of indigo precursors in Isatis tinctoria leaves - a comparative study of selected accessions and post-harvest treatments.

Phytochemistry 2004; 65, 3261-3268. 
45. Eder, M., Mehnert, W. Bedeutung pflanzlicher Begleitstoffe in Extrakten. Pharmazie 1998; 53, 285-293.

46. Eder, M., Mehnert, W. Pflanzliche Begleitstoffe - wertvolle Hilfsstoffe oder überflüssiger Ballast? Pharmazie in unserer Zeit 2000; 29, 377-384.

47. Hänsel, R., Spieß, E. Pfanzliche Arzneimittelzubereitungen. In: Pharmakognosie Phytopharmazie. $7^{\text {th }}$ ed.; Hänsel, R.; Sticher, O. (Eds.), Springer-Verlag: Heidelberg, 2004; pp 149-201.

48. Williamson, E.M. Synergy and other interactions in phytomedicines. Phytomedicine 2001; 8, 401-409.

49. Rietbrock, S. Interaktionen in Vielstoffgemischen bei Phytopharmaka. In: Phytopharmaka: Forschung und klinische Anwendung. Loew, D.; Rietbrock, N. (Eds.), Steinkopff Verlag: Darmstadt, Germany, 1996.

50. Wagner, H. New approaches in phytopharmacological research. Pure Appl Chem 1999; $71,1649-1654$.

51. Singh, Y.N., Blumenthal, M. Kava. An overview. Herbalgram 1997; 39, 33-56.

52. Keledjian, J., Duffield, P.H., Jamieson, D.D., Lidgard, R.O., Duffield, A.M. Uptake into mouse brain of four compounds present in the psychoactive beverage kava. J Pharm Sci 1988; 77, 1003-1006.

53. Nahrstedt, A. Das Pflanzenreich als Wirkstoffquelle. In: Phytopharmaka IV: Forschung und klinische Anwendung. Loew, D.; Rietbrock, N. (Eds.), Steinkopff Verlag: Darmstadt, 1998; pp 13-25.

54. Philippson, J.D. New drugs from nature: it could be yew. Phytotherapy Res 1999; 13, 1-7.

55. Schmidt, B., Ludke, R., Selbmann, H.-K., Kotter, I., Tschirdewahn, B., Schaffner, W., Heide, L. Efficacy and tolerability of a standardised willow bark extract in patients with ostearthritis: randomised, placebo-controlled, double blind clinical trial. Phytother Res $2001 ; 15,344-350$.

56. Butterweck, V., Nahrstedt, A., Evans, J., Hufeisen, S., Rauser, L., Savage, J., Popadak, B., Ernsberger, P., Roth, B.L. In vitro receptor screening of pure constituents of St. John's wort reveals novel interactions with a number of GPCRs. Psychopharmacology 2002; 162, 193202.

57. Watanabe, K., Fujino, H., Morita, T., Kasai, R., Tanaka, O. Solubilization of saponins of Bupleuri Radix with ginseng saponins: cooperative effect of dammarane saponins. Planta Med 1988; 54, 405-409.

58. Kimata, H., Sumida, N., Matsufuji, N., Morita, T., Ito, K., Yata, N., Tanaka, O. Interaction of saponin of Bupleuri radix with ginseng saponin: solubilization of saikosaponin-A with chikusetsusaponin V ( = Ginsenoside-Ro). Chem Pharm Bull 1985; 33, 2849-2853. 
59. Sasaki, Y., Mizutani, K., Kasai, R., Tanaka, O. Solubilizing properties of glycyrrhizin and its derivatives: solubilization of saikosaponin A, the saponin of Bupleuri Radix. Chem Pharm Bull 1988; 36, 3491-3495.

60. Zhou, X.-H., Kasai, R., Yoshikawa, M., Kitagawa, I., Tanaka, O. Solubilization of saponins of bupleuri radix with ginseng saponins: effect of malonylginsenosides on water solubility of saikosaponin-b1. Chem Pharm Bull 1991; 39, 1250-1252.

61. Schöpke, T., Bartlakowski, J. Effects of saponins on the water solubility of quercetin. Pharmazie 1997; 52, 232-234.

62. Miaorong, P., Jing, L. In Correlativity analysis on detoxifying effect of Radix Glycyrrhizae on Radix Aconiti Preparata in Sini Decotion. Proc $40^{\text {th }}$ Anniversary Conference, Beijing University of Chinese Medicine, 1996; Beijing University Press.

63. Schindler, H. Pharmazeutische Interaktionen von Glycyrrhizinsäure mit anderen Drogeninhaltsstoffen aus Glycyrrhiza glabra L. PhD thesis, Freie Universität Berlin, Germany, 1995.

64. Oberthür, C., Heinemann, C., Elsner, P., Benfeldt, E., Hamburger, M. A comparative study on the skin penetration of pure tryptanthrin and tryptanthrin in Isatis tinctoria extract by dermal microdialysis coupled with isotope dilution ESI-LC-MS. Planta Med 2003; 69, 385389.

65. Wichtl, M. Teedrogen und Phytopharmaka - ein Handbuch für die Praxis auf wissenschaftlicher Grundlage. $3^{\text {rd }}$ ed.; Wissenschaftl. Verlagsgesellschaft: Stuttgart, 1997; p 586.

66. Franz, G. Polysaccharides in pharmacy: current applications and future concepts. Planta Med 1989; 55, 493-497.

67. Brieskorn, C.H. Ballaststoffe bei der Herstellung von Arzneipräparaten aus Pflanzen. Planta Med 1995; 3, 83.

68. Cordell, G.A. Natural products in drug discovery - creating a new vision. Phytochem Rev 2003; 1, 261-273.

69. Hostettmann, K., Marston, A. Twenty years of research into medicinal plants: Results and perspectives. Phytochem Rev 2003; 1, 275-285.

70. Directorate for the Quality of Medicines of the Council of Europe. Extracts. In: European Pharmacopoeia, $6^{\text {th }}$ ed. (6.0), Vol. 1; Aubin: Ligugé, 2008; pp 682-683.

71. Hänsel, R., Spieß, E. Pfanzliche Arzneimittelzubereitungen. In: Pharmakognosie Phytopharmazie. $7^{\text {th }}$ ed.; Hänsel, R.; Sticher, O. (Eds.), Springer-Verlag: Heidelberg, 2004; p 166.

72. Sowers, W.F., Weary, P.E., Collins, O.D., Cawley, E.P. Ginkgo-tree dermatitis. Arch Dermatol 1965; 91, 452-456. 
73. Lepoittevin, J., Benezra, C., Asakawa, Y. Allergic contact dermatitis to Ginkgo biloba L.: relationship with urushiol. Arch Dermatol Res 1989; 281, 227-230.

74. Woerdenbag, H.J., Van Beek, T.A. Ginkgo biloba. In: Adverse effects of herbal drugs. De Smet, P.A.G.M.; Keller, K.; Hänsel, R.; Chandler, R.F. (Eds.), Springer-Verlag: Berlin, 1997; Vol. 3, pp 51-66.

75. Becker, L.E., Skipworth, G.B. Ginkgo- tree dermatitis, stomatitis, and proctitis. JAMA 1975; $231,1162-1163$.

76. DeFeudis, F.V. Chapter II. Chemical composition of Ginkgo biloba extract (EGb 761): Methods of standardization of the extract. In: Ginkgo biloba extract (EGb 761): from chemistry to the clinic. DeFeudis, F.V. (Ed.), Ullstein Medical Verlagsgesellschaft: Wiesbaden, 1998; pp 7-15.

77. Käufeler, R., Thomet, O.A.R., Simon, H.-U., Meier, B., Brattström, A. Der Pestwurzextrakt Ze339 - Wirkprinzipien und klinische Pharmakologie. In: Phytopharmaka VI: Forschung und klinische Anwendung. Rietbrock, N. (Ed.), Steinkopff Verlag: Darmstadt, 2000; pp 237246.

78. Brattström, A. A newly developed extract (Ze 339) from butterbur (Petasites hybridus L.) is clinically efficient in allergic rhinitis (hay fever). Phytomedicine 2003; 10 Suppl 4, 50-52.

79. Bailey, N.J., Sampson, J., Hylands, P.J., Nicholson, J.K., Holmes, E. Multi-component metabolic classification of commercial feverfew preparations via high-field ${ }^{1} \mathrm{H}-\mathrm{NMR}$ spectroscopy and chemometrics. Planta Med 2002; 68, 734-738.

80. Nicholson, J.K., Lindon, J.C., Holmes, E. "Metabonomics": understanding the metabolic responses of living systems to pathophysiological stimuli via multivariate statistical analysis of biological NMR spectroscopic data. Xenobiotica 1999; 29, 1181-1189.

81. Fiehn, O. Metabolomics - the link between genotypes and phenotypes. Plant Mol Biol 2002; 48, 155-171.

82. Dunn, W., Ellis, D.I. Metabolomics: Current analytical platforms and methodologies. Trends Anal Chem 2005; 24, 285-294.

83. Glinski, M., Weckwerth, W. The role of mass spectrometry in plant systems biology. Mass Spectrom Rev 2006; 25, 173-214.

84. van der Kooy, F., Maltese, F., Choi, Y.H., Kim, H.K., Verpoorte, R. Quality control of herbal material and phytopharmaceuticals with the use of MS and NMR based metabolic fingerprinting. Planta Med 2008, submitted for publication.

85. Seger, C., Sturm, S. Analytical aspects of plant metabolite profiling platforms: current standings and future aims. J Proteome Res 2007; 6, 480-497.

86. Guan, J., Lai, C.M., Li, S.P. A rapid method for the simultaneous determination of 11 saponins in Panax notoginseng using ultra performance liquid chromatography. $J$ Pharm Biomed Anal 2007; 44, 996-1000. 
87. Chen, X., Ji, H., Zhang, Q.W., Tu, P.F., Wang, Y.T., Guo, B.L., Li, S.P. A rapid method for simultaneous determination of 15 flavonoids in Epimedium using pressurized liquid extraction and ultra-performance liquid chromatography. J Pharm Biomed Anal 2008; 46, 226-235.

88. Defernez, M., Colquhoun, I.J. Factors affecting the robustness of metabolite fingerprinting using ${ }^{1} \mathrm{H}$ NMR spectra. Phytochemistry 2003; 62, 1009-1017.

89. Niessen, W.M.A. Progress in liquid chromatography-mass spectrometry instrumentation and its impact on high-throughput screening. J Chromatogr A 2003; 1000, 413-436.

90. Glish, G.L., Vachet, R.W. The basics of mass spectrometry in the twenty-first century. Nature Reviews Drug Discovery 2003; 2, 140-150.

91. De Vos, R.C.H., Moco, S., Lommen, A., Keurentjes, J.J.B., Bino, R.J., Hall, R.D. Untargeted large-scale plant metabolomics using liquid chromatography coupled to mass spectrometry. Nat Protoc 2007; 2, 778-791.

92. Wolfender, J.-L. HPLC in natural product analysis: The detection issue. Planta Med 2009, in press; DOI 10.1055/s-0028-1088393.

93. Vaidyanathan, S., Jones, D., Broadhurst, D.I., Ellis, J., Jenkins, T., Dunn, W.B., Hayes, A., Burton, N., Oliver, S.G., Kell, D.B., Goodacre, R. A laser desorption ionisation mass spectrometry approach for high throughput metabolomics. Metabolomics 2005; 1, 243-250.

94. Rochfort, S. Metabolomics reviewed: a new "omics" platform technology for systems biology and implications for natural products research. J Nat Prod 2005; 68, 1813-1820.

95. Wang, Y., Holmes, E., Nicholson, J.K., Cloarec, O., Chollet, J., Tanner, M., Singer, B.H., Utzinger, J. Metabonomic investigations in mice infected with Schistosoma mansoni: An approach for biomarker identification. Proc Nat Acad Sci U S A 2004; 101, 12676-12681.

96. Ohta, D., Shibata, D., Kanaya, S. Metabolic profiling using Fourier-transform ion-cyclotronresonance mass spectrometry. Anal Bioanal Chem 2007; 389, 1469-1475.

97. Makarov, A., Denisov, E., Kholomeev, A., Balschun, W., Lange, O., Strupat, K., Horning, S. Performance evaluation of a hybrid linear ion trap/orbitrap mass spectrometer. Anal Chem 2006; 78, 2113-2120.

98. Perry, R.H., Cooks, R.G., Noll, R.J. Orbitrap mass spectrometry: instrumentation, ion motion and applications. Mass Spectrom Rev 2008; 27, 661-699.

99. Schmitt-Kopplin, P., Frommberger, M. Capillary electrophoresis - mass spectrometry: 15 years of developments and applications. Electrophoresis 2003; 24, 3837-3867.

100. Monton, M., Soga, T. Metabolome analysis by capillary electrophoresis-mass spectrometry. J Chromatogr A 2007; 1168, 237-246.

101. Garcia-Villalba, R., Leon, C., Dinelli, G., Segura-Carretero, A., Fernandez-Gutierrez, A., Garcia-Canas, V., Cifuentes, A. Comparative metabolomic study of transgenic versus 
conventional soybean using capillary electrophoresis-time-of-flight mass spectrometry. $J$ Chromatogr A 2008; 1195, 164-173.

102. Timischl, B., Dettmer, K., Kaspar, H., Thieme, M., Oefner, P.J. Development of a quantitative, validated capillary electrophoresis-time of flight-mass spectrometry method with integrated high-confidence analyte identification for metabolomics. Electrophoresis 2008; 29, 2203-2214.

103. Le Gall, G., Metzdorff, S.B., Pedersen, J., Bennett, R.N., Colquhoun, I.J. Metabolite profiling of Arabidopsis thaliana (L.) plants transformed with an antisense chalcone synthase gene. Metabolomics 2005; 1, 181-198.

104. Fiehn, O., Kopka, J., Dormann, P., Altmann, T., Trethewey, R.N., Willmitzer, L. Metabolite profiling for plant functional genomics. Nat Biotechnol 2000; 18, 1157-1161.

105. Glauser, G., Grata, E., Rudaz, S., Wolfender, J.-L. High-resolution profiling of oxylipincontaining galactolipids in Arabidopsis extracts by ultra-performance liquid chromatography/time-of-flight mass spectrometry. Rapid Commun Mass Spectrom 2008; 22, 3154-3160.

106. Dan, M., Su, M., Gao, X., Zhao, T., Zhao, A., Xie, G., Qiu, Y., Zhou, M., Liu, Z., Jia, W. Metabolite profiling of Panax notoginseng using UPLC-ESI-MS. Phytochemistry 2008; 69, 2237-2244.

107. Jensen, A.G., Ndjoko, K., Wolfender, J.-L., Hostettmann, K., Camponovo, F., Soldati, F. Liquid chromatography-atmospheric pressure chemical ionisation/mass spectrometry: a rapid and selective method for the quantitative determination of ginkgolides and bilobalide in ginkgo leaf extracts and phytopharmaceuticals. Phytochem Anal 2002; 13, 31-38.

108. Xie, J., Ding, C., Ge, Q., Zhou, Z., Zhi, X. Simultaneous determination of ginkgolides A, B, $\mathrm{C}$ and bilobalide in plasma by LC-MS/MS and its application to the pharmacokinetic study of Ginkgo biloba extract in rats. J Chromatogr B 2008; 864, 87-94.

109. Ding, S., Dudley, E., Plummer, S., Tang, J., Newton, R.P., Brenton, A.G. Fingerprint profile of Ginkgo biloba nutritional supplements by LC/ESI-MS/MS. Phytochemistry 2008; 69, 1555-1564.

110. Klayman, D.L. Qinghaosu (artemisinin): an antimalarial drug from China. Science 1985; $228,1049-1055$.

111. van der Kooy, F., Verpoorte, R., Meyer, J.J.M. Metabolomic quality control of claimed antimalarial Artemisia afra herbal remedy and $A$. afra and $A$. annua plant extracts. $S$ Afr $J$ Bot 2008; 74, 186-189.

112. Wang, H.-K., Sakurai, N., Shih, C.Y., Lee, K.-H. LC/TIS-MS fingerprint profiling of Cimicifuga species and analysis of 23-epi-26-deoxyactein in Cimicifuga racemosa commercial products. J Agric Food Chem 2005; 53, 1379-1386.

113. Shibano, M., Lin, A.-S., Itokawa, H., Lee, K.-H. Separation and characterization of active flavonolignans of Silybum marianum by liquid chromatography connected with hybrid ion- 
trap and time-of-flight mass spectrometry (LC-MS/IT-TOF). J Nat Prod 2007; 70, 14241428.

114. Holmes, E., Tang, H., Wang, Y., Seger, C. The assessment of plant metabolite profiles by NMR-based methodologies. Planta Med 2006; 72, 771-785.

115. Pauli, G.F., Jaki, B.U., Lankin, D.C. Quantitative ${ }^{1} \mathrm{H}$ NMR: development and potential of a method for natural products analysis. J Nat Prod 2005; 68, 133-149.

116. Rasmussen, B., Cloarec, O., Tang, H., Staerk, D., Jaroszewski, J.W. Multivariate analysis of integrated and full-resolution ${ }^{1} \mathrm{H}-\mathrm{NMR}$ spectral data from complex pharmaceutical preparations: St. John's Wort. Planta Med 2006; 72, 556-563.

117. Seger, C., Sturm, S., Humpfer, E., Schäfer, H., Spraul, M., Stuppner, H. In Differentiation of Hypericum perforatum (St. John's wort) lots by NMR based metabolomics. $53^{\text {rd }}$ Congress of the Society of Medicinal Plant Research, Florence, Italy, 2005; Book of Abstracts, p 298.

118. Bilia, A., Bergonzi, M.C., Mazzi, G., Vincieri, F.F. NMR spectroscopy: a useful tool for characterization of plant extracts, the case of supercritical $\mathrm{CO}_{2}$ Arnica extract. J Pharm Biomed Anal 2002; 30, 321-330.

119. Bailey, N.J., Wang, Y., Sampson, J., Davis, W., Whitcombe, I., Hylands, P.J., Croft, S.L., Holmes, E. Prediction of anti-plasmodial activity of Artemisia annua extracts: application of ${ }^{1}$ H NMR spectroscopy and chemometrics. J Pharm Biomed Anal 2004; 35, 117-126.

120. Wang, Y., Tang, H., Nicholson, J.K., Hylands, P., Sampson, J., Whitcombe, I., Stewart, C.G., Caiger, S., Oru, I., Holmes, E. Metabolomic strategy for the classification and quality control of phytomedicine: a case study of chamomile flower (Matricaria recutita L.). Planta Med 2004; 70, 250-255.

121. Bilia, A.R., Bergonzi, M.C., Lazari, D., Vincieri, F.F. Characterization of commercial KavaKava herbal drug and herbal drug preparations by means of nuclear magnetic resonance spectroscopy. J Agric Food Chem 2002; 50, 5016-5025.

122. Choi, Y.H., Kim, H.K., Hazekamp, A., Erkelens, C., Lefeber, A.W.M., Verpoorte, R. Metabolomic differentiation of Cannabis sativa cultivars using ${ }^{1} \mathrm{H}$ NMR spectroscopy and principal component analysis. J Nat Prod 2004; 67, 953-957.

123. Yang, S.Y., Kim, H.K., Lefeber, A.W.M., Erkelens, C., Angelova, N., Choi, Y.H., Verpoorte, $\mathrm{R}$. Application of two-dimensional nuclear magnetic resonance spectroscopy to quality control of Ginseng commercial products. Planta Med 2006; 72, 364-369.

124. Tarachiwin, L., Katoh, A., Ute, K., Fukusaki, E. Quality evaluation of Angelica acutiloba Kitagawa roots by ${ }^{1} \mathrm{H}$ NMR-based metabolic fingerprinting. J Pharm Biomed Anal 2008; 48, 42-48.

125. Kim, H.K., Choi, Y.H., Erkelens, C., Lefeber, A.W.M., Verpoorte, R. Metabolic fingerprinting of Ephedra species using ${ }^{1} \mathrm{H}-\mathrm{NMR}$ spectroscopy and principal component analysis. Chem Pharm Bull 2005; 53, 105-109. 
126. Choi, Y.H., Sertic, S., Kim, H.K., Wilson, E.G., Michopoulos, F., Lefeber, A.W.M., Erkelens, C., Kricun, S.D.P., Verpoorte, R. Classification of Ilex species based on metabolomic fingerprinting using nuclear magnetic resonance and multivariate data analysis. J Agric Food Chem 2005; 53, 1237-1245.

127. Clarkson, C., Sibum, M., Mensen, R., Jaroszewski, J.W. Evaluation of on-line solid-phase extraction parameters for hyphenated, high-performance liquid chromatography-solidphase extraction-nuclear magnetic resonance applications. J Chromatogr A 2007; 1165, 1 9.

128. Lambert, M., Wolfender, J.-L., Stærk, D., Christensen, S.B., Hostettmann, K., Jaroszewski, J.W. Identification of natural products using HPLC-SPE combined with capNMR. Anal Chem 2007; 79, 727-735.

129. Wolfender, J.-L., Ndjoko, K., Hostettmann, K. Liquid chromatography with ultraviolet absorbance-mass spectrometric detection and with nuclear magnetic resonance spectrometry: a powerful combination for the on-line structural investigation of plant metabolites. J Chromatogr A 2003; 1000, 437-455.

130. Jaroszewski, J.W. Hyphenated NMR methods in natural products research, part 1: Direct hyphenation. Planta Med 2005; 71, 691-700.

131. Jaroszewski, J.W. Hyphenated NMR methods in natural products research, part 2: HPLCSPE-NMR and other new trends in NMR hyphenation. Planta Med 2005; 71, 795-802.

132. Bross-Walch, N., Kuehn, T., Moskau, D., Zerbe, O. Strategies and tools for structure determination of natural products using modern methods of NMR spectroscopy. Chem Biodiv 2005; 2, 147-177.

133. Wolfender, J.-L., Queiroz, E.F., Hostettmann, K. Development and application of LC-NMR techniques to the identification of bioactive natural products. In: Bioactive natural products: detection, isolation and structural determination. $2^{\text {nd }}$ ed.; Colegate, S.M.; Molyneux, R.J. (Eds.), CRC Press: Boca raton, FI, USA, 2008; pp 143-190.

134. Schlotterbeck, G., Ross, A., Hochstrasser, R., Senn, H., Kuehn, T., Marek, D., Schett, O. High-resolution capillary tube NMR. A miniaturized $5-\mu \mathrm{L}$ high-sensitivity TXI probe for mass-limited samples, off-line LC NMR, and HT NMR. Anal Chem 2002; 74, 4464-4471.

135. Griffin, J.L., Nicholls, A.W., Keun, H.C., Mortishire-Smith, R.J., Nicholson, J.K., Kuehn, T. Metabolic profiling of rodent biological fluids via ${ }^{1} \mathrm{H}$ NMR spectroscopy using a $1 \mathrm{~mm}$ microlitre probe. Analyst 2002; 127, 582-584.

136. Hostettmann, K., Potterat, O., Wolfender, J.-L. The potential of higher plants as a source of new drugs. Chimia 1998; 52, 10-17.

137. Hostettmann, K., Wolfender, J.-L., Terreaux, C. Modern screening techniques for plant extracts. Pharm Biol 2001; 39, 18-32.

138. Seger, C., Godejohann, M., Tseng, L.-H., Spraul, M., Girtler, A., Sturm, S., Stuppner, H. LC-DAD-MS/SPE-NMR Hyphenation. A tool for the analysis of pharmaceutically used plant 
extracts: identification of isobaric iridoid glycoside regioisomers from Harpagophytum procumbens. Anal Chem 2005; 77, 878-885.

139. Clarkson, C., Stærk, D., Hansen, S.H., Smith, P.J., Jaroszewski, J.W. Identification of major and minor constituents of Harpagophytum procumbens (Devil's claw) using HPLCSPE-NMR and HPLC-ESIMS/APCIMS. J Nat Prod 2006; 69, 1280-1288.

140. Ndjoko, K., Wolfender, J.-L., Roder, E., Hostettmann, K. Determination of pyrrolizidine alkaloids in Senecio species by liquid chromatography/thermospray-mass spectrometry and liquid chromatography/nuclear magnetic resonance spectroscopy. Planta Med 1999; $65,562-566$.

141. Cogne, A.L., Queiroz, E.F., Wolfender, J.L., Marston, A., Mavi, S., Hostettmann, K. On-line identification of unstable catalpol derivatives from Jamesbrittenia fodina by LC-MS and LCNMR. Phytochem Anal 2003; 14, 67-73.

142. Cogne, A.L., Queiroz, E.F., Marston, A., Wolfender, J.-L., Mavi, S., Hostettmann, K. Online identification of unstable iridoids from Jamesbrittenia fodina by HPLC-MS and HPLCNMR. Phytochem Anal 2005; 16, 429-439.

143. Thiocone, A., Farmer, E.E., Wolfender, J.-L. Screening for wound-induced oxylipins in Arabidopsis thaliana by differential HPLC-APCI/MS profiling of crude leaf extracts and subsequent characterisation by capillary-scale NMR. Phytochem Anal 2008; 19, 198-205.

144. Dachtler, M., Glaser, T., Kohler, K., Albert, K. Combined HPLC-MS and HPLC-NMR online coupling for the separation and determination of lutein and zeaxanthin stereoisomers in spinach and in retina. Anal Chem 2001; 73, 667-674.

145. Setzer, W.N., Vogler, B., Bates, R.B., Schmidt, J.M., Dicus, C.W., Nakkiew, P., Haber, W.A. HPLC-NMR/HPLC-MS analysis of the bark extract of Stauranthus perforatus. Phytochem Anal 2003; 14, 54-59.

146. Hansen, S.H., Jensen, A.G., Cornett, C., Bjornsdottir, I., Taylor, S., Wright, B., Wilson, I.D. High-performance liquid chromatography on-line coupled to high-field NMR and mass spectrometry for structure elucidation of constituents of Hypericum perforatum L. Anal Chem 1999; 71, 5235-5241.

147. Wolfender, J.L., Verotta, L., Belvisi, L., Fuzzati, N., Hostettmann, K. Structural investigations of isomeric oxidised forms of hyperforin by HPLC-NMR and HPLC-MS ${ }^{n}$. Phytochem Anal 2003; 14, 290-297.

148. Weber, B., Herrmann, M., Hartmann, B., Joppe, H., Schmidt, C.O., Bertram, H.-J. HPLC/MS and HPLC/NMR as hyphenated techniques for accelerated characterization of the main constituents in chamomile (Chamomilla recutita [L.] Rauschert). Eur Food Res Technol 2008; 226, 755-760.

149. Waridel, P., Wolfender, J.-L., Lachavanne, J.-B., Hostettmann, K. Identification of the polar constituents of Potamogeton species by HPLC-UV with post-column derivatization, HPLC$\mathrm{MS}^{\mathrm{n}}$ and HPLC-NMR, and isolation of a new ent-labdane diglycoside. Phytochemistry 2004; 65, 2401-2410. 
150. Waridel, P., Wolfender, J.-L., Lachavanne, J.-B., Hostettmann, K. ent-Labdane glycosides from the aquatic plant Potamogeton lucens and analytical evaluation of the lipophilic extract constituents of various Potamogeton species. Phytochemistry 2004; 65, 945-954.

151. Kraus, W., Ngoc, L.H., Conrad, J., Klaiber, I., Reeb, S., Vogler, B. Investigation of biologically active natural products using online LC-bioassay, LC-NMR, and LC-MS techniques. Phytochem Rev 2003; 1, 409-411.

152. Bringmann, G., Wohlfarth, M., Rischer, H., Schlauer, J., Brun, R. Extract screening by HPLC coupled to MS-MS, NMR, and CD: a dimeric and three monomeric naphthylisoquinoline alkaloids from Ancistrocladus griffithii. Phytochemistry 2002; 61, $195-$ 204.

153. Bringmann, G., Messer, K., Wohlfarth, M., Kraus, J., Dumbuya, K., Rueckert, M. HPLC-CD on-line coupling in combination with HPLC-NMR and HPLC-MS/MS for the determination of the full absolute stereostructure of new metabolites in plant extracts. Anal Chem 1999; $71,2678-2686$.

154. Gidman, E., Goodacre, R., Emmett, B., Smith, A.R., Gwynn-Jones, D. Investigating plantplant interference by metabolic fingerprinting. Phytochemistry 2003; 63, 705-710.

155. Johnson, H.E., Broadhurst, D., Goodacre, R., Smith, A.R. Metabolic fingerprinting of saltstressed tomatoes. Phytochemistry 2003; 62, 919-928.

156. Stecher, G., Huck, C.W., M, S.W., W, G., Bakry, R., Bonn, G.K. High performance separation technologies and spectroscopic tools for plant extract characterization in phytomics. Phytochem Rev 2002; 1, 413-426.

157. Huck, C.W., Maurer, R., Popp, M., Basener, N., Bonn, G.K. Quantitative Fourier transform near infrared reflectance spectroscopy (NIRS) compared to high performance liquid chromatography (HPLC) of a flavone in Primulae veris Flos extracts. Pharm Pharmacol Lett 1999; 9, 26-29.

158. Schneider, B., Hölscher, D. Laser microdissection and cryogenic nuclear magnetic resonance spectroscopy: An alliance for cell type-specific metabolite profiling. Planta 2007; $225,763-770$.

159. Li, S.-H., Schneider, B., Gershenzon, J. Microchemical analysis of laser-microdissected stone cells of Norway spruce by cryogenic nuclear magnetic resonance spectroscopy. Planta 2007; 225, 771-779. 
3. RESULTS AND DISCUSSION 

3.1 Quantification of active principles and pigments in leaf extracts of Isatis tinctoria by HPLC/UV/MS (Mohn et al., Planta Med 2007; 73:151-156). 


\section{Tobias Mohn
Quvier Potterat Extracts of Isatis tinctoria by HPLC/UV/MS}

\begin{abstract}
An HPLC method has been developed and validated for the quantification of the pharmacologically active principles tryptanthrin (1), 1,3-dihydro-3-[(4-hydroxy-3,5-dimethoxyphenyl)methylene]-2Hindol-2-one (indolinone) (3), indirubin (4), $\alpha$-linolenic acid (2), and indigo (5), an isomer of indirubin, in extracts from the traditional anti-inflammatory plant Isatis tinctoria (woad). The chromatographic separation was performed on a C-18 column with a linear gradient of acetonitrile in water containing $0.1 \%$ formic acid. The method combines UV and electrospray MS detection in the positive ion mode for the detection of the alkaloids, with a switch to the negative mode for the analysis of $\alpha$-linolenic acid. The method was applied to the analysis of woad extracts obtained
\end{abstract}

by supercritical fluid (SFE) $\mathrm{CO}_{2}$ extraction, and by pressurized liquid extraction (PLE) with dichloromethane and methanol, respectively. While the highest concentration of $\alpha$-linolenic acid was found in the SFE extract (7.43\%), the concentrations of tryptanthrin , indolinone, indirubin and indigo were the highest in the dichloromethane extract $(0.30,0.035,2.48$ and $0.84 \%$, respectively). Compound 3 was not detected in the methanolic extract and only traces of compounds $\mathbf{1}, \mathbf{4}$ and $\mathbf{5}$ and low amount of $\alpha$-linolenic acid $(0.39 \%)$ were present in this extract.

\section{Key words}

Isatis tinctoria - Brassicaceae · tryptanthrin · indirubin · indigo · indolin-2-one $\cdot$ linoleic acid $\cdot$ quantitative analysis $\cdot$ HPLC-MS

\section{Introduction}

Woad (Isatis tinctoria L., Brassicaceae) had been used in Central Europe since antiquity as indigo dye and as a medicinal plant for the treatment of inflammatory ailments [1] until it fell into oblivion due to the import of cheaper indigo and the disappearence of woad cultures. Woad was the main blue dye in the antique world and was reportedly used by Celtic and Teutonic warriors as a hair and skin colouring [1]. The taxonomically closely related Isatis indigotica remains until now one of the most important and popular herbal drugs of the Traditional Chinese Medicine (TCM) to be used in the context of inflammatory afflictions [2]. Based on this track record, we initiated some years ago a systematic investigation of the potential of Isatis tinctoria as an evidence-based herbal anti-inflammatory [3]. Among others, we identified several constituents responsible for the anti-inflammatory properties observed in vitro [3], [4], [5], [6], and confirmed the anti-inflammatory activity of lipophilic extracts and single compounds in animal models of acute and chronic inflammation, contact allergy, as well as rheumatoid arthritis [7], [8], and in a clinical pilot study of cutaneous irritation [9]. Tryptanthrin (1), $\alpha$-linolenic acid (2), and 1,3-dihydro-3-[(4-hydroxy-3,5-dimethoxyphenyl)methylene]-2H-indol-2-one (indolinone, 3 ) were shown to be active principles inhibiting cyclooxygenase-2, 5-lipoxygenase, the expression of inducible nitric oxide synthase, human neurophil elastase, and the release of histamine from mast cells [3], [4], [5], [6], [10]. Indirubin (4) inhibits inflammatory reactions in delayedtype hypersensitivity [11] and is a potent inhibitor of cyclin-de-

University of Basel · Klingelbergstrasse 50 - 4056 Basel · Switzerland · Phone: +41-61-267-1425 Fax: +41-61-267-1474 · E-mail: Matthias.hamburger@unibas.ch

Received September 6, 2006 - Accepted December 13, 2006 
pendent kinase 5 and glycogen synthase kinase 3 [12], whereas indigo (5) is a side product of indirubin formation from indigo precursors during the drying of woad [13].

A quantitative assay for simultaneous dosage of the pharmacologically relevant constituents in woad is important in view of a development towards a new phytopharmaceutical. While quantitative assays have been reported for indigo [14] and tryptanthrin [15], [16], no method was available which would encompass all active constituents of woad. Here, we describe an HPLC procedure combining electrospray ionization (ESI) in the positive and negative modes with UV detection for the determination of 1-5 (Fig. 1). We briefly report on validation and on the application of the assay to analysis of woad extracts obtained by accelerated solvent extraction (ASE) and supercritical fluid extraction (SFE).

\section{Materials and Methods}

\section{Plant material}

Leaf material was harvested in 2001 from first year plants (rosette stage) of a defined Isatis tinctoria L. genotype mix, "Thüringer Waid", grown on experimental plots of the Agricultural Research Station of Thuringia, Dornburg, Germany. A voucher specimen (ISAR01) is preserved in the Herbarium of the Institute of Pharmacy, University of Jena, Germany.

\section{Solvents and chemicals}

Tryptanthrin (1), indolinone (3), indirubin (4) and indigo (5) were synthesized according to established procedures [17], [18], [19]. Purities of $\mathbf{1}$ and $\mathbf{3 - 5}$ were $\geq 99 \%$ as determined by HPLC and NMR. $\alpha$-Linolenic acid (2) $(\geq 99.0 \%)$ was purchased from Sigma-Aldrich (Buchs, Switzerland). Solvents were of analytical grade (extraction) or HPLC grade (chromatography) and were from Scharlau (Barcelona, Spain). Formic acid was purchased from Sigma-Aldrich. HPLC grade water was obtained by an EASYpure II (Barnstead; Dubuque, IA, USA) water purification system.

\section{Supercritical $\mathrm{CO}_{2}$ extract}

Fresh leaves were dried on a band drier operating at $60^{\circ} \mathrm{C}$ and coarsely powdered with an SK 100 cross-beater mill (Retsch;
Haan, Germany) equipped with a $2 \mathrm{~mm}$ sieve. The supercritical $\mathrm{CO}_{2}$ (SFE) extract was prepared at the Adalbert-Raps-Zentrum, Technical University München-Weihenstephan, in a pilot-plant extractor by extraction with $\mathrm{CO}_{2}$ at 800 bar and $50{ }^{\circ} \mathrm{C}$ for $3 \mathrm{~h}$. The extraction yield was $0.8 \%$. The extract corresponded to the SFE extract used in previous pharmacological and clinical studies [3], [7], [8], [9].

\section{Dichloromethane and methanol PLE extracts}

The plant material was dried in a thermostatted oven at $40{ }^{\circ} \mathrm{C}$ and powdered with an ultracentrifugal mill (Retsch ZM100) under continuous cooling with liquid nitrogen. The extracts were obtained by pressurized liquid extraction (PLE) using an ASE 200 extractor with solvent module (Dionex; Sunnyvale, CA, USA). Two cycles of extraction of 5 min each were performed. To prepare the dichloromethane extract, $5 \mathrm{~g}$ of powdered drug were extracted in a $22-\mathrm{mL}$ cartridge at $70^{\circ} \mathrm{C}$ and 120 bar. The methanol extract was obtained by extracting $1.0 \mathrm{~g}$ of drug in an $11-\mathrm{mL}$ cartridge at $60^{\circ} \mathrm{C}$ and 120 bar. The extracts corresponded to methanolic and dichloromethane extracts used in previous pharmacological and clinical studies [3], [7], [8], [9].

\section{HPLC system}

HPLC separations were carried out on an Agilent series 1100 system equipped with a degasser, a binary pump, a column oven and a DAD detector (Agilent Technologies; Waldbronn, Germany). A liquid handler 215 (Gilson; Mettmenstetten, Switzerland) was used as autosampler. The HPLC was coupled to an Esquire 3000 plus ion trap mass spectrometer (Bruker Daltonics; Bremen, Germany) fitted with an ESI source. Data acquisition and processing were performed using HyStar 3.0 software (Bruker Daltonics).

\section{Optimization of the analytical method}

Several stationary phases from different suppliers [Purosphere and Lichrospher (Merck; Darmstadt, Germany), Nucleodur (Macherey Nagel; Düren, Germany), Sunfire (Waters; Milford, MA, USA)] were tested in preliminary experiments. Due to its superior resolution power, the Sunfire column clearly showed the best results and was selected for further work. A linear gradient of acetonitrile in water containing $0.1 \%$ formic acid<smiles>O=C1c2ccccc2-n2c1nc1ccccc1c2=O</smiles><smiles>CC/C=C\C/C=C\C/C=C\CCCCCCCC(=O)O</smiles><smiles>COc1cc(SC2C(=O)Nc3ccccc32)cc(OC)c1O</smiles>

$\mathbf{3}[\mathbf{3 a}(Z), \mathbf{3 b}(E)]$<smiles>O=C1Nc2ccccc2/C1=C1/Nc2ccccc2C1=O</smiles>

4<smiles>O=C1/C(=C2\Nc3ccccc3C2=O)Nc2ccccc21</smiles>

5

Fig. 1 Structures of compounds $\mathbf{1} \mathbf{- 5}$. 
proved to afford good separation and ionization of all compounds to be analyzed.

\section{HPLC-UV-MS Analyses}

Analyses were performed at $25{ }^{\circ} \mathrm{C}$ on a Sunfire C18 column (3.5 $\mu \mathrm{m}, 150 \times 3.0 \mathrm{~mm}$ I.D.; Waters), equipped with a guard column $(20 \times 3.0 \mathrm{~mm}$ I.D. $)$. The mobile phase consisted of water containing $0.1 \%$ formic acid (eluent A) and acetonitrile (eluent B). The gradient program used was as follows: $10 \%$ to $100 \%$ B (30 min), $100 \%$ B isocratic ( $5 \mathrm{~min}$ ), $100 \%$ to $10 \%$ B (3 min). Before each separation, an equilibration time of $7 \mathrm{~min}$ was allowed. The flow rate was $0.5 \mathrm{~mL} / \mathrm{min}$ and the injection volume was $20 \mu \mathrm{L}$. UV/Vis spectra were recorded in the range of $210-700$ $\mathrm{nm}$ at a spectral acquisition rate of 2 scans/s. ESI-MS conditions were as follows: spectra were recorded under ion charge control conditions (ICC 30000) at a scan speed of $13000 \mathrm{~m} / \mathrm{z} / \mathrm{s}$ with a Gauss filter width of $0.2 \mathrm{~m} / \mathrm{z}$. Nitrogen was used as drying gas at a flow rate of $10 \mathrm{~L} / \mathrm{min}$ and as nebulizing gas at a pressure of 30 psi. The nebulizer temperature was set at $300{ }^{\circ} \mathrm{C}$. Positive ions were detected between $0 \mathrm{~min}$ and $25 \mathrm{~min}$ and negative ions between $25 \mathrm{~min}$ and $35 \mathrm{~min}$. In the positive ion mode (0-25 min), spectra were recorded in the range from $\mathrm{m} / \mathrm{z} 200$ to $600 \mathrm{amu}$; capillary voltage was set at $-4500 \mathrm{~V}$, end plate offset at $-500 \mathrm{~V}$, capillary exit at $109.8 \mathrm{~V}$, skimmer voltage at $65.0 \mathrm{~V}$ and trap drive at 39.8 . In the negative ion mode (25-30 min), spectra were recorded in the range from $\mathrm{m} / \mathrm{z} 180$ to $650 \mathrm{amu}$; capillary voltage was set at $4500 \mathrm{~V}$, end plate offset at -500 , capillary end voltage at $-111.8 \mathrm{~V}$, skimmer voltage $-40 \mathrm{~V}$ and trap drive at 43.7 .

\section{Method validation}

Peak purity was established from the 2D-DAD ( $\mathbf{1}$ and $\mathbf{4}$ ) and MS data (1-5). Reproducibility was assessed with solutions of compounds $1-4$ at $10 \mu \mathrm{g} / \mathrm{mL}$ (UV detection) or $1 \mu \mathrm{g} / \mathrm{mL}$ (ESI-MS detection). For indigo (5), a solution of $0.4 \mu \mathrm{g} / \mathrm{mL}$ was used. Analyses were performed in five replicates and the relative standard deviation was calculated (Table $\mathbf{1}$ ). Retention time deviations were $\leq 0.03 \mathrm{~min}$. Intra-day and inter-day repeatability was assessed in the course of the analysis with a standard mixture of 1-4. No significant variation of UV signal intensity of $\mathbf{1}$ and $\mathbf{4}$ was observed ( $\leq 0.9 \%$ after $18 \mathrm{~h}, \leq 1.7 \%$ after $65 \mathrm{~h}$ ). MS signal sensitivity of 3 decreased over the time of analysis ( $-9.9 \%$ after 18 h, $-19.8 \%$ after $68 \mathrm{~h}$ ) while signal intensity of $\mathbf{2}$ remained less affected $(+4.3 \%$ after $18 \mathrm{~h},-10.9 \%$ after $65 \mathrm{~h})$. Limit of detection ( $\mathrm{S} / \mathrm{N}$ ratio of 3 ) and limit of quantification ( $\mathrm{S} / \mathrm{N}$ ratio of 10 ) were determined by serial dilution of a standard solution containing $\mathbf{1 - 5}$ and are listed in Table 2.

Accuracy was determined by spiking the dichloromethane extract with defined amounts of $\mathbf{1 - 5}$. The amounts added were selected to be in the same range as the amounts of compounds originally present in the extract. Extract concentration in analysis was $1 \mathrm{mg} / \mathrm{mL}$ for $\mathbf{1 - 4}$. For solubility reasons, indigo (5) was quantified in a separate experiment, at an extract concentration of $0.0025 \mathrm{mg} / \mathrm{mL}$. Amounts added and recovery rates of $\mathbf{1 - 5}$ are listed in Table 3.

\section{Calibration curves}

$1 \mathrm{mg} / \mathrm{mL}$ stock solutions of $\mathbf{1} \mathbf{-} \mathbf{5}$ were prepared in DMSO. Calibration solutions containing a mixture of compounds $\mathbf{1 - 4}$ and separate reference solution of $\mathbf{5}$ were prepared from the stock solu-
Table 1 RSD (\%) ( $\mathrm{n}=5)$ for ESI-MS and UV detection of compounds $1-5$

\begin{tabular}{llllll}
\hline & $\mathbf{1}$ & $\mathbf{2}$ & $\mathbf{3}$ & $\mathbf{4}$ & $\mathbf{5}$ \\
\hline UV & 0.3 & nd & nd & 0.8 & 10.6 \\
ESI-MS & 1.7 & 2.3 & 0.8 & 2.3 & 1.5 \\
\hline
\end{tabular}

Amounts of compounds: UV: $200 \mathrm{ng}$ (1 and 4) or $10 \mathrm{ng}$ (5); ESI-MS: $20 \mathrm{ng}$ (1-4) or $8 \mathrm{ng}$ (5). nd: not determined.

Table 2 Limits of detection (LOD) and quantification (LOQ). Amount of compound injected [ng]

\begin{tabular}{lll}
\hline & LOD & LOQ \\
\hline ESI-MS & & \\
\hline Tryptanthrin (1) & 0.5 & 1.5 \\
\hline Linolenic acid (2) & 0.5 & 1.5 \\
\hline Indolinone (3) & 0.5 & 1.5 \\
\hline Indirubin (4) & 0.25 & 0.75 \\
\hline Indigo (5) & 0.5 & 1.5 \\
\hline UV & & \\
\hline Tryptanthrin (1) (254 nm) & 2 & 5 \\
\hline Indirubin (4) (550 nm) & 3 & 10 \\
\hline Indigo (5) (600 nm) & 3 & 10 \\
\hline
\end{tabular}

Table 3 Recovery rates

\begin{tabular}{|lccccc|}
\hline Compound & Method & $\begin{array}{l}\text { Amount added } \\
\text { to extract }\end{array}$ & $\begin{array}{l}\text { Recovered } \\
\text { amount* }\end{array}$ & $\begin{array}{l}\text { Relative } \\
\text { recovery rates }\end{array}$ \\
\hline Tryptanthrin (1) & UV 254 & 60.0 & $60.5 \pm 0.3$ & 101 \\
\hline Tryptanthrin (1) & MS 249 & 60.0 & $60.8 \pm 0.9$ & 101 \\
\hline Linolenic acid (2) & MS 277 & 300.0 & $303.7 \pm 2.4$ & 101 \\
\hline Indolinone (3) & MS 298 & 5.00 & $5.31 \pm 0.04$ & 106 \\
\hline Indirubin (4) & UV 550 & 200.0 & $195.5 \pm 0.8$ & 98 \\
\hline Indirubin (4) & MS 263 & 200.0 & $211.7 \pm 1.9$ & 106 \\
\hline Indigo (5) & MS 263 & 4.00 & $3.51 \pm 0.06$ & 88 \\
\hline
\end{tabular}

Amounts in $\mathrm{ng}$ on column ( $20 \mu \mathrm{L}$ injection). Determinations were made in triplicate.

tions by dilution with methanol over a concentration range of $50-0.1 \mu \mathrm{g} / \mathrm{mL}(\mathbf{1}-\mathbf{4})$ or $0.5-0.1 \mu \mathrm{g} / \mathrm{mL}$ (5). Each standard solution was measured in triplicate. For indolinone $\mathbf{3}$, areas of MS signals corresponding to $Z$ and $E$ isomers were added. Calibration curves are shown in Table 4.

\section{Quantitative analysis of woad extracts}

The dried extracts were dissolved with DMSO-MeOH $(1: 1)$ at a concentration of $5 \mathrm{mg} / \mathrm{mL}$. Solutions at concentrations of $1.0 \mathrm{mg} /$ $\mathrm{mL}, \quad 0.1 \mathrm{mg} / \mathrm{mL}, \quad 0.02 \mathrm{mg} / \mathrm{mL}$ and $0.005 \mathrm{mg} / \mathrm{mL}$ were prepared from the stock solution by dilution with methanol. Analyses were made in triplicate. 
Table 4 Calibration curves for compounds $\mathbf{1}$ - $\mathbf{5}$ with ESI-MS or UV detection

\begin{tabular}{|c|c|c|c|}
\hline Compound & Method & Curve & Concentration ${ }^{*}[\mathrm{mg} / \mathrm{mL}], R^{2}$ \\
\hline Tryptanthrin (1) & UV 254 & $y=8.6488 x-33.267$ & $0.001-0.05 ; R^{2}=0.9999$ \\
\hline Tryptanthrin (1) & MS 249 & $y=-609.42 x^{2}+282895 x+76422$ & $0.0001-0.005 ; R^{2}=0.9998$ \\
\hline Linolenic acid (2) & MS 277 & $y=-63.702 x^{2}+107169 x-101983$ & $0.0001-0.02 ; R^{2}=0.9985$ \\
\hline Indolinone (3) & MS 298 & $y=-181.53 x^{2}+263424 x+339242-68630$ & $0.0001-0.01 ; R^{2}=0.9998$ \\
\hline Indirubin (4) & UV 550 & $y=2.4893 x-17.573$ & $0.001-0.05 ; R^{2}=0.9999$ \\
\hline Indirubin (4) & MS 263 & $y=-826.86 x^{2}+179170 x+62576$ & $0.0001-0.005 ; R^{2}=0.9994$ \\
\hline Indigo (5) & MS 263 & $y=-253.84 x^{2}+31017 x-4739.7$ & $0.0001-0.0005 ; R^{2}=0.9994$ \\
\hline
\end{tabular}

Solutions were analysed in triplicates. For indolinone, areas of MS signals corresponding to $Z$ and $E$ isomers were added up.

* Ranges of concentration where the curves apply.

\section{Results}

The HPLC-MS analysis of a standard mixture of $\mathbf{1}-\mathbf{5}$ under optimized conditions is shown in Fig. 2. Separation on a reversed phase $\mathrm{C}-18$ column with a linear gradient of acetonitrile in water containing $0.1 \%$ formic acid provided a good separation of compounds $\mathbf{1 - 5}$ within $30 \mathrm{~min}$. The separation was carried out at a flow rate of $0.5 \mathrm{~mL} / \mathrm{min}$ without post-column eluent split. ESIMS detection of the alkaloids $\mathbf{1}$ and $\mathbf{3 - 5}$ was performed in the positive ion mode. After 25 minutes, the polarity was switched to the negative mode for the measurement of $\alpha$-linolenic acid. The positive ESI mass spectra showed strong $[\mathrm{M}+\mathrm{H}]^{+}$quasimolecular ions together with $[\mathrm{M}+\mathrm{Na}]^{+}$adducts. In the spectrum of $\alpha$-linolenic acid, [M - $\mathrm{H}]^{-}$was the base peak. At the same time, UV detection at 254 and $550 \mathrm{~nm}$ could be used for the detection of tryptanthrin and indirubin, respectively. Calibration curves (see Table 4) were found to be linear over a broad concentration range for UV detection in case of $\mathbf{1}$ and $\mathbf{4}\left(R^{2}>0.999\right)$, or fitted quadratic functions in the case of mass spectrometric detection $\left(\mathrm{R}^{2}>\right.$ 0.998). Spiking experiments demonstrated the accuracy of the method. Recovery rates between 98 and 106\% were obtained for compounds $1-4$. A recovery rate of $88 \%$ was found for indigo (5) which had to be quantified in a highly diluted extract solution due to its poor solubility (see Table $\mathbf{3}$ ).

The RSD for UV detection was lower than for MS detection (0.3$0.8 \%$ vs. $0.8-2.5 \%$ ), but LOD and LOQ were approximatively 5fold lower for MS (Table 2 ). Due to better reproducibility and repeatability, UV detection was selected for the quantitative assay of tryptanthrin (1) and indirubin (4). Determination of indigo (5), indolinone (3) and $\alpha$-linolenic acid (2) was performed with ESIMS. Extracted ion traces corresponding to $[\mathrm{M}+\mathrm{H}]^{+}$and $[\mathrm{M}-\mathrm{H}]^{-}$ quasimolecular ions, respectively, were used for signal integration. Due to the extremely low solubility of indigo, the calibration curve had to be measured with highly dilute solutions. Thus, the calibration range was much smaller than for other con-

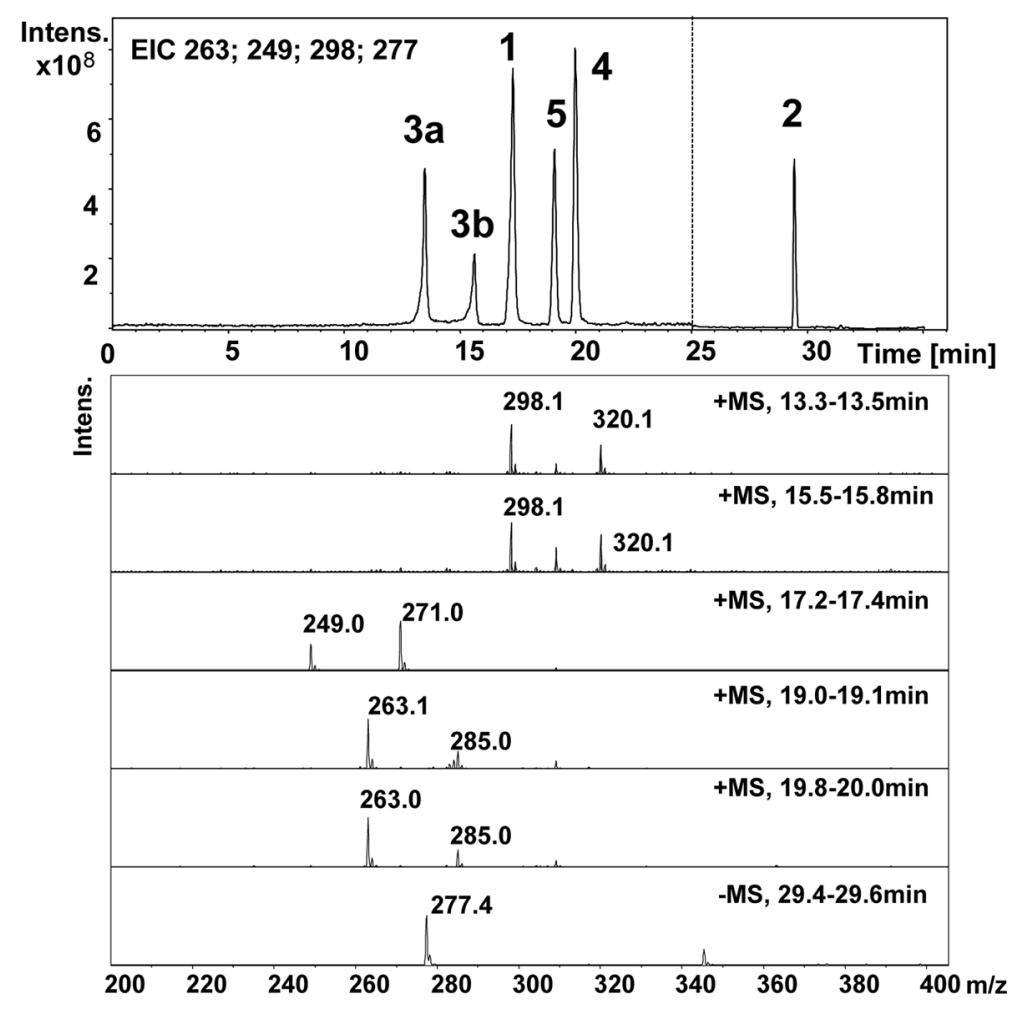

Fig. 2 HPLC/MS analysis of a mixture of $\mathbf{1}-\mathbf{5}$ (10 $\mathrm{ng}$ each). Compound $\mathbf{3}$ exists as a mixture of $Z(\mathbf{3 a})$ and $E(\mathbf{3 b})$ isomers in equilibrium. 
Table 5 Content (\%) of compounds $\mathbf{1}$ - $\mathbf{5}$ in woad extracts

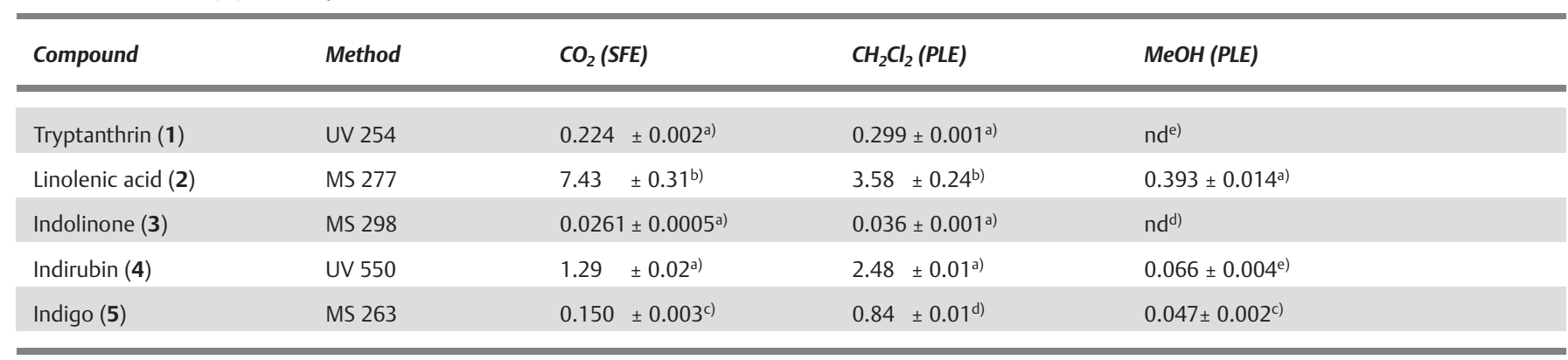

Measurements were made in triplicates.

Extract concentrations used were: a) $1.0 \mathrm{mg} / \mathrm{mL}$, b) $0.1 \mathrm{mg} / \mathrm{mL}$, c) $0.02 \mathrm{mg} / \mathrm{mL}$, d) $0.005 \mathrm{mg} / \mathrm{mL}$, e) $5.0 \mathrm{mg} / \mathrm{mL}$. nd: not detected.

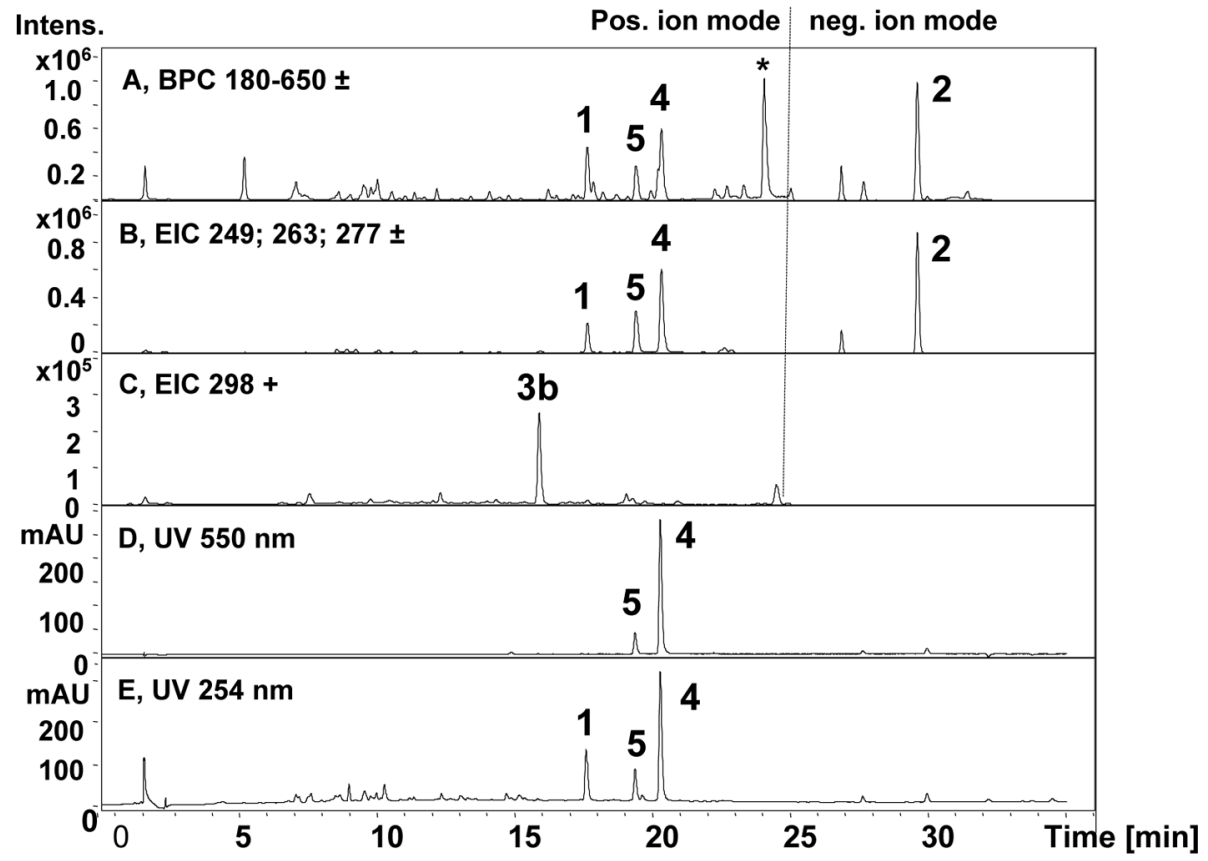

Fig. 3 HPLC/UV/MS analysis of the dichloromethane PLE extract of woad. Traces A (base peak chromatogram) and B: $2 \mu \mathrm{g}$ of extract; traces C-E: $20 \mu \mathrm{g}$ of extract. Only the $E$ isomer of indolinone was detected. * System peak. stituents (see Table 4 ). In the case of indolinone $3, E$ and $Z$ isomers which are known to undergo slow inter-conversion at room temperature [4], [18] were both present in the reference substance. Since comparable ionization properties can be reasonably assumed for both isomers, the peak areas of both isomers were added for quantitative determination.

We then applied the method for the determination of compounds $\mathbf{1 - 5}$ in different woad extracts. The SFE and dichloromethane extracts corresponded to the preparations which had been previously found to possess in vivo anti-inflammatory properties in various animal models and in the clinical pilot study [7], [8], [9], while the methanolic PLE extract was supposed to contain the entire spectrum of secondary metabolites of woad. The compounds to be dosed in these extracts were thus present at different concentrations. For this reason and due to the higher sensitivity of MS detection as well, different extract concentrations were used for the quantitative determinations, depending on compound, extract and detection mode (see Table 5 ). In particular, high dilutions of extracts $(0.002 \mathrm{mg} / \mathrm{mL}$ for SFE and methanol extracts, $0.0005 \mathrm{mg} / \mathrm{mL}$ for the dichloromethane extract) were required for the quantification of indigo due to the poor solubility of this compound. Interestingly, while both geometric isomers of $\mathbf{3}$ were present in the reference compound, only $\mathbf{3 b}$ was detected in the extracts. It has been tentatively assigned the $E$ configuration since only the $E$ isomer has been reported until now in the genus Isatis [20]. The analysis of $\mathbf{1 - 5}$ in the dichloromethane extract is shown in Fig. 3, together with the UV and extracted ion traces used for peak integration.

The highest concentration of $\alpha$-linolenic acid (2) was found in the SFE extract whereas the highest concentrations of the alkaloids were present in the dichloromethane extract. The quantitative differences between the two extracts were in accord with their lipophilicity and respective solubilities in the two extraction media. Compound $\mathbf{3}$ was not detected in the methanolic extract, and only traces of compounds $\mathbf{1 , 4}$ and $\mathbf{5}$ and a low amount of $\alpha$-linolenic acid $(0.39 \%)$ were found (Table 4$)$. This extract contained mainly highly polar compounds which eluted very early. Isatis tinctoria is known to contain high concentrations of indigo precursors [21], [22], glucosinolates [3] and other glycosides [23]. 


\section{Discussion}

The method presented here enables a quantitative determination of the pharmacologically relevant constituents in Isatis tinctoria extracts and the analysis of the dye indigo in a single run. We had previously developed assays for the determination of tryptanthrin in woad extracts [15] and in dialysates collected by cutaneous microdialysis [16]. This isocratic method, however, was not suitable for the dosage of compounds with a broad polarity range as for $\mathbf{1} \mathbf{- 5}$. For tryptanthrin (1), the sensitivity (LOD and LOQ) in MS detection in the method developed here is comparable to that achieved in the previous assay with external standard (LOQ $1 \mathrm{ng}$ ) [15], and slightly lower than that of the stable isotope dilution assay (LOQ 500 pg) [16]. However, given that the tryptanthrin concentration in the lipophilic extracts is sufficiently high, UV detection was preferred here because of smaller RSD.

A major difficulty in the dosage resulted from the widely differing concentrations of compounds $\mathbf{1 - 5}$ in extracts. Compounds such as the pharmacologically highly potent alkaloids tryptanthrin (1) and indolinone (3), and indigo (5) were present in very low concentrations, whereas linolenic acid (2) reached up to $7.4 \%$ in the SFE extract. Indigo (5) is per se not a pharmacologically relevant compound. However, it is here an unwanted side product in the formation of the bioactive indirubin (4) from indigo precurors [13] and, as such, should be determined.

We recently carried out extensive surveys of seasonal and postharvest changes in the content in indigo precursors and tryptanthrin, analyzing shock-frozen and conventionally dried Isatis tinctoria and I. indigotica, and observed profound changes in the secondary metabolite profiles during the drying process [21], [22]. Pharmacologically important compounds such as tryptanthrin (1) and indirubin (4) are formed after harvest from indigo precursors in the case of $\mathbf{4}$ [13], or via unknown pathways in the case of 1 [24]. Quantitative determination of these compounds and the other anti-inflammatory compounds in herbal raw material and in extracts is thus important for quality control in the development of a phytomedicine based on woad extract. Given the phytochemical similarity and taxonomical proximity with European woad, the assay developed here will also be useful for the quality assessment of the TCM herb Isatis indigotica and products derived from it.

\section{Acknowledgements}

We thank Dr. A. Vetter and Mrs A. Biertümpfel, Agricultural Research Station of Thuringia, Jena and Dornburg, for the provision of the plant material from the experimental field plots, and Dr. B. Weinreich, Adalbert-Raps-Forschungszentrum, TU MünchenWeihenstephan, for preparation of the SFE extract.

\section{References}

${ }^{1}$ Hurry JB. The woad plant and its dye. London: Oxford University Press; 1930: $8-23$.
2 Tang W, Eisenbrand G. Chinese drugs of plant origin. Berlin: SpringerVerlag; 1992: 805-8.

${ }^{3}$ Hamburger M. Isatis tinctoria - From the rediscovery of an ancient medicinal plant towards a novel anti-inflammatory phytopharmaceutical. Phytochem Rev 2002; 1: 333-44.

${ }^{4}$ Rüster GU, Hoffmann B, Hamburger M. Inhibitory activity of indolin2-one derivatives on compound 48/80-induced histamine release from mast cells. Pharmazie 2004; 59: 236 - 7.

${ }^{5}$ Oberthür C, Jäggi R, Hamburger M. HPLC based activity profiling for 5lipoxygenase inhibitory activity in Isatis tinctoria leaf extracts. Fitoterapia 2005; 76: $324-32$.

${ }^{6}$ Hamburger M, Rüster GU, Melzig MF. HPLC based activity profiling for inhibitors of human neutrophil elastase in Isatis tinctoria leaf extracts. Nat Prod Commun 2006; 1: 1107-10.

${ }^{7}$ Recio MC, Cerda-Nicolas M, Potterat O, Hamburger M, Rios L. Anti-inflammatory and antiallergic activity in vivo of lipophilic Isatis tinctoria extracts and tryptanthrin. Planta Med 2006; 72: 539-46.

${ }^{8}$ Recio MC, Cerda-Nicolas M, Hamburger M, Rios L. Anti-arthritic activity of a lipophilic woad (Isatis tinctoria) extract. Planta Med 2006; 72: $715-20$.

${ }^{9}$ Heinemann C, Schliemann-Willers S, Oberthür C, Hamburger M, Elsner P. Prevention of experimentally induced irritant contact dermatitis by extracts of Isatis tinctoria compared to pure tryptanthrin and its impact on UVB-induced erythema. Planta Med 2004; 70: 385 - 90.

${ }^{10}$ Ishihara T, Kohno K, Ushio S, Iwaki K, Ikeda M, Kurimoto M. Tryptanthrin inhibits nitric oxide and prostaglandin E2 synthesis by murine macrophages. Eur J Pharmacol 2000; 407: 197-204.

${ }^{11}$ Kunikata T, Tatefuji T, Aga H, Iwaki K, Ikeda M, Kurimoto M. Indirubin inhibits inflammatory reactions in delayed-type hypersensitivity. Eur J Pharmacol 2000; 410: 93-100.

12 Leclerc S, Garnier M, Hoessel R, Marko D, Bibb JA, Snyder GL et al. Indirubins inhibit glycogen synthase kinase- $3 \beta$ and CDK5/P25, two protein kinases involved in abnormal tau phosphorylation in Alzheimer's disease. J Biol Chem 2001; 276: 251 -60.

${ }^{13}$ Kokubun T, Edmonds J, John P. Indoxyl derivatives in woad in relation to medieval indigo production. Phytochemistry 1998; 49: 79-87.

14 Gilbert KG, Maule HG, Rudolph B, Lewis M, Vandenburg H, Sales E et al. Quantitative analysis of indigo and indigo precursors in leaves of Isatis spp. and Polygonum tinctorium. Biotechnol Prog 2004; 20: 1289-92.

${ }^{15}$ Danz H, Baumann D, Hamburger M. Quantitative determination of the dual COX-2/5-LOX inhibitor tryptanthrin in Isatis tinctoria by ESI-LCMS. Planta Med 2002; 68: $152-7$.

16 Oberthür C, Heinemann C, Elsner P, Benfeldt E, Hamburger M. A comparative study on the skin penetration of pure tryptanthrin and tryptanthrin in Isatis tinctoria extract by dermal microdialysis coupled with isotope dilution ESI-LC-MS. Planta Med 2003; 69: 385-9.

17 Friedländer P, Roschdestwenski N. Über ein Oxidationsprodukt des Indigoblaus. Ber Dtsch Chem Ges 1915; 48: 1841 - 7 .

18 Sun L, Tran N, Tang F, App H, Hirth P, McMahon G et al. Synthesis and biological evaluations of 3-substituted indolin-2-ones: a novel class of tyrosine kinase inhibitors that exhibit selectivity toward particular receptor tyrosine kinases. J Med Chem 1998; 41: 2588-603.

${ }^{19}$ Hoessel R, Leclerc S, Endicott JA, Nobel MEM, Lawrie A, Tunnah P et al. Indirubin, the active constituent of a Chinese antileukemia medicine. Nat Cell Biol 1999; 1: 60-7.

${ }^{20}$ Wu X, Liu Y, Sheng W, Sun J, Qin G. Chemical constituents of Isatis indigotica. Planta Med 1977; 63: 55 - 7.

${ }^{21}$ Oberthür C, Schneider B, Graf H, Hamburger M. The elusive indigo precursor in woad (Isatis tinctoria L.) - identification of the major indigo precursor, isatan A, and a structure revision of isatan B. Chem Biodivers $2004 ; 1: 174-82$.

22 Oberthür C, Graf H, Hamburger M. The content of indigo precursors in Isatis tinctoria leaves - a comparative study of selected accessions and post-harvest treatments. Phytochemistry 2004; 65: 3261 -8.

${ }^{23}$ Cheng Y, Schneider B, Oberthür C, Adler S, Hamburger M. Flavone Cglycosides from Isatis tinctoria leaves. Heterocycles 2005; 65: 1655 61.

${ }^{24}$ Oberthür C, Hamburger M. Tryptanthrin content in Isatis tinctoria leaves - a comparative study of selected strains and post-harvest treatments. Planta Med 2004; 70: 642-5. 

3.2 A comprehensive metabolite profiling of Isatis tinctoria leaf extracts

(Mohn et al., Phytochemistry; submitted for publication). 


\section{A comprehensive metabolite profiling of}

\section{Isatis tinctoria leaf extracts}

Tobias Mohn, Inken Plitzko, Matthias Hamburger*

Institute of Pharmaceutical Biology, University of Basel, Klingelbergstrasse 50, $\mathrm{CH}-4056$ Basel, Switzerland

${ }^{*}$ Corresponding author. Tel: +41-61-2671425; fax: +41-61-2671474.

E-mail address: matthias.hamburger@unibas.ch

submitted for publication to 'Phytochemistry' 


\begin{abstract}
A broad-based characterisation of a pharmacologically active dichloromethane extract from Isatis tinctoria leaves was carried out. For a comprehensive picture we also included the polar constituents of $I$. tinctoria (MeOH extract) and, for comparative purposes, the taxonomically closely related TCM plant $I$. indigotica. PDA, ELSD, APCI- and ESI-MS, and ESI-TOF-MS detectors were used in parallel to ensure a wide coverage of secondary metabolites with highly diverging analytical properties. Off-line microprobe NMR after peak purification by semi-preparative HPLC served for structure elucidation of some minor constituents.
\end{abstract}

More than 65 compounds belonging to various structural classes such as alkaloids, flavonoids, fatty acids, porphyrins, lignans, carotenoids, glucosinolates and cyclohexenones were unambiguously identified, and tentative structures proposed for additional compounds. Numerous compounds were identified for the first time in the genus Isatis, and a new indolic alkaloid was discovered.

Keywords: Isatis tinctoria, Isatis indigotica, Brassicaceae, Metabolite profile, LC-MS, Pressurised Liquid Extraction, offline LC-NMR 


\section{Introduction}

Woad (Isatis tinctoria L., Brassicaceae) has been used in Central Europe since antiquity as indigo dye and as medicinal plant for the treatment of inflammatory diseases until it fell into oblivion due to import of cheaper indigo and, as a consequence, the disappearance of woad cultures (Hamburger 2003). In China, Banlangen (Isatis root) and Daqingye (Isatis leaf) from the taxonomically closely related Isatis indigotica Fort. remain until now important and popular herbal drugs in Traditional Chinese Medicine (TCM) for the treatment of inflammatory diseases. Over the past years, we have been exploring the potential of Isatis tinctoria extracts as new active ingredient for anti-inflammatory phytopharmaceuticals. As a starting point we confirmed the anti-inflammatory potential of lipophilic $\left(\mathrm{CO}_{2}\right.$ and dichloromethane) I. tinctoria leaf extracts in a broad-based pharmacological screening (Hamburger, 2003). With the aid of HPLC-based activity profiling (Potterat and Hamburger, 2006) we then identified several pharmacologically active metabolites in the extracts, such as tryptanthrin (13), $\alpha$-linolenic acid (22) and (E)-3-(3',5'-dimethoxy-4'-hydroxybenzylidene)-2-indolinone (9) as inhibitors of cyclooxygenase-2, 5-lipoxygenase, expression of inducible nitric oxide synthase (iNOS), human neutrophil elastase, and release of histamine from mast cells (Danz et al., 2001; Danz et al., 2002; Hamburger et al., 2006; Oberthür et al., 2005; Rüster et al., 2004). These findings were corroborated by pharmacological studies on tryptanthrin (13) and indirubin (15) performed by other groups (Hoessel et al., 1999; Honda et al., 1980; Ishihara et al., 2000; Kimoto et al., 1999). The potential of lipophilic Isatis tinctoria extracts was substantiated by in vivo studies in models of acute and chronic inflammation, contact allergy, and rheumatoid arthritis (Recio et al., 2006a, b), and by a clinical pilot study in experimentally induced skin erythema (Heinemann et al., 2004). With the aid of a skin microdialysis study, we demonstrated that in topical application the extract matrix had a solubilising and penetration enhancing effect on the poorly soluble alkaloid tryptanthrin (13) (Oberthür et al., 2003).

Parallel to these pharmacological investigations, we identified the correct structure of the major indigo precursors in woad (Oberthür et al. 2004) and identified new flavone 
glycosides (Cheng et al., 2005). We analysed composition and seasonal variation of indigo precursors and glucosinolates in defined accessions of Isatis tinctoria and $I$. indigotica leaves and seeds, and investigated the influence of harvest regimen on the chemical composition of woad leaves (Oberthür et al., 2004; Mohn and Hamburger, 2008; Mohn et al., 2008). We observed profound post-harvest changes in metabolite pattern during the drying of leaves, chiefly the virtual disappearance of glucosinolates and indigo precursors, and the appearance of tryptanthrin (13) (Oberthür and Hamburger, 2004), besides the well known post-harvest artefacts indigo (14) and indirubin (15).

There is a difficulty with the chemical characterisation of herbal extracts used as phytomedicines. Regulatory agencies such as BfArM (Germany) or Swissmedic (Switzerland) consider the extract in its entiety as active ingredient. Manufacturers of phytomedicines often use active marker substances for quality control purposes. For very few phytopharmaceuticals, the global composition of the active ingredient (extract) has been analysed in a more comprehensive manner and data published. Notable examples include the special extracts EGb 761 (derived from Ginkgo biloba leaves) (Hänsel and Spie $\beta, 2004$ ) and ZE 331 (obtained from Petasites hybridus leaves) (Brattström, 2003). However, the analyses include only a limited number of compound classes, and major portions of these extracts remain uncharacterised.

In recent years, significant advances in LC-based on-line spectroscopy opened new avenues for increasingly comprehensive analysis of plant extracts. These possibilities have been exploited in metabolite profiling studies in which plant secondary metabolism was investigated from various perspectives (Burns et al., 2003; Dan et al., 2008; Ding et al, 2008; lijima et al., 2008; Le Gall et al., 2005; Long et al., 2006; Qiao et al., 2008; Schliemann et al., 2008; Yamazaki et al., 2003). However, given the enormous difficulties of a comprehensive analysis, these studies have been usually focused on a limited range of compound classes.

Here, we report on a broad-based characterisation of the pharmacologically active extract from Isatis tinctoria leaves, using multiple detection systems to ensure a wide coverage of secondary metabolites with highly diverging analytical properties. For a comprehensive picture we also included the polar constituents of I. tinctoria $(\mathrm{MeOH}$ 
extract) and, for comparative purposes, the taxonomically closely related TCM plant $I$. indigotica.

\section{Results}

\subsection{Metabolite profile of Isatis dichloromethane extracts}

Isatis tinctoria and Isatis indigotica leaves were submitted to pressurised liquid extraction (PLE) using dichloromethane and methanol. The dichloromethane extract corresponded to the pharmacologically active lipophilic extract reported earlier (Hamburger, 2003). Extracts were analysed by HPLC-PDA-MS and HPLC-TOF-MS. An overview of identified compounds is given in Figure 1. Figure 2A shows the HPLC profile of an I. tinctoria dichloromethane extract on $\mathrm{C}_{18}$ column (HPLC system 1). For the characterisation of the pharmacologically active extract in its full complexity, we combined several detectors as PDA, ESI-MS and APCI-MS (positive and negative ion mode). The unspecific evaporative light scattering detector (ELSD) was used to ensure that all separated compounds were assigned with at least one mass spectrometric detection mode. Additional structural information was obtained by MS/MS experiments and by high-resolution mass spectra recorded by ESI-TOF-MS (traces are not shown in Figure 2A). An overview of all compounds identified in the dichloromethane extract, and molecular formulae and UV data of further compounds is given in Table 1. Compounds 1-4, 6-7, 9-10, 13-15, 18, 22-25, 29, 30, 33, 34 and 37 were identified by analysis of on-line spectroscopic data and subsequent confirmation by co-chromatography with reference compounds. 
Indole derivatives and miscellaneous alkaloids

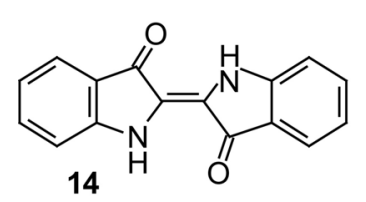<smiles>O=C1Nc2ccccc2/C1=C1\Nc2ccccc2C1=O</smiles><smiles>O=C1Nc2ccccc2C1=C1C(=O)Nc2ccccc21</smiles><smiles>O=C1/C(=C/c2c[nH]c3ccccc23)Nc2ccccc21</smiles><smiles>O=C1c2ccccc2-n2c1nc1ccccc1c2=O</smiles><smiles>O=c1c2ccccc2nc2n1CCC2</smiles><smiles>O=C1CNc2ccccc21</smiles><smiles>O=CNc1ccccc1C(=O)O</smiles><smiles>O=C1Cc2cc(O)ccc2N1</smiles><smiles>O=C(O)c1ccccc1-n1cnc2ccccc2c1=O</smiles><smiles>COc1cc(C)cc(OC)c1O</smiles><smiles>OC1COC(Oc2c[nH]c3ccccc23)C(O)C(O)CO1</smiles><smiles>N#CCc1c[nH]c2ccccc12</smiles>

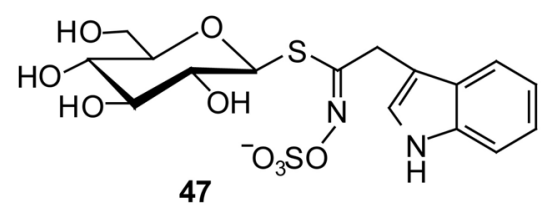<smiles></smiles>

\section{Porphyrins}

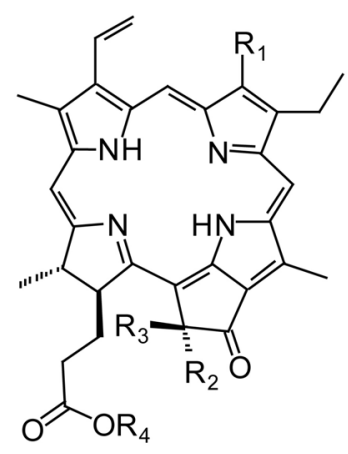

$\begin{array}{llll}\mathbf{R}_{\mathbf{1}} & \mathbf{R}_{\mathbf{2}} & \mathbf{R}_{\mathbf{3}} & \mathbf{R}_{\mathbf{4}}\end{array}$

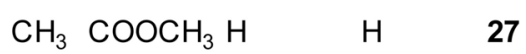
$\begin{array}{lll}\mathrm{CH}_{3} \mathrm{H} & \mathrm{COOCH}_{3} \mathrm{H} & \mathbf{2 8}\end{array}$ $\begin{array}{llll}\mathrm{CH}_{3} \mathrm{H} & \mathrm{H} & \mathrm{H} & \mathbf{3 1}\end{array}$ $\mathrm{CH}_{3} \mathrm{COOCH}_{3} \mathrm{OH} \quad \mathrm{H} \quad 26$ $\mathrm{CHO} \mathrm{COOCH}_{3} \mathrm{H} \quad \mathrm{C}_{20} \mathrm{H}_{39} \mathbf{5 6}$ $\begin{array}{ll}\mathrm{CH}_{3} \mathrm{COOCH}_{3} \mathrm{H} & \text { (phytyl-) } \\ \mathrm{C}_{20} \mathrm{H}_{39} \mathbf{5 7}\end{array}$ (phytyl-) $\mathrm{CHOH} \quad \mathrm{H} \quad \mathrm{C}_{20} \mathrm{H}_{39} \quad 58$ $\mathrm{CH}_{3} \mathrm{H}^{2} \quad$ (phytyl-) $\mathrm{CH}_{3} \mathrm{H} \quad \mathrm{H} \quad \mathrm{C}_{20} \mathrm{H}_{39} \quad \mathbf{5 9}$ (phytyl-)
Fatty acids
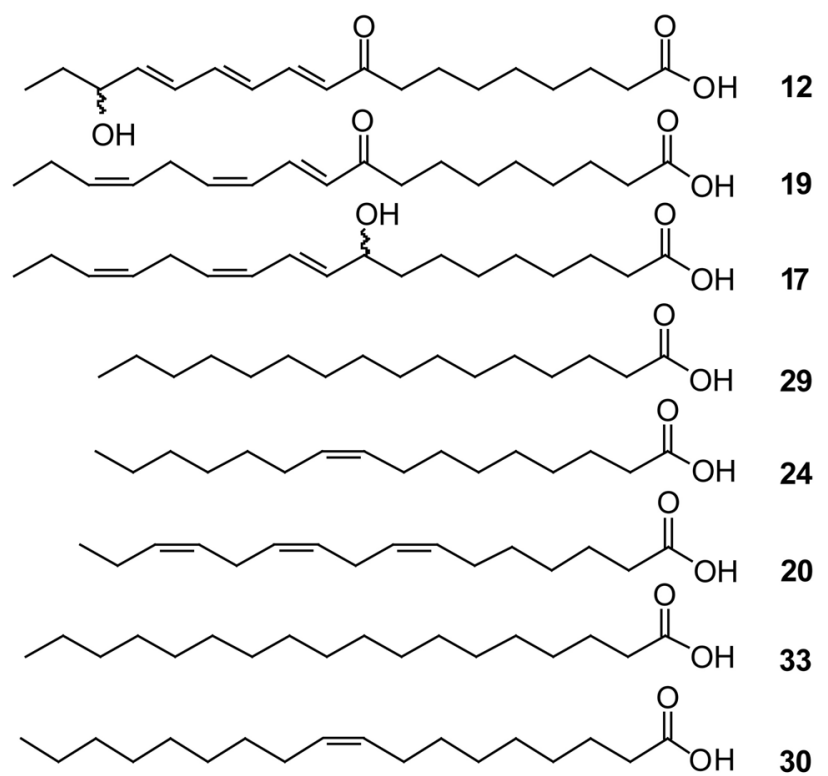

30

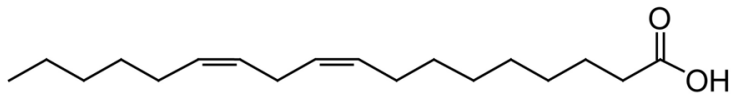

25

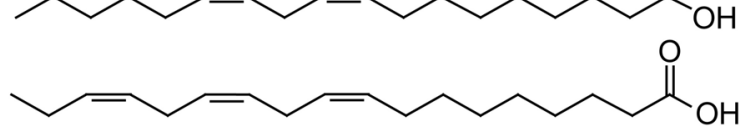

22

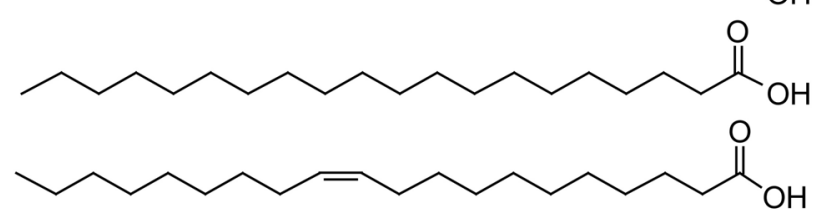

37 


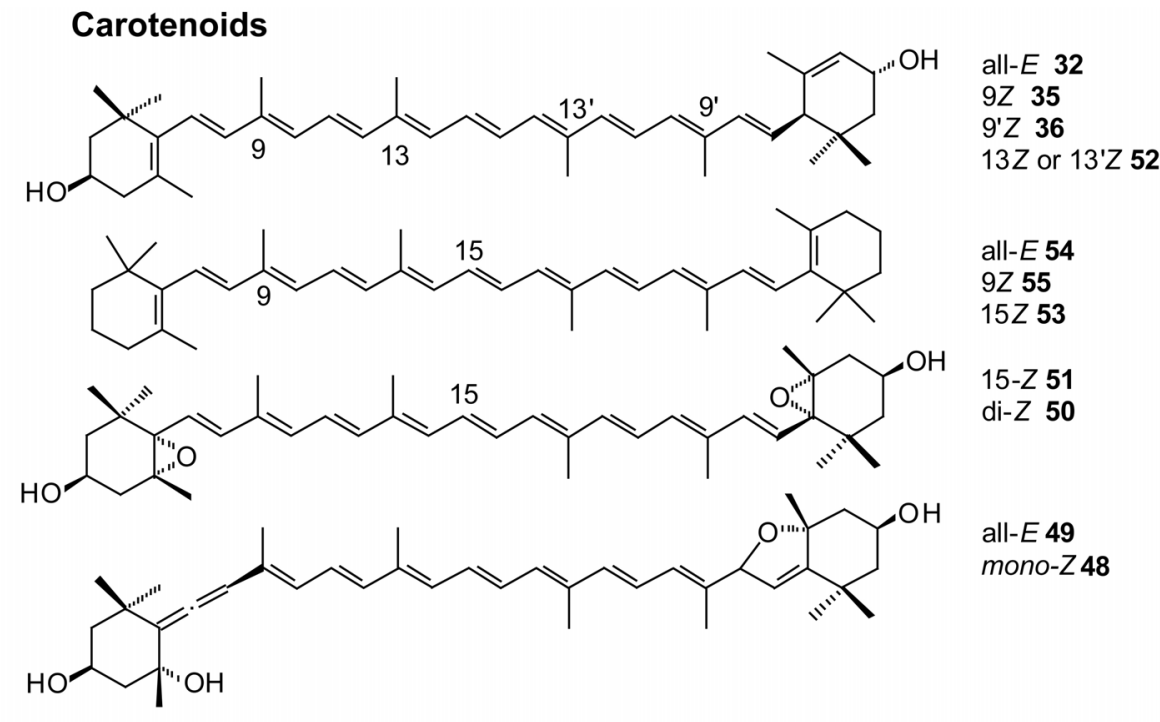

Flavonoids

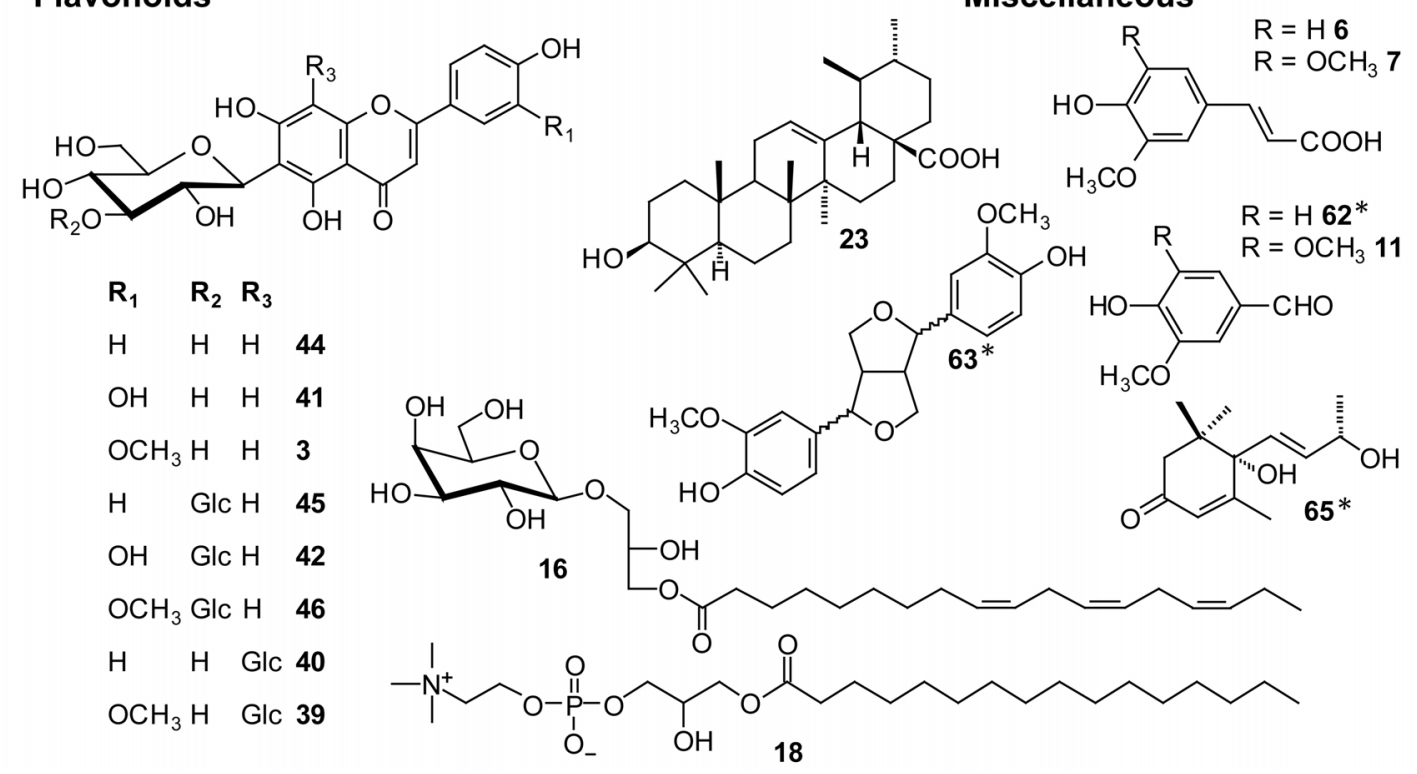

Figure 1. Structures of compounds 1 to 65 . Consecutive numbering is according to their chromatographic retention. Compounds designated with (symbol *) were not detectable in the crude extracts and were identified only after MPLC pre-fractionation.

Compounds $5,8,20,21,26-28,31,32,35$ and 36 were identified on the basis of their UV data in combination with $\mathrm{MS}^{n}$, high resolution-MS, and literature data on their chromatographic retention (Terasaki et al., 2002; van Breemen et al., 1991; Canjura and Schwartz, 1991; de Rosso and Mercadante, 2007a, b). The alkaloids 5hydroxyoxindole (5), 3-(2'-carboxyphenyl)-quinazolin-4-on (8) and bisindigotin (21) have been described for I. tinctoria or I. indigotica before (Li et al., 2000; Wei et al., 2005; Wu et al., 1997) while the unsaturated fatty acid ((7Z, 10Z, 13Z)hexadecatrienoic acid (20)) and the porphyrins 10-hydroxy-phaeophorbide (26), phaeophorbide a (27), its epimeric form phaeophorbide a' (28) and 
pyrophaeophorbide a (31), and the lutein isomers (32), (35) und (36) are compounds that are widely occurring in higher plant families.
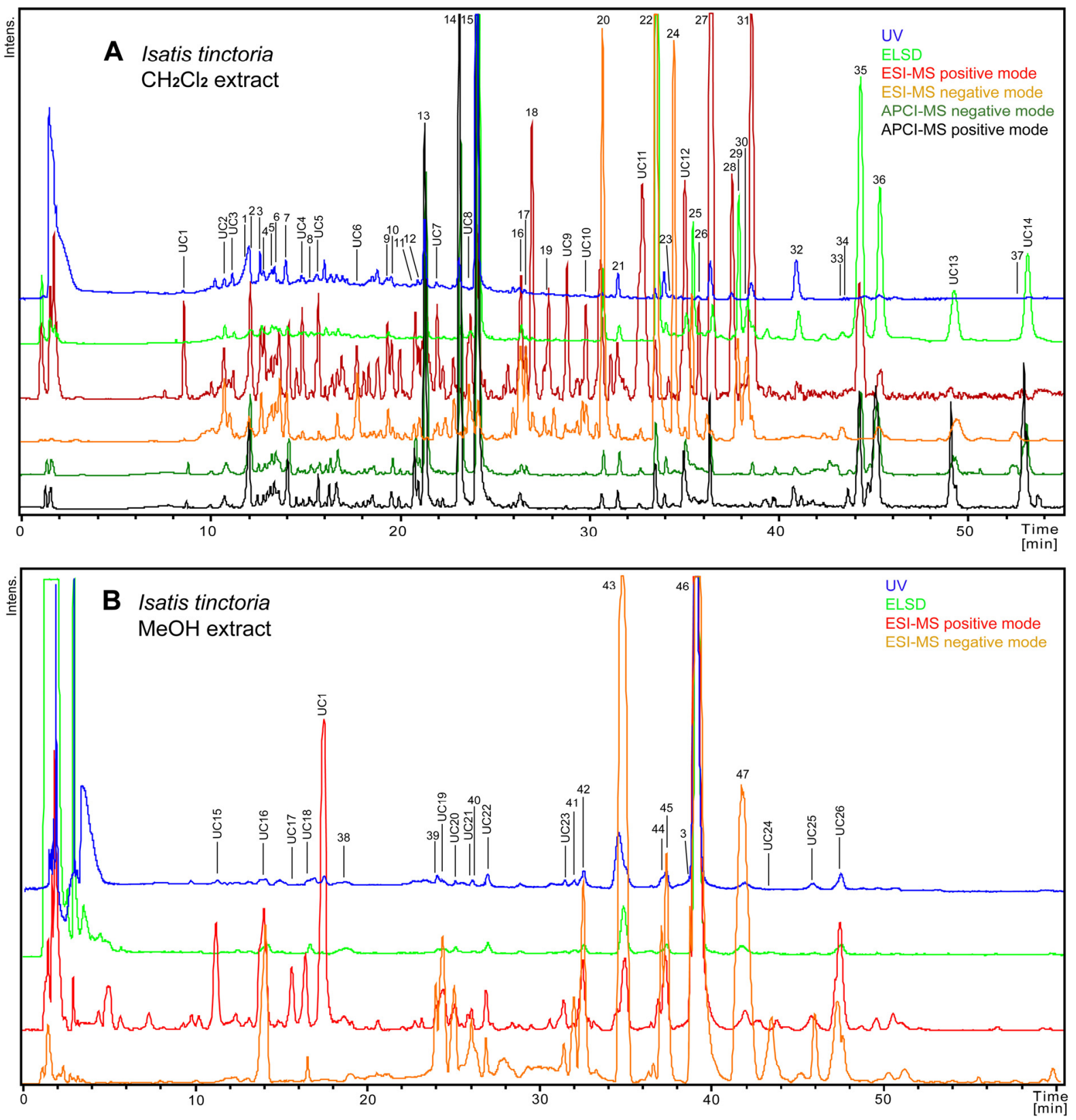

Figure 2. HPLC profiles of Isatis tinctoria dichloromethane $(\mathbf{A})$ and methanol $(\mathbf{B})$ extracts recorded with UV, ELSD, and ESI-MS and APCI-MS detectors in positive and negative ion mode. Peak labelling designates unambiguously identified compounds, and compounds for which only partial structural information was obtained (UC1 to UC26). 
Additional peaks of interest which could not be identified by on-line spectroscopy and reference compounds were earmarked for small scale purification and off-line NMR analysis. The dichloromethane extract was separated by MPLC into seven fractions, and fractions 2 and 3 were separated by semi-preparative HPLC. Collected peaks were submitted to NMR and TOF-MS analysis after removal of solvents. Structures of additional 12 compounds $(11,12,16,17,19,43,60-65)$ were elucidated with this approach. NMR spectra of 60-62 were identical with those of available reference compounds. Other compounds were identified by comparison with literature data, e.g. syringic aldehyde (11) (Hiltunen et al., 2006), 16-hydroxy-9-oxo-(10E, 12E, 14E)octadecatrienoic acid (12) (Yoshikawa et al., 1998) , 1-O- $\beta-D-g a l a c t o p y r a n o s y l-3-O-$ linolenylglycerol (16) (Hohmann et al., 1996), 9-hydroxy-(10E, 12Z, 15Z)octadecatrienoic acid (17) (McLean and Reynolds, 1996), 9-oxo-(10E, 12Z, 15Z)octadecatrienoic acid (19) (Koch et al., 2002), pinoresinol (63) (Xie et al., 2003) and 6,9-dihydroxy-4,7-megastigmadien-3-one (65) (Cutillo et al., 2005) (configurations of hydroxyl groups for compounds 12 and 17, and absolute and relative configurations for compounds 63 and 65 were not determined). The separation of fraction 3 gave a peak at 48.5 min which was identified as a new compound, (2Z)-2-(1H-indol3ylmethylidene)-1,2-dihydro-3H-indol-3-one (64) (Fig.1). Its molecular formula was established as $\mathrm{C}_{17} \mathrm{H}_{12} \mathrm{~N}_{2} \mathrm{O}$ by HR-ESI-MS (m/z $261.1031\left([\mathrm{M}+\mathrm{H}]^{+}\right.$, calc. 261.1029). HSQC and HMBC spectra (Fig. 2S) revealed that the ${ }^{13} \mathrm{C}$ resonances of 16 carbons were in the range of $105-153$ ppm and indicated a highly aromatic character of 64 . A carbonyl resonance appeared at $\delta 185.0$ ppm. Two NH groups ( $\delta 9.28$ and 11.91) and ten additional protons were observed in the ${ }^{1} \mathrm{H}-\mathrm{NMR}$ spectrum. The signals at $\delta$ $6.89(\mathrm{H}-5), 7.17(\mathrm{H}-7), 7.17\left(\mathrm{H}^{-} 5^{\prime}\right), 7.22\left(\mathrm{H}-6^{\prime}\right), 7.48(\mathrm{H}-6), 7.48\left(\mathrm{H}-7^{\prime}\right), 7.57(\mathrm{H}-4)$, $7.83\left(\mathrm{H}-4^{\prime}\right)$ were characteristic for two ortho-substituted benzene moieties, and two singulets at $\delta 7.07(\mathrm{H}-10)$ and $8.17\left(\mathrm{H}-2^{\prime}\right)$ indicated two additional double bonds. 1DTOCSY experiments were used for the determination of overlapping aromatic signals, while HSQC and HMBC correlations (Figure 3) were used for further structure assignments. 1D NOESY experiments indicated spacial proximity of $\mathrm{H}-1$ (9.28 ppm), $\mathrm{H}-10$ (7.07 ppm) and H-2' (8.17 ppm) and, consequently, a Zconfiguration of the linkage of the two indole moieties in $\mathbf{6 4 .}$ 


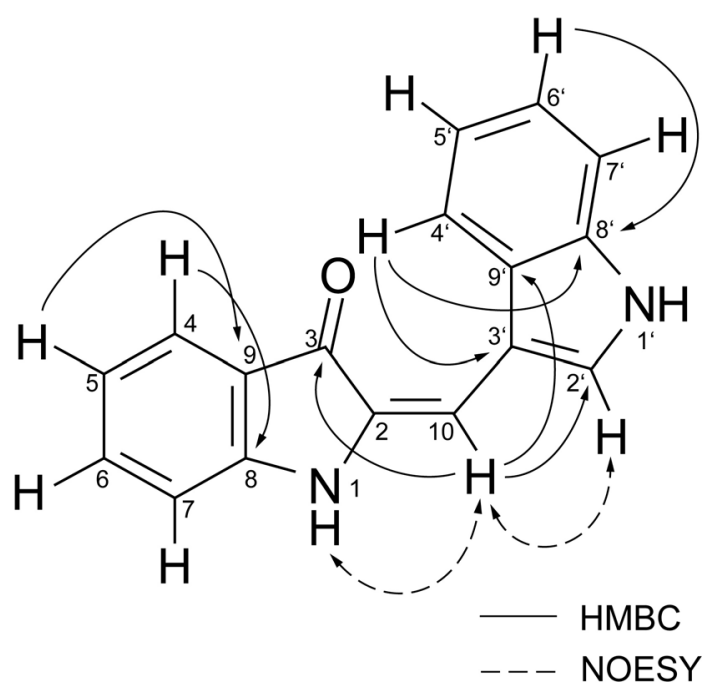

Figure 3. Structure of new indole alkaloid 64 (2Z)-2-(1H-indol-3-ylmethylidene)-1,2-dihydro$3 H$-indol-3-one with key HMBC and NOESY correlations.

Numerous compounds from the dichloromethane extract of $I$. tinctoria could be also detected in the closely related species I. indigotica. A complete list of identified compounds and HPLC profiles obtained with PDA, ELSD and MS detectors are given as supplementary data (Table $1 \mathrm{~S}$ and Figure $1 \mathrm{~S}$ ).

\subsection{Profiling of Isatis methanol extracts}

In previous studies (Oberthür et al., 2004, Mohn et al., 2008), we had observed profound changes in the spectrum of polar metabolites in woad leaves during the drying process. Therefore, we carried out a profiling of the $\mathrm{MeOH}$ extracts following extraction with dichloromethane. The separation (HPLC system 2) of the I. tinctoria $\mathrm{MeOH}$ extract is shown in Figure 2B. With exception of peaks $\mathbf{3 8}$ and $\mathbf{4 7}$ (indican and glucobrassicin), the extract mainly contained flavone-O- and $\mathrm{C}$-glycosides. Compounds 3, 38, 41, 44-47 were identified with the aid of spectroscopic data (Table 2 ), and structures were confirmed by co-chromatography with reference substances. Characteristic MS/MS fragments in combination with UV and HRMS spectra, retention time and literature data were used for the identification of the flavone-di-Cglycosides 39 and $\mathbf{4 0}$ and for compound $\mathbf{4 2}$ with $\mathrm{O}$ - and $C$-linked sugar moieties (Gattuso et al., 2006; Deng et al., 2008). No fragments corresponding to a cleavage of a hexosyl moiety $\left([\mathrm{M}-162]^{+}\right)$were observed in the ESI-MS spectra of $\mathbf{3 9}$ and $\mathbf{4 0}$ 
recorded in positive ion mode, but numerous small fragments resulting from two $C$ glycosidic moieties. In contrast, the spectrum of $\mathbf{4 2}$ showed loss of an O-glycosidic hexosyl moiety, followed by a partial fragmentation of a $C$-linked hexosyl moiety in $\mathrm{MS}^{2}$ and $\mathrm{MS}^{3}$. These results are in agreement with literature reports (Gattuso et al., 2006; Li and Claeys, 1994; Waridel et al., 2004; Wolfender et al., 2001) and own experiments with flavone $O$ - and $C$-glycosides. Glucobrassicin (47) and indican (38) were the only glucosinolates and indigo precursors that could be detected.

Semi-preparative isolation and NMR analysis of a peak at $35.0 \mathrm{~min}$ lead to the structure of $N$-formyl anthranilic acid (43), a compound which has been described for I. tinctoria by Hartleb (1994).

The majority of compounds identified from the $\mathrm{MeOH}$ extract of $I$. tinctoria were also present in I. indigotica (Fig. $1 S$ and Table 2S; supplementary data). Besides the absence of some unidentified minor compounds only $\mathrm{N}$-formyl anthranlic acid (43) and glucobrassicin (47) were not detected in I. indigotica. Absence of the latter compound in I. indigotica leaves had already been observed (Mohn et al. 2008).

\subsection{Profiling of carotenoids}

Several carotenoids $(32,35$ and 36$)$ were detected in the dichloromethane extract of Isatis tinctoria and I. indigotica leaves. Extraction and separation conditions, however, were not optimal for analysis of these highly lipophilic metabolites. For a more comprehensive analysis of the carotenoid pattern in dried leaves, we used dedicated extraction and separation protocols (extraction with hexane / acetone (1:1) (Britton, 1995) and HPLC on a $\mathrm{C}_{30}$ column (de Rosso and Mercadante, 2007b)). A HPLC chromatogram is shown in Figure 4, and an overview of identified compounds and spectroscopic data is given in Table 3. Although only (all-E)- $\beta$-carotene (54) was available as reference compound, it was possible to identify other carotenoids (32, 35,36 and 48-55) by a combination of spectroscopic and chromatographic information, including UV-vis spectra ( $\lambda_{\max }$, relative intensities of absorption maxima, and presence/absence of an absorption band at approximately $330 \mathrm{~nm}$ indicative of cis-configured double bonds), elution order on a $\mathrm{C}_{30}$ column, APCI-MS and MS/MS 
data, and comparison with published literature (de Rosso and Mercadante, 2007a, b). The elution order for $E$ - and Z- isomers has been described for lutein by Updike and Schwartz (2003), for violaxanthin by Meléndez-Martínez et al. (2007), and for $\beta$ carotene by Jaime et al. (2007).

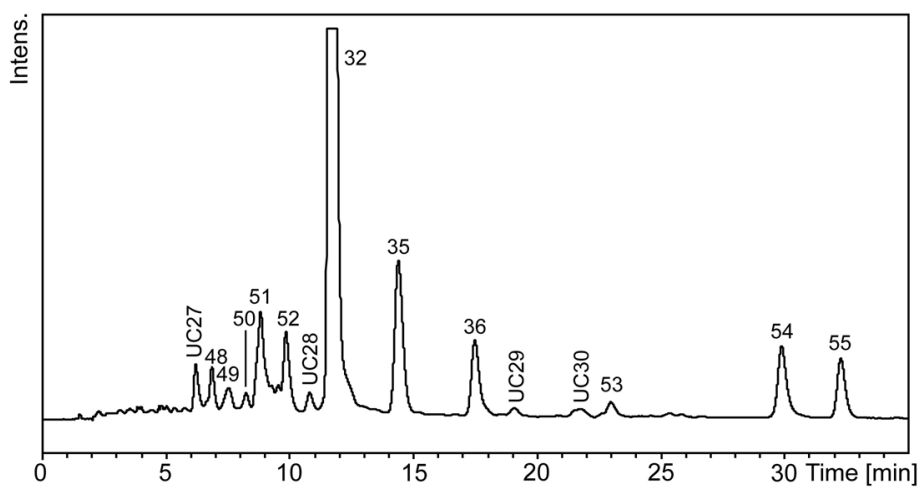

Figure 4. Carotenoid profile of Isatis tinctoria hexane/acetone leaf extract. Peak labelling $\mathbf{3 2}, \mathbf{3 5}, \mathbf{3 6}$, and 48-55 designates characterised compounds. UC27 to UC30 are carotenoids which could not be unambiguously identified.

The lipophilic chlorophyll degradation products phaeophytin b (56), phaeophytin a (57), pyrophaeophytin b (58) and pyrophaeophytin a (59) were detected, if no saponification procedure was carried out. Spectral properties (UV, MS and MS/MS data) and elution order of these compounds were in accord with previously published data (van Breemen et al., 1991; Canjura and Schwartz, 1991).

\section{Discussion and conclusion}

The purpose of this study was to analyse the spectrum of extracted metabolites as comprehensively as reasonably possible, for the pharmacologically active lipophilic leaf extract of Isatis tinctoria, and to complement this profiling study with an analysis of polar metabolites and the closely related I. indigotica. In total, 65 compounds belonging to various structural classes could be unambiguously identified, including alkaloids, flavone glycosides, glucosinolates and indigo precursors, fatty acids, porphyrins, carotenoids, lignans, cyclohexenones and phenylpropanoids. Additional 
compounds could be assigned to specific compound classes, or earmarked on the basis of their molecular formula derived from ESI-TOF-MS data. Numerous compounds have been identified for the first time in the genus Isatis (compounds 11, $12,16-19,26-28,32,35,36,39,40,48-59)$, and compound 64 is a new natural product. Compounds 2, 8, 20, 21, 31, 41, 46, 63 and 65 were known so far only for $I$. indigotica and are reported here for I. tinctoria.

The example demonstrates that only the parallel use of multiple detectors and detection modes can adequately reveal the complexity of a plant extract. With a combination of PDA, ELSD, ESI- and APCI-MS in positive and negative ion modes, virtually all peaks could be detected with at least two independent detection modes, and molecular formula could be derived in a second step from ESI-TOF-MS data. For a number of peaks, UV-vis and MS data did not permit unambiguous structural assignment. This was, for example, the case with fatty acids, where location of functional groups and E/Z geometry of double bonds could not be established. Offline microprobe NMR after peak purification by semi-preparative HPLC proved to be complementary. For truly minor constituents, a rapid pre-fractionation of the extract by MPLC was necessary to render compounds detectable by LC-PDA-MS and amenable to semi-prep. purification for NMR spectroscopy. The power of this approach could be demonstrated by the identification of a new indole alkaloid in the dichloromethane extract.

Analysis of the $\mathrm{MeOH}$ extract of Isatis tinctoria and I. indigotica corroborated previous observations of an nearly complete disapearance of labile indigo precursors isatan A and $B$, and of glucosinolates. These two compound classes together correspond to approx. $5 \%$ to $10 \%$ of dry weight of fresh Isatis leaves (Oberthür et al., 2004, Mohn et al. 2008). Only the rather stable indigo precursor indican (38) and small amounts of the major glucosinolate glucobrassicin (47) could be detected. Thus, the $\mathrm{MeOH}$ extract of dry leaves consisted mainly of flavone glycosides. In contrast to the notable differences in glucosinolate profiles (Mohn et al., 2008; Mohn and Hamburger, 2008), the flavonoid patterns of Isatis tinctoria and $I$. indigotica were rather similar qualitatively even though differing quantitatively. The drying of leaves has been shown to be a prerequisite for anti-inflammatory activity of woad extracts 
(Hamburger, 2003), and at least two of the known active compounds, tryptanthrin (13) and indirubin (15), are formed during the drying process.

Taking the relative peak areas in the ELSD profile as a measure, one can estimate that approximately $90 \%$ of the dichloromethane extract could be assigned to particular compounds or compound classes, respectively. This is comparable or better than the state of knowledge for well-characterised special extracts, such as EGb 761 from Gingko biloba L. (Hänsel and Spieß) and ZE 331 from Petasites hybridus L. (Brattström, 2003) which are active ingredients in well-known phytopharmaceuticals. However, in Isatis, pharmacologically active compounds (9, 13, and 15) known so far amount to a small portion (3.6\% (Mohn et al., 2007) of the total extract only, if one excludes linolenic acid (22). The promising activity of Isatis extract can be explained, in part, by the high potency of compounds such as tryptanthrin (13) and indirubin (15). However, we assume that additional compounds contribute to the pronounced in vivo activity of Isatis extracts (Recio et al., 2006a, b). Potential candidates are likely to be found among the minor alkaloids which form a highly complex pattern in the HPLC profile (chiefly peaks between 8 and 24 min in Fig. 1a, with high signal intensity in positive ion ESI-MS). The extract matrix mainly consists of fatty acid derivatives, porphyrins and carotenoids, which account for $>70 \%$ of the extract as estimated from the ELSD trace. We assume that these compounds are responsible for increasing the solubility of poorly soluble alkaloids, a fact that was previously observed, directly and indirectly, in the skin penetration study and in the clinical pilot trial comparing tryptanthrin and Isatis extract (Heinemann et al., 2004; Oberthür et al., 2003). Synergistic effects of constituents in a herbal extract are thought to play a central role, as the low amounts of individual compounds would not explain clinical efficacy of these products (Williamson, 2001). However, experimental evidence in support of this central paradigm of phytotherapy is relatively scarce (Eder and Mehnert, 1998). In case of the lipophilic Isatis tinctoria extract, a combination of pharmacological synergies (through compounds acting on different targets involved in inflammation) and bioavailability enhancement (through solubility enhancement by the extract matrix) seems to occur. 


\section{Experimental}

\subsection{Chemicals and reference compounds}

Analytical grade solvents for extraction and HPLC grade solvents for chromatography were purchased from Scharlau (Barcelona, Spain). HPLC grade water was obtained by an EASY-pure II (Barnstead, Dubuque IA, USA) water purification system. Deuterated solvents were purchased from Armar Chemicals (Döttingen, Switzerland). Isatin (1), sinapic acid (6), ferulic acid (7), syringic aldehyde (11), indigo (14), linolenic acid (22), palmitoleic acid (24), linoleic acid (25), palmitic acid (29), oleic acid (30), stearic acid (33), eicosenoic acid (34), eicosanoic acid (37), indican (38), $\beta$-carotene (54), indole-3-carboxaldehyde (60), indole-3-acetonitrile (61), vanillin (62), butylated hydroxytoluene, butylated hydroxyanisole and formic acid were purchased from Sigma-Aldrich (Buchs, Switzerland). Isoscoparin (3), ursolic acid (23), isoorientin (41) and isovitexin (44) were from Extrasynthese (Genay, France), and $\alpha$-lysolecithin (18) was from Alexis (Lausen, Switzerland). Deoxyvasicinone (2), indoxyl (4), 3-(4Hydroxy-3,5-dimethoxybenzylidene)-2-indolinone (9), isoindigo (10), tryptanthrin (13), indirubin (15) had been previously synthesised at the Institute of Pharmaceutical Biology, University of Jena according to published procedures (Hoessel et al., 1999; Friedländer and Roschdestwenski, 1915; Sun et al., 1998). Isovitexin-3"-O- $\beta$-Dglucopyranoside (45), isoscoparin-3"-O- $\beta$-D-glucopyranoside (46) and glucobrassicin (47) were isolated and characterised as previously described (Cheng et al., 2005; Mohn et al., 2007).

\subsection{Plant material}

Leaf material of defined strains of $I$. tinctoria ("Thüringer Waid"), and Isatis indigotica was harvested on $15^{\text {th }}$ September 2003 from first year plants (rosette stage). Plants were cultivated on experimental plots of the Agricultural Research Station of Thuringia (TLL), Dornburg, Germany as previously described (Mohn et al., 2008). Specimens of seeds from the strains are kept at the TLL, under accession numbers 153/PG 1 (Thüringer Waid) and 153 PG 12 (Isatis indigotica). 


\subsection{Sample preparation and extraction}

Freshly harvested Isatis leaf material was cut into small pieces of 2-3 cm length and immediately shock frozen with liquid nitrogen. Prior to extraction, the leaves were dried in a thermostatted oven at $40{ }^{\circ} \mathrm{C}$. Temperature, relative humidity and weight loss were monitored during the drying process. Constant weight was achieved after 3-4 d. The dried leaf samples were stored at room temperature for a few days in brown glass bottles in the dark. Immediately before extraction, dried leaf material was ground with a ZM 1 ultracentrifugal mill (Retsch, Haan, Germany, with $0.75 \mathrm{~mm}$ Conidur sieve. Pressurised liquid extraction (PLE) of $1.0 \mathrm{~g}$ frozen and powdered samples was carried out with an ASE 200 instrument (Dionex, Sunnyvale, CA, USA) with attached solvent controller. Conditions for all extractions were as follows: extraction solvent: dichloromethane, temperature: $70^{\circ} \mathrm{C}$; 2 extraction cycles of $5 \mathrm{~min}$; preheat time: $1 \mathrm{~min}$; flush: $100 \%$ of cell volume; purge: $80 \mathrm{~s}$ with nitrogen; pressure: $120 \mathrm{bar} ; 22 \mathrm{ml}$ steel cartridges. The extracts of two extraction cycles were combined, and the same plant material was extracted with methanol under same conditions.

\subsection{HPLC conditions}

HPLC separations were carried out on an Agilent series 1100 system equipped with degasser, binary high pressure mixing pump, column thermostat and photodiode array (PDA) detector (Agilent Technologies; Waldbronn, Germany). A liquid handler 215 (Gilson; Mettmenstetten, Switzerland) was used as autosampler. The HPLC was coupled to an Esquire 3000 plus ion trap mass spectrometer equipped with electrospray $(\mathrm{ESI})$ or atmospheric pressure chemical ionisation (APCl) interface (Bruker Daltonics; Bremen, Germany). High resolution mass spectra were obtained on a micrOTOF ESI-MS system (Bruker Daltonics) connected to an Agilent 1100 series HPLC. Data acquisition and processing was performed using HyStar 3.0 software (Bruker Daltonics).

Separation conditions for the dichloromethane extracts (HPLC system 1): SunFire $\mathrm{C}_{18}$ column ( $3.5 \mu \mathrm{m}, 150 \times 3.0 \mathrm{~mm}$ I.D., Waters, Milford, MA, USA) equipped with a 
guard column (20.0 x $3.0 \mathrm{~mm}$ I.D.); mobile phase A: water with formic acid $0.1 \%$, mobile phase B: acetonitrile, flow rate: $0.5 \mathrm{ml} / \mathrm{min}$, column temperature: $25.0{ }^{\circ} \mathrm{C}$, sample injection volume: $10 \mu \mathrm{l}$, solvent composition: $5 \% \mathrm{~B}$ isocratic for $2 \mathrm{~min}, 5 \%$ to $93 \% \mathrm{~B}$ in $30 \mathrm{~min}), 93 \% \mathrm{~B}$ isocratic for $17 \mathrm{~min}, 93 \% \mathrm{~B}$ to $100 \% \mathrm{~B}$ in $6 \mathrm{~min}$. A split ratio of $1: 3$ was used with the ESI interface.

An evaporative light scattering detector (ELSD series 2000, Alltech, Deerfield II, USA) was coupled to the second splitter outlet. ELSD conditions were: nitrogen flow: 1.5 I/min, impactor: on, temperature: $55^{\circ} \mathrm{C}$, detector gain: 8 .

Separation conditions for the MeOH extracts (HPLC system 2): same conditions as for HPLC system 1 but with the following solvent composition: $5 \%$ B for 2 min, 5\% B to $18 \% \mathrm{~B}$ in $30 \mathrm{~min}, 18 \% \mathrm{~B}$ to $24 \% \mathrm{~B}$ in $28 \mathrm{~min}$.

Sample preparation for carotenoids and chlorophyll degradation products was carried out with an Isatis tinctoria dichloromethane extract according to a previously reported method (Britton, 1995), with some modfications: The extract was dried in vacuo and $300 \mathrm{mg}$ of the residue was re-dissolved in $100 \mathrm{ml}$ of a mixture of acetone and hexane (1:1) containing butylated hydroxytoluene $(62.5 \mathrm{mg} / 100 \mathrm{ml})$ and butylated hydroxyanisole $(62.5 \mathrm{mg} / 100 \mathrm{ml})$. After filtration, the solution was transferred to a separatory funnel and $100 \mathrm{ml}$ of a sodium chloride solution $(10 \mathrm{~g} / 100 \mathrm{ml})$ was added. The suspension was shaken in a separatory funnel. After phase separation, the aqueous phase was discarded and the organic layer washed twice with water $(2 \mathrm{x}$ $100 \mathrm{ml}$ ), dried with anhydrous sodium sulphate and evaporated in vacuo. For identification of the chlorophyll degradation products 56-59, the residue was dissolved in 2-propanol, filtered through a membrane filter $(0.2 \mu \mathrm{m})$ prior to HPLC-MS analysis. For identification of carotenoids, chlorophyll had to be degraded by saponification. The residue was dissolved in $10 \mathrm{ml}$ diethyl ether and mixed with $10 \mathrm{ml}$ of methanolic $\mathrm{KOH}(10 \%)$. The flask was flushed with nitrogen and kept in the dark at ambient temperature for $3 \mathrm{~h}$. The alkaline mixture was transferred to a separatory funnel containing $100 \mathrm{ml}$ of diethyl ether. The organic solution was washed three times with water, dried with anhydrous sodium sulphate and evaporated to dryness. The residue was dissolved in mobile phase, filtered $(0.2 \mu \mathrm{m})$ and analysed by HPLCMS. 
Separation conditions for the carotenoid separation (HPLC system 3) were adopted from de Rosso and Mercadante (2007a, b) using a YMC $\mathrm{C}_{30}$ column (3 $\mu \mathrm{m}, 150.0 \mathrm{x}$ $3.0 \mathrm{~mm}$ I.D.; Stagroma, Reinach, Switzerland) with guard column $(10.0 \times 3.0 \mathrm{~mm}$ I.D.) and a linear gradient of methanol / methyl-tert-butyl ether (MTBE).

\subsection{MS instrumentation and parameters}

Positive and negative ion LC-MS spectra on the ion trap instrument with electrospray ionisation $(\mathrm{ESI})$ were recorded after optimisation of settings, under ion charge conditions (positive mode: ICC 30000; negative mode: ICC 20000) at a scan speed of $13000 \mathrm{~m} / \mathrm{z} / \mathrm{s}$, using a gauss filter width of $0.2 \mathrm{~m} / \mathrm{z}$. Nitrogen was used as a drying gas at a flow rate of $10 \mathrm{l} / \mathrm{min}$ and as a nebulising gas at a pressure of $30 \mathrm{psi}$. The nebuliser temperature was set at $300{ }^{\circ} \mathrm{C}$. Spectra were recorded in the range of $\mathrm{m} / \mathrm{z}$ 100 to 800 . Capillary voltage was at $-4500 \mathrm{~V}$ (negative mode: $+4500 \mathrm{~V}$ ), endplate offset at $-500 \mathrm{~V}$, capillary exit voltage at $111.8 \mathrm{~V}$ (negative mode: $-111.8 \mathrm{~V}$ ), skimmer voltage $40.0 \mathrm{~V}$ (negative mode: $-40.0 \mathrm{~V}$ ) and trap drive at 41.8. $\mathrm{MS}^{\mathrm{n}}$ experiments were performed on the quasimolecular ions $[\mathrm{M}+\mathrm{H}]^{+}$or $[\mathrm{M}-\mathrm{H}]^{-}$using helium as collision gas. The isolation width was set to $4.0 \mathrm{~m} / \mathrm{z}$ and the fragmentation amplitude was set to $1.00 \mathrm{~V}$ in the 'smart fragmentation' mode.

Settings for APCI were as follows: lon charge conditions (ICC 30000 positive mode; ICC 20000 negative mode), scan speed: $13000 \mathrm{~m} / \mathrm{z} / \mathrm{s}$, gauss filter: $0.2 \mathrm{~m} / \mathrm{z}$, nitrogen as drying gas (flow rate $5 \mathrm{l} / \mathrm{min}$ ) and nebulising gas (pressure: $30 \mathrm{psi}$ ), nebuliser temperature: $375{ }^{\circ} \mathrm{C}$, drying temperature: $250{ }^{\circ} \mathrm{C}$, scan range $\mathrm{m} / \mathrm{z} 100-800$ (for detection of carotenoids and porphyrins in the hexane/acetone extract: $\mathrm{m} / \mathrm{z} 100$ 1200), capillary voltage: $-4500 \mathrm{~V}$ (negative mode: $+4500 \mathrm{~V}$ ), endplate offset: $-500 \mathrm{~V}$, capillary exit voltage: $128.5 \mathrm{~V}$ (negative mode: $-128.5 \mathrm{~V}$ ), skimmer voltage: $40 \mathrm{~V}$ (negative mode: $-40 \mathrm{~V}$ ), trap drive: 58.8 (negative mode: 61.4). For $\mathrm{MS}^{\mathrm{n}}$ experiments: 'smart fragmentation mode', isolation width: $4.0 \mathrm{~m} / \mathrm{z}$, fragmentation amplitude: 1.00 $\mathrm{V}$, helium as collision gas.

Conditions for LC-TOF-MS were as follows: spectra were recorded in the range of $m / z$ 100-800 in positive and negative mode. Nitrogen was used as nebulising gas at 
a pressure of 2.0 bar and as drying gas at a flow rate of $9.01 / \mathrm{min}$ (dry gas temperature $\left.240{ }^{\circ} \mathrm{C}\right)$. Capillary voltage was at $-4500 \mathrm{~V}(+4500 \mathrm{~V}$ in negative mode), endplate offset at $-500 \mathrm{~V}$, hexapole at $250.0 \mathrm{Vpp}$ (negative mode: $230 \mathrm{Vpp}$ ), skimmer 1 at $40 \mathrm{~V}$ (negative mode: $-50 \mathrm{~V}$ ) and skimmer 2 at $22.5 \mathrm{~V}$ (negative mode: $-22.5 \mathrm{~V})$. Instrument calibration was performed using a reference solution of sodium formate $0.1 \%$ in isopropanol/water $(1: 1)$ containing $5 \mathrm{mM}$ sodium hydroxide. Typical mass accuracy was $\pm 2 \mathrm{ppm}$.

\subsection{Off-line semi-preparative HPLC-NMR analysis}

Powdered Isatis tinctoria leave material $(400 \mathrm{~g})$ was percolated with $600 \mathrm{ml}$ petrol ether (boiling point $40-60{ }^{\circ} \mathrm{C}$ ) followed by 2 I of dichloromethane to afford $14.5 \mathrm{~g}$ of dichloromethane extract. Pre-fractionation of the dichloromethane extract was carried out on a Sepacore MPLC system equipped with two pump modules C-605, UV photometer C-635, fraction collector C-660 and Sepacore record software (Büchi, Flawil, Switzerland). Due to poor solubility of the dichloromethane extract, $1 \mathrm{~g}$ of extract was adsorbed on $10 \mathrm{~g} \mathrm{C}_{18}$ packing material and filled into an empty precolumn cartridge (120 x $17 \mathrm{~mm}$ I.D.). Adsorbed analytes were eluted onto a prepacked Sepacore $\mathrm{C}_{18}$ column $(50 \mu \mathrm{m}, 150 \times 40 \mathrm{~mm}$ I.D) for separation. Conditions were as follows: mobile phase $\mathrm{A}$ : $\mathrm{H}_{2} \mathrm{O}$, mobile phase $\mathrm{B}$ : $\mathrm{MeOH}$, flow rate: $15 \mathrm{ml} / \mathrm{min}$, mobile phase composition: $15 \% \mathrm{~B}$ isocratic for $2 \mathrm{~min}, 15 \% \mathrm{~B}$ to $85 \% \mathrm{~B}$ in $68 \mathrm{~min}$, $85 \% \mathrm{~B}$ to $100 \% \mathrm{~B}$ in $10 \mathrm{~min}, 100 \% \mathrm{~B}$ for $20 \mathrm{~min}$. One fraction per minute was collected and appropriate fractions were combined (fractions 1-7). Fractions 2 (29.4 $\mathrm{mg})$ and $3(32.6 \mathrm{mg})$ were selected for semi-preparative HPLC on a SunFire $\mathrm{C}_{18}$ column, $5 \mu \mathrm{m}, 150 \times 10.0 \mathrm{~mm}$ I.D., (Waters, Milford, MA, USA) equipped with a guard column (10.0 x $10.0 \mathrm{~mm}$ I.D.). Separation conditions were as follows: mobile phase A: $\mathrm{H}_{2} \mathrm{O}$ with formic acid $0.1 \%$, mobile phase $\mathrm{B}$ : $\mathrm{MeOH}$, flow rate: $5 \mathrm{ml} / \mathrm{min}$, column temperature: $25{ }^{\circ} \mathrm{C}$, injection volume: $900 \mu \mathrm{l}$ (corresponding to $15 \mathrm{mg}$ of the respective fraction) dissolved in $5 \% \mathrm{~B}$. Gradient for the separation of fraction 2 was: $5 \%$ B for $2 \mathrm{~min}, 5 \% \mathrm{~B}$ to $65 \% \mathrm{~B}$ in $98 \mathrm{~min}, 65 \% \mathrm{~B}$ to $70 \% \mathrm{~B}$ in $10 \mathrm{~min}$; gradient for the separation of fraction 3 was: $34 \%$ B for $13 \mathrm{~min}, 34 \%$ B to $85 \%$ B in $87 \mathrm{~min}$. 
Conditions for the semi-preparative isolation of compound $\mathbf{4 3}$ from the methanol extract of Isatis tinctoria were identical as for HPLC system 2 with exception of column dimensions (SunFire $\mathrm{C}_{18}, 5 \mu \mathrm{m}, 150 \times 10.0 \mathrm{~mm}$ I.D; Waters) and flow rate (5 $\mathrm{ml} / \mathrm{min}$ ). Peak based collection was monitored at $210 \mathrm{~nm}$. Mobile phase was removed by parallel evaporation (Genevac EZ-2, Genevac, Gardiner, NY, USA), and samples were submitted to LC-TOF-MS and NMR analysis.

NMR spectra were obtained with a $500 \mathrm{MHz}$ Avance III system (Bruker, Fällanden, Switzerland) equipped with a $1 \mathrm{~mm}$ TXI probe. Data processing was with Topspin 2.1 (Bruker).

(2Z)-2-[1H-indol-3-ylmethylidene)-1,2-dihydro-3H-indol-3-one (64): orange film, UV (online, $\mathrm{MeOH} / 0.1 \%$ aq $\mathrm{HCOOH}$ ) $\lambda_{\max }=269,392$ and $494 \mathrm{~nm}$; ESI-HRMS, $\mathrm{m} / \mathrm{z}$ $261.1031\left([\mathrm{M}+\mathrm{H}]^{+}, \mathrm{C}_{17} \mathrm{H}_{12} \mathrm{~N}_{2} \mathrm{O}\right.$, calc. 261.1029). ESI-MS, $\mathrm{m} / \mathrm{z}$ (rel. int.): $261[\mathrm{M}+\mathrm{H}]^{+}$, $283[\mathrm{M}+\mathrm{Na}]^{+} ;{ }^{1} \mathrm{H}-\mathrm{NMR}\left(500 \mathrm{MHz}, \mathrm{DMSO}-\mathrm{d}_{6}\right): \delta 6.89\left(1 \mathrm{H}, d d, \mathrm{H}-5, J_{4,5}=7.4 \mathrm{~Hz}, J_{5,6}=\right.$ $7.4 \mathrm{~Hz}), 7.07(1 \mathrm{H}, s, \mathrm{H}-10), 7.17\left(1 \mathrm{H}, d, \mathrm{H}-7, J_{6,7}=7.7 \mathrm{~Hz}\right), 7.17\left(1 \mathrm{H}, d d, \mathrm{H}-5^{\prime}, J_{4^{\prime}, 5^{\prime}}=\right.$ $\left.7.7 \mathrm{~Hz}, \mathrm{~J}_{5^{\prime}, 6^{\prime}}=7.7 \mathrm{~Hz}\right), 7.22\left(1 \mathrm{H}, d d, \mathrm{H}-6^{\prime}, J_{5^{\prime}, 6^{\prime}}=7.7 \mathrm{~Hz}, \mathrm{~J}_{6^{\prime}, 7^{\prime}}=7.7 \mathrm{~Hz}\right), 7.48(1 \mathrm{H}, d d$, $\left.\mathrm{H}-6, J_{5,6}=7.4 \mathrm{~Hz}, \mathrm{~J}_{6,7}=7.7 \mathrm{~Hz}\right), 7.48\left(1 \mathrm{H}, d, \mathrm{H}-7^{\prime}, J_{6^{\prime} 7^{\prime}}=7.7 \mathrm{~Hz}\right), 7.57(1 \mathrm{H}, d, \mathrm{H}-4$, $\left.J_{4,5}=7.7 \mathrm{~Hz}\right), 7.83\left(1 \mathrm{H}, d, \mathrm{H}^{\prime} 4^{\prime}, J_{4^{\prime}, 5^{\prime}}=7.7 \mathrm{~Hz}\right), 8.17\left(1 \mathrm{H}, s, \mathrm{H}-2^{\prime}\right), 9.28(1 \mathrm{H}, b s, \mathrm{H}-1)$, $11.91\left(1 \mathrm{H}, b s, \mathrm{H}-1\right.$ '). ${ }^{13} \mathrm{C}-\mathrm{NMR}$ (extracted from $2 \mathrm{D}-\mathrm{HMBC}$ and HSQC spectra): $\delta$ 104.6 (C-10), 105.2 (C-3'), 112.5 (C-7'), 112.8 (C-7), 118.7 (C-4'), 119.6 (C-5), 120.8 (C-5'), 121.4 (C-9), 122.9 (C-6'), 124.0 (C-9'), 127.6 (C-9'), 127.9 (C-2'), 135.2 (C-6'), 135.6 (C-6), 136.6 (C-8'), 153.5 (C-2), 185.0 (C-3). 2D-NMR spectra of 64 are shown in Figure $2 S$ (supplementary data).

\section{Acknowledgements}

We thank Dr. A. Vetter and A. Biertümpfel, Thüringische Landesanstalt für Landwirtschaft (TLL), Jena and Dornburg, for the provision of woad samples from the experimental field plots in Dornburg. 


\section{Supplementary Data}

Figures representing HPLC profiles of Isatis indigotica dichloromethane and methanol extracts (Fig. 1S) and 2D-NMR spectra of 64 (Fig. 2S). Tables of identified compounds in I. indigotica dichloromethane (Table 1S) and methanol extracts (Table 2S).

\section{References}

Brattström, A., 2003. A newly developed extract (Ze 339) from butterbur (Petasites hybridus L.) is clinically efficient in allergic rhinitis (hay fever). Phytomedicine 10, 50-52.

Britton, G., 1995. Extraction of carotenoids from leaves. In: Britton, G., Liaaen-Jensen, S., Pfander, H. (Eds.), Carotenoids Volume 1A: Isolation and analysis, vol. 1a. Birkhäuser Verlag, Basel, Switzerland, pp. 203-206.

Burns, J., Fraser, P.D., Bramley, P.F., 2003. Identification and quantification of carotenoids, tocopherols and chlorophylls in commonly consumed fruits and vegetables. Phytochemistry 62, 939-947.

Canjura, F.L., Schwartz, S.J., 1991. Separation of chlorophyll compounds and their polar derivatives by high-performance liquid chromatography. J. Agric. Food Chem. 39, 11021105.

Cheng, Y., Schneider, B., Oberthür, C., Graf, H., Adler, S., Hamburger, M., 2005. Flavone Cglycosides from Isatis tinctoria leaves. Heterocycles 65, 1655-1661.

Cutillo, F., Dellagreca M., Previtera, L., Zarrelli, A., 2005. $C_{13}$ norisoprenoids from Brassica fruticulosa. Nat. Prod. Res. 19, 99-103.

Dan, M., Su, M., Gao, X., Zhao, T., Zhao, A., Xie, G., Qiu, Y., Zhou, M., Liu, Z., Jia, W., 2008. Metabolite profiling of Panax notoginseng using UPLC-ESI-MS. Phytochemistry 69, $2237-$ 2244.

Danz, H., Stoyanova, S., Thomet, O.A.R., Simon, H.-U., Dannhardt, G., Ulbrich, H., Hamburger, M., 2002. Inhibitory activity of tryptanthrin on prostaglandin and leukotriene synthesis. Planta Med. 68, 875-880. 
Danz, H., Stoyanova, S., Wippich, P., Brattström, A., Hamburger, M., 2001. Identification and isolation of the cyclooxygenase-2 inhibitory principle in Isatis tinctoria. Planta Med. 67, 411416.

Deng, X., Gao, G., Zheng, S., Li, F., 2008. Qualitative and quantitative analysis of flavonoids in the leaves of Isatis indigotica Fort. by ultra-performance liquid chromatography with PDA and electrospray ionization tandem mass spectrometry detection. J. Pharm. Biomed. Anal. $48,562-567$.

de Rosso, V.V., Mercadante, A.Z., 2007a. HPLC-PDA-MS/MS of anthocyanins and carotenoids from dovyalis and tamarillo fruits. J. Agric. Food Chem. 55, 9135-9141.

de Rosso, V.V., Mercadante, A.Z., 2007b. Identification and quantification of carotenoids, by HPLC-PDA-MS/MS, from Amazonian fruits. J. Agric. Food Chem. 55, 5062-5072.

Ding, S., Dudley, E., Plummer, S., Tang, J., Newton, R.P., Brenton, A.G., 2008. Fingerprint profile of Ginkgo biloba nutritional supplements by LC/ESI-MS/MS. Phytochemistry 69, 15551564.

Eder, M., Mehnert, W., 1998. Bedeutung pflanzlicher Begleitstoffe in Extrakten. Pharmazie 53, 285-293.

Friedländer, P., Roschdestwenski, N., 1915. Über ein Oxidationsprodukt des Indigoblaus. Ber. Dtsch. Chem. Ges. 48, 1841-1847.

Gattuso, G., Caristi, C., Gargiulli, C., Bellocco, E., Toscano, G., Leuzzi, U., 2006. Flavonoid glycosides in bergamot juice (Citrus bergamia Risso). J. Agric. Food Chem. 54, 3929-3935.

Hänsel, R., Spieß, E., 2004. Pharmakognosie - Phytopharmazie, $7^{\text {th }}$ edition. Springer Verlag, Heidelberg, Germany, p.166.

Hamburger, M., 2003. Isatis tinctoria - from the rediscovery of an ancient medicinal plant towards a novel anti-inflammatory phytopharmaceutical. Phytochemistry Rev. 1, 333-344.

Hamburger, M., Rüster, G.-U., Melzig, M.F., 2006. HPLC based activity profiling for inhibitors of human neutrophil elastase in Isatis tinctoria leaf extracts. Nat. Prod. Commun. 1, 11071110.

Hartleb, I., 1994. Inhaltsstoffe von Isatis tinctoria L. und Verbascum songaricum Schrenk. $\mathrm{PhD}$ thesis at the Institute of Organic Chemistry, University of Bayreuth, Germany. 
Heinemann, C., Schliemann-Willers, S., Oberthür, C., Hamburger, M., Elsner, P., 2004. Prevention of experimentally induced irritant contact dermatitis by extracts of Isatis tinctoria compared to pure tryptanthrin and its impact on UVB-induced erythema. Planta Med. 70, 385-390

Hiltunen, E., Pakkanen, T.T., Alvila, L., 2006. Phenolic compounds in silver birch (Betula pendula Roth) wood. Holzforschung 60, 519-527.

Hoessel, R., Leclerc, S., Endicott, J.A., Nobel, M.E., Lawrie, A., Tunnah, P., Leost, M., Damiens, E., Marie, D., Marko, D., Niederberger, E., Tang, W., Eisenbrand, G., Meijer, L., 1999. Indirubin, the active constituent of a Chinese antileukaemia medicine, inhibits cyclindependent kinases. Nat. Cell Biol. 1, 60-67.

Honda, G., Tosirisuk, V., Tabata M., 1980. Isolation of an antidermatophytic, tryptanthrin, from indigo plants, Polygonum tinctorium and Isatis tinctoria. Planta Med. 38, 275-276.

Hohmann, J., Tóth, L., Máthé, I., 1996. Monoacylgalactolipids from Stellaria media. Fitoterapia 67, 381-382.

lijima, Y., Suda, K., Suzuki, T., Aoki, K., Shibata, D., 2008. Metabolite profiling of chalcones and flavanones in tomato fruit. J. Japan. Soc. Hort. Sci. 77, 94-102.

Ishihara, T., Kohno, K., Ushio, S., Kanso, I., Ikeda, M., Kurimoto, M., 2000. Tryptanthrin inhibits nitric oxide and prostaglandin E2 synthesis by murine macrophages. Eur. J. Pharmacol. 407, 197-204.

Jaime, L., Mendiola, J.A., Ibáñez, E., Martin-Álvarez, P.J., Cifuentes, E., Reglero, G., Señoráns, F.J., 2007. $\beta$-Carotene isomer composition of sub- and supercritical carbon dioxide extracts. Antioxidant activity measurement. J. Agric. Food Chem. 55, 10585-10590.

Kimoto, T., Yamamoto, Y., Hino, K., Koay, S., Aga, H., Hashimoto, T., Hanaya, T., 1999. Cytotoxic effects of substances in indigo plant (Polygonum tinctorium Lour.) on maligant tumour cells. Natural Med. 53, 72-79.

Koch, T., 2002. Efficient syntheses of (10E,12Z,15Z)-9-oxo- and (9Z,11E,15Z)-13-oxooctadecatrienoic acids; two stress metabolites of wounded plants. Tetrahedron 58, 32713274 .

Lee, H.S., Castle, W.S., Coates, G.A., 2001. High-performance liquid chromatography for the characterization of carotenoids in the new sweet orange (Earlygold) grown in Florida, USA. J. Chromatogr. A 913, 371-377. 
Le Gall, G., Metzdorff, S.B., Perdersen, J., Bennett, R.N., Colquhoun I.J., 2005. Metabolite profiling of Arabidopsis thaliana (L.) plants transformed with an antisense chalcone synthase gene. Metabolomics 1, 181-198.

Li, B., Chen, W.-S., Zheng, S.-Q., Yang, G.-J., Qiao, C.-Z., 2000. Two new alkaloids isolated from tetraploid Banlangen. Yaoxue Xuebao 35, 508-510.

Li, Q.M., Claeys, M., 1994. Characterization and differentiation of diglycosyl flavonoids by positive ion fast atom bombardment and tandem mass spectrometry. Biol. Mass Spectrom. 23, 406-416.

Long, M., Millar, D.J., Kimura, Y., Donovan, G., Rees, J., Fraser, P.D., Bramley, P.M., Bolwell, G.P., 2006. Metabolite profiling of carotenoid and phenolic pathways in mutant and transgenic lines of tomato: Identification of a high antioxidant fruit line. Phytochemistry 67, 1750-1757.

McLean, S., Reynolds W.F., 1996. Complete ${ }^{13} \mathrm{C}$ and ${ }^{1} \mathrm{H}$ spectral assignments of prenylated flavonoids and a hydroxy fatty acid from the leaves of Caribbean Artocarpus communis. Magn. Reson. Chem. 34, 719-722.

Meléndez-Martínez, A.J., Vicario, I.M., Heredia, F.J., 2007. Geometrical isomers of violaxanthin in orange juice. Food Chem. 104, 169-175.

Mohn, T., Cutting, B., Ernst, B., Hamburger, M., 2007a. Extraction and analysis of intact glucosinolates - a validated pressurized liquid extraction/liquid chromatography-mass spectrometry protocol for Isatis tinctoria, and qualitative analysis of other cruciferous plants. J. Chromatogr. A 1166, 142-151.

Mohn, T., Hamburger, M., 2008. Glucosinolate pattern in Isatis tinctoria and I. indigotica seeds. Planta Med. 74, 885-888.

Mohn, T., Potterat, O., Hamburger, M., 2007b. Quantification of active principles and pigments in leaf extracts of Isatis tinctoria by HPLC/UV/MS. Planta Med. 73, 151-156.

Mohn, T., Suter, K., Hamburger, M., 2008. Seasonal changes and effect of harvest on glucosinolates in Isatis leaves. Planta Med. 74, 582-587.

Oberthür, C., Heinemann, C., Elsner, P., Benfeldt, E., Hamburger, M., 2003. A comparative study on the skin penetration of pure tryptanthrin and tryptanthrin in /satis tinctoria extract by dermal microdialysis coupled with isotope dilution ESI-LC-MS. Planta Med. 69, 385-389. 
Oberthür, C., Graf, H., Hamburger, M., 2004. The content of indigo precursors in Isatis tinctoria leaves - a comparative study of selected accessions and post-harvest treatments. Phytochemistry, 65, 3261-3268.

Oberthür, C., Jäggi, R., Hamburger, M., 2005. HPLC based activity profiling for 5lipoxygenase inhibitory activity in Isatis tinctoria leaf extracts. Fitoterapia 76, 324-332.

Potterat, O., Hamburger, M., 2006. Natural products in drug discovery - concepts and approaches for tracking bioactivity. Curr. Org. Chem. 10, 899-920.

Qiao, X., Han, J., Xu, M., Zhan, Z., Sun, S., Li, H., Wang, B., Ye, M., Guo, D., 2008. Characterisation of chemical constituents in Guan Xin II decoction by liquid chromatography coupled with electrospray ionizatition-mass spectrometry. Planta Med. 74, 1720-1729.

Recio, M.C., Cerdá-Nicolás, M., Hamburger, M., Ríos, J.-L., 2006a. Anti-arthritic activity of a lipophilic woad (Isatis tinctoria) extract. Planta Med. 72, 715-720.

Recio, M.C., Cerdá-Nicolás, M., Potterat, O., Hamburger, M., Ríos, J.-L., 2006b. Antiinflammatory and antiallergic activity in vivo of lipophilic /satis tinctoria extracts and tryptanthrin. Planta Med. 72, 539-546.

Rüster, G.-U., Hoffmann, B., Hamburger, M., 2004. Inhibitory activity of indolin-2-one derivatives on compound 48/80-induced histamine release from mast cells. Pharmazie 59, 236-237.

Schliemann, W., Ammer., C., Strack., D., 2008. Metabolite profiling of mycorrhizal roots of Medicago truncatula. Phytochemistry 69, 112-146.

Sun, L., Tran, N., App, H., Hirth, P., McMahon, G., Tang, C., 1998. Synthesis and biological evaluations of 3-substituted Indolin-2-ones: A novel class of tyrosine kinase inhibitors that exhibit selectivity toward particular receptor tyrosine kinases. J. Med. Chem. 41, 2588-2603.

Terasaki, M., Itabashi, Y., Suzuki, T., Nishimura, K., 2002. An improved method for determining the composition of FFA in red tide flagellates by RP-HPLC with fluorescence detection. J. Am. Oil Chem. Soc. 79, 1181-1186.

Updike A.A., Schwartz, S.J., 2003. Thermal processing of vegetables increases cis isomers of lutein and zeaxanthin. J. Agric. Food Chem. 51, 6184-6190.

van Breemen, R.B., Canjura, F.L., Schwartz, S.J., 1991. Identification of chlorophyll derivatives by mass spectrometry. J. Agric. Food Chem. 39, 1452-1456. 
Waridel, P., Wolfender, J.-L., Lachavanne, J.-B., Hostettmann, K., 2004. Identification of the polar constituents of Potamogeton species by HPLC-UV with post-column derivatization, HPLC-MS $^{n}$ and HPLC-NMR, and isolation of a new ent-labdane diglycoside. Phytochemistry $65,2401-2410$.

Wei, X.Y., Leung, C.Y., Wong, C.K.C., Shen, X.L., Wong, R.N.S., Cai, Z.W., Mak, N.K., 2005. Bisindigotin, a TCDD antagonist from the Chinese medicinal herb Isatis indigotica. J. Nat. Prod. 68, 427-429.

Williamson E.M., 2001. Synergy and other interactions in phytomedicines. Phytomedicine 8, 401-409.

Wolfender, J.-L., Waridel, P., Ndjoko, K., Hobby, K.R., Major, H.J. Hostettmann, K., 2001. Evaluation of Q-TOF-MS/MS and multiple stage IT-MS ${ }^{n}$ for the dereplication of flavonoids and related compounds in crude plant extracts. Analusis 28, 895-906.

Wu, X., Liu, Y., Sheng, W., Sun, J., Qin, G., 1997. Chemical constituents of Isatis indigotica. Planta Med. 63, 55-57.

Xie, L.-H., Akao, T., Hamasaki, K., Deyama, T., Hattori, M., 2003. Biotransformation of pinoresinol diglucoside to mammalian lignans by human intestinal microflora, and isolation of Enterococcus faecalis strain PDG-1 responsible for the transformation of (+)-pinoresinol to (+)-lariciresinol. Chem. Pharm. Bull. 51, 508-515.

Yamazaki, Y., Urano, A., Sudo, H., Kitajima, M., Takayama, H., Yamazaki, M., Aimi, N., Saito, K., 2003. Metabolite profiling of alkaloids and strictosidine synthase activity in camptothecin producing plants. Phytochemistry 62, 461-470.

Yoshikawa, M., Murakami, T., Shimada, H., Yoshizumi, S., Saka, M., Yamahara, J., Matsuda, H., 1998. Medicinal foodstuffs. XIV. On the bioactive constituents of moroheiya. (2): new fatty acids, corchorifatty acids A, B, C, D, E, and F, from the leaves of Corchorus olitorius L. (Tiliaceae): structures and inhibitory effect on NO production in mouse peritoneal macrophages. Chem. Pharm. Bull. 46, 1008-1014. 


\section{Tables}

Table 1. Compounds identified from dichloromethane extract of Isatis tinctoria leaves.

\begin{tabular}{|c|c|c|c|c|c|c|c|c|c|}
\hline Peak & $\begin{array}{c}R_{\mathbf{t}} \\
(\min )\end{array}$ & $\lambda_{\max }(\mathrm{nm})$ & $\mathrm{ESI}^{+}$ & $\mathrm{ESI}^{-}$ & $\mathrm{APCl}^{+}$ & $\mathrm{APCl}^{-}$ & $\begin{array}{l}\text { Acc. mass } \\
\text { found }^{a}\end{array}$ & $\begin{array}{l}\text { Acc. } \\
\text { mass } \\
\text { calc. }^{\text {a }}\end{array}$ & Assignment \\
\hline UC1 & 8.7 & $235 ; 310$ & $337[\mathrm{M}+\mathrm{H}]^{+}$ & $335[\mathrm{M}-\mathrm{H}]^{-}$ & $337[\mathrm{M}+\mathrm{H}]^{+}$ & $335[\mathrm{M}-\mathrm{H}]^{-}$ & 337.1852 & 337.1838 & $\mathrm{C}_{21} \mathrm{H}_{22} \mathrm{~N}_{2} \mathrm{O}_{2}$ \\
\hline UC2 & 10.8 & 240 & fragments & - & - & - & n.d. & - & unknown \\
\hline UC3 & 11.3 & $207 ; 247 ; 300$ & $297[\mathrm{M}+\mathrm{H}]^{+}$ & - & - & - & n.d. & - & unknown \\
\hline 1 & 11.8 & $209 ; 241 ; 303 ; 416$ & $148[\mathrm{M}+\mathrm{H}]^{+}$ & - & $148[\mathrm{M}+\mathrm{H}]^{+}$ & - & 148.0406 & 148.0399 & Isatin \\
\hline 2 & 12.2 & $\begin{array}{l}207 ; 226 ; 259 \\
\quad 302 ; 313\end{array}$ & $187[\mathrm{M}+\mathrm{H}]^{+}$ & - & $187[\mathrm{M}+\mathrm{H}]^{+}$ & - & 187.0868 & 187.0872 & Deoxyvasicinone \\
\hline 3 & 12.7 & $216 ; 270 ; 345$ & $463[\mathrm{M}+\mathrm{H}]^{+} ; 485[\mathrm{M}+\mathrm{Na}]^{+}$ & $461[\mathrm{M}-\mathrm{H}]^{-}$ & $463[\mathrm{M}+\mathrm{H}]^{+}$ & $461[\mathrm{M}-\mathrm{H}]^{-}$ & 463.1248 & 463.1241 & Isoscoparin \\
\hline 4 & 12.9 & $205 ; 248$ & $134[\mathrm{M}+\mathrm{H}]^{+}$ & - & $134[\mathrm{M}+\mathrm{H}]^{+}$ & - & 134.0612 & 134.0607 & Indoxyl \\
\hline 5 & 13.2 & $258 ; 302$ & $150[\mathrm{M}+\mathrm{H}]^{+}$ & $148[\mathrm{M}-\mathrm{H}]^{-}$ & $150[\mathrm{M}+\mathrm{H}]^{+}$ & - & 150.0552 & 150.0556 & 5-Hydroxyoxindole \\
\hline 6 & 13.3 & $235 ; 322$ & $225[\mathrm{M}+\mathrm{H}]^{+}$ & $223[\mathrm{M}-\mathrm{H}]^{-}$ & - & $223[\mathrm{M}-\mathrm{H}]^{-}$ & 225.0758 & 225.0764 & Sinapic acid \\
\hline 7 & 14.0 & $238 ; 322$ & $195[\mathrm{M}+\mathrm{H}]^{+} ; 411[2 \mathrm{M}+\mathrm{Na}]^{+}$ & $193[\mathrm{M}-\mathrm{H}]^{-}$ & $195[\mathrm{M}+\mathrm{H}]^{+}$ & $193[\mathrm{M}-\mathrm{H}]^{-}$ & 195.0653 & 195.0658 & Ferulic acid \\
\hline UC4 & 15.0 & 309 & $517[\mathrm{M}+\mathrm{H}]^{+}$ & $515[\mathrm{M}-\mathrm{H}]^{-}$ & $517[\mathrm{M}+\mathrm{H}]^{+}$ & $515[\mathrm{M}-\mathrm{H}]^{-}$ & 517.1963 & 517.1976 & $\mathrm{C}_{29} \mathrm{H}_{28} \mathrm{~N}_{2} \mathrm{O}_{7}$ \\
\hline 8 & 15.3 & $220 ; 275 ; 309$ & $267[\mathrm{M}+\mathrm{H}]^{+}$ & $265[\mathrm{M}-\mathrm{H}]^{-}$ & $267[\mathrm{M}+\mathrm{H}]^{+}$ & $265\left[^{\mathrm{M}-\mathrm{H}}\right]^{-}$ & 267.0779 & 267.0770 & 3-(2'-Carboxyphenyl)-quinazolin-4-one \\
\hline UC5 & 15.8 & 316 & $501[\mathrm{M}+\mathrm{H}]^{+}$ & $499[\mathrm{M}-\mathrm{H}]^{-}$ & $501[\mathrm{M}+\mathrm{H}]^{+}$ & $499[\mathrm{M}-\mathrm{H}]^{-}$ & 501.2055 & 501.2067 & $\mathrm{C}_{34} \mathrm{H}_{28} \mathrm{O}_{4}$ \\
\hline UC6 & 17.8 & - & $351[\mathrm{M}+\mathrm{Na}]^{+}$ & $327[\mathrm{M}-\mathrm{H}]^{-}$ & - & $327\left[^{\mathrm{M}-\mathrm{H}]^{-}}\right.$ & 327.2178 & 327.2171 & $\mathrm{C}_{18} \mathrm{H}_{32} \mathrm{O}_{5}$ probably trihydroxyoctadienoic acid \\
\hline 9 & 19.5 & $210 ; 258 ; 380$ & $298[\mathrm{M}+\mathrm{H}]^{+}$ & - & $298[\mathrm{M}+\mathrm{H}]^{+}$ & - & 298.1087 & 298.1080 & $\begin{array}{l}(E)-3-\left(3^{\prime}, 5^{\prime}-\text { dimethoxy-4'-hydroxy- }\right. \\
\text { benzylidene)-2-indolinone }\end{array}$ \\
\hline
\end{tabular}




\begin{tabular}{|c|c|c|c|c|c|c|c|c|c|}
\hline 10 & 19.8 & 203; 266; 391; 478 & $263[\mathrm{M}+\mathrm{H}]^{+}$ & - & $263[\mathrm{M}+\mathrm{H}]^{+}$ & - & 263.0828 & 263.0821 & Isoindigo \\
\hline 11 & 20.9 & $227 ; 307$ & $183[\mathrm{M}+\mathrm{H}]^{+} ; 205[\mathrm{M}+\mathrm{Na}]^{+}$ & - & $183[\mathrm{M}+\mathrm{H}]^{+}$ & - & 183.0657 & 183.0658 & Syringic aldehyde \\
\hline 12 & 21.0 & 309 & $309[\mathrm{M}+\mathrm{H}]^{+} ; 331[\mathrm{M}+\mathrm{Na}]^{+}$ & $307[\mathrm{M}-\mathrm{H}]^{-}$ & $309[\mathrm{M}+\mathrm{H}]^{+}$ & $307[\mathrm{M}+\mathrm{H}]^{-}$ & 309.2064 & 309.2067 & Corchorifatty acid B \\
\hline 13 & 21.4 & $252 ; 311 ; 392$ & $249[\mathrm{M}+\mathrm{H}]^{+} ; 271[\mathrm{M}+\mathrm{Na}]^{+}$ & - & $249[\mathrm{M}+\mathrm{H}]^{+}$ & - & 249.0664 & 249.0665 & Tryptanthrin \\
\hline UC7 & 22.0 & 260 & $267[\mathrm{M}+\mathrm{H}]^{+}$ & $265[\mathrm{M}-\mathrm{H}]^{-}$ & - & - & n.d. & - & unknown \\
\hline 14 & 23.2 & $243 ; 285 ; 606$ & $263[\mathrm{M}+\mathrm{H}]^{+}$ & - & $263[\mathrm{M}+\mathrm{H}]^{+}$ & - & 263.0821 & 263.0821 & Indigo \\
\hline UC8 & 23.8 & - & $699[\mathrm{M}+\mathrm{Na}]^{+}$ & $675[\mathrm{M}-\mathrm{H}]^{-}$ & - & $675[\mathrm{M}-\mathrm{H}]^{-}$ & n.d. & - & unknown \\
\hline 15 & 24.1 & $240 ; 290 ; 362 ; 541$ & $263[\mathrm{M}+\mathrm{H}]^{+}, 285[\mathrm{M}+\mathrm{Na}]^{+}$ & - & $263[\mathrm{M}+\mathrm{H}]^{+}$ & - & 263.0829 & 263.0821 & Indirubin \\
\hline 16 & 26.4 & - & $537[\mathrm{M}+\mathrm{Na}]^{+}$ & $513[\mathrm{M}-\mathrm{H}]^{-}$ & - & $513[\mathrm{M}-\mathrm{H}]^{-}$ & 513.3057 & 513.3063 & $\begin{array}{l}\text { 1-O- } \beta \text {-D-galactopyranosyl-3-O- } \\
\text { linolenylglycerol }\end{array}$ \\
\hline 17 & 26.7 & 240 & $317[\mathrm{M}+\mathrm{Na}]^{+}$ & $293[\mathrm{M}-\mathrm{H}]^{-}$ & - & $293[\mathrm{M}-\mathrm{H}]^{-}$ & 293.2107 & 293.2116 & $\begin{array}{l}\text { 9-Hydroxy-(10E, 12Z, 15Z)-octadecatrienoic } \\
\text { acid }\end{array}$ \\
\hline 18 & 27.1 & - & $496[\mathrm{M}+\mathrm{H}]^{+} ; 518[\mathrm{M}+\mathrm{Na}]^{+}$ & - & - & - & 496.3392 & 496.3404 & $\alpha$-Lysolecithin \\
\hline 19 & 27.6 & 279 & $315[\mathrm{M}+\mathrm{Na}]^{+}$ & $291[\mathrm{M}-\mathrm{H}]^{-}$ & - & - & 291.1953 & 291.1959 & 9-Oxo-(10E, 12Z, 15Z)-octadecatrienoic acid \\
\hline UC9 & 28.8 & 250 & $381[\mathrm{M}+\mathrm{H}]^{+} ; 403[\mathrm{M}+\mathrm{Na}]^{+}$ & - & $381[\mathrm{M}+\mathrm{H}]^{+}$ & - & 381.1596 & 381.1604 & $\mathrm{C}_{25} \mathrm{H}_{20} \mathrm{~N}_{2} \mathrm{O}_{2}$ \\
\hline UC10 & 29.8 & - & $509[\mathrm{M}+\mathrm{H}]^{+} ; 531[\mathrm{M}+\mathrm{Na}]^{+}$ & $507[\mathrm{M}-\mathrm{H}]^{-}$ & - & - & 509.3025 & 509.3016 & $\mathrm{C}_{30} \mathrm{H}_{40} \mathrm{~N}_{2} \mathrm{O}_{5}$ \\
\hline 20 & 30.7 & - & - & $249[\mathrm{M}-\mathrm{H}]^{-}$ & - & $249[\mathrm{M}-\mathrm{H}]^{-}$ & 249.1851 & 249.1854 & (7Z, 10Z,13Z)-Hexadecatrienoic acid \\
\hline 21 & 31.5 & $261 ; 351 ; 568$ & $491[\mathrm{M}+\mathrm{H}]^{+}$ & $489[\mathrm{M}-\mathrm{H}]^{-}$ & $491[\mathrm{M}+\mathrm{H}]^{+}$ & $489[\mathrm{M}-\mathrm{H}]^{-}$ & 491.1506 & 491.1508 & Bisindigotin \\
\hline UC11 & 32.8 & - & 672 & - & - & - & n.d. & - & unknown \\
\hline 22 & 33.5 & - & $279[\mathrm{M}+\mathrm{H}]^{+} ; 301[\mathrm{M}+\mathrm{Na}]^{+}$ & $277[\mathrm{M}-\mathrm{H}]^{-}$ & $279[\mathrm{M}+\mathrm{H}]^{+}$ & $277[\mathrm{M}-\mathrm{H}]^{-}$ & 277.2161 & 277.2167 & Linolenic acid \\
\hline 23 & 34.3 & - & $457[\mathrm{M}+\mathrm{H}]^{+}$ & $455[\mathrm{M}-\mathrm{H}]^{-}$ & - & - & 457.3683 & 457.3682 & Ursolic acid \\
\hline 24 & 34.7 & - & - & $253[\mathrm{M}-\mathrm{H}]^{-}$ & - & - & 253.2182 & 253.2167 & Palmitoleic acid \\
\hline
\end{tabular}




\begin{tabular}{|c|c|c|c|c|c|c|c|c|c|}
\hline UC12 & 35.1 & $410 ; 664$ & $563[\mathrm{M}+\mathrm{H}]^{+}$ & $561[\mathrm{M}-\mathrm{H}]^{-}$ & 282 & 282 & n.d. & - & unknown porphyrin derivative \\
\hline 25 & 35.4 & - & - & $279[\mathrm{M}-\mathrm{H}]^{-}$ & - & - & 279.2321 & 279.2323 & Linoleic acid \\
\hline 26 & 35.8 & $\begin{array}{l}325 ; 407 ; 505 \\
533 ; 605 ; 664\end{array}$ & $609[\mathrm{M}+\mathrm{H}]^{+} ; 631[\mathrm{M}+\mathrm{Na}]^{+}$ & $607[\mathrm{M}-\mathrm{H}]^{-}$ & - & - & 609.2723 & 609.2714 & 10-Hydroxy phaeophorbide \\
\hline 27 & 36.5 & $\begin{array}{l}320 ; 409 ; 505 ; \\
534 ; 606 ; 664\end{array}$ & $593[\mathrm{M}+\mathrm{H}]^{+} ; 693[\mathrm{M}+\mathrm{Na}]^{+}$ & $591[\mathrm{M}-\mathrm{H}]^{-}$ & $593[\mathrm{M}+\mathrm{H}]^{+}$ & $591[\mathrm{M}-\mathrm{H}]^{-}$ & 593.2763 & 593.2765 & Phaeophorbide a \\
\hline 28 & 37.5 & $\begin{array}{l}321 ; 408 ; 506 ; \\
535 ; 606 ; 666\end{array}$ & $593[\mathrm{M}+\mathrm{H}]^{+} ; 693[\mathrm{M}+\mathrm{Na}]^{+}$ & $591[\mathrm{M}-\mathrm{H}]^{-}$ & $593[\mathrm{M}+\mathrm{H}]^{+}$ & $591[\mathrm{M}-\mathrm{H}]^{-}$ & 593.2768 & 593.2765 & Phaeophorbide a' \\
\hline 29 & 37.8 & - & - & $255[\mathrm{M}-\mathrm{H}]^{-}$ & - & $255[\mathrm{M}-\mathrm{H}]^{-}$ & 255.2316 & 255.2323 & Palmitic acid \\
\hline 30 & 38.3 & - & - & $281[\mathrm{M}-\mathrm{H}]^{-}$ & - & $281[\mathrm{M}-\mathrm{H}]^{-}$ & 281.2474 & 281.248 & Oleic acid \\
\hline 31 & 38.6 & $\begin{array}{l}321 ; 410 ; 507 ; \\
537 ; 606 ; 666\end{array}$ & $535[\mathrm{M}+\mathrm{H}]^{+}$ & $533[\mathrm{M}-\mathrm{H}]^{-}$ & $535[\mathrm{M}+\mathrm{H}]^{+}$ & $533[\mathrm{M}-\mathrm{H}]^{-}$ & 535.2712 & 535.2710 & Pyrophaeophorbide a \\
\hline 32 & 41.0 & $420 ; 443 ; 470$ & $569[\mathrm{M}+\mathrm{H}]^{+}$ & - & $569[\mathrm{M}+\mathrm{H}]^{+}$ & $567[\mathrm{M}-\mathrm{H}]^{-}$ & 569.4362 & 569.4359 & (all-E)-Lutein \\
\hline 33 & 43.3 & - & - & $283[\mathrm{M}-\mathrm{H}]^{-}$ & - & - & 283.2630 & 283.2636 & Stearic acid \\
\hline 34 & 43.5 & - & - & $309[\mathrm{M}-\mathrm{H}]^{-}$ & - & - & 309.2809 & 309.2793 & Eicosenoic acid \\
\hline 35 & 44.1 & $328 ; 416 ; 439 ; 465$ & - & - & $569[\mathrm{M}+\mathrm{H}]^{+}$ & - & 569.4357 & 569.4359 & (9Z)-Lutein \\
\hline 36 & 45.0 & $328 ; 416 ; 440 ; 467$ & - & - & $569[\mathrm{M}+\mathrm{H}]^{+}$ & - & 569.4361 & 569.4359 & $\left(9^{\prime} Z\right)$-Lutein \\
\hline UC13 & 49.0 & - & - & 621 & 397 & 621 & n.d. & - & unknown \\
\hline 37 & 52.4 & - & - & $311[\mathrm{M}-\mathrm{H}]^{-}$ & - & - & 311.2970 & 311.2949 & Eicosanoic acid \\
\hline UC14 & 52.7 & - & - & - & $855 ; 792$ & 819 & n.d. & - & unknown \\
\hline
\end{tabular}

n.d. $=$ not detected; ${ }^{a}=$ found and calculated accurate mass for the respective $[\mathrm{M}+\mathrm{H}]^{+}$or $[\mathrm{M}-\mathrm{H}]^{-}$ion; $\mathrm{UC} 1$ to UC 14 are compounds for which only partial structure information was obtained. 
Table 2. Compounds identified from methanol extract of Isatis tinctoria leaves.

\begin{tabular}{|c|c|c|c|c|c|c|c|}
\hline Peak & $\begin{array}{c}R_{\mathrm{t}} \\
(\min )\end{array}$ & $\lambda_{\max }(\mathrm{nm})$ & $\mathrm{ESI}^{+}$ & $\mathrm{ESI}^{-}$ & $\begin{array}{c}\text { Acc. } \\
\text { mass } \\
\text { found }^{\mathrm{a}}\end{array}$ & $\begin{array}{l}\text { Acc. } \\
\text { mass } \\
\text { calc. }^{\text {a }}\end{array}$ & Assignment \\
\hline UC15 & 11.3 & n.d. & $337[\mathrm{M}+\mathrm{H}]^{+}$ & - & 337.1852 & 337.1838 & $\mathrm{C}_{21} \mathrm{H}_{24} \mathrm{~N}_{2} \mathrm{O}_{2}$ \\
\hline UC16 & 14.2 & $209 ; 253 ; 301$ & $317[\mathrm{M}+\mathrm{H}]^{+} ; 339[\mathrm{M}+\mathrm{Na}]^{+}$ & $315[\mathrm{M}-\mathrm{H}]^{-}$ & 317.1131 & 317.1138 & $\mathrm{C}_{16} \mathrm{H}_{16} \mathrm{~N}_{2} \mathrm{O}_{5}$ unknown anthranilic acid derivative \\
\hline UC17 & 15.8 & n.d. & $307[\mathrm{M}+\mathrm{H}]^{+}$ & - & 307.1745 & 307.1732 & $\mathrm{C}_{20} \mathrm{H}_{22} \mathrm{~N}_{2} \mathrm{O}$ \\
\hline UC18 & 16.5 & n.d. & $337[\mathrm{M}+\mathrm{H}]^{+}$ & - & 337.1853 & 337.1838 & $\mathrm{C}_{21} \mathrm{H}_{24} \mathrm{~N}_{2} \mathrm{O}_{2}$ \\
\hline UC1 & 17.6 & $236 ; 312$ & $337[\mathrm{M}+\mathrm{H}]^{+}$ & - & 337.1850 & 337.1838 & $\mathrm{C}_{21} \mathrm{H}_{24} \mathrm{~N}_{2} \mathrm{O}_{2}$ \\
\hline 38 & 18.3 & $222 ; 280$ & - & $294[\mathrm{M}-\mathrm{H}]^{-}$ & 294.0971 & 294.0977 & Indican \\
\hline 39 & 24.1 & $210 ; 269 ; 334$ & $595[\mathrm{M}+\mathrm{H}]^{+} ; 617[\mathrm{M}+\mathrm{Na}]^{+}$ & $593[\mathrm{M}-\mathrm{H}]^{-}$ & 595.1652 & 595.1664 & Vicenin-2 \\
\hline UC19 & 24.5 & 238 & $409[\mathrm{M}+\mathrm{H}]^{+}$ & $407[\mathrm{M}-\mathrm{H}]^{-}$ & 409.1772 & 409.1764 & $\mathrm{C}_{23} \mathrm{H}_{24} \mathrm{~N}_{2} \mathrm{O}_{5}$ \\
\hline UC20 & 25.2 & $213 ; 268 ; 330$ & $757[\mathrm{M}+\mathrm{H}]^{+} ; 779[\mathrm{M}+\mathrm{Na}]^{+}$ & $755[\mathrm{M}-\mathrm{H}]^{-}$ & 757.2192 & 757.2191 & $\begin{array}{l}\mathrm{C}_{33} \mathrm{H}_{40} \mathrm{O}_{20} \text { unknown flavone triglycoside with two } \mathrm{C} \text {-linked and one } \mathrm{O} \text {-linked } \\
\text { hexosyl moieties }\end{array}$ \\
\hline UC21 & 25.9 & $210 ; 270 ; 333$ & $625[\mathrm{M}+\mathrm{H}]^{+} ; 647[\mathrm{M}+\mathrm{Na}]^{+}$ & $623[\mathrm{M}-\mathrm{H}]^{-}$ & 625.1765 & 625.1769 & $\mathrm{C}_{28} \mathrm{H}_{32} \mathrm{O}_{16}$ unknown flavone di-C-glycoside similar to Stellarin-2 \\
\hline 40 & 26.2 & $210 ; 270 ; 343$ & $625[\mathrm{M}+\mathrm{H}]^{+} ; 647[\mathrm{M}+\mathrm{Na}]^{+}$ & $623[\mathrm{M}-\mathrm{H}]^{-}$ & 625.1763 & 625.1769 & Stellarin-2 \\
\hline UC22 & 27.0 & $211 ; 270 ; 338$ & $787[\mathrm{M}+\mathrm{H}]^{+} ; 809[\mathrm{M}+\mathrm{Na}]^{+}$ & $785[\mathrm{M}-\mathrm{H}]^{-}$ & 787.2298 & 787.2298 & $\begin{array}{l}\mathrm{C}_{34} \mathrm{H}_{42} \mathrm{O}_{21} \text { unkown flavone triglycoside with two } \mathrm{C} \text {-linked and one } \mathrm{O} \text {-linked } \\
\text { hexosyl moieties }\end{array}$ \\
\hline UC23 & 31.5 & $213 ; 268 ; 342$ & $625[\mathrm{M}+\mathrm{H}]^{+} ; 647[\mathrm{M}+\mathrm{Na}]^{+}$ & $623[\mathrm{M}-\mathrm{H}]-$ & 625.1759 & 625.1769 & $\mathrm{C}_{28} \mathrm{H}_{32} \mathrm{O}_{16}$ unknown flavone di-C-glycoside \\
\hline 41 & 32.1 & $211 ; 268 ; 348$ & $449[\mathrm{M}+\mathrm{H}]^{+} ; 471[\mathrm{M}+\mathrm{Na}]^{+}$ & $447[\mathrm{M}-\mathrm{H}]^{-}$ & 449.1093 & 449.1085 & Isoorientin \\
\hline 42 & 32.6 & $212 ; 269 ; 348$ & $611[\mathrm{M}+\mathrm{H}]^{+} ; 633[\mathrm{M}+\mathrm{Na}]^{+}$ & $609[\mathrm{M}-\mathrm{H}]^{-}$ & 611.1617 & 611.1613 & Isoorientin 3"-O- $\beta$-D-glucopyranoside \\
\hline 43 & 35.0 & $207 ; 249 ; 301$ & $166[\mathrm{M}+\mathrm{H}]^{+} ; 148\left[\mathrm{M}-\mathrm{H}_{2} \mathrm{O}\right]^{+}$ & $164[\mathrm{M}-\mathrm{H}]^{-}$ & 164.0344 & 164.0347 & $\mathrm{~N}$-formyl anthranilic acid \\
\hline
\end{tabular}




\begin{tabular}{|c|c|c|c|c|c|c|c|}
\hline 44 & 37.1 & $213 ; 269 ; 336$ & $433[\mathrm{M}+\mathrm{H}]^{+} ; 455[\mathrm{M}+\mathrm{Na}]^{+}$ & $431[\mathrm{M}-\mathrm{H}]^{-}$ & 433.1132 & 433.1135 & Isovitexin \\
\hline 45 & 37.4 & $214 ; 269 ; 335$ & $595[\mathrm{M}+\mathrm{H}]^{+} ; 617[\mathrm{M}+\mathrm{Na}]^{+}$ & $593[\mathrm{M}-\mathrm{H}]^{-}$ & 595.1659 & 595.1664 & Isovitexin 3"-O- $\beta$-D-glucopyranoside \\
\hline 3 & 38.8 & $216 ; 269 ; 345$ & $463[\mathrm{M}+\mathrm{H}]^{+} ; 485[\mathrm{M}+\mathrm{H}]^{+}$ & $461[\mathrm{M}-\mathrm{H}]^{-}$ & 463.1237 & 463.1241 & Isoscoparin \\
\hline 46 & 39.4 & $213 ; 269 ; 348$ & $625[\mathrm{M}+\mathrm{H}]^{+} ; 647[\mathrm{M}+\mathrm{Na}]^{+}$ & $623[\mathrm{M}-\mathrm{H}]^{-}$ & 625.1763 & 625.1769 & Isoscoparin 3"-O- $\beta$-D-glucopyranoside \\
\hline 47 & 41.8 & $215 ; 274$ & - & $447[\mathrm{M}-\mathrm{H}]^{-}$ & 447.0526 & 447.0531 & Glucobrassicin \\
\hline UC24 & 43.5 & n.d. & - & $621[\mathrm{M}-\mathrm{H}]^{-}$ & 621.1447 & 621.1454 & $\mathrm{C}_{28} \mathrm{H}_{30} \mathrm{O}_{16}$ unknown flavonoid with two O-linked hexosyl moieties \\
\hline UC25 & 46.0 & $295 ; 321$ & - & $591[\mathrm{M}-\mathrm{H}]^{-}$ & 591.1341 & 591.1349 & $\mathrm{C}_{27} \mathrm{H}_{26} \mathrm{O}_{15}$ unknown flavonoid with two O-linked hexosyl moieties \\
\hline UC26 & 47.8 & $240 ; 325$ & - & $621[\mathrm{M}-\mathrm{H}]^{-}$ & 621.1444 & 621.1454 & $\mathrm{C}_{28} \mathrm{H}_{30} \mathrm{O}_{16}$ unknown flavonoid with two O-linked hexosyl moieties \\
\hline
\end{tabular}

n.d. = not detected; ${ }^{a}=$ found and calculated accurate mass for the respective $[\mathrm{M}+\mathrm{H}]^{+}$or $[\mathrm{M}-\mathrm{H}]^{-}$ion; $\mathrm{UC} 1$ and $\mathrm{UC} 15$ to $\mathrm{UC} 26$ are compounds for which only partial structures were obtained. 
Table 3. Identified carotenoids from an acetone/hexane (1:1) extract of Isatis tinctoria leaves

\begin{tabular}{|c|c|c|c|c|c|c|}
\hline Peak & $\underset{(\mathbf{m i n})}{\mathbf{R t}}$ & $\lambda_{\max }(\mathrm{nm})$ & $\begin{array}{c}\% \\
111 / I^{\mathrm{a}}\end{array}$ & $\begin{array}{c}{[\mathrm{M}+\mathrm{H}]^{+}} \\
(\mathrm{m} / \mathrm{z})\end{array}$ & MS/MS & Assignment \\
\hline UC27 & 6.2 & $399,420,447$ & 80 & 601 & $583,565,221$ & unknown \\
\hline 48 & 6.9 & $399,419,446$ & 75 & 601 & $583,565,221$ & (Z)-Neochrome \\
\hline 49 & 7.5 & $400,420,446$ & 80 & 601 & n.d. & (all-E)-Neochrome \\
\hline 50 & 8.2 & $329,407,430,455$ & 10 & 601 & $583,565,221$ & (di-Z)-Violaxanthin \\
\hline 51 & 8.9 & $330,415,437,464$ & 40 & 601 & $583,565,509$ & (15Z)-Violaxanthin \\
\hline 52 & 9.8 & $330,415,437,464$ & 45 & 569 & $551,533,476$ & (13Z)- or (13'Z)-Lutein \\
\hline UC28 & 10.8 & $382,401,425,444,471$ & n.c. & 601 & n.d. & mixture \\
\hline 32 & 11.9 & $420,443,470$ & 60 & 569 & $551,533,459$ & (all-E)-Lutein \\
\hline 35 & 14.4 & $328,416,439,465$ & 65 & 569 & $551,533,509$ & (9Z)-Lutein \\
\hline 36 & 17.5 & $328,416,440,467$ & 60 & 569 & 551,533 & (9'Z)-Lutein \\
\hline UC29 & 19.1 & $327,418,442,467$ & 15 & 569 & 551 & unknown \\
\hline UC30 & 21.7 & $336,405,428,451$ & n.c. & 569 & 551 & unknown \\
\hline 53 & 23.0 & $338,422,446,470$ & 10 & 537 & n.d. & (15Z)- $\beta$-Carotene \\
\hline 54 & 30.0 & $423,451,477$ & 25 & 537 & $444,347,197$ & (all-E)- $\beta$-Carotene \\
\hline 55 & 32.3 & $340,423,443,469$ & 30 & 537 & $444,209,357$ & (9Z)- $\beta$-Carotene \\
\hline
\end{tabular}

n.d. $=$ not detected; n.c. $=$ not calculated; ${ }^{a}=$ spectral fine structure obtained according to the method of Lee et al. $(2001)$. UC27 to UC30 are carotenoids which could not be unambiguously identified. 
Supplementary Data

\title{
A comprehensive metabolite profiling of
}

\author{
Isatis tinctoria leaf extracts
}

Tobias Mohn, Inken Plitzko, Matthias Hamburger*

Institute of Pharmaceutical Biology, University of Basel, Klingelbergstrasse 50, CH-4056

Basel, Switzerland

${ }^{*}$ Corresponding author. Tel: +41-61-2671425; fax: +41-61-2671474. E-mail address:

matthias.hamburger@unibas.ch 

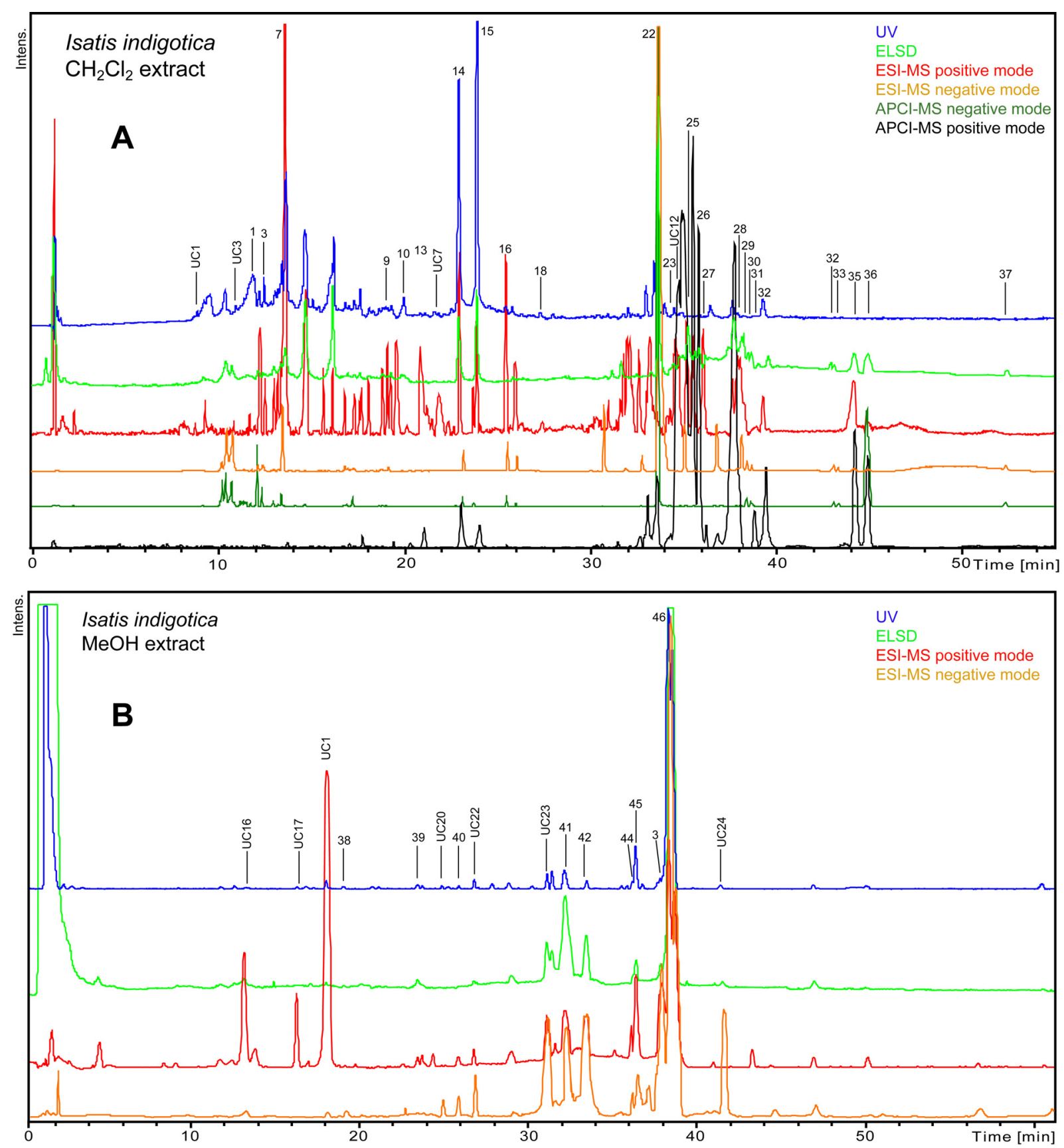

Fig.1S. Dichloromethane (A) and methanol (B) extracts of Isatis indigotica were separated by HPLC. Application of several detectors as PDA, ELSD, and mass spectrometric systems with electrospray (ESI) and atmospheric pressure chemical ionisation (APCl) techniques in positive and negative mode reveal the complexity of both extracts. The majority of compounds were identical with compounds observed in the closely related species Isatis tinctoria. 


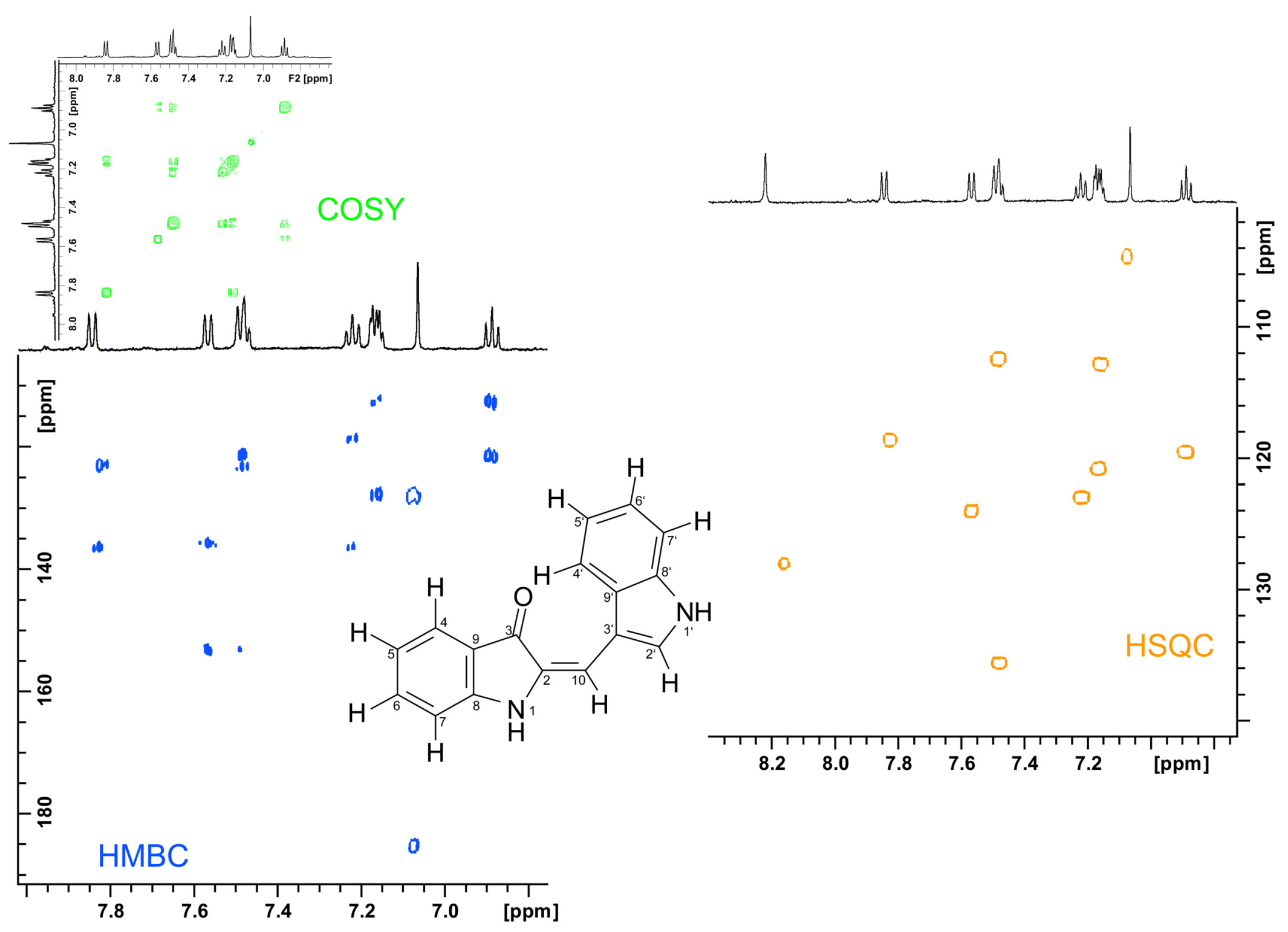

Fig. 2S. 2D-NMR spectra of compound 64 . 
Table 1S. Identified compounds 1-37 in a dichloromethane extract of Isatis indigotica. All compounds were identified on the basis of mass spectrometric, high-resolution-mass spectrometric and UV data or by reference compounds. Details are available in Table 1.

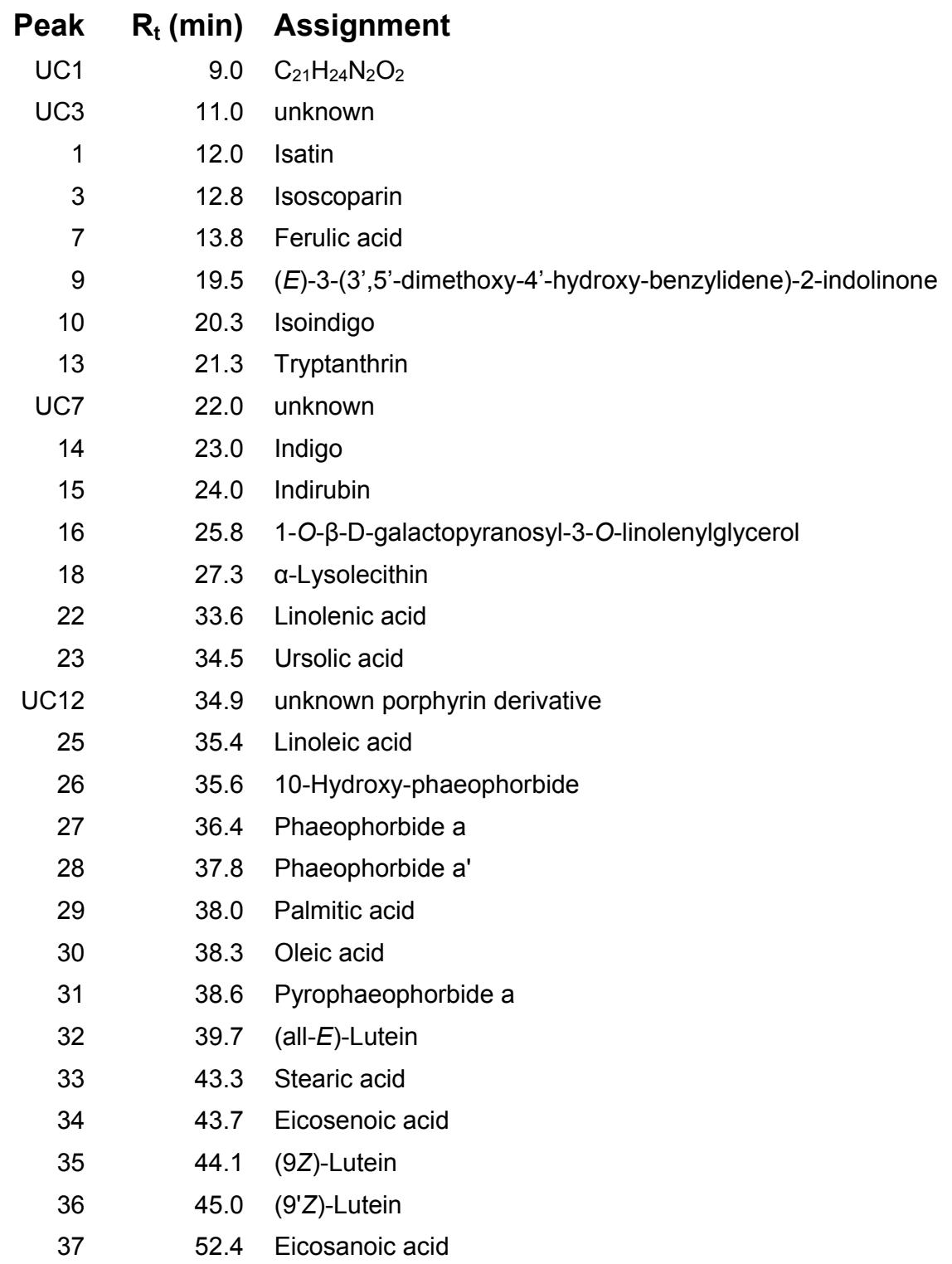


Table 2S. Identified compounds 3, 38-45 in a methanol extract of Isatis indigotica. All compounds were identified on the basis of mass spectrometric, high-resolution-mass spectrometric and UV data or by reference compounds. Details are available in Table 2.

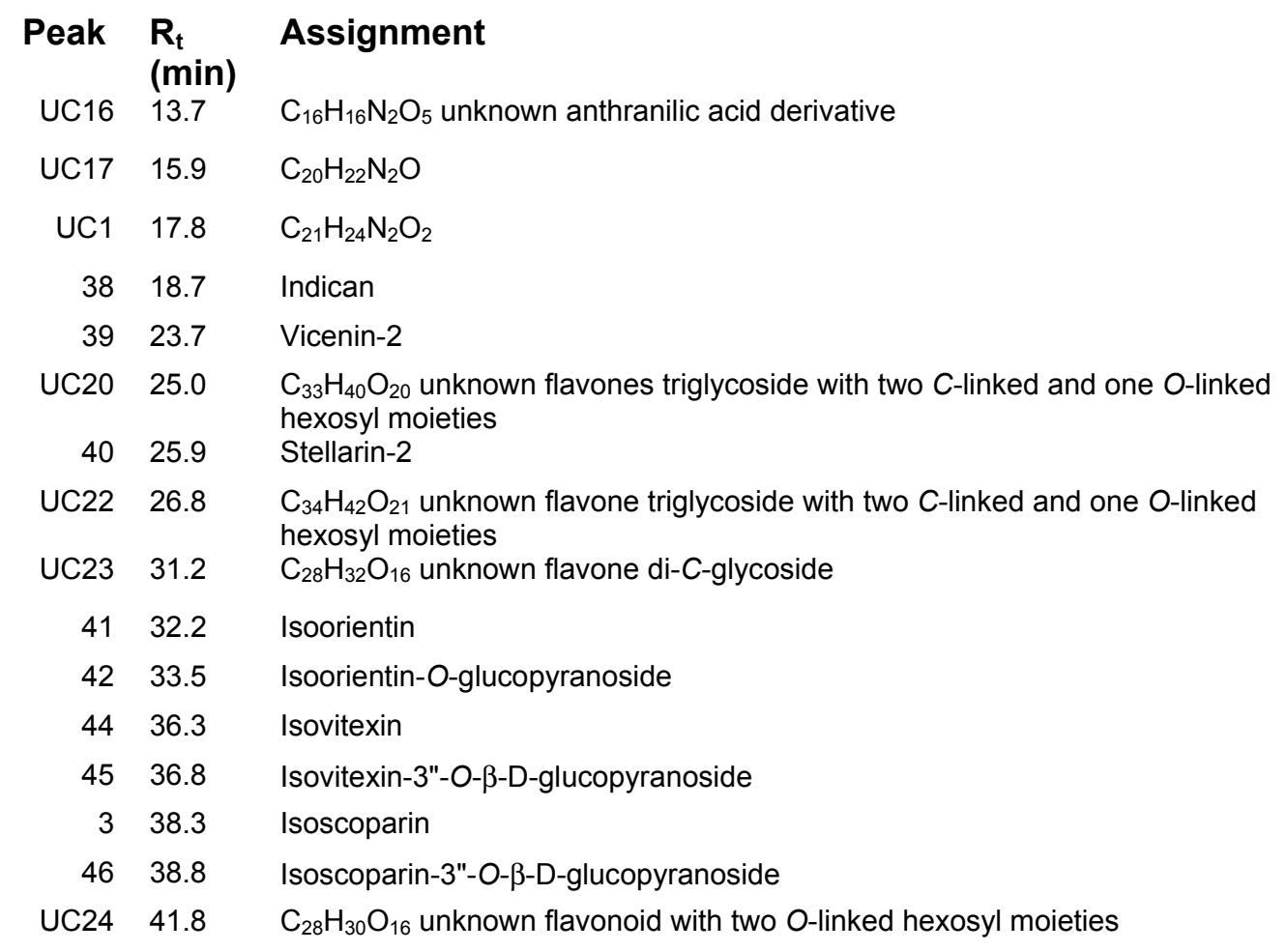


3.3 Extraction and analysis of intact glucosinolates - A validated pressurized liquid extraction / liquid chromatography - mass spectrometry protocol for Isatis tinctoria, and qualitative analysis of other cruciferous plants

(Mohn et al., J Chromatogr A 2007; 1166:142-151). 


\title{
Extraction and analysis of intact glucosinolates - A validated pressurized liquid extraction/liquid chromatography-mass spectrometry protocol for Isatis tinctoria, and qualitative analysis of other cruciferous plants
}

\author{
Tobias Mohn ${ }^{\mathrm{a}}$, Brian Cutting ${ }^{\mathrm{b}}$, Beat Ernst ${ }^{\mathrm{b}}$, Matthias Hamburger ${ }^{\mathrm{a}, *}$ \\ a Institute of Pharmaceutical Biology, University of Basel, Klingelbergstrasse 50, CH-4056 Basel, Switzerland \\ ${ }^{\mathrm{b}}$ Institute of Molecular Pharmacy, University of Basel, Klingelbergstrasse 50, CH-4056 Basel, Switzerland \\ Received 5 June 2007; received in revised form 6 August 2007; accepted 13 August 2007 \\ Available online 17 August 2007
}

\begin{abstract}
Glucosinolates have attracted significant interest due to the chemopreventive properties of some of their transformation products. Numerous protocols for the extraction and analysis of glucosinolates have been published, but limited effort has been devoted to optimize and validate crucial extraction parameters and sample preparation steps. We carried out a systematic optimization and validation of a quantitative assay for the direct analysis of intact glucosinolates in Isatis tinctoria leaves (woad, Brassicaceae). Various parameters such as solvent composition, particle size, temperature, and number of required extraction steps were optimized using pressurized liquid extraction (PLE). We observed thermal degradation of glucosinolates at temperatures above $50{ }^{\circ} \mathrm{C}$, and loss of $>60 \%$ within $10 \mathrm{~min}$ at $100^{\circ} \mathrm{C}$, but no enzymatic degradation in the leaf samples at ambient temperature. Excellent peak shape and resolution was obtained by reversed-phase chromatography on a Phenomenex Aqua column using $10 \mathrm{mM}$ ammonium formate as ion-pair reagent. Detection was carried out by electrospray ionisation mass spectrometry in the negative ion mode. Analysis of cruciferous vegetables and spices such as broccoli (Brassica oleracea L. var. italica), garden cress (Lepidium sativum L.) and black mustard (Sinapis nigra L.) demonstrated the general applicability of the method.
\end{abstract}

(c) 2007 Elsevier B.V. All rights reserved.

Keywords: Glucosinolates; Isatis tinctoria; Brassicaceae; Pressurized liquid extraction (PLE); Accelerated solvent extraction (ASE); Quantitative analysis; Quantitative NMR; LC-MS; Ion-pair chromatography; Broccoli; Mustard; Garden cress

\section{Introduction}

Glucosinolates are a class of nitrogen and sulfur containing secondary metabolites which are characteristic of the plant order of Capparales. More than 120 glucosinolates have been described so far, mostly from the family Brassicaceae [1]. The structure of glucosinolates consists of a $\beta$-D-glucopyranosyl moiety linked via a sulfur atom to an $N$-hydroximinosulfate ester, and of a modified amino acid side chain. The highly variable structure of the side chain includes aliphatic (straight chain, branched chain, hydroxylated, sulfur containing, ketoderivatives), alkenylic, aromatic, hydroxyalkyl benzoated or indolic moieties and can be multiply glycosylated. Glucosi-

\footnotetext{
* Corresponding author. Tel.: +41 6126714 25; fax: +41 612671474

E-mail address: matthias.hamburger@unibas.ch (M. Hamburger).
}

nolates are found in all plant parts, but occurrence and concentration vary according to species, environmental factors, age or type of tissue [2]. Following tissue damage, these nonvolatile precursors undergo enzymatic hydrolysis by a thioglucohydrolase (E.C. 3.2.1.147, myrosinase) to glucose and a variety of degradation products (isothiocyanates, nitriles, thiocyanates, epithiocyanates, epithionitriles and oxazolidines), which are responsible for the hot, pungent taste and most biological activities of glucosinolates [3].

Intact glucosinolates and their breakdown products possess chemoecological functions and serve not only as defense mechanisms against herbivores and pathogens, but also as attractant to specialized toxin tolerant insects [4-6].

Glucosinolates occur in numerous vegetables and spices such as cabbage, broccoli, cauliflower, cress, mustard, and horseradish. Interest in the role of dietary glucosinolates has been stimulated by the observation of cancer chemopreventive 
properties of certain breakdown products, such as sulforaphane derived from glucoraphanin (4-methylsulfinyl butyl glucosinolate) found in broccoli. Sulforaphane and other isothiocyanates prevent tumor growth in animal models by blocking cell cycle progression and promotion of apoptosis [2,4,7,8].

Given the importance of glucosinolates, numerous methods for extraction and analysis of these compounds have been published. In addition, official protocols have been issued, e.g. for quantitative analysis of glucosinolates in vegetable and spices [9]. Typically, extraction is carried out in water [10-12] or a mixture of methanol and water [13-15]. To prevent enzymatic degradation by myrosinase, the material to be extracted is first treated at $100{ }^{\circ} \mathrm{C}$ [16-19]. Others have performed extraction at elevated temperature, typically $70-100{ }^{\circ} \mathrm{C}$, to inactivate myrosinase [10-15]. However, these conditions have not been optimized or validated.

The majority of methods analyze glucosinolates by reversedphase HPLC of their desulfo-derivatives. In these cases, the extracted glucosinolates are adsorbed onto a solid support, typically Sephadex A-25, followed by enzymatic desulfation and elution of the desulfoglucosinolates $[9,20]$. More recently, methods for direct separation of intact glucosinolates have been proposed to circumvent this tedious sample preparation. Here, ion-pairing reagents such as tetraalkyl ammonium bromide $[21,22]$, trifluoroacetic acid [16,18,23,24], ammonium acetate [25] or triethylamine/formic acid buffers [26] have been used in conjunction with reversed-phase chromatography on RP-18 columns. However, peaks usually suffered from inacceptable tailing, and separation was usually not optimal. The general problem with published protocols for extraction and analysis of glucosinolates was that, in most cases, insufficient information is available concerning method validation.

Due to the fact that specific biological effects of different glucosinolates vary considerably, it is critical to develop sensitive and reliable methods for efficient identification and quantification of the particular glucosinolate under investigation. We here report on the optimization and validation of a method for extraction and direct analysis of glucosinolates, and we demonstrate the applicability of the assay with the analysis of woad (Isatis tinctoria and I. indigotica), a dye and medicinal plant with a long history in Europe and in Traditional Chinese Medicine. The general applicability of the HPLC conditions for the analysis of intact glucosinolates is explored with a number of glucosinolatecontaining dietary plants and spices such as broccoli (Brassica oleracea L. var. italica), garden cress (Lepidium sativum L.) and black mustard (Sinapis nigra L.).

\section{Experimental}

\subsection{Plant material}

Leaf material of woad was harvested in August 2003 from first year plants (rosette stage) of defined I. tinctoria L. selections "Jenaer Waid", and "Kieler Waid" and Isatis indigotica Fort. cultures, which were grown on experimental plots of the Agricultural Research Station of Thuringia (TLL), Dornburg, Germany. Seeds from I. tinctoria were also obtained from TLL, Dornburg.
Broccoli heads (B. oleracea L. var. italica) and garden cress (L. sativum L.) were purchased on the local market in Basel, Switzerland. Black mustard seeds (Brassica nigra L.) were purchased from Hänseler AG, Herisau, Switzerland.

Fresh Isatis leaf material was shock frozen with liquid nitrogen immediately after harvest. Prior to extraction, the leaves were lyophilized, powdered with a ZM 1 ultracentrifugal mill (Retsch, Haan, Germany) and kept frozen at below $-20^{\circ} \mathrm{C}$ until extraction. Broccoli and garden cress were treated the same way, black mustard seeds were shock frozen and cryomilled before extraction.

\subsection{Chemicals}

Analytical grade solvents for extraction and HPLC grade solvents for chromatography were purchased from Scharlau (Barcelona, Spain). HPLC grade water was obtained by an EASY-pure II (Barnstead; Dubuque IA, USA) water purification system. Ammonium formate $(\geq 99.995 \%)$, formic acid (98.0-100\%), sinigrin (2) (2-propenyl glucosinolate) ( $\geq 99 \%)$ and 1,3,5-trimethoxybenzene $(\geq 99 \%)$ were purchased from Sigma-Aldrich (Buchs, Switzerland).

Potassium salts of progoitrin (3) (2(R)-2-hydroxy-3-butenyl glucosinolate), epiprogoitrin (1) (2(S)-2-hydroxy-3-butenyl glucosinolate), gluconapin (4) (3-butenyl glucosinolate) and glucotropaeolin (7) (phenylmethyl glucosinolate) were purchased from the Department of Natural Sciences, University of Copenhagen, Denmark.

\subsection{Isolation of glucosinolates}

Glucobrassicin (8) (3-indolylmethyl glucosinolate), sulfoglucobrassicin (5) (1-sulfo-3-indolylmethyl glucosinolate), 4hydroxyglucobrassicin (6) (4-hydroxy-3-indolylmethyl glucosinolate) and neoglucobrassicin (9) ( $N$-methoxy-3-indolylmethyl glucosinolate) were isolated from seeds of I. tinctoria ("Kieler Waid").

Isatis seeds (21.6 g) were defatted by Soxhlet-extraction for $8 \mathrm{~h}$ with $400 \mathrm{~mL}$ petrolether (boiling range $40-60^{\circ} \mathrm{C}$ ). After evaporation to dryness, the residue was extracted three times with water (room temperature, $3 \times 150 \mathrm{~mL}$ ), centrifuged $(5 \mathrm{~min}$, $1600 \times g$, room temperature) and filtered (standard laboratory paper filter, 7-12 $\mu \mathrm{m}$ pore size, Schleicher \& Schuell, Feldbach, Switzerland). The aqueous solutions were concentrated to $45 \mathrm{~mL}$ in vacuo, and $5 \mathrm{~mL}$ acetonitrile were added. After centrifugation, the supernatant was introduced into a column packed with DEAE-Sephadex A-25 (50 g). The column was eluted with water/acetonitrile 80:20 until the eluate was colorless. Glucosinolates were eluted with a mixture of $0.1 \mathrm{M} \mathrm{K}_{2} \mathrm{SO}_{4}$ /acetonitrile $80: 20$ at $3.2 \mathrm{~mL} / \mathrm{min}$ and monitored with UV detection (Pharmacia Uvicord S II) at $229 \mathrm{~nm}$. Fractions were analyzed by HPLC-MS and appropriate fractions combined and evaporated to dryness. For desalting, isolated sulfoglucobrassicin (5) was dissolved in aqua dest., applied on a Sephadex G10 column (Sephadex G10, particle size 40-120 $\mu \mathrm{m}$ in water and filled in a column of $2.5 \mathrm{~cm}$ diameter) and eluted with water. Finally, isolated glucosinolates were freeze dried. Purity and structures 
of isolated compounds were confirmed by NMR and LC-MS experiments.

\subsection{Quantitative NMR (qHNMR) for purity assessment of reference compounds}

The purity of reference glucosinolates was determined by quantitative NMR with 1,3,5-trimethoxybenzene as internal standard. All NMR spectra were recorded at $303 \mathrm{~K}$ on a Bruker DRX500 NMR spectrometer equipped with a $5 \mathrm{~mm}$ SEI probe with radio-frequency coils optimized for the detection of ${ }^{1} \mathrm{H}$.

The longitudinal relaxation constant, $\mathrm{T} 1$, was measured to determine the recycle delay needed for the magnetization to return to equilibrium. This was achieved with the pulse sequence "tlir" from Bruker. Trimethoxybenzene was measured with 40 equally spaced inversion recovery delays between 0.25 and $10.0 \mathrm{~s}$. Following four dummy scans, eight scans were recorded for each inversion recovery delay with a recycle delay of $100 \mathrm{~s}$ between successive scans. The T1 value of the trimethoxy hydrogens in trimethoxybenzene was measured to be $2.4 \mathrm{~s}$.

To determine the concentration of the glucosinolates, the data was recorded using the pulse sequence "zgpr" from Bruker. The carrier frequency was set to the resonance frequency of the residual HOD solvent signal at $4.705 \mathrm{ppm}$. The presaturation pulse consisted of a rectangular pulse applied for $1 \mathrm{~s}$ at an intensity of $24 \mathrm{~Hz}$. A spectral width of $20 \mathrm{ppm}$ was monitored with $64 \mathrm{k}$ points, implying an FID resolution of $0.16 \mathrm{~Hz}$ per point. For each sample, following two dummy scans, 16 scans were recorded. To ensure the full recovery of the magnetization following each $90^{\circ}$ pulse, a recycle delay of $20 \mathrm{~s}$, a value longer than five times the T1 of any signal used to quantify the concentration.

Trimethoxybenzene ( $1.0 \mathrm{mg}$; Mettler Toledo AT 20 microbalance, reproducibility: $4 \mu \mathrm{g}$ ) was dissolved in $1.8 \mathrm{~mL}$ methanol$\mathrm{d}_{4}$ (adjusted to give a concentration of $3.333 \mathrm{mM}$ ). This solution was diluted by a factor of 10 with $\mathrm{D}_{2} \mathrm{O}$. Glucosinolates were separately weighed into NMR tubes $(1.0 \mathrm{mg})$ and dissolved with the diluted trimethoxybenzene solution to give an exact concentration of $3 \mathrm{mM}$ glucosinolate. Data were processed and analyzed using XWIN-NMR version 3.6 running on a Linux PC. Each data size for each experiment was doubled by zero-filling in the time domain. The FID was then multiplied by an exponential decay apodization function of $0.3 \mathrm{~Hz}$ prior to Fourier transformation. To determine the concentration of compounds 5-9, the aromatic region of the spectrum between 7 and $8 \mathrm{ppm}$ was integrated and divided by the appropriate number of hydrogens from which it originated. The concentration of glucosinolates 1-4, which do not contain aromatic hydrogens, was determined by integration of the anomeric hydrogen at $4.5 \mathrm{ppm}$. The obtained values were compared to that of the integrated trimethoxy signal from trimethoxybenzene whereas nine protons of trimethoxybenzene $(0.333 \mathrm{mM})$ corresponded to one proton glucosinolate $(3 \mathrm{mM})$.

\subsection{Pressurized liquid extraction (PLE) of plant samples}

Pressurized liquid extraction was carried out with an ASE 200 instrument (Dionex; Sunnyvale, CA, USA) with attached solvent controller. Extraction of $1.0 \mathrm{~g}$ frozen, powdered plant material

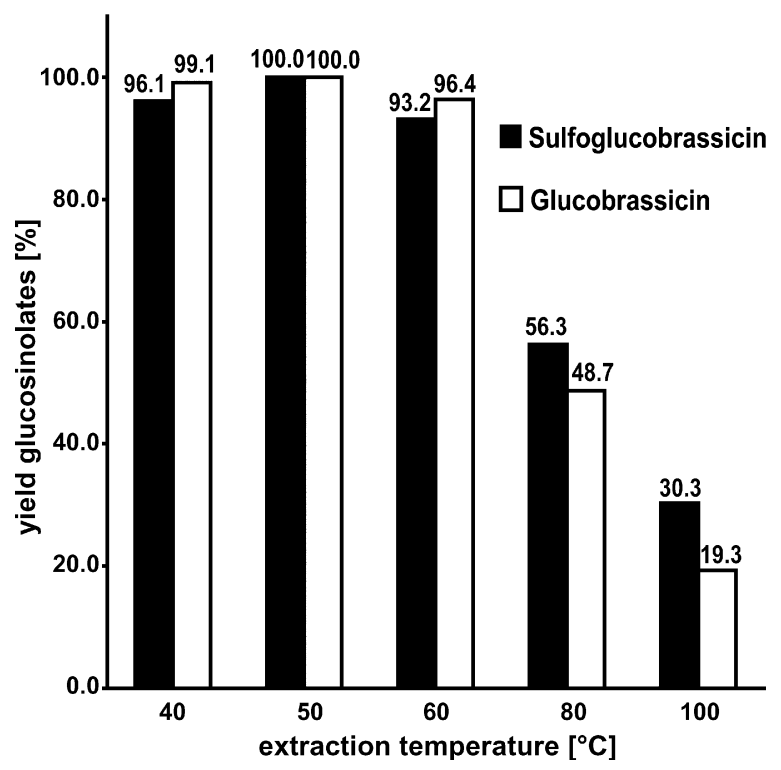

Fig. 1. Optimization of extraction parameters: influence of the extraction temperature on the yield of glucosinolates $\mathbf{5}$ and $\mathbf{8}$ from Isatis tinctoria leaves ("Jenaer Waid") obtained with $70 \% \mathrm{MeOH}$ and three extraction cycles. The yields obtained at $50{ }^{\circ} \mathrm{C}$ were set as $100 \%$.

was carried out in $11 \mathrm{~mL}$ steel cartridges. Standard conditions for all extractions were as follows: preheat time: $1 \mathrm{~min}$; static extraction per cycle: 5 min; flush: $100 \%$ of cell volume; purge: 80 s with nitrogen; pressure: 120 bar.

Solvent composition (Supplementary Material, Fig. 1), temperature $\left(40-100^{\circ} \mathrm{C}\right)$ (Fig. 1), number of required extraction steps (Fig. 2) and particle size (sieve size 0.5, 0.75 and $1.0 \mathrm{~mm}$ ) (Supplementary Material, Fig. 2) were optimized by repeated extractions and changing the parameter of choice. Final conditions were: particle size $0.5 \mathrm{~mm}, 50^{\circ} \mathrm{C}, 70 \%$ methanol in water, three extraction cycles of $5 \mathrm{~min}$. Possible degradation of glucosinolates by myrosinase activity was analyzed by extraction of freshly thawed leaf material at defined time points of 0 , 50, 100 and $200 \mathrm{~min}$ after filling the cartridge (Supplementary Material, Fig. 3).

\subsection{LC-MS instrumentation and conditions}

HPLC separations were carried out on an Agilent series 1100 system equipped with degasser, binary high pressure mixing pump, column thermostat and photodiode array (PDA) detector (Agilent Technologies; Waldbronn, Germany). A liquid handler 215 (Gilson; Mettmenstetten, Switzerland) was used as autosampler. The HPLC was coupled to an Esquire 3000 plus ion trap mass spectrometer equipped with an electrospray (ESI) interface (Bruker Daltonics; Bremen, Germany). Highresolution mass spectra were obtained on a micrOTOF ESI-MS system (Bruker Daltonics) connected to an Agilent 1100 series HPLC. Data acquisition and processing was performed using HyStar 3.0 software (Bruker Daltonics).

Negative ion LC-MS spectra on the ion trap instrument were recorded after optimization of settings, under ion charge control conditions (ICC 30000) at a scan speed of $13000 \mathrm{~m} / \mathrm{z} / \mathrm{s}$, using a 

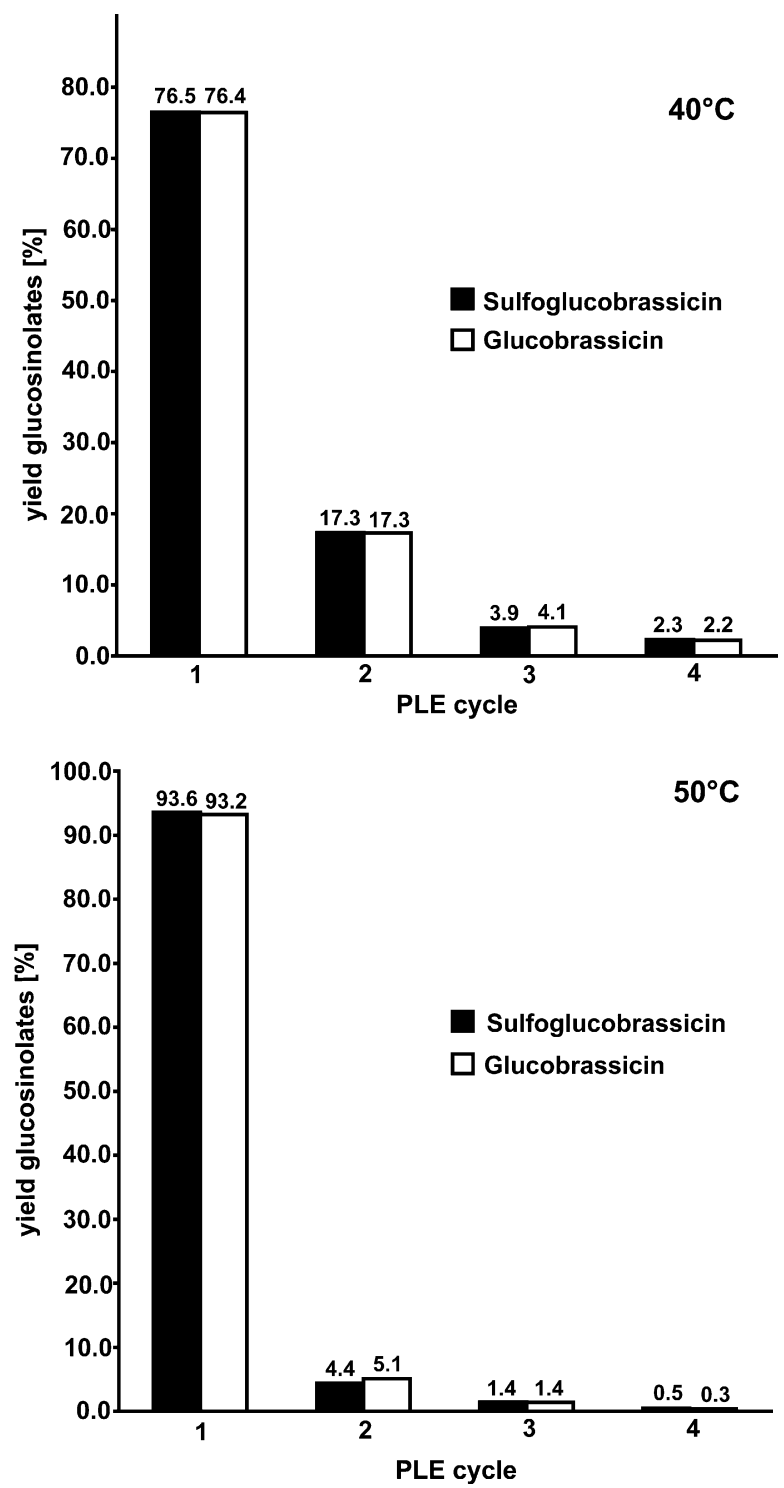

Fig. 2. Influence of the extraction temperature on yields of glucosinolates $\mathbf{5}$ and 8 in successive PLE extraction cycles. Plant material was identical with that used in Fig. 1. The cumulative yields of four extraction cycles were set as $100 \%$.

gauss filter width of $0.2 \mathrm{~m} / \mathrm{z}$. Nitrogen was used as a drying gas at a flow rate of $10 \mathrm{~L} / \mathrm{min}$ and as a nebulizing gas at a pressure of $30 \mathrm{psi}$. The nebulizer temperature was set at $300^{\circ} \mathrm{C}$. Spectra were recorded between $0 \mathrm{~min}$ and $25 \mathrm{~min}$ in the range of $\mathrm{m} / \mathrm{z}$ 100-800. Capillary voltage was at $4500 \mathrm{~V}$, endplate offset at $-500 \mathrm{~V}$, capillary end voltage at $-115.0 \mathrm{~V}$, skimmer voltage $-40.0 \mathrm{~V}$ and trap drive at 53.4.

Conditions for LC-TOF MS were as follows: spectra were recorded in the range of $m / z, 100-600$ in negative mode. Nitrogen was used as a nebulizing gas at a pressure of $2.0 \mathrm{bar}$ and as a drying gas at a flow rate of $9.0 \mathrm{~L} / \mathrm{min}$ (dry gas temperature $240^{\circ} \mathrm{C}$ ). Capillary voltage was at $4500 \mathrm{~V}$, endplate offset at $-500 \mathrm{~V}$, hexapole at $250.0 \mathrm{~V}_{\mathrm{pp}}$, skimmer 1 at $-50 \mathrm{~V}$ and skimmer 2 at $-22.5 \mathrm{~V}$. Instrument calibration was performed using a reference solution of sodium formate $0.1 \%$ in isopropanol/water (1:1) containing $5 \mathrm{mM}$ sodium hydroxide. Typical mass accuracy was $\pm 1 \mathrm{ppm}$.

\subsection{HPLC-MS method development and validation}

RP-18 columns from different manufacturers, including Atlantis and Sunfire (Waters; Milford, MA, USA), Luna and Aqua (Phenomenex; Aschaffenburg, Germany)], OmniPac pax 500 (Dionex; Sunnyvale, CA, USA) and LiChrospher 60 rpselect b (Merck; Darmstadt, Germany) columns, were tested for suitability in glucosinolate analysis. Finally separations were carried out on an Aqua C18 $125 \AA$ Å column $(5 \mu \mathrm{m}, 250 \times 4.6 \mathrm{~mm}$ I.D.; Phenomenex $)$ equipped with a guard column $(4.0 \times 3.0 \mathrm{~mm}$ I.D.). Mobile Phase A consisted of a solution of $10 \mathrm{mM}$ aqueous ammonium formate, adjusted to $\mathrm{pH} 6.4$ with formic acid, and mobile phase $\mathrm{B}$ was acetonitrile. A linear gradient starting at $1 \%$ $\mathrm{B}$ to $3 \% \mathrm{~B}$ (7 min), $3 \% \mathrm{~B}$ to $15 \% \mathrm{~B}(5 \mathrm{~min}), 15 \% \mathrm{~B}$ to $30 \% \mathrm{~B}$ (13 $\mathrm{min}$ ) was shown to give best separation of all compounds to be analyzed. Flow rate was $1.0 \mathrm{~mL} / \mathrm{min}$. A split ratio of $1: 4$ was used with the ESI interface. Column temperature was $20.0^{\circ} \mathrm{C}$. The sample injection volume was $20 \mu \mathrm{L}$.

Reproducibility was assessed in five replicates with a standard solution of all glucosinolates at a concentration of $1 \mu \mathrm{g} / \mathrm{mL}$ and the relative standard deviation was calculated. Intra-day and inter-day repeatability was verified in the course of the analysis. Limit of detection (S/N ratio of 3 ) and limit of quantification ( $\mathrm{S} / \mathrm{N}$ ratio of 10 ) were determined by serial dilution of a standard solution containing all glucosinolates (Table 1). Accuracy was determined for the major compounds sulfoglucobrassicin and glucobrassicin, and the minor compound progoitrin. An extract of "Jenaer Waid" was spiked with defined amounts, whereby the amounts added were comparable to those of compounds originally present in the extract. Amounts added and recovery rates are listed in Supplementary Material, Table 1.

\subsection{Quantitative analysis}

A solution of $10 \mathrm{mM}$ ammonium formate containing sinigrin $(2 \mathrm{mg} / \mathrm{L})$ as internal standard (IS solution) was used for all dilution steps. Stock solutions $(1 \mathrm{mg} / \mathrm{mL})$ of all reference compounds were prepared in IS solution, serial dilutions covered a concentration range of $20-0.1 \mu \mathrm{g} / \mathrm{mL}$. Each standard solution was measured as five replicates. Calibration curves are shown in Supplementary Material, Table 2.

The dried extracts, obtained by extraction of $1.0 \mathrm{~g}$ frozen, powdered plant material, were dissolved in $100.0 \mathrm{~mL}$ IS solu-

Table 1

Limits of detection (LOD) and quantification (LOQ) for glucosinolates 1-9

\begin{tabular}{llc}
\hline Compound & LOD & LOQ \\
\hline Epiprogoitrin (1) & 1 & 3 \\
Sinigrin (2) & 1 & 3 \\
Progoitrin (3) & 1 & 3 \\
Gluconapin (4) & 0.5 & 1 \\
Sulfoglucobrassicin (5) & 4 & 12 \\
4-Hydroxyglucobrassicin (6) & 2 & 5 \\
Glucotropaeolin (7) & 0.2 & 0.5 \\
Glucobrassicin (8) & 1 & 3 \\
Neoglucobrassicin (9) & 1 & 3 \\
\hline
\end{tabular}

Amount of compound injected (ng). 
tion. Dilutions of 1:10 and 1:100 were prepared with IS solution. All solutions were centrifuged $\left(5 \mathrm{~min}, 1600 \times g, 4^{\circ} \mathrm{C}\right)$ prior to HPLC analysis. Measurements were done in triplicate.

\section{Results}

\subsection{Isolation of reference compounds and control of purity}

Most glucosinolates used in this study (Fig. 3) were not commercially available and had to be isolated as reference compounds (see Section 2). LC-MS analysis of isolated compounds showed a purity of higher than $99 \%$. Structures were also confirmed by NMR. The spectra did not show any additional signals of organic impurities. Given that the glucosinolates used as reference compounds are present as potassium salts and may contain an unknown amount of water of crystallization, we determined the absolute content with the aid of quantitative ${ }^{1} \mathrm{H}$ NMR (qHNMR). The purity was $>99 \%$ for sinigrin (2) (calculated as $\mathrm{C}_{10} \mathrm{H}_{17} \mathrm{NO}_{9} \mathrm{~S}_{2}$ ), $87 \%$ for epiprogoitrin (1) (as $\left.\mathrm{C}_{11} \mathrm{H}_{19} \mathrm{NO}_{10} \mathrm{~S}_{2}\right), 90 \%$ for progoitrin (3) (as $\left.\mathrm{C}_{11} \mathrm{H}_{19} \mathrm{NO}_{10} \mathrm{~S}_{2}\right)$, $71 \%$ for gluconapin (4) (as $\mathrm{C}_{11} \mathrm{H}_{19} \mathrm{NO}_{9} \mathrm{~S}_{2}$ ) and $>99 \%$ for glucotropaeolin (7) (as $\mathrm{C}_{14} \mathrm{H}_{19} \mathrm{NO}_{9} \mathrm{~S}_{2}$ ), and $70 \%$ for glucobrassicin (8) (as $\left.\mathrm{C}_{16} \mathrm{H}_{20} \mathrm{~N}_{2} \mathrm{O}_{9} \mathrm{~S}_{2}\right), 61 \%$ for neoglucobrassicin

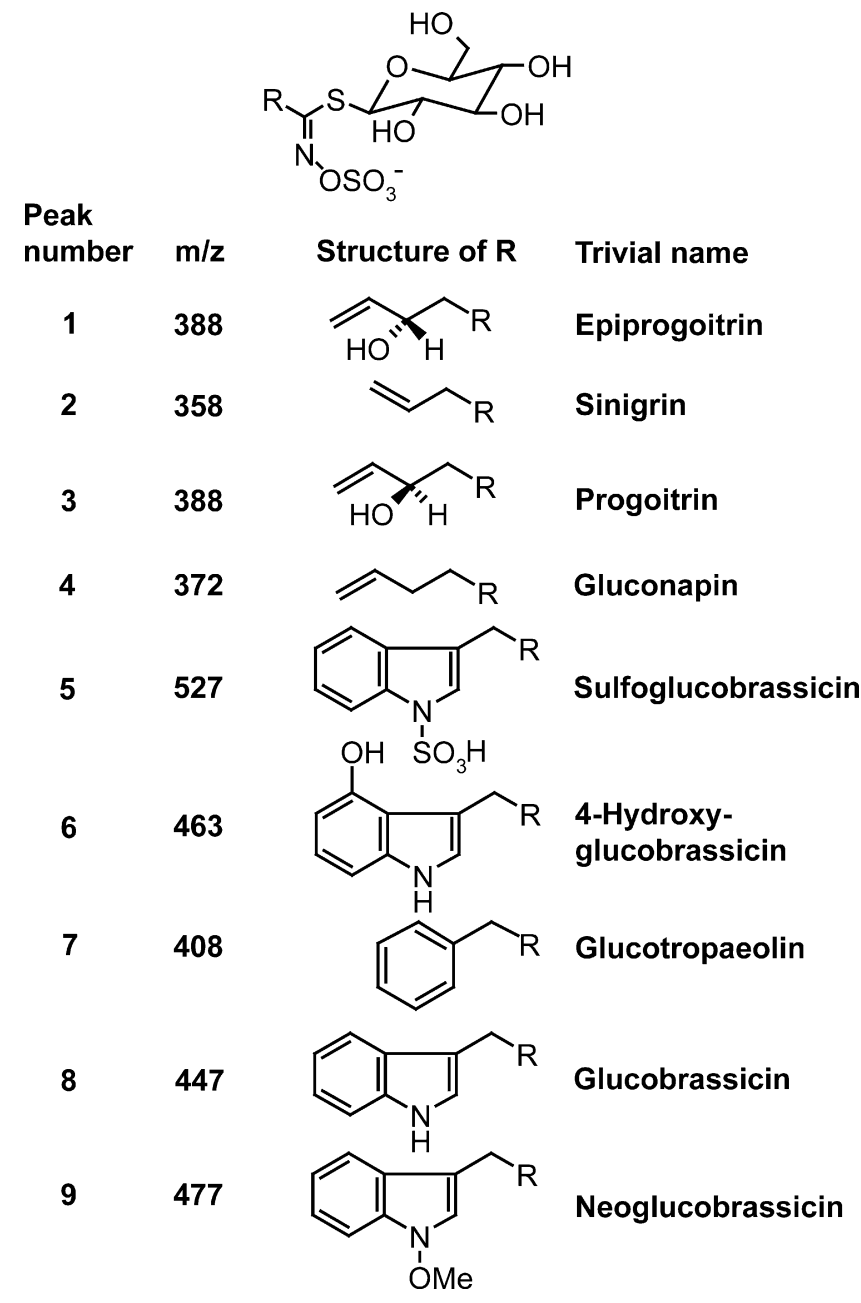

Fig. 3. Structures of glucosinolates 1-9.
(9) (as $\left.\mathrm{C}_{17} \mathrm{H}_{22} \mathrm{~N}_{2} \mathrm{O}_{10} \mathrm{~S}_{2}\right), 19 \%$ for sulfoglucobrassicin (5) (as $\mathrm{C}_{16} \mathrm{H}_{20} \mathrm{~N}_{2} \mathrm{O}_{12} \mathrm{~S}_{3}$ ) and $17 \%$ for 4-hydroxyglucobrassicin (6) (as $\mathrm{C}_{16} \mathrm{H}_{20} \mathrm{~N}_{2} \mathrm{O}_{10} \mathrm{~S}_{2}$ ).

\subsection{Development and validation of $L C-M S$ conditions}

LC-MS analysis of intact glucosinolates requires the use of ion-pair reagents to neutralize the negative charge of the sulfate groups. Preliminary tests with trifluoracetic acid (TFA; $0.05 \%$, $0.1 \%$ and $0.5 \%$ ) resulted in inacceptable peak tailing and separation, especially for sulfoglucobrassicin which contains two sulfate groups. Non-volatile ion-pair reagents such as tetraalkyl ammonium bromides could not be used because of MS detection. However, symmetrical peak shapes and good separation were also obtained with ammonium formate which was then used for all further separations.

We initially tested a range of RP-18 columns in conjunction with TFA and ammonium formate buffer in several concentrations. Best results were obtained on a Phenomenex Aqua column which was used for all subsequent experiments. The influence of the concentration of ammonium formate buffer $(1$, 5,10 and $20 \mathrm{mM}$ ) on peak shape and resolution was investigated. Best results were obtained with $10 \mathrm{mM}$ ammonium formate. In a range between $5 \mathrm{mM}$ and $20 \mathrm{mM}$ only minor shifts in retention time $(<0.2 \mathrm{~min})$ were observed, without change in peak shape, but a severe decline in peak symmetry and resolution occurred with a $1 \mathrm{mM}$ buffer concentration. For further optimization of chromatographic separation, we investigated the influence of column temperature $\left(15.0^{\circ} \mathrm{C}\right.$, $20.0^{\circ} \mathrm{C}, 25.0^{\circ} \mathrm{C}$ and $30.0^{\circ} \mathrm{C}$ ). Best resolution and peak shape was observed at $20.0^{\circ} \mathrm{C}$, in particular for compounds $\mathbf{1 - 3}$. At $30.0^{\circ} \mathrm{C}$, peaks $1-3$ could not be resolved. The solvent used for dissolution of samples proved to be critical. Injecting methanolic or $70 \%$ aqueous-methanolic solutions of reference compounds and extracts resulted in peak tailing, but symmetrical and sharp peaks were obtained when samples were dissolved in mobile phase A. The HPLC-MS analysis of a standard mixture of 1-9 under optimized conditions is shown in Fig. 4.

For quantitative analysis, extracted ion traces corresponding to $[M-\mathrm{H}]^{-}$quasimolecular ions were used for signal integration, with exception of sulfoglucobrassicin $(\mathbf{5})$. Here, the highest signal $(\mathrm{m} / \mathrm{z}, 447)$ in the spectrum, corresponding to the loss of a sulfate moiety, was used. Sinigrin (2), a glucosinolate which is not present in the genus Isatis, was used as internal standard for quantitative analysis of woad (I. tinctoria and I. indigotica) samples. Calibration curves (Supplementary Material, Table 2) were found to be quadratic functions for mass spectrometric detection $\left(R^{2} \geq 0.9998\right)$. Reproducibility was satisfactory (RSD $1.0-2.5 \% ; n=5$ ). Inter-day repeatability over time of analysis for 1-9 was between $96.5 \%$ and $101.0 \%$ after $67 \mathrm{~h}$. Limit of detection ( $\mathrm{S} / \mathrm{N}$ ratio of 3$)$ and limit of quantification ( $\mathrm{S} / \mathrm{N}$ ratio of 10) were determined by serial dilution of a standard solution of all glucosinolates (Table 1).

Accuracy of the method was determined with spiking experiments. Recovery rates for the major compounds sulfoglucobrassicin (5) (98\%) and glucobrassicin (8) (97\%), as well 


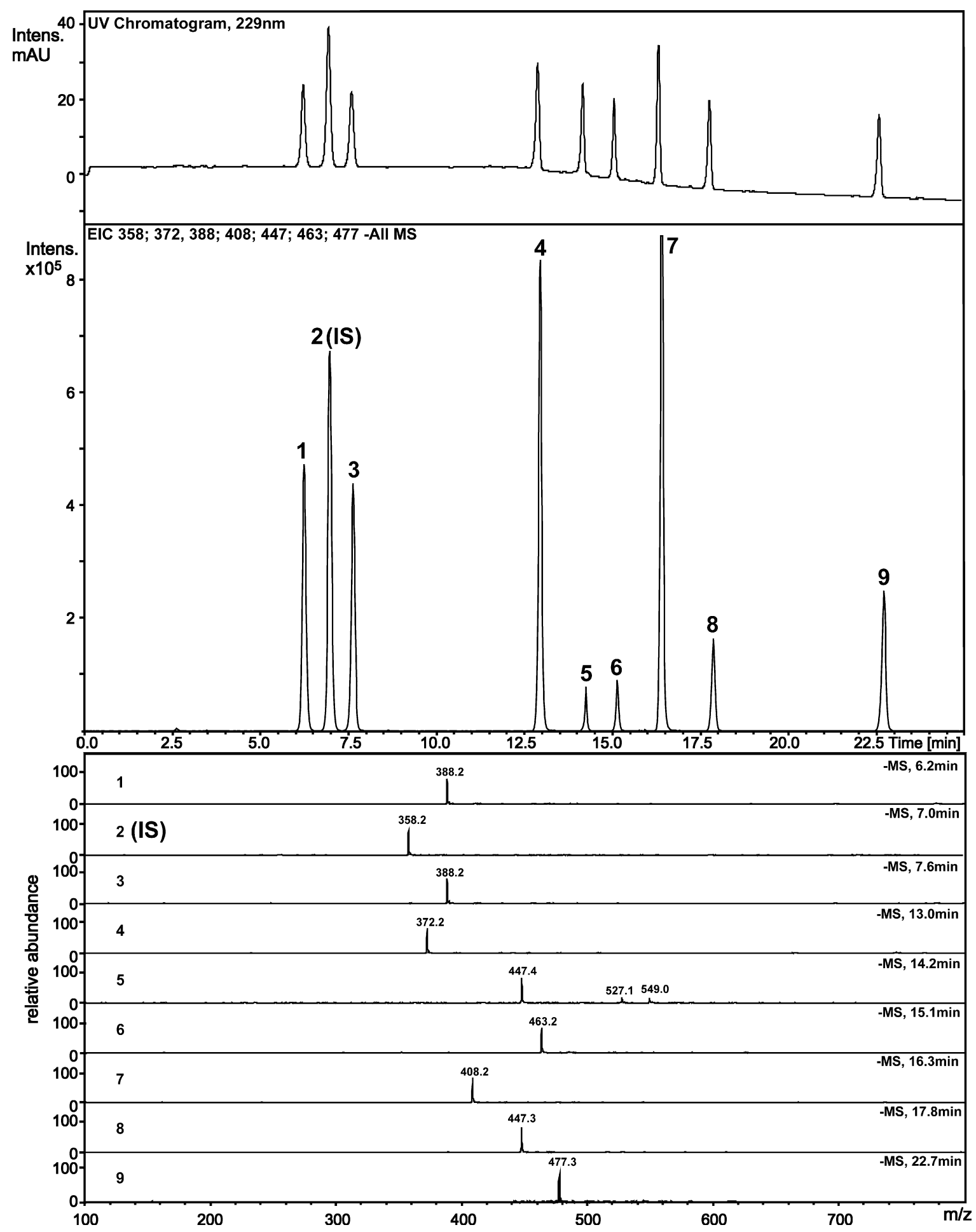

Fig. 4. HPLC separation of a mixture of reference compounds 1-9. Sinigrin (2) is used as internal standard (IS). The chromatogram on top was recorded at $229 \mathrm{~nm}$; below are the extracted ion chromatogram (EIC) obtained by ESI-MS in the negative ion mode, and the mass spectra of the individual compounds.

as for progoitrin (3) (102\%) were obtained (Supplementary Material, Table 1).

\subsection{Optimization and validation of the extraction protocol}

The optimized LC-MS conditions were then employed for the optimization and validation of an extraction protocol with Isatis samples. We decided upon pressurized liquid extraction
(PLE) as an extraction technique, given the numerous advantages over other methods of plant extraction and our own experience with the method [27-30]. We selected the major glucosinolates $\mathbf{5}$ and $\mathbf{8}$ as markers for the optimization and validation procedure.

In a preliminary experiment, solvent compositions and extraction temperatures typically used in published methods were compared. The results showed that a combination of aque- 
ous $\mathrm{MeOH}(70 \%)$ and moderately elevated temperatures were likely to give the highest yields (Supplementary Material, Fig. $1)$. In the next step, we investigated the influence of extraction temperature on the yield of $\mathbf{5}$ and $\mathbf{8}$ in more detail. As shown in Fig. 1, thermal degradation of glucosinolates was observed at temperatures above $50{ }^{\circ} \mathrm{C}$. A loss of $>60 \%$ was found at $100{ }^{\circ} \mathrm{C}$ when using three extraction cycles of $5 \mathrm{~min}$ each. The total yield of glucobrassicin (8) and sulfoglucobrassicin (5) at $40{ }^{\circ} \mathrm{C}$ was almost as high as at $50^{\circ} \mathrm{C}$. Analysis of the yield of the successive extraction cycles (Fig. 2), showed that extraction efficiency was clearly better at $50^{\circ} \mathrm{C}$. Cumulative yields of $99.4 \%$ and 99.7\% were achieved for $\mathbf{5}$ and $\mathbf{8}$ with three extraction cycles of $5 \mathrm{~min}$, whereas only $97.7 \%$ and $97.8 \%$ were obtained at $40^{\circ} \mathrm{C}$. An extraction temperature of $50{ }^{\circ} \mathrm{C}$ and three extraction cycles of $5 \mathrm{~min}$ each were used for all subsequent experiments. We also investigated the influence of particle size of the herbal material on the yields of extracted glucosinolates. Isatis leaves were cryomilled in an ultracentrifugal mill, using sieve sizes of $1.0,0.75$ and $0.5 \mathrm{~mm}$. Differences observed in cumulative yields were small. With a sieve size of $1 \mathrm{~mm}, 98.5 \%$ of sulfoglucobrassicin (5) were extracted after 3 extraction cycles, compared to $99.5 \%$ with sieve sizes 0.75 and $0.5 \mathrm{~mm}$. For glucobrassicin (8), the yields were $98.9 \%$ for sieve size of $1.0 \mathrm{~mm}$, and $99.7 \%$ for 0.75 and $0.5 \mathrm{~mm}$. (Supplementary Material, Fig. 2).

The enzyme thioglucohydrolase (E.C. 3.2.1.147, myrosinase), is responsible for the hydrolysis of glucosinolates to glucose and a variety of breakdown products, which are responsible for the hot and pungent taste of many cruciferous vegetable and spices. Myrosinase is known to be quite stable in dried plant material at room temperature and can be reactivated upon addition of water, e.g. during extraction. To determine whether myrosinase activity in thawed Isatis leaf material possibly confounded the yields of glucosinolates in extractions with our PLE protocol, we carried out an experiment in which PLE cartridges filled with identical Isatis leaf samples were extracted at defined times after thawing. The sample extracted immediately ( 0 min) served as reference (100\%). No measurable decrease of sulfoglucobrassicin (5) and glucobrassicin (8) was seen in cartridges which were kept at ambient temperature up to $200 \mathrm{~min}$ after the start of the experiment (Supplementary Material, Fig. 3). We concluded that myrosinase activity was negligible in our assay conditions and that, consequently, larger sample series could be prepared for extraction without undue risk of loss in analytes.

\subsection{Quantitative analysis of woad extracts}

The optimized and validated method for sample preparation and LC-MS analysis was used to determine the content in glucosinolates 1, and 3-9 in three different woad samples. PLE extracts of two defined cultures of I. tinctoria ("Jenaer Waid" and "Kieler Waid") and of the taxiconomically closely related Isatis indigotica were prepared. The two Isatis species are indigo dyes and medicinal plants with important anti-inflammatory and anti-allergic properties [31-34]. Fig. 5 shows the base peak chromatogram (BPC) of the extract and the extracted ion chro-

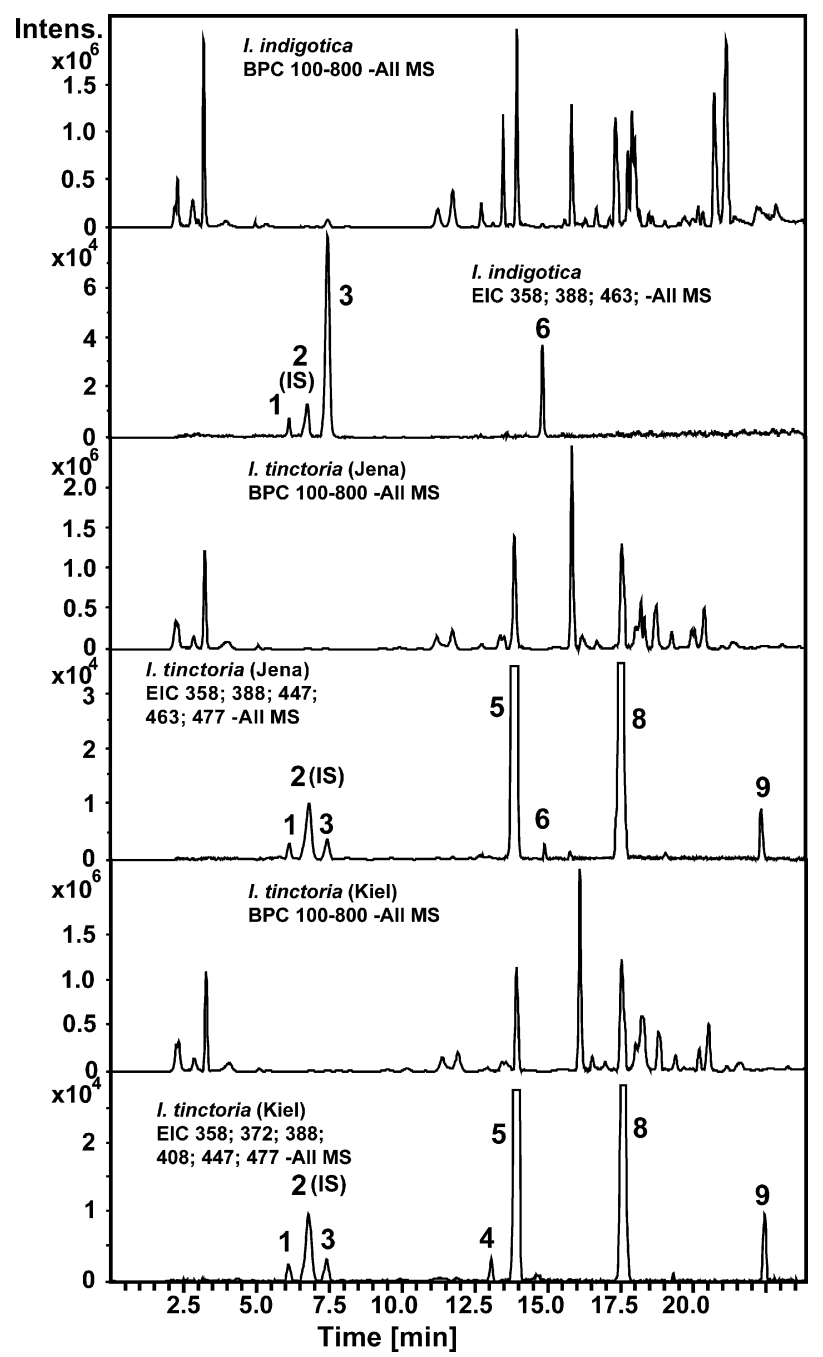

Fig. 5. Glucosinolates in Isatis leaf extracts. Base peak chromatograms (BPC) and extracted ion chromatograms (EIC) of major glucosinolates are shown for two Isatis tinctoria accessions ("Jenaer Waid" and "Kieler Waid"), and for I. indigotica. Sinigrin (2) is used as internal standard (IS).

matograms (EIC) used for peak integration of the identified glucosinolates.

Due to large differences in concentration of glucosinolates, it was necessary to analyze the extracts in different dilutions for quantification. In particular, high dilutions (1:100) of I. tinctoria extracts were prepared to determine sulfoglucobrassicin (5) and glucobrassicin (8), while progoitrin (3) and hydroxyglucobrassicin (6) were measured in a 1:10 extract dilution of I. indigotica. The remaining glucosinolates were quantified in undiluted extracts (Table 2).

The glucosinolate spectra of both Isatis species varied remarkably. In comparison, the extract of I. indigotica did not contain sulfoglucobrassicin (5) or glucobrassicin (8) which are the major glucosinolates of I. tinctoria. Progoitrin (3) and 4hydroxyglucobrassicin (6) were the main glucosinolates in the I. indigotica extract. The aromatic glucotropaeolin (7) as well as other indole-type glucosinolates such as glucoisatisin and hydroxyglucoisatisin which have been reported from I. tinctoria L. seeds could not be found in the Isatis leaf samples. 
Table 2

Glucosinolate content (in $\mu \mathrm{mol} / \mathrm{g}$ dry weight) in woad extracts

\begin{tabular}{|c|c|c|c|}
\hline Compound & I. indigotica & I. tinctoria (Kiel) & I. tinctoria (Jena) \\
\hline Epiprogoitrin (1) & $0.16 \pm 0.01^{\mathrm{a}}$ & $0.10 \pm 0.01^{\mathrm{a}}$ & $0.16 \pm 0.01^{\mathrm{a}}$ \\
\hline Progoitrin (3) & $2.54 \pm 0.03^{b}$ & $0.15 \pm 0.01^{\mathrm{a}}$ & $0.20 \pm 0.01^{\mathrm{a}}$ \\
\hline Gluconapin (4) & n.d. & $0.03 \pm 0.01^{\mathrm{a}}$ & n.d. \\
\hline Sulfoglucobrassicin (5) & n.d. & $11.38 \pm 0.37^{\mathrm{c}}$ & $13.51 \pm 0.23^{\mathrm{c}}$ \\
\hline 4-Hydroxyglucobrassicin (6) & $0.43 \pm 0.01^{\mathrm{b}}$ & n.d. & $0.04 \pm 0.01^{\mathrm{a}}$ \\
\hline Glucotropaeolin (7) & n.d. & n.d. & n.d. \\
\hline Glucobrassicin (8) & n.d. & $6.14 \pm 0.12^{\mathrm{c}}$ & $14.29 \pm 0.25^{\mathrm{c}}$ \\
\hline Neoglucobrassicin (9) & n.d. & $0.19 \pm 0.01^{\mathrm{a}}$ & $0.16 \pm 0.01^{\mathrm{a}}$ \\
\hline
\end{tabular}

All measurements were in triplicate.; n.d.: not detected.

a Undiluted extract.

b Dilution 1:10.

c Dilution 1:100.

\subsection{Qualitative analysis of glucosinolates in cruciferous vegetables and spices}

Cruciferous vegetables and spices such as broccoli, garden cress and black mustard were analyzed to demonstrate the general applicability of the method. LC-TOFMS in negative mode was used to confirm the molecular formula of glucosinolates. Fig. 6 shows extracted ion chromatograms of glucosinolates identified in broccoli extracts. Besides minor glucosinolates, glucoerucin $\left(\mathrm{C}_{12} \mathrm{H}_{23} \mathrm{NO}_{9} \mathrm{~S}_{3}\right.$, calc. 421.0535; found: 421.0535),

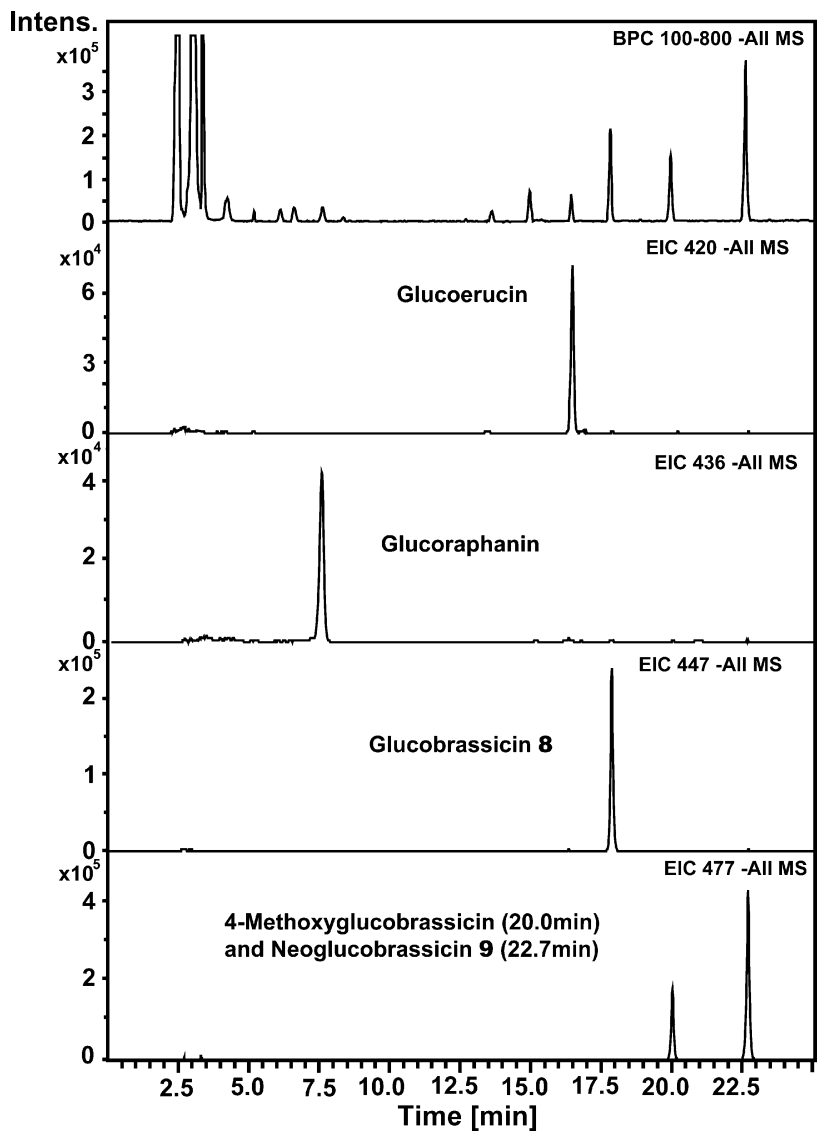

Fig. 6. Major glucosinolates identified in broccoli. Base peak chromatogram (BPC) of the extract (top) and extracted ion chromatograms (EIC) of major glucosinolates are shown. glucoraphanin $\left(\mathrm{C}_{12} \mathrm{H}_{23} \mathrm{NO}_{10} \mathrm{~S}_{3}\right.$, calc.: 437.0484; found: 437.0483), glucobrassicin (8) $\left(\mathrm{C}_{16} \mathrm{H}_{20} \mathrm{~N}_{2} \mathrm{O}_{9} \mathrm{~S}_{2}\right.$, calc.: 448.0610; found 448.0608), 4-methoxyglucobrassicin $\left(\mathrm{C}_{17} \mathrm{H}_{22} \mathrm{~N}_{2} \mathrm{O}_{10} \mathrm{~S}_{2}\right.$, calc.: 478.0716 found: 478.0719) and neoglucobrassicin (9) $\left(\mathrm{C}_{17} \mathrm{H}_{22} \mathrm{~N}_{2} \mathrm{O}_{10} \mathrm{~S}_{2}\right.$, calc.: 478.0716 found: 478.0715$)$ could be identified.

Glucotropaeolin (7) $\left(\mathrm{C}_{14} \mathrm{H}_{19} \mathrm{NO}_{9} \mathrm{~S}_{2}\right.$, calc.: 409.0501; found 409.0503 ) eluted at $16.2 \mathrm{~min}$ was the major glucosinolate in garden cress, followed by 4-methoxyglucobrassicin $\left(\mathrm{C}_{17} \mathrm{H}_{22} \mathrm{~N}_{2} \mathrm{O}_{10} \mathrm{~S}_{2}\right.$, calc.: 478.0716; found 478.0715) at $19.9 \mathrm{~min}$ as a minor compound (Fig. 7). Black mustard seeds contained sinigrin (2) $\left(\mathrm{C}_{10} \mathrm{H}_{17} \mathrm{NO}_{9} \mathrm{~S}_{2}\right.$, calc.: 359.0345; found 359.0346 ) as the dominant compound, and gluconapin (4) $\left(\mathrm{C}_{11} \mathrm{H}_{19} \mathrm{NO}_{9} \mathrm{~S}_{2}\right.$, calc.: 373.0501 ; found 373.0498$)$, glucoibervirin $\left(\mathrm{C}_{11} \mathrm{H}_{21} \mathrm{NO}_{9} \mathrm{~S}_{3}\right.$, calc.: 407.0378; found 407.0376), gluconasturtiin $\left(\mathrm{C}_{15} \mathrm{H}_{21} \mathrm{NO}_{9} \mathrm{~S}_{2}\right.$, calc.: 423.0658; found 423.0656) and 4-hydroxyglucobrassicin (6) $\left(\mathrm{C}_{16} \mathrm{H}_{20} \mathrm{~N}_{2} \mathrm{O}_{10} \mathrm{~S}_{2}\right.$, calc.: 464.0559; found 464.0557) as minor glucosinolates (Fig. 8).

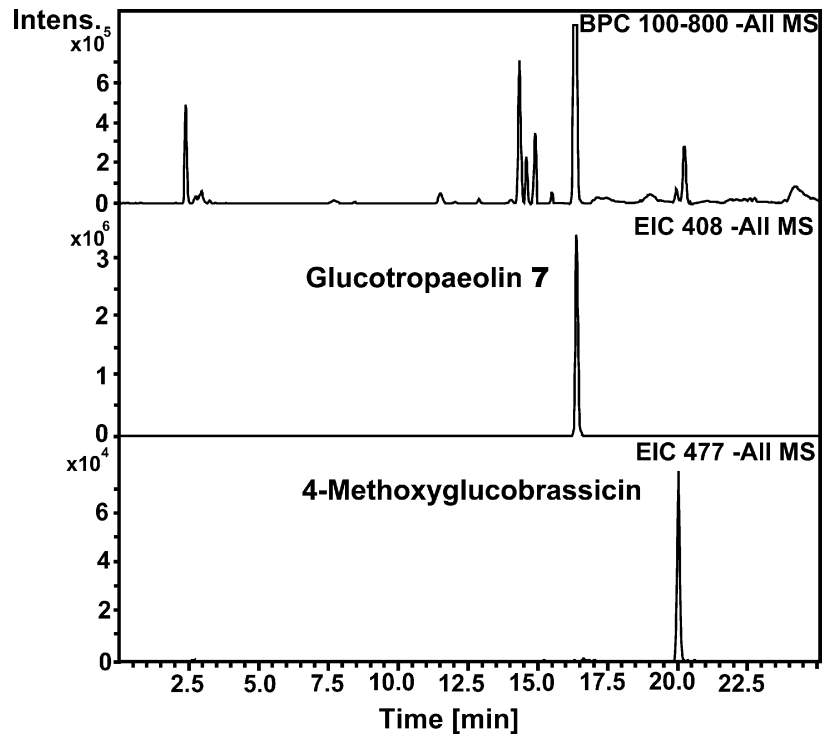

Fig. 7. Major glucosinolates identified in garden cress. Base peak chromatogram (BPC) of the extract (top) and extracted ion chromatograms (EIC) of major glucosinolates are shown. 


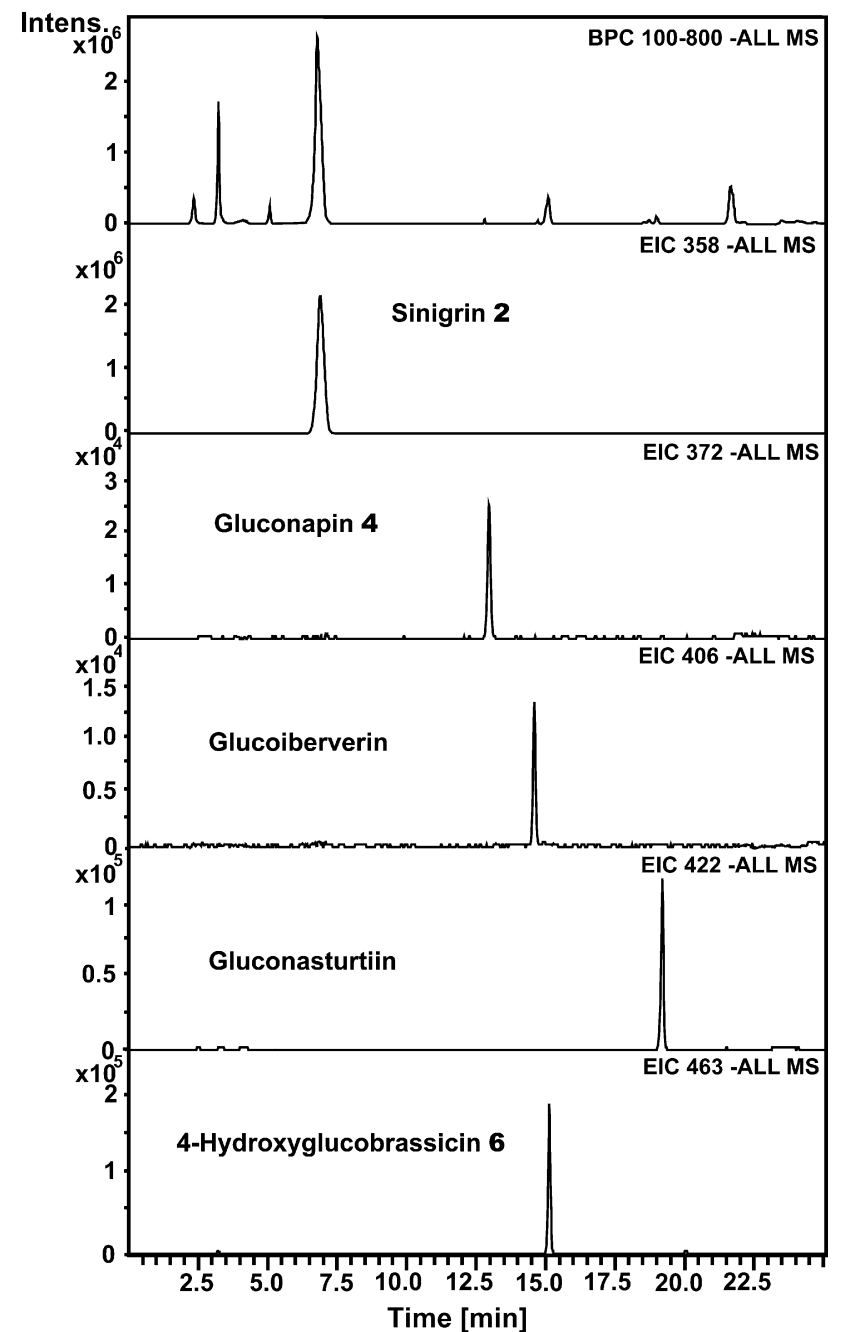

Fig. 8. Major glucosinolates identified in black mustard seeds. Base peak chromatogram (BPC) of the extract (top) and extracted ion chromatograms (EIC) of major glucosinolates are shown.

\section{Discussion}

In 1982, Minchinton et al. [20] published a desulfatation procedure for the quantification of glucosinolates, which served as the basis for the official method of the European Community [9], and for the majority of publications reporting quantitative data on glucosinolates. Comparatively few publications have recently attempted a direct analysis of glucosinolates, and limited information is available concerning validation of extraction, sample workup and chromatographic analysis.

For natural product analysis, purity assessment of reference compounds is often incomplete or even lacking. This is also the case for glucosinolates $[10,15,24]$. Due to their ionic nature, assessment of the true content is particularly critical, as reference samples may contain unknown amounts of salts and water of crystallization. Quantitative ${ }^{1} \mathrm{H}$ NMR (qHNMR) is the currently most appropriate method to determine the absolute amount of compound in a reference sample, and has been successfully applied in natural product analysis $[35,36]$. Using 1,3,5-trimethoxybenzene as reference, we determined the con- tent of all purchased and isolated glucosinolates references. For compounds 1-9, previous analysis by HPLC and by qualitative NMR gave $>99 \%$ purity. However, qHNMR data revealed significant differences of true content, ranging from $>99 \%$ for sinigrin (2) to $17 \%$ for 4-hydroxyglucobrassicin (6). The majority of references were in the range of 60-90\% purity.

The result of any quantitative assay of a herbal drug critically depends on the extraction step which precedes the dosage. In all published methods for glucosinolate analysis, limited effort was devoted to optimization and validation of crucial extraction parameters and sample preparation steps. In our study, we used pressurized liquid extraction (PLE), a technique that is well suited for plant extraction [30,37]. Based on own experience in development of validated PLE procedures [27-29,38-40], we optimized critical parameters such as solvent composition, particle size of herbal drug, temperature, and number of required extraction steps. An unexpected finding was the extent of thermal degradation at temperature above $50^{\circ} \mathrm{C}$. This observation revealed a problem with existing methods [9-15], where extractions were typically carried out at temperatures between $70^{\circ} \mathrm{C}$ and $100^{\circ} \mathrm{C}$ to inactivate myrosinase, even though thermal degradation of glucosinolates during cooking of vegetables has been reported [3,41,42]. Compared to other classes of plant metabolites, glucosinolates appeared particularly sensitive to heat. Temperatures of $60-70^{\circ} \mathrm{C}$ have been, typically used in validated PLE methods for various classes of natural products [27-29,38] including labile compounds such as the indigo precursors isatan A and B in woad [39], and temperatures as high as $120^{\circ} \mathrm{C}$ were optimal for the extraction of triterpenoidal esters in evening primrose seeds [40].

Enzymatic hydrolysis of glucosinolates by myrosinase has been considered a critical issue in extraction, and published quantitative assays therefore aimed at inactivating the enzyme, by using denaturing solvents [13-15,25,26] or extraction at elevated temperatures [9-15,20,22]. We investigated possible loss of $\mathbf{5}$ and $\mathbf{8}$ due to myrosinase. In I. tinctoria leaves which had been freeze-dried, stored at $-20^{\circ} \mathrm{C}$ and thawed prior to extraction, we found no enzymatic degradation over $200 \mathrm{~min}$ at ambient temperature (Supplementary Material, Fig. 3). These data, however, cannot be extrapolated to fresh plant material, where myrosinase activity is expected due to the high water content.

Chromatography of intact glucosinolates requires suitable additives in the mobile phase. Trifluoracetic acid has been used in earlier studies $[16,18,23]$ but did not result in acceptable peak shape and chromatographic resolution in our preliminary tests. Better results were obtained with ammonium formate, but extensive testing of several stationary phases from different manufacturers revealed major differences in performance. Sample preparation for HPLC analysis turned out to be critical. Removal of the extraction solvent (70\% methanol) and redissolving in mobile phase A substantially improved peak shape.

Thanks to the use of the internal standard sinigrin (2), the LC-MS performance was sufficiently stable over extended periods. Inter-day repeatability was in the range of $96.5 \%$ to $101.0 \%$ over $67 \mathrm{~h}$. Accuracy was satisfactory, as determined by spiking experiments with the major glucosinolates sulfoglucobrassicin 
(5) (98\%) and glucobrassicin (8) (97\%), and with the minor compound progoitrin $(\mathbf{3})(102 \%)$ (Supplementary Material, Table 1). Limited information is available concerning method validation of published procedures. Song et al. [18] and Tian et al. [24] determined validation parameters such as limit of detection, accuracy and intra-assay precision with intact glucosinolates. Reported LODs (0.4-0.6 pmol [24]) were comparable to our findings. However, analyte recoveries determined by spiking experiments were lower $(\geq 85 \%)$ than in our experiments $(\geq 97 \%)$.

\section{Acknowledgments}

We thank Dr. A. Vetter and A. Biertümpfel, Thüringische Landesanstalt für Landwirtschaft (TLL), Jena and Dornburg, for the provision of Isatis samples from the experimental field plots at Dornburg, and for detailed information on breeding and agriculture of the Isatis accessions analyzed in this study. G.U. Rüster, formerly Institute of Pharmaceutical Biology, University of Jena, is kindly acknowledged for isolation of some reference compounds.

\section{Appendix A. Supplementary data}

Supplementary data associated with this article can be found, in the online version, at doi:10.1016/j.chroma.2007.08.028.

\section{References}

[1] J.W. Fahey, A.T. Zalcmann, P. Talalay, Phytochemistry 56 (2001) 5.

[2] B. Holst, G. Williamson, Nat. Prod. Rep. 21 (2004) 425.

[3] A.M. Bones, J.T. Rossiter, Phytochemistry 67 (2006) 1053.

[4] B.A. Halkier, J. Gershenzon, Annu. Rev. Plant Biol. 57 (2006) 303.

[5] U. Wittstock, D.J. Kliebenstein, V. Lambrix, M. Reichelt, J. Gershenzon, Recent Adv. Phytochem. 37 (2003) 101.

[6] P.D. Brown, J.G. Tokuhisa, M. Reichelt, J. Gershenzon, J. Agric. Food Chem. 43 (1995) 3070.

[7] P.J. Thornalley, Anti-Cancer Drugs 13 (2002) 331.

[8] Y.-S. Keum, W.-S. Jeong, A.N.T. Kong, Mutat. Res. 555 (2004) 191.

[9] EEC Regulation No. 1864/90, Off. J. Eur. Communities L170 (1990) 27.

[10] W. Guo, L. Yuan, P. Chen, J. Guo, Anal. Lett. 38 (2005) 343.

[11] M.M. Kushad, A.F. Brown, A.C. Kurilich, J.A. Juvik, B.P. Klein, M.A. Wallig, E.H. Jeffery, J. Agric. Food Chem. 47 (1999) 1541.
[12] A.M. Szmigielska, J.J. Schoenau, J. Agric. Food Chem. 48 (2000) 5190.

[13] G. Kiddle, R.N. Bennett, N.P. Botting, N.E. Davidson, A.A.B. Robertson, R.M. Wallsgrove, Phytochem. Anal. 12 (2001) 226.

[14] R. Verkerk, M. Dekker, W.M.F. Jongen, J. Sci. Food Agric. 81 (2001) 953.

[15] R.N. Bennett, R. Carvalho, F.A. Mellon, J. Eagles, E.A.S. Rosa, J. Agric. Food Chem. 55 (2007) 67.

[16] F.A. Mellon, R.N. Bennett, B. Holst, G. Williamson, Anal. Biochem. 306 (2002) 83

[17] C.H. Botting, N.E. Davidson, D.W. Griffiths, R.N. Bennett, N.P. Botting, J. Agric. Food Chem. 50 (2002) 983.

[18] L. Song, J.J. Morrison, N.P. Botting, P.J. Thornalley, Anal. Biochem. 347 (2005) 234.

[19] R.N. Bennett, F.A. Mellon, P.A. Kroon, J. Agric. Food Chem. 52 (2004) 428.

[20] I. Minchinton, S.D. Burke, R.J.W. Truscott, J. Chromatogr. 247 (1982) 141.

[21] A. Frechard, N. Fabre, C. Péan, S. Montaut, M.-T. Fauvel, P. Rollin, I. Fourasté, Tetrahedron Lett. 42 (2001) 9015

[22] T. Prestera, J.W. Fahey, W.D. Hotzclaw, C. Abeygunawardana, J.L. Kachinski, P. Talalay, Anal. Biochem. 239 (1996) 168.

[23] G. Bringmann, I. Kajahn, C. Neusuess, M. Pelzing, S. Laug, M. Unger, U. Holzgrabe, Electrophoresis 26 (2005) 1513.

[24] Q. Tian, R.A. Rosselot, S.J. Schwartz, Anal. Biochem. 343 (2005) 93.

[25] P.S. Kokkonen, J. van der Greef, W.M.A. Niessen, U.R. Tjaden, G.J. ten Hove, G. van de Werken, Biol. Mass Spectrom. 20 (1991) 259.

[26] C.L. Zrybko, E.K. Fukuda, R.T. Rosen, J. Chromatogr. A 767 (1997) 43.

[27] C. Basalo, T. Mohn, M. Hamburger, Planta Med. 72 (2006) 1157.

[28] B. Benthin, H. Danz, M. Hamburger, J. Chromatogr. A 837 (1999) 211.

[29] T. Mohn, O. Potterat, M. Hamburger, Planta Med. 73 (2007) 151.

[30] C.W. Huie, Anal. Bioanal. Chem. 373 (2002) 23.

[31] C. Heinemann, S. Schliemann-Willers, C. Oberthuer, M. Hamburger, P. Elsner, Planta Med. 70 (2004) 385.

[32] M.-C. Recio, M. Cerda-Nicolas, M. Hamburger, J.-L. Rios, Planta Med. 72 (2006) 715 .

[33] M.-C. Recio, M. Cerda-Nicolas, O. Potterat, M. Hamburger, J.-L. Rios, Planta Med. 72 (2006) 539.

[34] M. Hamburger, Phytochem. Rev. 1 (2003) 333.

[35] G.F. Pauli, B.U. Jaki, D.C. Lankin, J. Nat. Prod. 68 (2005) 133.

[36] B. Jaki, O. Sticher, M. Veit, R. Fröhlich, G.F. Pauli, J. Nat. Prod. 65 (2002) 517.

[37] B. Kaufmann, P. Christen, Phytochem. Anal. 13 (2002) 105.

[38] C. Oberthür, M. Hamburger, Planta Med. 70 (2004) 642.

[39] C. Oberthür, H. Graf, M. Hamburger, Phytochemistry 65 (2004) 3261.

[40] J. Zaugg, O. Potterat, A. Plescher, B. Honermeier, M. Hamburger, J. Agric. Food Chem. 54 (2006) 6623.

[41] B.A. Slominski, L.D. Campbell, J. Agric. Food Chem. 37 (1989) 1297.

[42] K. Oerlemans, D.M. Barrett, C.B. Suades, R. Verkerk, M. Dekker, Food Chem. 95 (2005) 19. 
Supplementary Material

\section{Extraction and Quantitative Analysis of non-derivatized Glucosinolates in Plant Extracts - a Validated PLE/LC-MS Protocol}

Tobias Mohn ${ }^{a}$, Brian Cutting ${ }^{b}$, Beat Ernst ${ }^{b}$, Matthias Hamburger $^{a, *}$

anstitute of Pharmaceutical Biology, University of Basel, Klingelbergstrasse 50, CH-4056 Basel, Switzerland

${ }^{b}$ Institute of Molecular Pharmacy, University of Basel, Klingelbergstrasse 50, CH-4056 Basel, Switzerland

*Corresponding author. Tel.: +416126714 25; Fax: +41612671474.

E-mail address: matthias.hamburger@unibas.ch (M.Hamburger). 


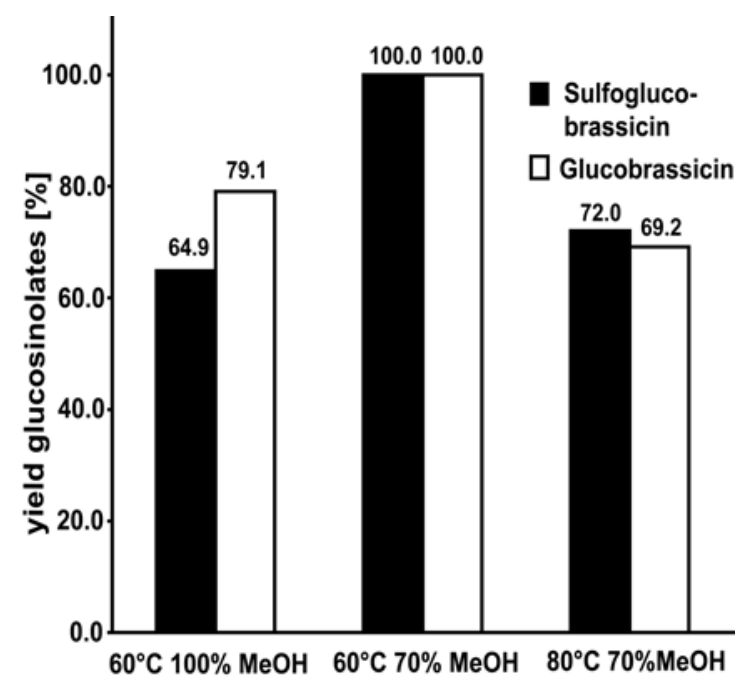

Figure 1: Optimization of extraction parameters. Influence of the solvent composition on the yield of glucosinolates $\mathbf{5}$ and $\mathbf{8}$ from Isatis tinctoria leaves ("Jenaer Waid"). The yields obtained at $60^{\circ} \mathrm{C}$ with $70 \% \mathrm{MeOH}$ were set as $100 \%$.
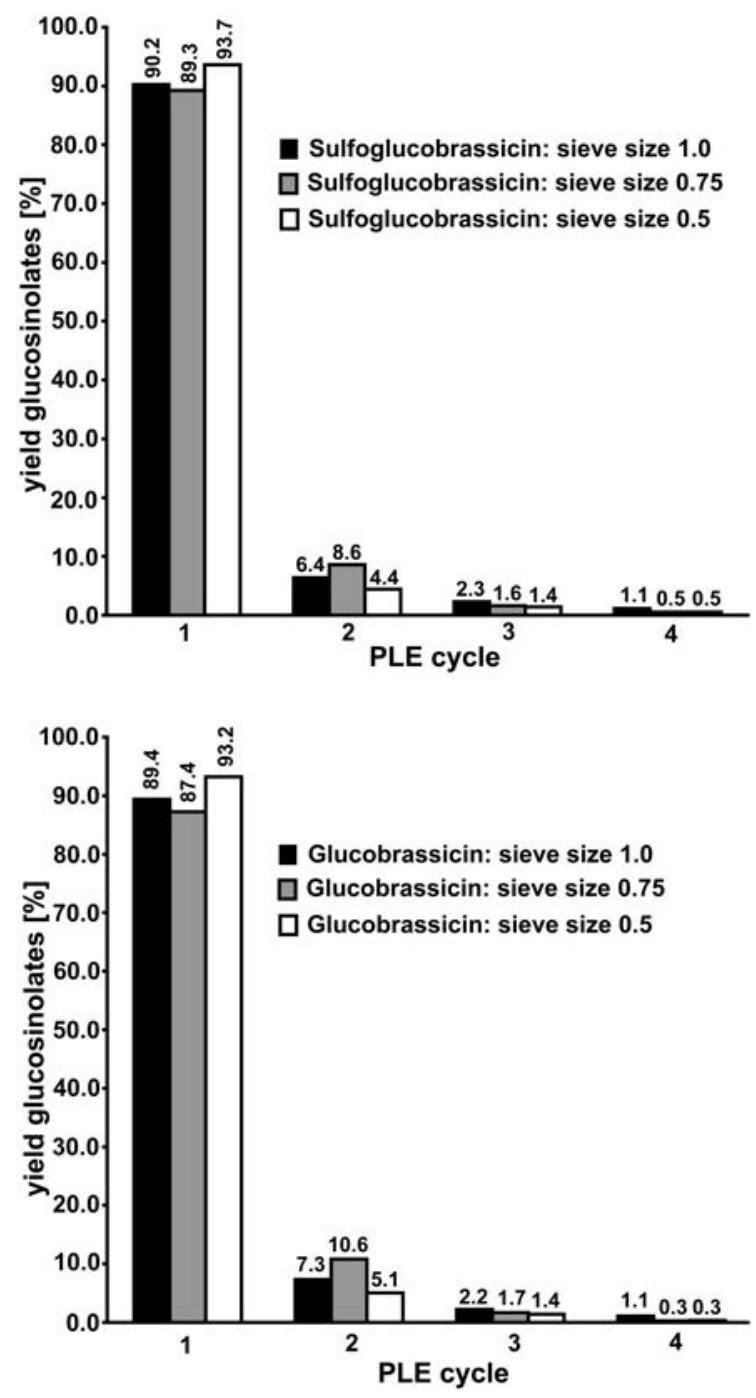

Figure 2: Optimization of extraction parameters. Influence of the particle size on the yield of glucosinolates $\mathbf{5}$ and $\mathbf{8}$ extracted from Isatis tinctoria leaves (“Jenaer Waid"). The cumulative yields of four extraction cycles were set as $100 \%$. 
Table 1: Recovery rates for compounds $\mathbf{3}, \mathbf{5}$ and $\mathbf{8 .}$

\section{Compound}

Progoitrin (3)

Sulfoglucobrassicin (5)

Glucobrassicin (8)

\section{Amount added to extract}

10.0

70.0

20.0

\section{Recovered amount*}

$10.2 \pm 0.6$

$68.5 \pm 0.3$

$19.4 \pm 0.3$

\section{Relative recovery} rates

$102 \%$

$98 \%$

$97 \%$

${ }^{*}$ Amounts in ng on column $(20 \mu \mathrm{l}$ injection). Determinations were made in triplicate.

Table 2: Calibration curves for compounds 1, and 3-9

Compound

Epiprogoitrin (1)

Progoitrin (3)

Gluconapin (4)

Sulfoglucobrassicin (5)

4-Hydroxyglucobrassicin (6)

Glucotropaeolin (7)

Glucobrassicin (8)

Neoglucobrassicin (9)

\section{Curve}

$y=85.907 x^{2}-3115.1 x+71372$

$y=97.22 x^{2}-3818.4 x+88592$

$y=192.58 x^{2}+1023.1 x+28740$

$y=7.7837 x^{2}+596.33 x-7186.8$

$y=18.002 x^{2}-34.08 x+14458$

$y=189.91 x^{2}+9274.3 x-58217$

$y=48.575 x^{2}-1221.7 x+46037$

$y=69.715 x^{2}+856.11 x+27276$
Concentration* $[\mathrm{mg} / \mathrm{ml}], \mathbf{R}^{2}$

$0.0001-0.02 ; R^{2}=0.9999$

$0.0002-0.02 ; R^{2}=0.9999$

$0.0001-0.02 ; R^{2}=1$

$0.001-0.02 ; R^{2}=0.9999$

$0.0005-0.02 ; R^{2}=1$

$0.0001-0.02 ; R^{2}=0.9998$

$0.0002-0.02 ; R^{2}=0.9999$

$0.0002-0.02 ; R^{2}=1$

${ }^{*}$ Concentration range for which the curves apply. Solutions were analyzed in five replicates. 
3.4 Seasonal changes and effect of harvest on glucosinolates in Isatis leaves

(Mohn et al., Planta Med 2008; 74:582-587). 


\section{Seasonal Changes and Effect of Harvest on Glucosinolates in Isatis leaves}

Author

Affiliation
Tobias Mohn, Kathrin Suter, Matthias Hamburger

Institute of Pharmaceutical Biology, University of Basel, Basel, Switzerland
Key words

- Isatis tinctoria

- Isatis indigotica

- Brassicaceae

- seasonal variation

- harvest

- glucosinolates received January 9, 2008 revised March 4, 2008

accepted March 9, 2008

Bibliography

DOI $10.1055 / \mathrm{s}-2008-1074504$

Planta Med 2008; 74: 582-587

(c) Georg Thieme Verlag KG

Stuttgart · New York

Published online April 8, 2008

ISSN 0032-0943

Correspondence

Prof. Dr. Matthias Hamburger Institute of Pharmaceutical Biology

Department of Pharmaceutical Sciences

University of Basel

Klingelbergstrasse 50

4056 Basel

Switzerland

Tel.: +41-61-267-1425

Fax: +41-61-267-1474

matthias.hamburger@unibas.ch

\section{Abstract}

$\nabla$

The seasonal fluctuation of glucosinolates in five defined Isatis tinctoria and one Isatis indigotica accessions (first year, rosette stage), grown on field plots under identical conditions, was investigated. Analysis of the intact glucosinolates was carried out with shock frozen, freeze dried leaf samples using a recently developed and validated PLE (pressurized liquid extraction) protocol and ion-pair HPLC coupled with ESI-MS in the negative mode. When comparing the two Isatis species, significant qualitative and quantitative differences in the glucosinolate patterns were observed. Differences among the various Isatis tinctoria accessions were much smaller. We studied the effects of repeated harvesting during the growth season on glucosinolate concentrations and found that repeated harvest did not have a major effect on glucosinolate concentrations of newly grown leaves. Glucosinolates could not be detected in woad leaves submitted to conventional drying.

\section{Introduction}

$\checkmark$

Woad (Isatis tinctoria L., family Brassicaceae) had been used as an indigo dye in Central Europe since antiquity and as a medicinal plant for the treatment of inflammatory diseases [1]. In China, Banlangen (Isatis root) and Daqingye (Isatis leaf) from the taxonomically closely related Isatis indigotica Fort. remain until now important herbal drugs in Traditional Chinese Medicine (TCM) for the treatment of inflammatory ailments. We investigated the anti-inflammatory potential of I. tinctoria leaf extracts in a broad-based pharmacological screening, and tryptanthrin, $\gamma$-linolenic acid and 1,3-dihydro-3-[(4-hydroxy-3,5-dimethoxyphenyl)methylene]-2H-indol-2-one were identified as active principles inhibiting cyclooxy-

\section{Abbreviations \\ $\nabla$}

AFLP: amplified fragment length polymorphism

BPC: base peak chromatogram

COX2: cyclooxygenase 2

EIC: extracted ion chromatogram

FW: "French woad"

IS: internal standard

JW: "Jenaer Waid"

KW: "Kieler Waid"

5-LOX: 5-lipoxygenase

PLE: $\quad$ pressurized liquid extraction

SW: "Swiss woad"

TW: "Thüringer Waid"

TCM: Traditional Chinese Medicine

TLL: Agricultural Research Station of Thuringia

Supporting information available online at http://www.thieme-connect.de/ejournals/toc/ plantamedica genase-2, 5-lipoxygenase, the expression of the inducible nitric oxide synthase, human neutrophil elastase, and the release of histamine from mast cells [2], [3], [4], [5], [6]. Animal pharmacological studies [7], [8] and a clinical pilot study [9] corroborated the potential of lipophilic Isatis extracts as an anti-inflammatory.

Parallel to these pharmacological investigations, phytochemical and analytical studies of the plant were carried out. We previously reported seasonal variations of indigo precursors in woad leaves and observed that the phytochemical profiles of Isatis tinctoria L. (woad) and I. indigotica Fort. underwent profound changes during post-harvest treatment. Indigo precursors largely dissappeared whereas pharmacologically active compounds such as tryptanthrin were formed during 
the drying process [10], [11]. In fresh woad leaves, two classes of secondary metabolites occur in rather high concentrations, namely the indigo precursors, such as indican, and isatans $\mathrm{A}$ and B [12], and glucosinolates [13], [14], [15], [16].

As part of a comprehensive metabolite profiling, we here report on the seasonal fluctuation of glucosinolates in five I. tinctoria accessions grown under identical conditions. For comparative purposes, we also analyzed the glucosinolate pattern of the closely related I. indigotica. The effects of repeated harvesting during the growth season on glucosinolate concentrations, and the influence of post-harvest processing were studied.

\section{Materials and Methods}

$\nabla$

\section{Chemicals and reference compounds}

Analytical grade solvents for extraction and HPLC grade solvents for chromatography were purchased from Scharlau. HPLC grade water was obtained by an EASY-pure II (Barnstead) water purification system. Ammonium formate ( $\geq 99.995 \%$ ) and sinigrin (2) (propenyl glucosinolate) (> 99\%) were purchased from SigmaAldrich.

Potassium salts of progoitrin (3) [2(R)-2-hydroxy-3-butenyl glucosinolate], epiprogoitrin (1) [2(S)-2-hydroxy-3-butenyl glucosinolate], gluconapin (4) (3-butenyl glucosinolate) and glucotropaeolin (7) (phenylmethyl glucosinolate) were purchased from the Department of Natural Sciences, University of Copenhagen, Denmark. Glucobrassicin (8) (3-indolmethyl glucosinolate), sulfoglucobrassicin (5) (1-sulfo-3-indolylmethyl glucosinolate), 4hydroxyglucobrassicin (6) (4-hydroxy-3-indolylmethyl glucosinolate) and neoglucobrassicin (9) ( $\mathrm{N}$-methoxy-3-indolylmethyl glucosinolate) were isolated from seeds of I. tinctoria. Purity and structures of isolated compounds were confirmed by NMR and LC-MS experiments as previously described [17].

\section{Plant material}

Leaf material of five defined strains of I. tinctoria ("Thüringer Waid", "Jenaer Waid", "Kieler Waid", "French Woad" and "Swiss Woad") was harvested in 2003 on June 11 and 23, on July 16 and 29, on August 21, and on September 15, from one-year-old plants (rosette stage). Furthermore, leaf material of I. indigotica Fort. was collected on the same days as I. tinctoria. Plants were grown under identical conditions on experimental plots of the Agricultural Research Station of Thuringia (TLL), Dornburg, Germany, in uniform rows without randomization. "Thüringer Waid is a mix of genotypes growing in the state of Thuringia which has been cultured for many years. The strains "Jenaer Waid", "Kieler Waid" and "Swiss woad" originated from plants grown at the botanical gardens of the University of Jena, Germany, the University of Kiel, Germany, and the University of Lausanne, Switzerland, respectively. "French woad" is from a collection of wild plants growing at Château de Magrin, near Toulouse, France. I. indigotica was from the botanical garden of the University of Bristol, England. The strains were obtained in 1991/1992 by selection breeding of plants with positive traits grown and multiplied under isolation conditions. Annual elimination of plants which did not correspond to the desired phenotype led to a high degree of phenotypical homogeneity of the strains by the year 2003. Specimens of seeds from the strains are kept at the TLL, under accession numbers 153/PG 1 (Thüringer Waid), 153/ PG 4 (Swiss woad, 153 PG 5 (French woad), 153 PG 9 (Kieler Waid), 153 PG 10 (Jenaer Waid) and 153 PG 12 (Isatis indigotica). Sowing was in early spring at $5 \mathrm{~kg}$ seeds/ha, nitrogen fertilization was at $120 \mathrm{~kg} \mathrm{~N} / \mathrm{ha}$ at the time of sowing, and $50 \mathrm{~kg}$ $\mathrm{N} /$ ha each after first and second cuts. A defined treatment of herbicides was applied for weed control. In addition to plants that were left to grow over the entire growth period without being cut, further plants from the strains "Jenaer Waid" and "Thüringer Waid" were cultivated under identical conditions but leaf rosettes were cut with a mowing machine on June 24 and July 31 , and the newly grown leaves were analyzed to study the effects of repeated harvesting. Samples were taken on the same harvest dates as described above, with the exception of June 11.

\section{Sample preparation and extraction}

Freshly harvested Isatis leaf material was cut into small pieces of $2-3 \mathrm{~cm}$ length and immediately shock frozen with liquid nitrogen. Prior to extraction, the leaves were lyophilized for $48 \mathrm{~h}$ (Freezemobile 12XL, Virtis), powdered frozen in liquid nitrogen with a ZM 1 ultracentrifugal mill (Retsch, with $0.75 \mathrm{~mm}$ Conidur sieve) and kept frozen at below $-20^{\circ} \mathrm{C}$ until extraction. In addition, entire leaves were dried at room temperature or at $40^{\circ} \mathrm{C}$ in a thermostatted oven as described previously [11] to investigate the influence of different post-harvest treatments. Pressurized liquid extraction (PLE) of $1.0 \mathrm{~g}$ frozen and powdered samples was carried out with an ASE 200 instrument (Dionex) with attached solvent controller. Conditions for all extractions were as follows: extraction solvent: $70 \%$ methanol in water; temperature: $50^{\circ} \mathrm{C}$; 3 extraction cycles of $5 \mathrm{~min}$; preheat time: $1 \mathrm{~min}$; flush: $100 \%$ of cell volume; purge: $80 \mathrm{~s}$ with nitrogen; pressure: 120 bar; $11 \mathrm{~mL}$ steel cartridges. The extracts of 3 extraction cycles were combined, and the solvent was evaporated under reduced pressure. Dried extracts were stored at below $-20^{\circ} \mathrm{C}$ until analysis.

\section{LC-MS instrumentation and conditions}

HPLC separations were carried out on an Agilent series 1100 system equipped with degasser, binary high pressure mixing pump, column thermostat and photodiode array (PDA) detector (Agilent Technologies). A liquid handler 215 (Gilson) was used as autosampler. The HPLC was coupled to an Esquire 3000 plus ion trap mass spectrometer equipped with an electrospray (ESI) interface (Bruker Daltonics). Data acquisition and processing was performed using HyStar 3.0 software (Bruker Daltonics).

Separations were carried out on an Aqua C18 $125 \AA$ column ( $5 \mu \mathrm{m}, 250 \times 4.5 \mathrm{~mm}$ I.D.; Phenomenex) equipped with a guard column $(4.0 \times 3.0 \mathrm{~mm}$ I.D.). Mobile Phase A consisted of a solution of $10 \mathrm{mM}$ aqueous ammonium formate, adjusted to $\mathrm{pH}$ 6.4. Mobile phase $B$ was acetonitrile. A linear gradient starting at $1 \%$ B to $3 \%$ B (7 min), 3 \% B to $15 \%$ B (5 min), $15 \%$ B to $30 \%$ B (13 min) was used to separate all compounds of interest. Flow rate was $1.0 \mathrm{~mL} / \mathrm{min}$. A split ratio of $1: 4$ was used with the ESI interface. Column temperature was $20.0^{\circ} \mathrm{C}$. The sample injection volume was $20 \mu \mathrm{L}$.

Negative ion LC-MS on the ion trap instrument were recorded after optimization of settings, under ion charge conditions (ICC 30000 ) at a scan speed of $13000 \mathrm{~m} / \mathrm{z} / \mathrm{s}$, using a Gauss filter width of $0.2 \mathrm{~m} / \mathrm{z}$. Nitrogen was used as a drying gas at a flow rate of 10 $\mathrm{L} / \mathrm{min}$ and as a nebulizing gas at a pressure of $30 \mathrm{psi}$. The nebulizer temperature was set at $300^{\circ} \mathrm{C}$. Spectra were recorded between $0 \mathrm{~min}$ and $25 \mathrm{~min}$ in the range of $\mathrm{m} / \mathrm{z} 100$ to 800 . Capillary voltage was at $4500 \mathrm{~V}$, endplate offset at $-500 \mathrm{~V}$, capillary end voltage at $-115.0 \mathrm{~V}$, skimmer voltage $-40.0 \mathrm{~V}$ and trap drive at 53.4. Details on method development and validation procedures for the PLE/LC-MS protocol have been reported [17]. 


\section{Quantitative analysis}

A solution of $10 \mathrm{mM}$ ammonium formate containing sinigrin ( $2 \mathrm{mg} / \mathrm{L}$ ) as internal standard (IS solution) was used for all dilution steps. Stock solutions ( $1 \mathrm{mg} / \mathrm{mL}$ ) of all reference compounds were prepared in IS solution, serial dilutions covered a concentration range of 20 to $0.1 \mu \mathrm{g} / \mathrm{mL}$. Each standard solution was measured in triplicate.

The dried extracts, obtained by extraction of $1.0 \mathrm{~g}$ frozen, powdered leaf material, were dissolved in $100.0 \mathrm{~mL}$ IS solution. Furthermore, a dilution of $1: 100$ was prepared with IS solution. All solutions were centrifuged $\left(5 \mathrm{~min}, 1600 \times \mathrm{g}, 4^{\circ} \mathrm{C}\right.$ ) prior to LC-MS analysis. Measurements were made in triplicate.

\section{Supporting information}

Figures representing seasonal changes for individual glucosinolates of Isatis tinctoria accessions, and Isatis indigotica are available as Supporting Information.

\section{Results and Discussion}

$\nabla$

Analysis of glucosinolates 1-9 ( $\bullet$ Fig. 1) was carried out with a recently developed and validated PLE protocol and ion-pair HPLC coupled with ESI-MS detection in negative mode [17]. Calibration curves were found to be quadratic functions over a concentration range of 0.1 to $20 \mu \mathrm{g} / \mathrm{mL}$. Regression coefficients ranged between 0.9995 and 1 . 0 Fig. 2 shows the extracted ion chromatogram (EIC) of the reference compounds $\mathbf{1 - 9}$, the base peak chromatogram (BPC) of the extracts, and the EIC used for peak integration of the identified glucosinolates.

Leaf extracts of I. tinctoria and I. indigotica showed significant qualitative and quantitative differences in their glucosinolate pattern ( $\odot$ Fig. 2). Glucobrassicin (5) and sulfoglucobrassicin (8), the major glucosinolates of I. tinctoria, could not be identified in the taxiconomically closely related species I. indigotica. Progoitrin (3) and 4-hydroxyglucobrassicin (6) constituted the main glucosinolates in I. indigotica. The aliphatic glucosinolates epiprogoitrin (1) and epiprogoitrin (3) were present in higher concentrations than in leaves of I. tinctoria (Supporting Information Fig. 8S). The total glucosinolate content in $I$. indigotica $(28.6 \mu \mathrm{mol} / \mathrm{g}$ dry weight) was only about $50 \%$ of the average total glucosinolate content in I. tinctoria (accession "Jenaer Waid") $(50.5 \mu \mathrm{mol} / \mathrm{g}$ dry weight). Until recently, $I$. indigotica was considered to be a subspecies of I. tinctoria , but amplified fragment length polymorphism (AFLP) analysis showed that they have to be considered as two different species [18]. The differences in glucosinolate pattern corroborate these findings.

The analysis of leaves from different I. tinctoria accessions showed that the glucosinolate pattern was subject to seasonal changes. The aliphatic glucosinolates examined here were gluconapin (4), progoitrin (3), and its epimer epiprogoitrin (1). Although these compounds constitute minor glucosinolates in Isatis leaves $(0.1-1.3 \mu \mathrm{mol} / \mathrm{g}$ for 1 and $\mathbf{3}$, and $0.01-0.04 \mu \mathrm{mol} / \mathrm{g}$ for 4) compared to the indole glucosinolates, changes within the growth period were observed. Samples collected on six different dates showed that four out of five accessions reached highest concentrations of aliphatic glucosinolates towards end of June, whereas peak concentrations were earlier in the case of "French woad" ( $\odot$ Fig. 3). A steady decline was observed in the later dates of sampling. Sampling before the June 11 date was not possible, since the plantlets were too small. June represents

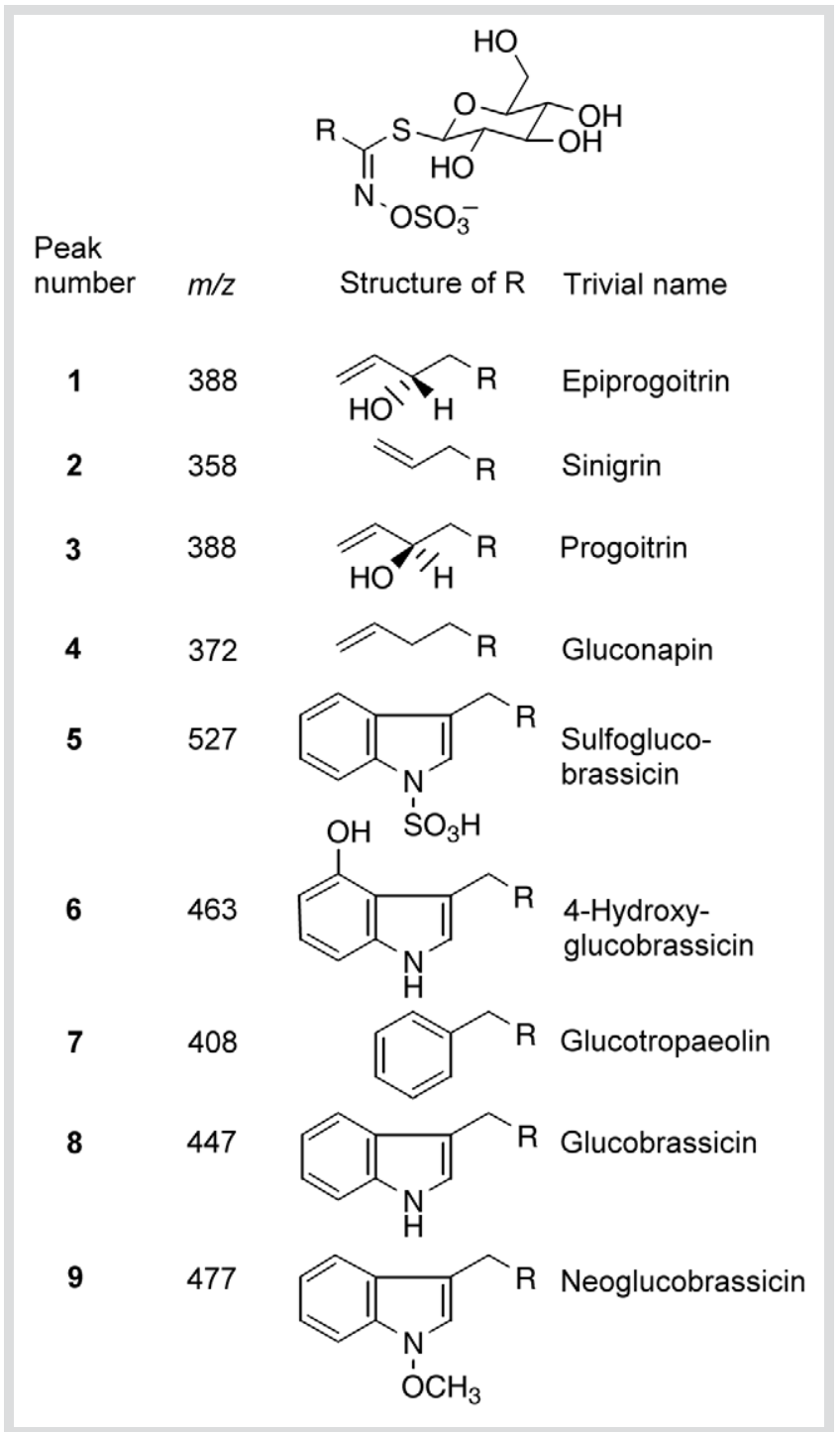

Fig. 1 Structures of glucosinolates $\mathbf{1 - 9}$.

the earlier part of the vegetation period for woad in its first year culture (rosette stage). Similar decrease of aliphatic glucosinolate concentration during the vegetative stage has been observed for other cruciferous species, such as rape (Brassica napus) [19], [20].

Glucobrassicin (8), and its derivatives sulfoglucobrassicin (5), 4hydroxyglucobrassicin (6) and neoglucobrassicin (9) are indolic glucosinolates in I. tinctoria. The concentrations of the major compounds $\mathbf{5}$ and $\mathbf{8}$ were approx. 100-fold higher than those of aliphatic glucosinolates epiprogoitrin (1) and progoitrin (3). For the five accessions in our study, the concentrations of total indole glucosinolates were lowest in the young plantlets, and increased several fold to reach a maximum in July/August ( $\bullet$ Fig. 4). A closer analysis of data revealed that the increase was due to sulfoglucobrassicin (5), whereas the concentration of glucobrassicin (8) remained fairly constant throughout the vegetation season. This trend is illustrated here with the example of the accession "Thüringer Waid" ( $\bullet$ Fig. 5). The other indole glucosinolates in leaves, 4-hydroxyglucobrassicin (6) and neoglucobrassicin (9) occurred in approx. 100-fold lower concentrations (Supporting Information, Figs. $4 \mathrm{~S}$ and $7 \mathrm{~S}$ ), and did not show a consistent pattern of seasonal change. Neither glucotropaeolin (7), a simple aromatic glu- 


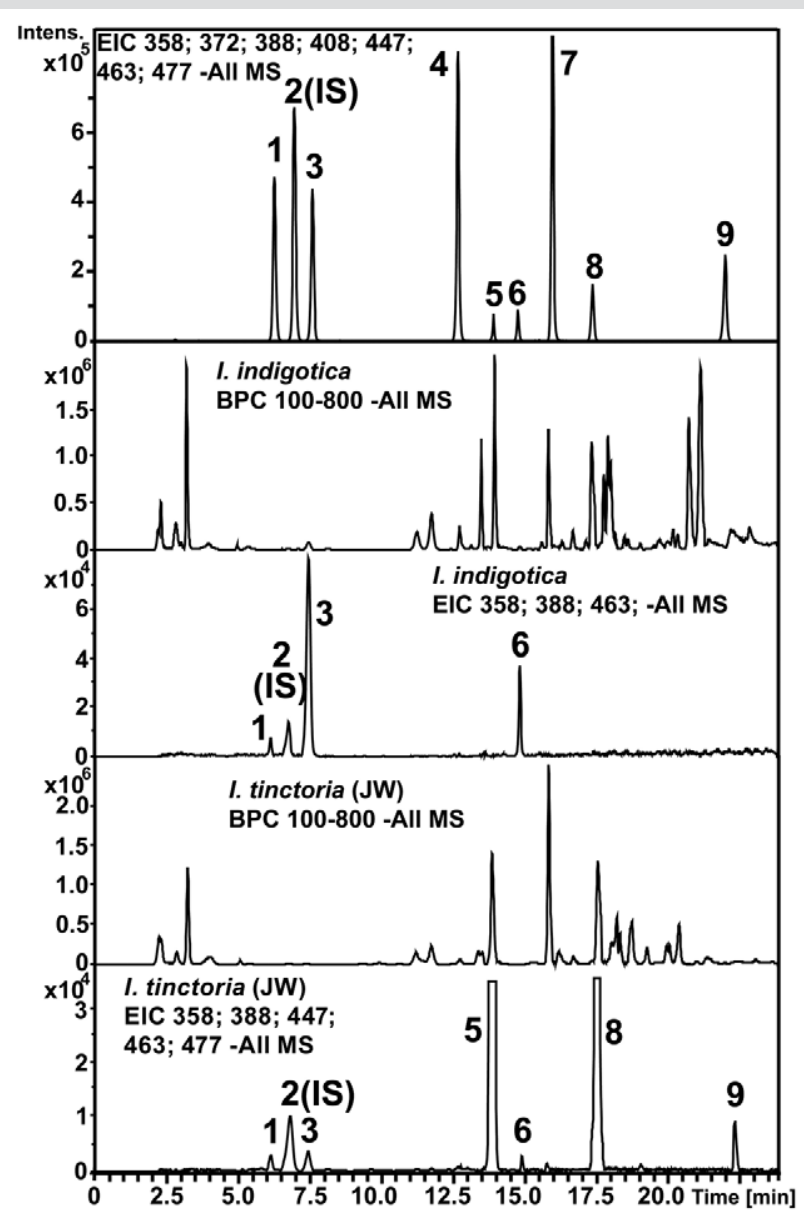

Fig. 2 HPLC separation of a mixture of reference compounds 1-9 (top). Sinigrin (IS) is used as internal standard. Base peak chromatograms (BPC) and Extracted ion chromatograms (EIC) of the major glucosinolates are shown below for leaf extracts of Isatis tinctoria "Jenaer Waid" and Isatis indigotica.

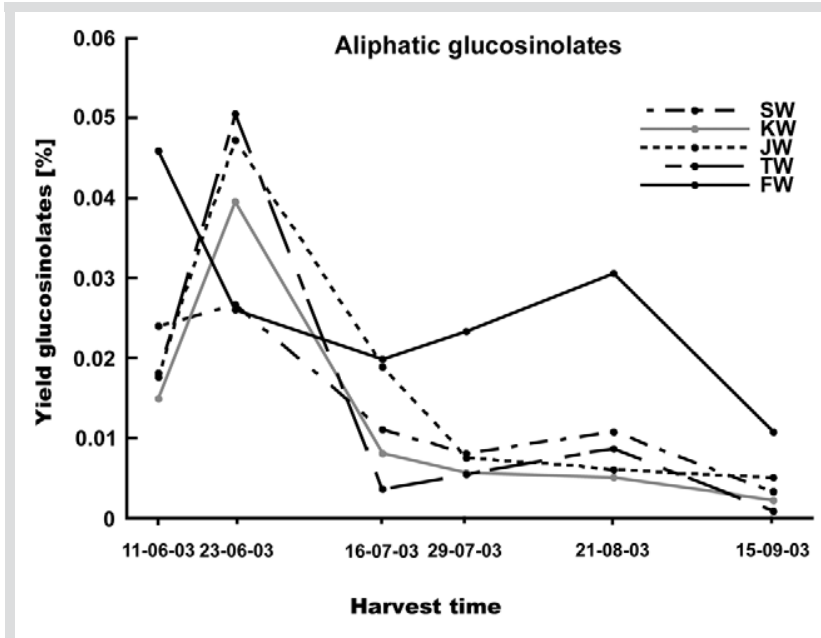

Fig. 3 Concentration of total aliphatic glucosinolates epiprogoitrin (1), progoitrin (3) and gluconapin (4) in shock frozen, freeze-dried leaves of Isatis tinctoria accessions "Swiss woad" (SW), "Kieler Waid" (KW), "Jenaer Waid" (JW), "Thüringer Waid" (TW) and "French woad" (FW). The datapoints represent the sum calculated for dried plant material at the respective dates of sampling. Data for individual glucosinolates are given as Supporting Information.

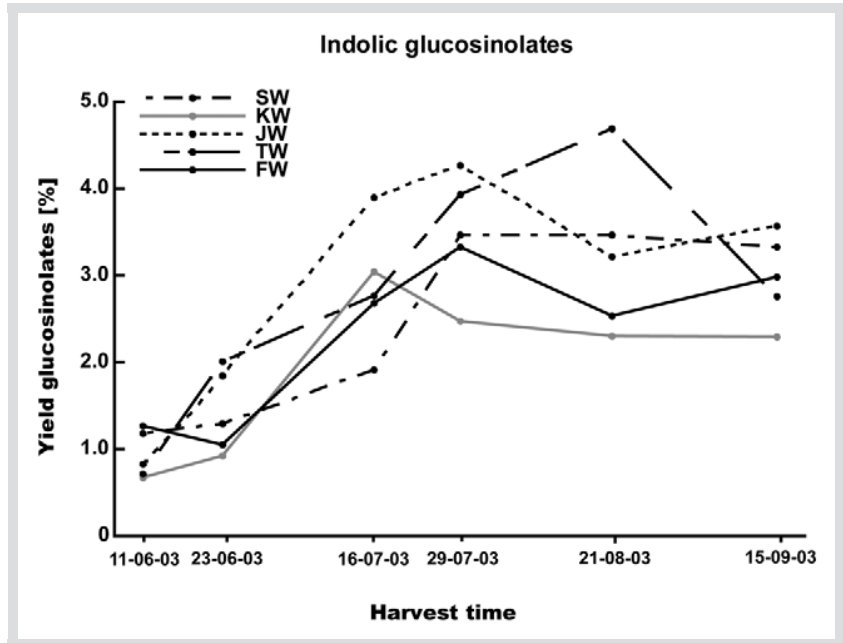

Fig. 4 Concentration of total indolic glucosinolates sulfoglucobrassicin (5), 4-hydroxyglucobrassicin (6), glucobrassicin (8), and neoglucobrassicin (9) in shock frozen, freeze-dried leaves of Isatis tinctoria accessions "Swiss woad" (SW), "Kieler Waid" (KW), "Jenaer Waid" (JW), "Thüringer Waid" (TW) and "French woad" (FW). The data points represent the sum calculated for dried plant material at the respective dates of sampling. Data for individual glucosinolates are given as Supporting Information.

cosinolate, nor further indolic glucosinolates reported from $I$. tinctoria seeds [16] were detected in any of the leaf samples.

The comparison of five different I. tinctoria accessions revealed some differences in their glucosinolate patterns. Leaf samples of the strain "Kieler Waid" had the lowest total glucosinolate concentration. The highest concentration of the major compound sulfoglucobrassicin (5) was found in "Thüringer Waid" which, on the other hand, exhibited the least diverse spectrum in other glucosinolates. Gluconapin (4) and neoglucobrassicin (9) were not detectable in "Jenaer Waid and "Thüringer Waid", and the latter also did not contain 4-hydroxyglucobrassicin (6) (Supporting Information, Figs. 1S-7S). The differences in glucosinolate pattern seem to reflect the relatively high degree of genetic diversity and varying phenotypic characteristics that were recently reported for European I. tinctoria landraces [18].

The effect of repeated harvesting on the qualitative and quantitative composition in glucosinolates was studied with the accessions "Jenaer Waid" and "Thüringer Waid". On one half of the experimental plots plants were left untouched, and only small leaf samples were taken for analysis. On the other part of the plot, the fully grown leaf rosettes were cut with a mowing machine on June 24 and July 31, in order to simulate subsequent harvests during the vegetation season. From the regrown leaf rosettes of these plants, small leaf samples were then taken for analysis at the indicated dates ( $\bullet$ Fig. $\mathbf{6}$ ). A comparison of glucosinolate concentrations in these leaf samples revealed no substantial differences between the untouched plants and those with a newly regrown leaf rosette. As shown for sulfoglucobrassicin (5) ( $\bullet$ Fig. 6), repeated harvest did not have a major effect on the glucosinolate concentration of newly grown leaves. Data for epiprogoitrin (1), progoitrin (3) and glucobrassicin (8) are given as Supporting Information, Figs. 9S-11S.

This study is the first to address seasonal changes of glucosinolates in Isatis sp., and in particular in I. tinctoria. Sulfoglucobrassicin (5), the main indole glucosinolate, accumulated in the leaves over most of the vegetation period. Biosynthetic studies on indolic glucosinolates suggest that glucobrassicin (8) is con- 


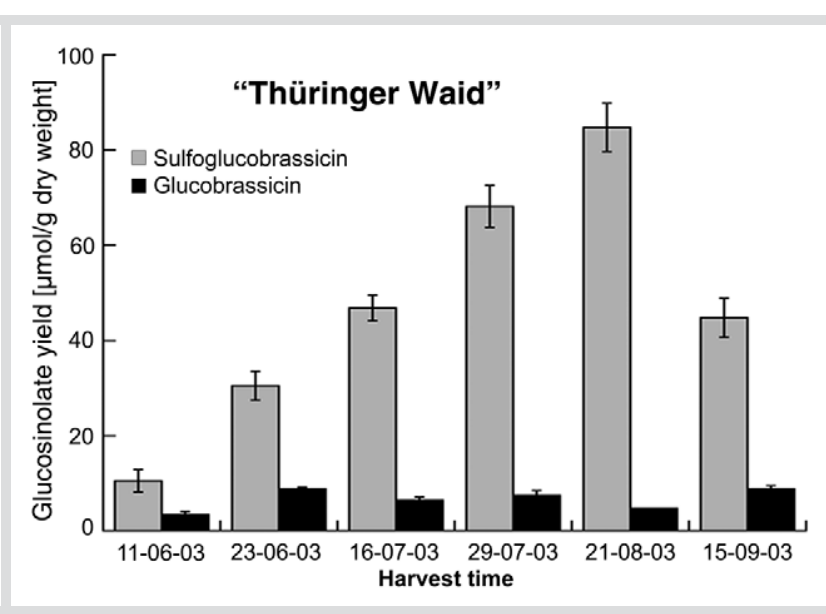

Fig. 5 Concentration of the major glucosinolates sulfoglucobrassicin (5) and glucobrassicin (8) in the Isatis tinctoria accession "Thüringer Waid" harvested at the indicated dates.

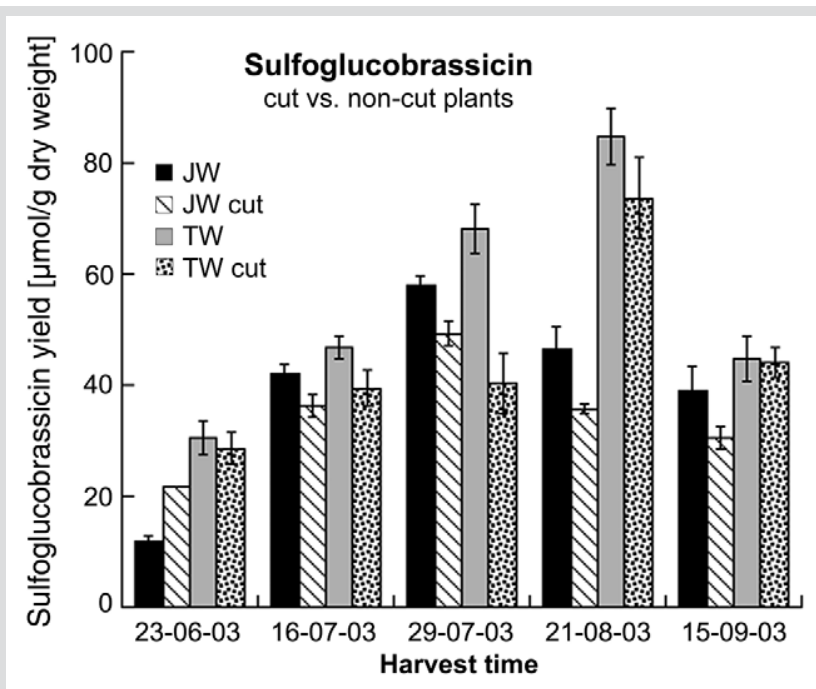

Fig. 6 Concentration ( $\mu \mathrm{mol} / \mathrm{g}$ ) of sulfoglucobrassicin (5) in leaf samples of Isatis tinctoria accessions “Jenaer Waid” (JW) and “Thüringer Waid” (TW) at the indicated harvest dates, compared to sulfoglucobrassicin concentration in leaf material from plants which were subjected to periodical mowing (JW cut) and (TW cut)

verted to sulfoglucobrassicin (5), neoglucobrassicin (9) and 4hydroxyglucobrassicin (5) before the initiation of a de novo biosynthesis of glucobrassicin (8) [21].

Glucosinolates are considered as typical defense compounds of Brassicaceae [22], and their synthesis can be induced to a certain extent by stress. We, therefore, initially thought that glucosinolate concentrations in the regrown leave rosette of the mowed plants would be possibly higher than in the control plants. Increase of indole glucosinolates after puncturing leaves with needles had been reported with rape and mustard cotyledons [23]. However, this upregulation of biosynthesis was only a transient phenomenon with a maximum one day after wounding, and two weeks later the concentration had dropped to the level of untreated control plants. Considering the mowing and sampling regime in our study, the observed lack of marked changes in glucosinolate pattern is in line with these findings. Multiple har- vesting of leaf rosette would increase the overall yield of plant material without significantly modifying the phytochemical composition of the leaves, at least for glucosinolates.

As for indigo precursors [10] and tryptanthrin [11], we investigated the influence of the drying procedure on glucosinolate content. In contrast to the shock frozen freeze dried leaf samples, none of the glucosinolates including the major compounds sulfoglucobrassicin (5) and glucobrassicin (8), could be detected in plant material that had been dried at ambient temperature or at $40^{\circ} \mathrm{C}$ (data not shown). However, we were not able to detect any of the known breakdown products of indolic glucosinolates such as indole-3-carbinols [( $1 \mathrm{H}$-indol-3-yl)methanol and derivatives], indole-3-acetonitriles [2-(1H-indol-3-yl)acetonitrile and derivatives] and its corresponding isothiocyanates as well as dimeric compounds as 3,3'-diindolylmethanes [bis( $1 H$-indol-3yl)methane and derivatives] or indolyl ascorbigens (indol-3ylascorbigen and derivatives) described in earlier studies [24], [25], [26], [27]. The degradation products of indol glucosinolates in woad are presently unknown, and it remains to be clarified whether they contribute in any form to the post-harvest formation of indol-derived compounds such as tryptanthrin.

We previously analyzed the indigo precursors isatan A, isatan B and indican in the same Isatis samples [10]. The concentration of total indigo precursors was approximately in the same range as that of the indole glucosinolates ( $3-5 \%$ of dry weight). Hence, tryptophan-derived secondary metabolites clearly dominate in woad. However, the concentration of indole glucosinolates was higher in I. tinctoria than in I. indigotica, whereas the indigo precursors were higher in I. indigotica. This suggests that the biosynthesis of these compounds may be limited by the supply in the precursor amino acid, and secondary metabolism of $I$. tinctoria may tend more towards indole glucosinolate synthesis, and I. indigotica towards production of indigo precursors.

\section{Acknowledgements}

$\nabla$

We thank Dr. A. Vetter and A. Biertümpfel, Thüringische Landesanstalt für Landwirtschaft (TLL), Jena and Dornburg, for the provision of woad samples from the experimental field plots in Dornburg. The major part of the study was carried out as the Master Thesis of K. Suter.

\section{References}

1 Hamburger M. Isatis tinctoria - from the rediscovery of an ancient medicinal plant towards a novel anti-inflammatory phytopharmaceutical. Phytochem Rev 2002; 1: 333-44

2 Oberthür C, Jaeggi R, Hamburger M. HPLC based activity profiling for 5 lipoxygenase inhibitory activity in Isatis tinctoria leaf extracts. Fitoterapia 2005; 76: $324-32$

3 Danz H, Stoyanova S, Thomet OAR, Simon HU, Dannhardt G, Ulbrich H et al. Inhibitory activity of tryptanthrin on prostaglandin and leukotriene synthesis. Planta Med 2002; 68: 875-80

4 Danz H, Stoyanova S, Wippich P, Brattström A, Hamburger M. Identification and isolation of the cyclooxygenase-2 inhibitory principle in Isatis tinctoria. Planta Med 2001; 67: 411 - 6

5 Rüster GU, Hoffmann B, Hamburger M. Inhibitory activity of indolin-2one derivatives on compound 48/80-induced histamine release from mast cells. Pharmazie 2004; 59: $236-7$

6 Hamburger M, Rüster GU, Melzig MF. HPLC based activity profiling for inhibitors of human neutrophil elastase in Isatis tinctoria leaf extracts. Nat Prod Commun 2006; 1: 1107-10

7 Recio MC, Cerda-Nicolas M, Hamburger M, Rios JL. Anti-arthritic activity of a lipophilic woad (Isatis tinctoria) extract. Planta Med 2006; 72: $715-20$ 
8 Recio MC, Cerda-Nicolas M, Potterat O, Hamburger M, Rios JL. Anti-inflammatory and antiallergic activity in vivo of lipophilic Isatis tinctoria extracts and tryptanthrin. Planta Med 2006; 72: 539-46

9 Heinemann C, Schliemann-Willers S, Oberthür C, Hamburger M, Elsner $P$. Prevention of experimentally induced irritant contact dermatitis by extracts of Isatis tinctoria compared to pure tryptanthrin and its impact on UVB-induced erythema. Planta Med 2004; 70: 385 - 90

10 Oberthür C, Graf H, Hamburger M. The content of indigo precursors in Isatis tinctoria leaves - a comparative study of selected accessions and post-harvest treatments. Phytochemistry 2004; 65: 3261 -8

11 Oberthür C, Hamburger M. Tryptanthrin content in Isatis tinctoria leaves - a comparative study of selected strains and post-harvest treatments. Planta Med 2004; 70: 642 - 5

12 Oberthür C, Schneider B, Graf H, Hamburger M. The elusive indigo precursors in woad (Isatis tinctoria L.) - identification of the major indigo precursor, isatan A, and a structure revision of isatan B. Chem Biodivers 2004; 1 : $174-82$

13 Lockwood GB, Belkhiri A. Glucosinolate spectrum of some Algerian Cruciferae. Plant Syst Evol 1991; 176: 11 - 20

14 Elliott MC, Stowe BB. Novel sulfonated natural indole. Phytochemistry 1970; 9: $1629-32$

15 Elliott $M C$, Stowe BB. Distribution and variation of indole glucosinolates in woad (Isatis tinctoria). Plant Physiol 1971; 48: 498-503

16 Frechard A, Fabre N, Pean C, Montaut S, Fauvel MT, Rollin P et al. Novel indole-type glucosinolates from woad (Isatis tinctoria L.). Tetrahedron Lett 2001; 42: 9015-7

17 Mohn T, Cutting B, Ernst B, Hamburger M. Extraction and analysis of intact glucosinolates - a validated pressurized liquid extraction/liquid chromatography-mass spectrometry protocol for Isatis tinctoria, and qualitative analysis of other cruciferous plants. J Chromatogr A 2007; 1166: $142-51$
18 Gilbert KG, Garton S, Karam MA, Arnold GM, Karp A, Edwards KJ et al. A high degree of genetic diversity is revealed in Isatis spp. (dyer's woad) by amplified fragment length polymorphism (AFLP). Theor Appl Genet $2002 ; 104: 1150-6$

19 Rosa EAS, Heaney RK, Portas CAM, Fenwick GR. Changes in glucosinolate concentrations in Brassica crops (B. oleracea and B. napus) throughout growing seasons. J Sci Food Agric 1996; 71: 237-44

20 Clossais-Besnard N, Larher F. Physiological role of glucosinolates in Brassica napus. Concentration and distribution pattern of glucosinolates among plant organs during a complete life cycle. J Sci Food Agric 1991; $56: 25-38$

21 Mahadevan S, Stowe BB. Intermediate in the synthesis of glucobrassicins from 3-indoleacetaldoxime by woad leaves. Plant Physiol 1972; 50: $43-50$

22 Halkier BA, Gershenzon J. Biology and biochemistry of glucosinolates. Annu Rev Plant Biol 2006; 57: 303 -3

23 Bodnaryk RP. Effects of wounding on glucosinolates in the cotyledons of oilseed rape and mustard. Phytochemistry 1992; 31: $2671-7$

24 Bones AM, Rossiter JT. The enzymatic and chemically induced decomposition of glucosinolates. Phytochemistry 2006; 67: 1053-67

25 Hanley $A B$, Parsley KR. Identification of 1-methoxyindolyl-3-methyl isothiocyanate as an indole glucosinolate breakdown product. Phytochemistry 1990; 29: 769-71

26 Slominski BA, Campbell LD. Formation of indole glucosinolate breakdown products in autolyzed, steamed, and cooked Brassica vegetables. J Agric Food Chem 1989; 37: 1297- 302

27 Hrncirik K, Valusek J, Velisek J. Investigation of ascorbigen as a breakdown product of glucobrassicin autolysis in Brassica vegetables. Eur Food Res Technol 2001; 212: 576-81 


\section{Supporting Information to:}

\section{Seasonal Changes and Effect of Harvest on Glucosinolates in}

\section{Isatis leaves}

Tobias Mohn

Kathrin Suter

Matthias Hamburger

\section{Affiliation}

Institute of Pharmaceutical Biology, University of Basel, Basel, Switzerland

\section{Correspondence}

Prof. Dr. Matthias Hamburger

Institute of Pharmaceutical Biology

Department of Pharmaceutical Sciences

University of Basel

Klingelbergstrasse 50

4056 Basel

Switzerland

Phone: +41-61-267-1425

Fax: + 41-61-267-1474

E-mail: Matthias.hamburger@unibas.ch 


\section{Epiprogoitrin}

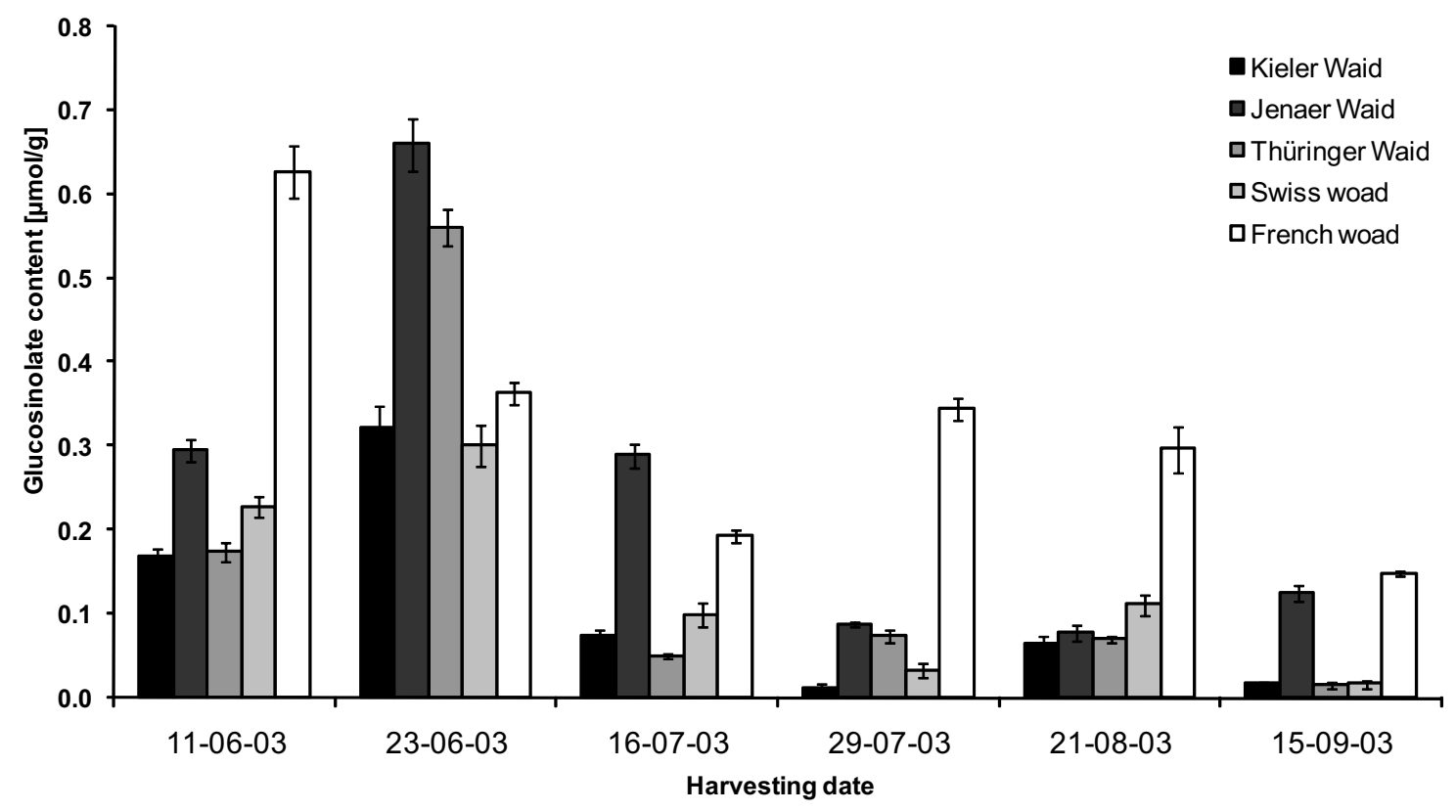

Fig. 1S Concentration of epiprogoitrin (1), in shock frozen, freeze-dried leaves of Isatis tinctoria accessions. The dates of sampling are indicated in the graph.

\section{Progoitrin}

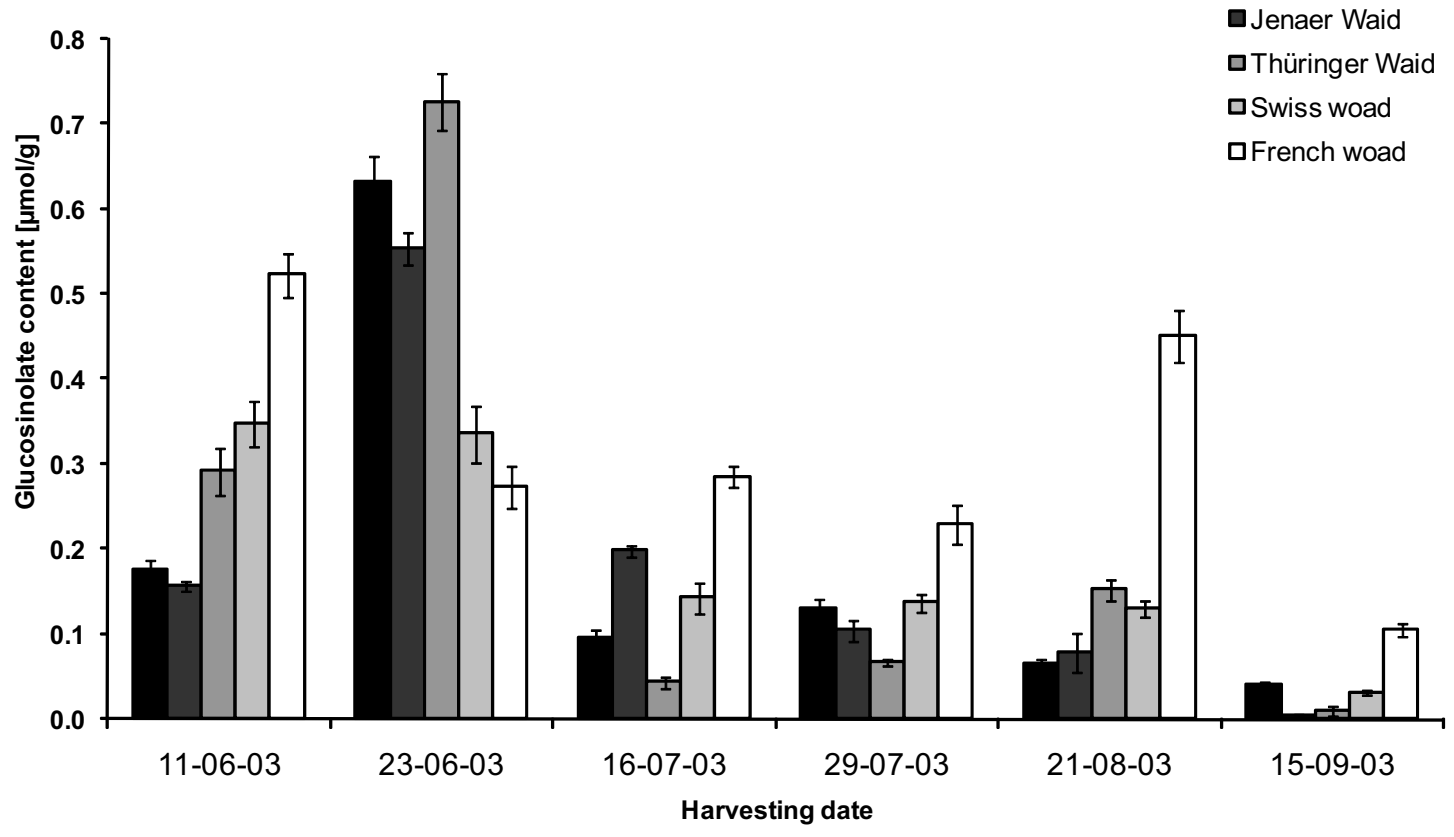

Fig. 2S Concentration of progoitrin (3), in shock frozen, freeze-dried leaves of Isatis tinctoria accessions. The dates of sampling are indicated in the graph. 


\section{Gluconapin}

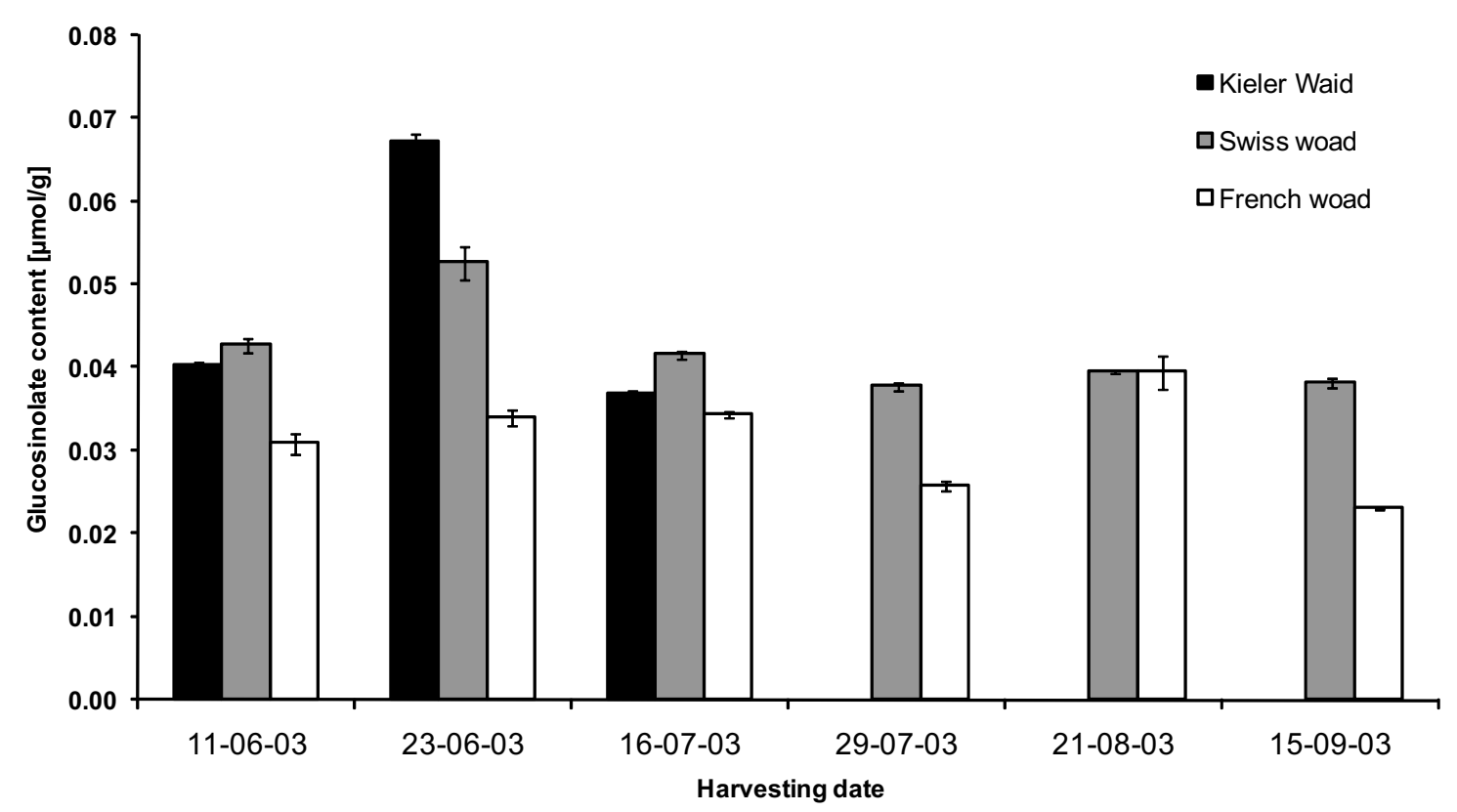

Fig. 3S Concentration of gluconapin (4), in shock frozen, freeze-dried leaves of Isatis tinctoria accessions. The dates of sampling are indicated in the graph. The compound was below detection limit in the accessions "Jenaer Waid" and "Thüringer Waid".

4-Hydroxyglucobrassicin

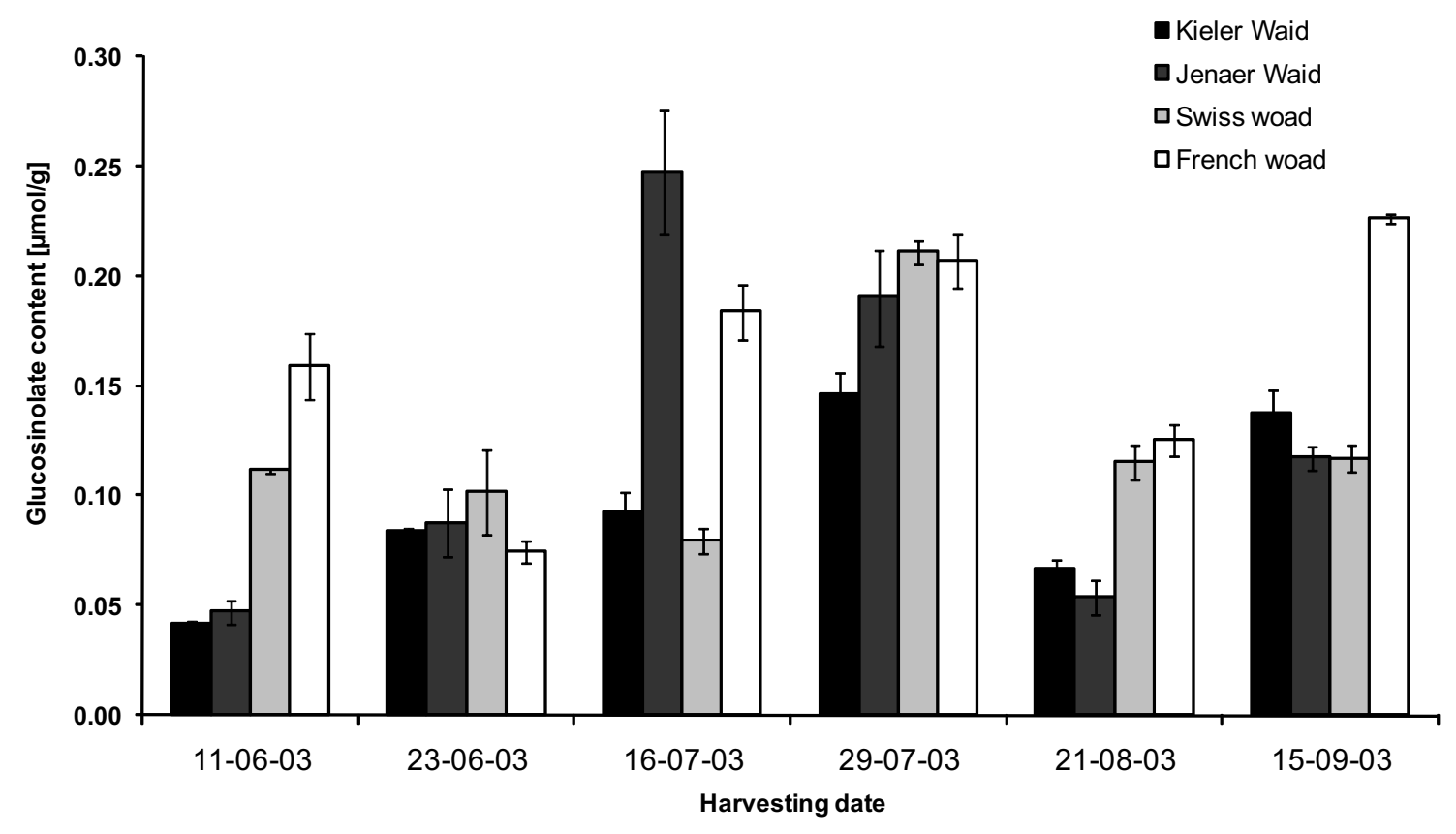

Fig. 4S Concentration of 4-hydroxyglucobrassicin (6), in shock frozen, freeze-dried leaves of Isatis tinctoria accessions. The dates of sampling are indicated in the graph. The compound was below detection limit in the accession "Thüringer Waid". 


\section{Sulfoglucobrassicin}

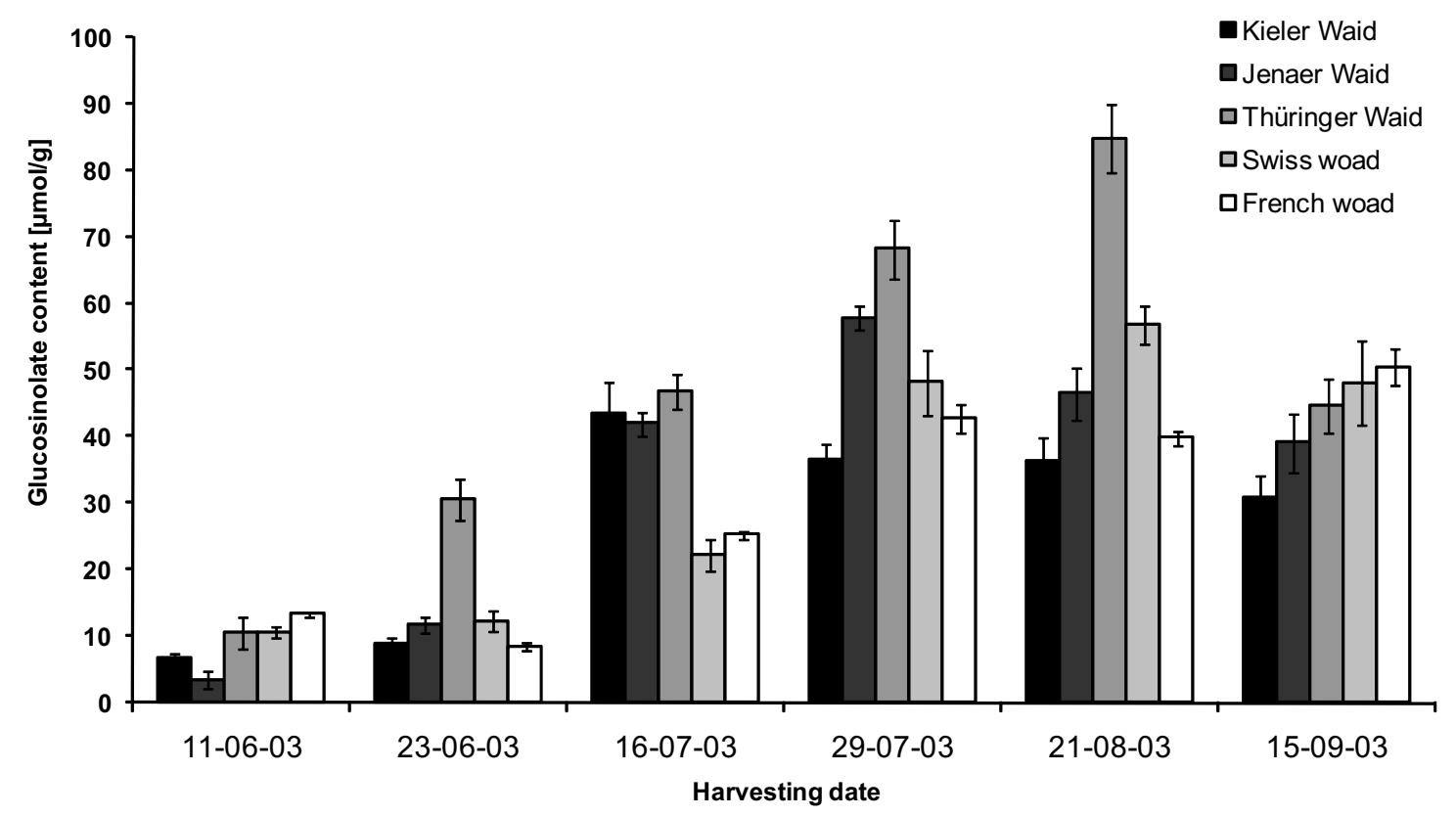

Fig. 5S Concentration of sulfoglucobrassicin (5), in shock frozen, freeze-dried leaves of Isatis tinctoria accessions. The dates of sampling are indicated in the graph.

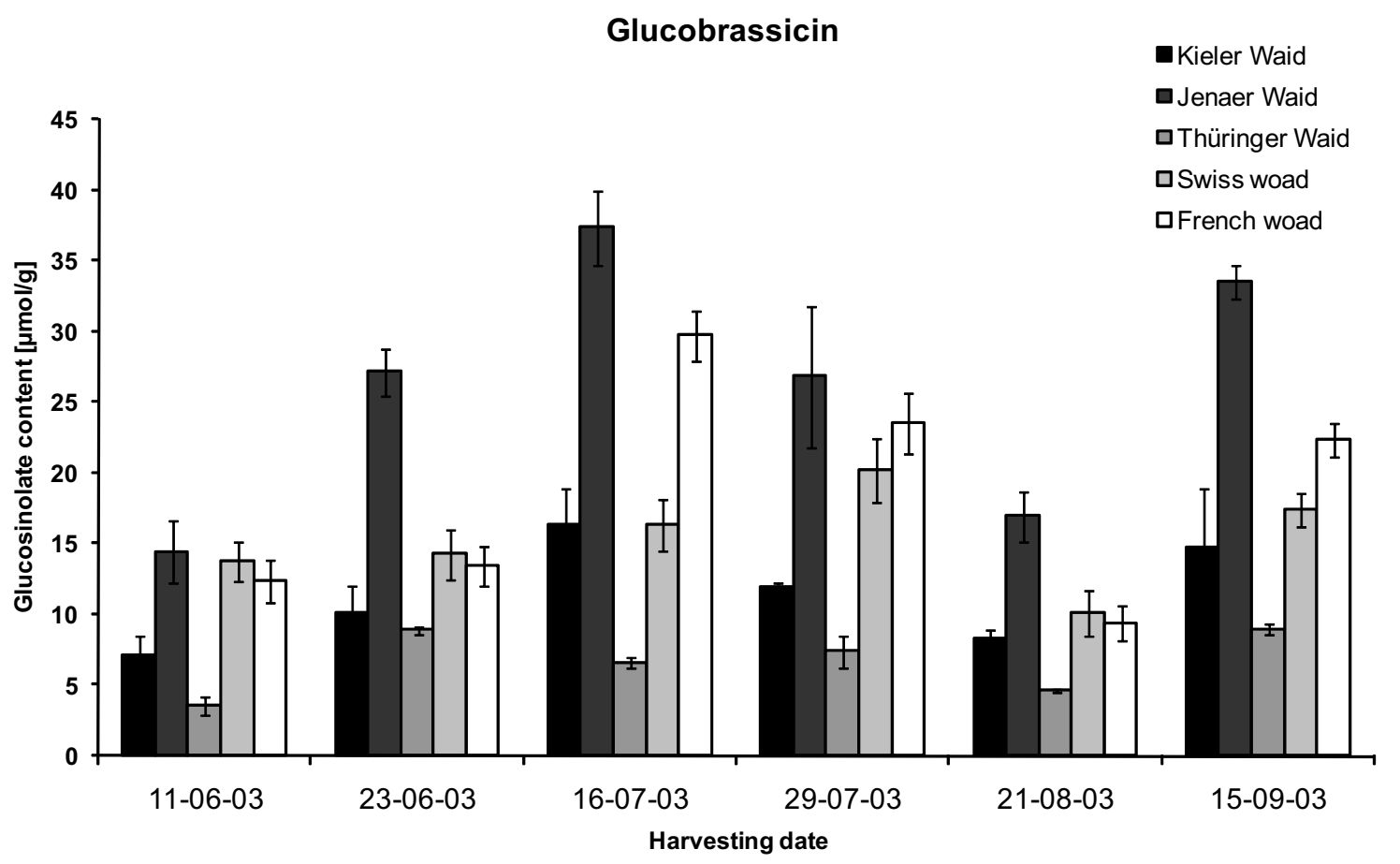

Fig. 6S Concentration of glucobrassicin (8), in shock frozen, freeze-dried leaves of Isatis tinctoria accessions. The dates of sampling are indicated in the graph. 


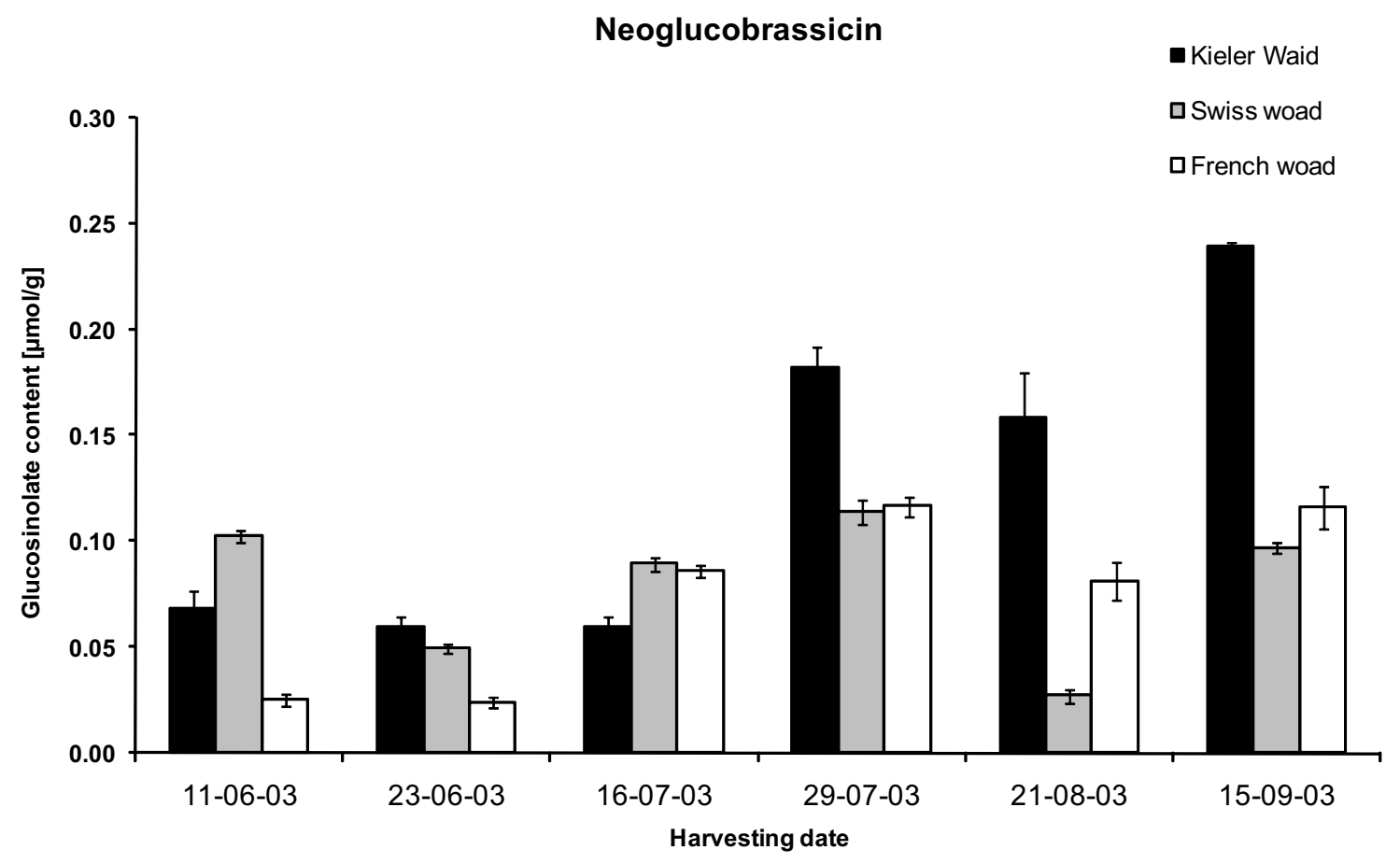

Fig. 7S Concentration of neoglucobrassicin (9), in shock frozen, freeze-dried leaves of Isatis tinctoria accessions. The dates of sampling are indicated in the graph. The compound was below detection limit in the accessions "Jenaer Waid" and "Thüringer Waid".

\section{Isatis indigotica}

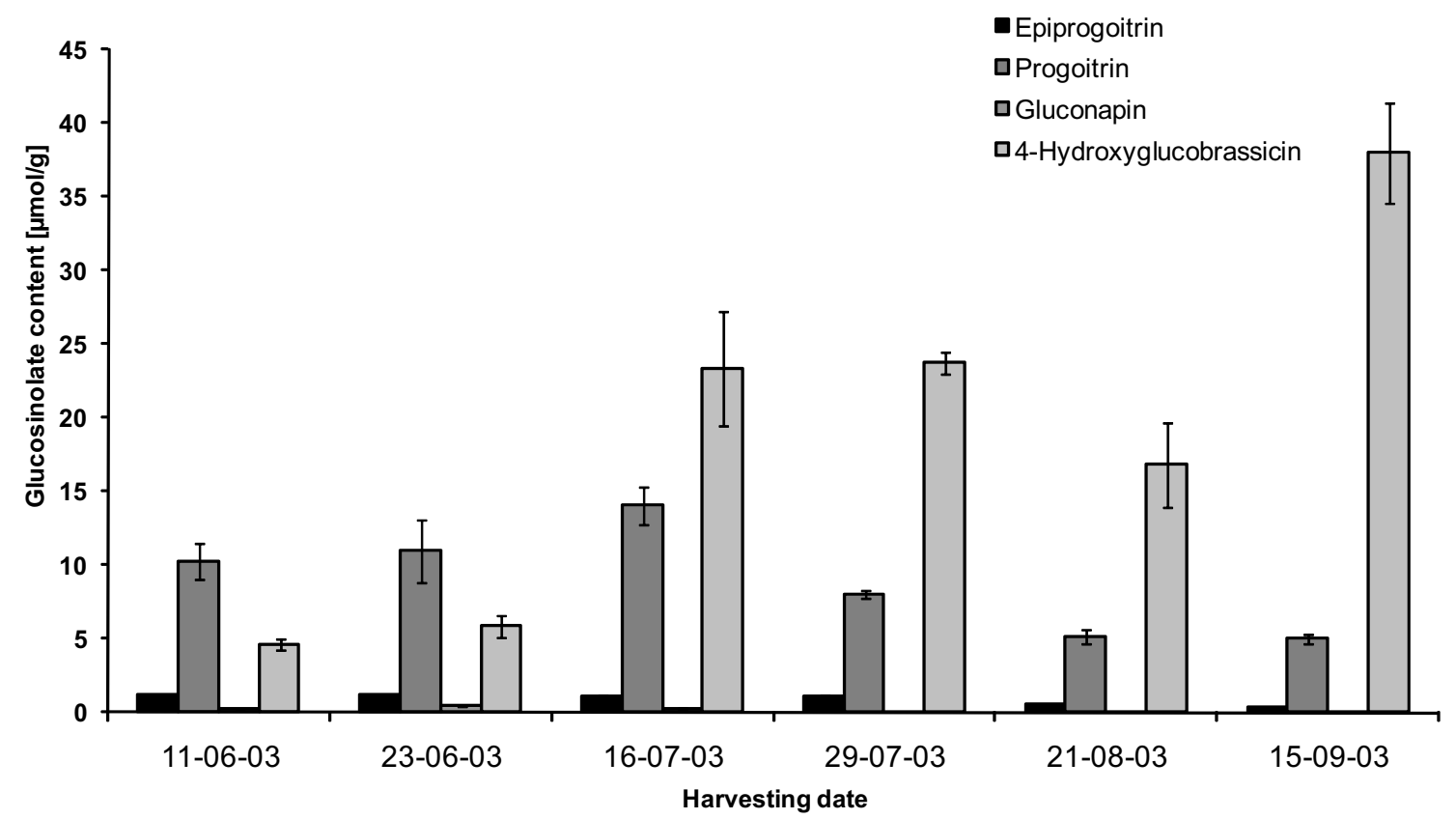

Fig. 8S Concentration of epiprogoitrin (1), progoitrin (3), gluconapin (4) and 4hydroxyglucobrassicin (6) in shock frozen, freeze-dried leaves of Isatis indigotica. The dates of sampling are indicated in the graph. 


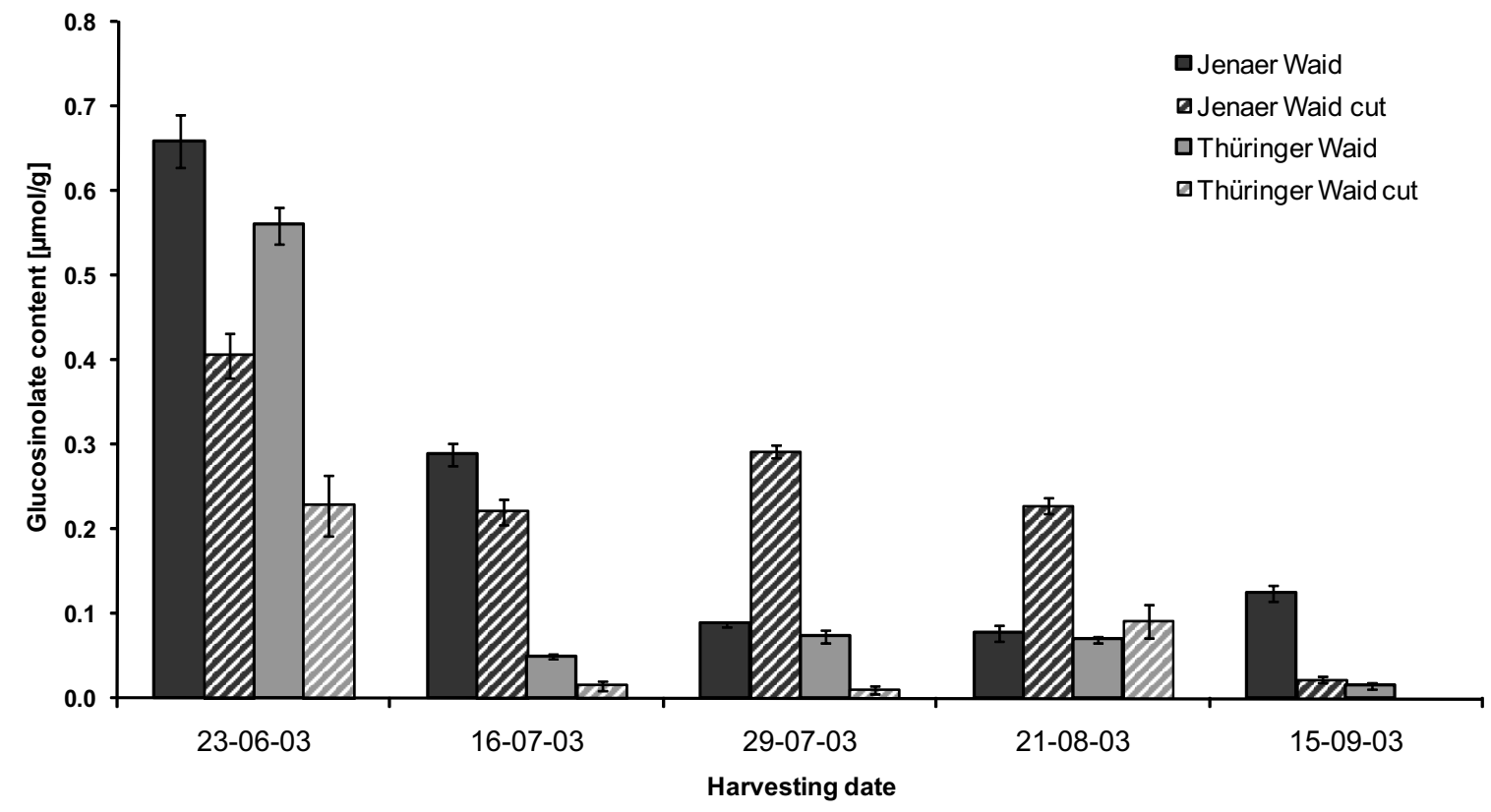

Fig. 9S Concentration $(\mu \mathrm{mol} / \mathrm{g})$ of epiprogoitrin (1) in leaf samples of Isatis tinctoria accessions "Jenaer Waid" (JW) and "Thüringer Waid" (TW) at the indicated harvest dates, compared to epiprogoitrin concentration in leaf material from plants which were subjected to periodical mowing (JW cut) and (TW cut).

\section{Progoitrin}

cut vs. non-cut

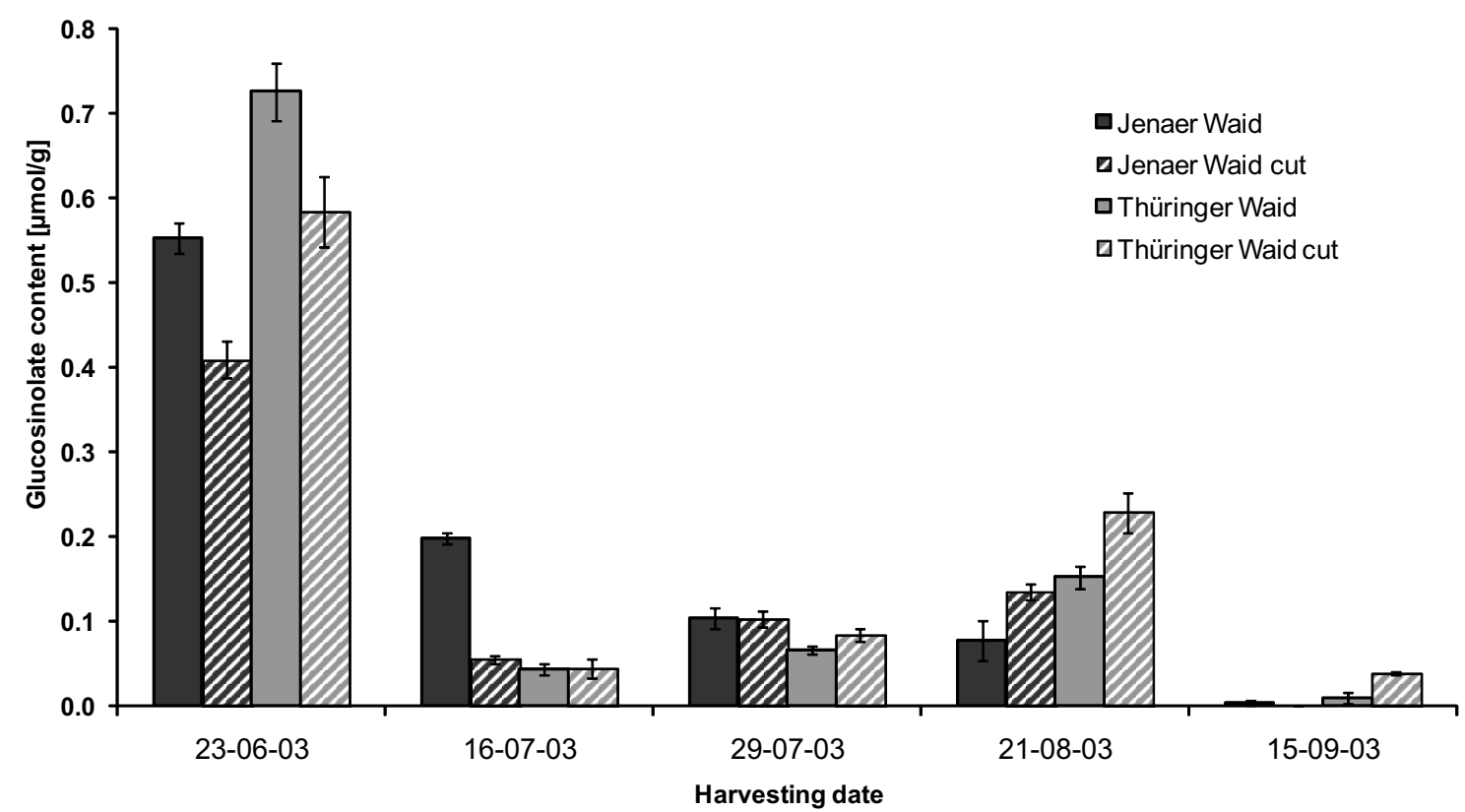

Fig. $10 \mathrm{~S}$ Concentration $(\mu \mathrm{mol} / \mathrm{g})$ of progoitrin (3) in leaf samples of Isatis tinctoria accessions "Jenaer Waid" (JW) and "Thüringer Waid" (TW) at the indicated harvest dates, compared to progoitrin concentration in leaf material from plants which were subjected to periodical mowing (JW cut) and (TW cut). 


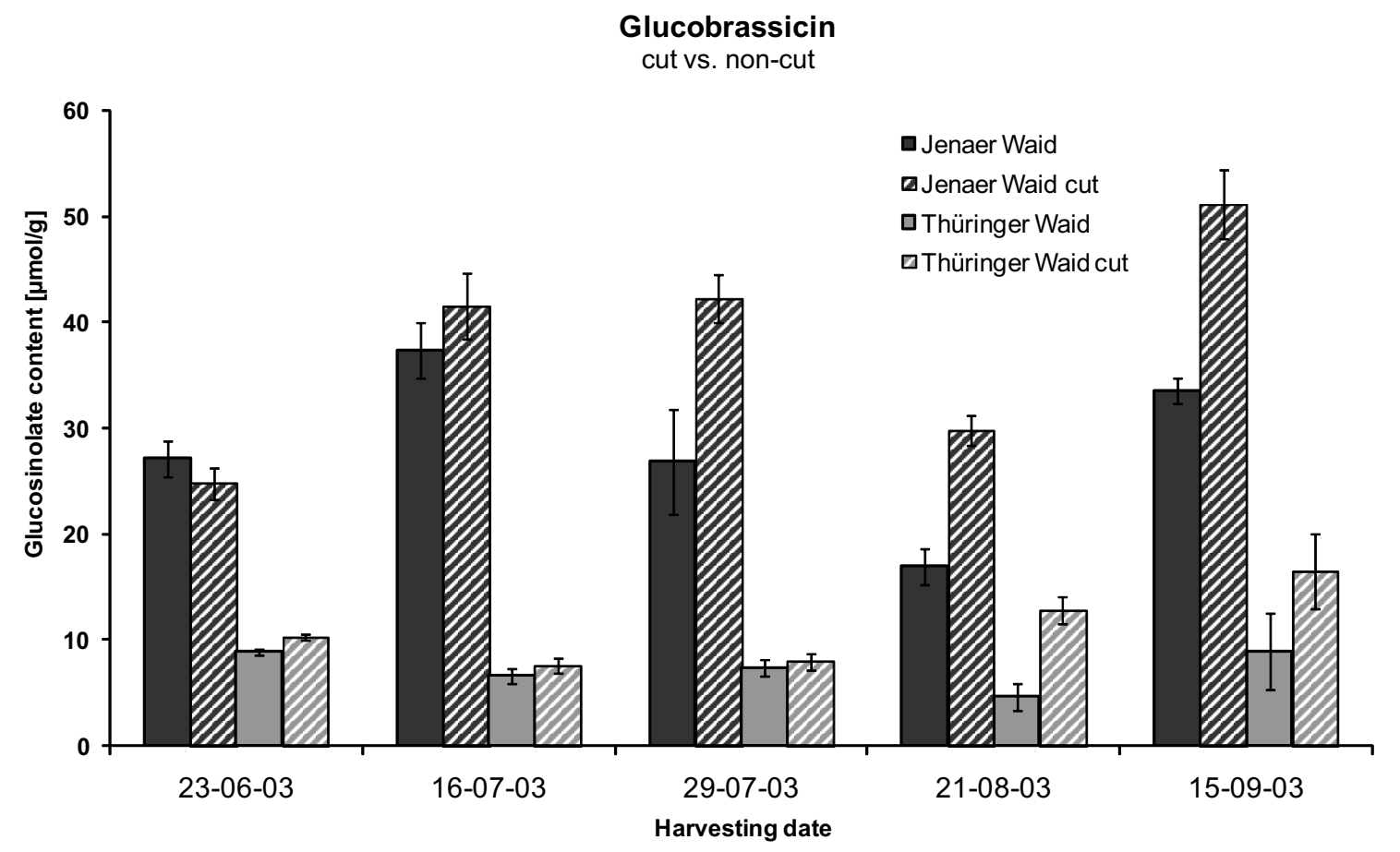

Fig. 11S Concentration $(\mu \mathrm{mol} / \mathrm{g}$ ) of glucobrassicin (8) in leaf samples of Isatis tinctoria accessions "Jenaer Waid" (JW) and "Thüringer Waid" (TW) at the indicated harvest dates, compared to glucobrassicin concentration in leaf material from plants which were subjected to periodical mowing (JW cut) and (TW cut). 
3.5 Glucosinolate pattern in Isatis tinctoria and I. indigotica seeds

(Mohn et al., Planta Med 2008; 74:885-888). 


\section{Glucosinolate Pattern in Isatis tinctoria and $I$. indigotica Seeds}

\section{Tobias Mohn, Matthias Hamburger}

Institute of Pharmaceutical Biology, Department of

Pharmaceutical Sciences, University of Basel, Basel, Switzerland

\section{Abstract \\ $\nabla$}

The glucosinolate patterns in seeds of five Isatis tinctoria and two Isatis indigotica accessions were assessed with a recently developed and validated LC-MS assay for direct analysis of glucosinolates without prior desulfatation. Glucosinolate peaks were identified with in-source fragmentation and detection of the sulfate anion $(m / z=97)$, and by MS/MS experiments. The glucosinolate patterns of the seeds showed characteristic differences compared to leaves. Glucoisatisin and epiglucoisatisin were diagnostic of seed samples. Qualitative and quantitative differences in glucosinolate patterns between both Isatis species were found for seed samples, enabling a differentiation of the two medicinal plants at the level of seed material.

\section{Key words}

$\nabla$

Isatis tinctoria $\cdot$ Isatis indigotica $\cdot$ Brassicaceae $\cdot$ pressurized liquid extraction $\cdot$ LC-MS $\cdot$ glucosinolates

\section{Abbreviations \\ $\nabla$ \\ BPC: base peak chromatogram \\ COX-2: cyclooxygenase-2 \\ EIC: $\quad$ extracted ion chromatogram \\ 5-LOX: 5-lipoxygenase \\ PLE: $\quad$ pressurized liquid extraction}

Supporting information available online at http://www.thieme-connect.de/ejournals/toc/plantamedica

Isatis tinctoria L. and I. indigotica Fort. (Brassicaceae) are ancient indigo dyes and medicinal plants in Europe and in Traditional Chinese Medicine (TCM), respectively [1]. In recent years, the two species were intensively investigated from a phytochemical and pharmacological viewpoint [2], [3], [4], [5], [6], [7], and in a clinical pilot study [8]. Seasonal variation of the two most abundant classes of secondary metabolites in Isatis leaves, indigo precursors and glucosinolates, and changes in metabolite profiles during post-harvest treatment have been studied [9], [10], [11]. Characteristic differences in glucosinolate pattern were observed in leaves of I. tinctoria and I. indigotica, corroborating the recent separation into two distinct species [12].

Comparatively little is known about the glucosinolates in seeds [13], [14], [15]. We here report on the identification of further indole glucosinolates in seeds of five different I. tinctoria and two I. indigotica accessions. First, analysis of glucosinolates (structures see Fig. 1) was undertaken with a recently developed and validated pressurized liquid extraction (PLE) protocol and ion-pair HPLC coupled with ESI-MS detection in negative ion mode under full scan conditions [16]. In a second HPLC run, peaks corre-

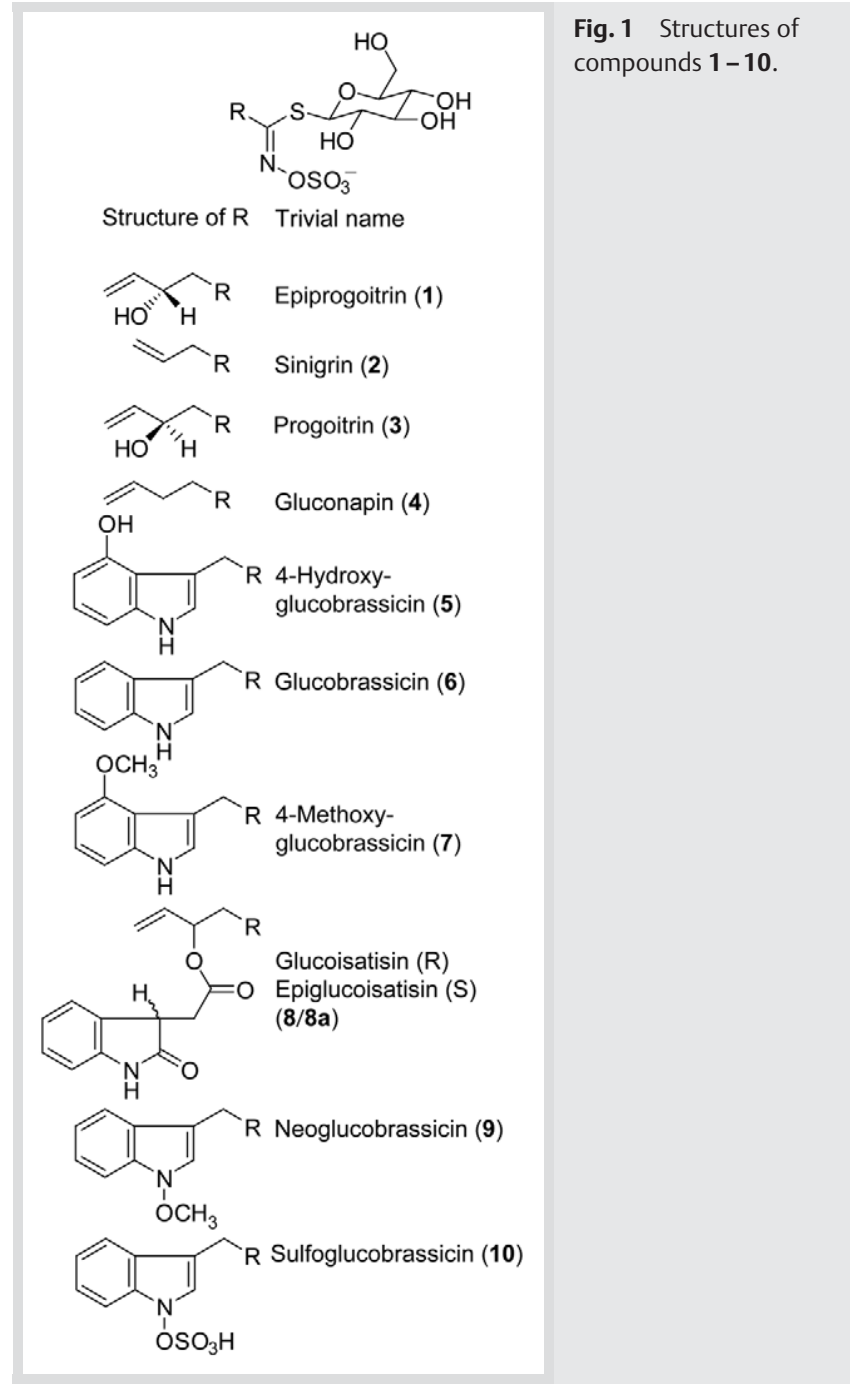

sponding to glucosinolates were earmarked via in-source fragmentation and detection of the fragment ion $m / z=97\left(\left[\mathrm{SO}_{4} \mathrm{H}\right]^{-}\right)$. In addition, MS/MS experiments were carried out to observe the elimination of the sulfate anion. Fig. 2 shows the base peak and extracted ion chromatograms of compounds $1-6,8 / 8 a$ and 9 in I. tinctoria seeds, the ion trace of the $m / z=97$ fragment, and ESI-MS recorded under non-fragmenting conditions. LC-TOF-MS in negative mode was used to determine the accurate molecular mass of compounds (conditions see Mohn et al. [16]). Methods for the identification of glucosinolates by MS/MS [17] and quantification by multiple reaction monitoring (MRM) have been recently described [18], [19], [20]. For a rapid search for glucosinolates, we found in-source fragmentation and detection of the characteristic $m / z=97\left[\mathrm{SO}_{4} \mathrm{H}\right]^{-}$fragment ion to be more sensitive and easy to perform than MS/MS fragmentation. Absolute peak intensities were 10 to 33 times higher for individual glucosinolates caused by in-source fragmentation while MS/MS fragmentation gave equal or lower relative peak intensities for the $m / z=$ $97\left[\mathrm{SO}_{4} \mathrm{H}\right]^{-}$fragment ion ( $\bullet$ Table 1 ). These findings are in agreement with observations of Mellon et al. [18].

Characteristic differences in the glucosinolate patterns between leaves and seeds were found. Sulfoglucobrassicin (10), the major glucosinolate in I. tinctoria leaves, was absent in the seed extracts of either species. Glucoisatisin and epiglucoisatisin (8/8a; calcd. 562.0927; found 562.0930 and 562.0932) were found in 


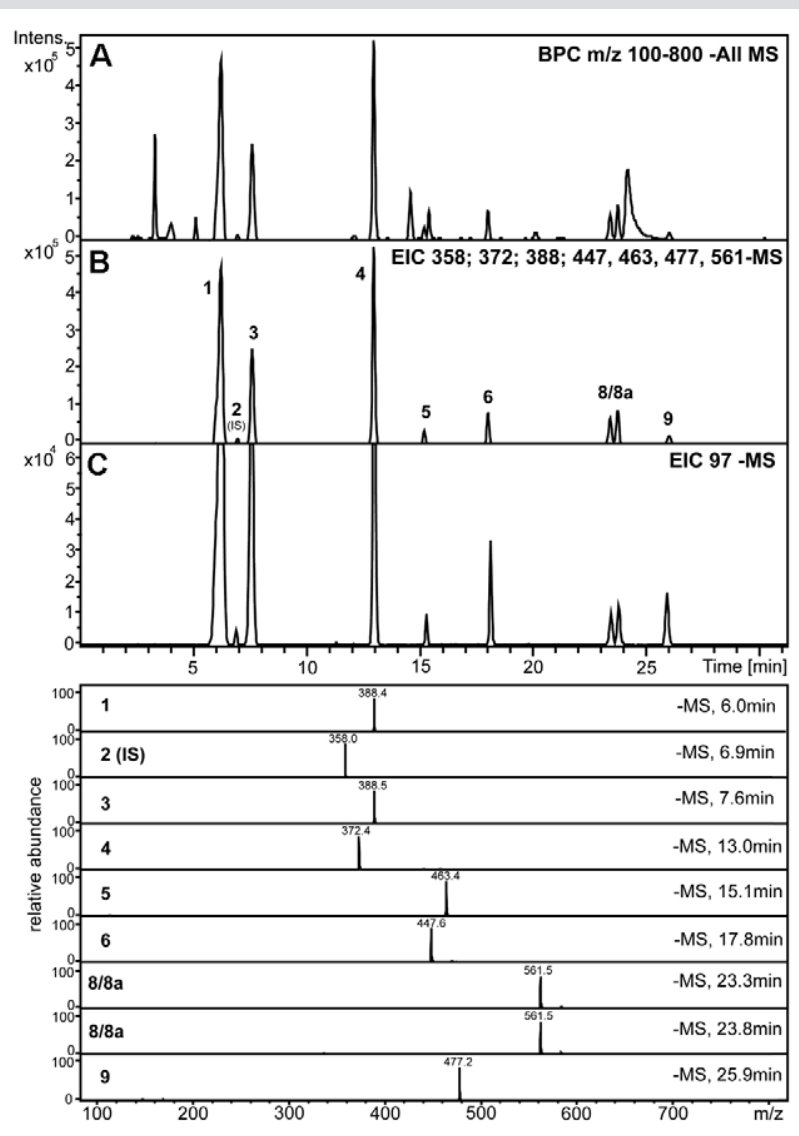

Fig. 2 Glucosinolates in Isatis seed extracts. Base peak chromatogram (BPC; A) and extracted ion chromatogram (EIC; B) of major glucosinolates are shown for Isatis tinctoria accession “Thüringer Waid". Sinigrin (2) was used as internal standard (IS). The trace of ion $97 \mathrm{~m} / \mathrm{z}\left(\left[\mathrm{SO}_{4} \mathrm{H}\right]^{-}\right)$ resulting from in-source fragmentation was used to selectively detect all glucosinolate peaks (C). Mass spectra of compounds $\mathbf{1 - 9}$ recorded under non-fragmenting conditions are shown below (C).

the seeds of both Isatis species. These two compounds have been recently identified as an unseparable epimeric mixture from $I$. tinctoria seeds [14]. The two compounds were not found in leaves of the two species [11] and thus can be considered as markers of seed material. Two other glucosinolates reported by Frechard et al. [14], 3'-hydroxyglucoisatisin and 3'-hydroxyepiglucoisatisin, could not be detected in any of the Isatis seed samples. A further indolic glucosinolate, 4-methoxyglucobrassicin (7; calcd. 478.0716, found: 478.0713), was detected as a trace compound in both I. indigotica seed samples, but was absent from any of the I. tinctoria accessions.

A recent comparison of glucosinolate patterns in leaves revealed significant qualitative and quantitative differences between the two Isatis sp., but comparativey small differences between the $I$. tinctoria accessions [11]. A similar observation could be made in case of the seeds. Comparison of HPLC profiles ( $\bullet$ Fig. 3, and Fig. $1 \mathrm{~S}$ in Supporting Information) showed that glucobrassicin (6) and neoglucobrassicin (9) were only present in I. tinctoria seeds, whereas 4-methoxyglucobrassicin (7) was only found in I. indigotica.

Only one study (Elliott and Stowe [13]) has been carried out to investigate the distribution of glucosinolates in seeds and leaves of I. tinctoria. They found glucobrassicin (6) to be the only glucosinolate in the seeds while glucobrassicin (6), neoglucobrassicin (9) and sulfoglucobrassicin (10) were identified in the leaves in considerable amounts. Our results support these findings, with the exception of neoglucobrassicin (9) which was present in all strains of Isatis tinctoria seeds. However, Elliott and Stowe did not analyze other indolic glucosinolates in their study and did not investigate differences between the Isatis species. The content of total glucosinolates in seeds of both species was lower than in the corresponding leaf samples ( $\bullet$ Table 2, and Table 1S in Supporting Information). Isatis tincoria seeds contained mainly aliphatic glucosinolates, whereas indolic glucosinolates were

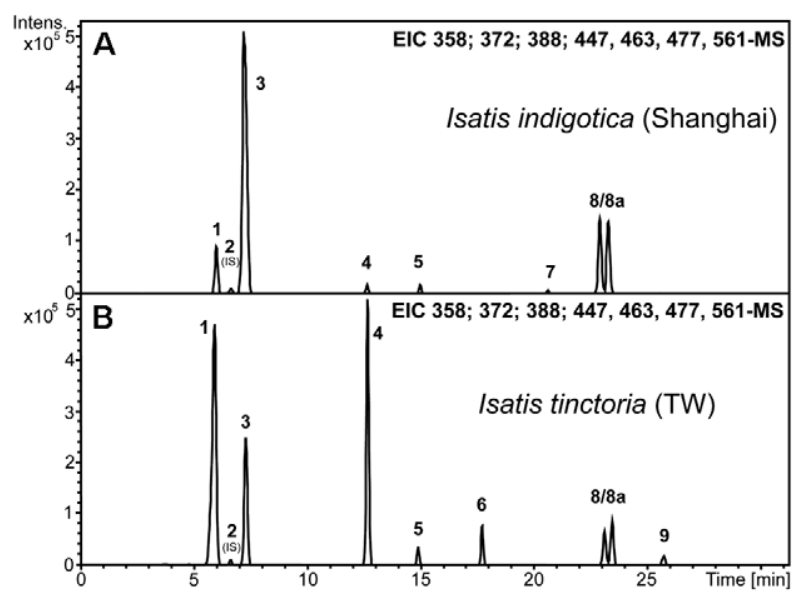

Fig. 3 Comparison of glucosinolates in Isatis seed extracts. Extracted ion chromatograms (EIC) of glucosinolates in Isatis indigotica (Shanghai) and of the Isatis tinctoria accession "Thüringer Waid" (TW). Sinigrin (2) was used as internal standard (IS).

Table 1 Comparison of fragmentation conditions. In-source fragmentation gave equal or higher relative signal intensities compared to fragmentation by MS/ MS, and the absolute signal intensity was clearly higher for the sulfate fragment $m / z=97$ via in-source fragmentation

\begin{tabular}{|c|c|c|c|}
\hline \multirow[t]{2}{*}{ Compound } & \multicolumn{2}{|c|}{ Relative signal intensity of the $\mathrm{m} / \mathrm{z}=97\left[\mathrm{SO}_{4} \mathrm{H}\right]$-fragment ion } & \multirow[t]{2}{*}{$\begin{array}{l}\text { Absolute signal intensity ratio in-source } \\
\text { vs. MS/MS fragmentation }\end{array}$} \\
\hline & In-source fragmentation & Fragmentation by MS/MS & \\
\hline Epiprogoitrin (1) & $100 \%$ & $100 \%$ & $16: 1$ \\
\hline Progoitrin (3) & $100 \%$ & $100 \%$ & $12: 1$ \\
\hline Gluconapin (4) & $100 \%$ & $100 \%$ & $33: 1$ \\
\hline 4-Hydroxyglucobrassicin (5) & $51 \%$ & $24 \%$ & $10: 1$ \\
\hline Glucobrassicin (6) & $79 \%$ & $62 \%$ & $16: 1$ \\
\hline Glucoisatisin/Epiglucoisatisin (8/8a) & $100 \%$ & $16 \%$ & $20: 1$ \\
\hline Neoglucobrassicin (9) & $100 \%$ & $15 \%$ & $10: 1$ \\
\hline
\end{tabular}


Table 2 Differences of the glucosinolate content between Isatis tinctoria and Isatis indigotica seeds

\begin{tabular}{|c|c|c|}
\hline Glucosinolate & $\begin{array}{l}\text { Isatis tinctoria ("Thüringer Waid") amount" in mg/ } \\
100 \mathrm{~g} \mathrm{dw}\end{array}$ & Isatis indigotica (Shanghai) amount ${ }^{\mathrm{b}}$ in $\mathrm{mg} / 100 \mathrm{~g} \mathrm{dw}$ \\
\hline Epiprogoitrin (1) & 130 & 50 \\
\hline Progoitrin (3) & 90 & 140 \\
\hline Gluconapin (4) & 55 & 10 \\
\hline Sulfoglucobrassicin (10) & n.d. & n.d. \\
\hline 4-Hydroxyglucobrassicin (5) & 15 & 10 \\
\hline Glucobrassicin (6) & 45 & n.d. \\
\hline 4-Methoxyglucobrassicin (7) & n.d. & traces \\
\hline Glucoisatisin $(\mathbf{8} / 8 \mathbf{a})^{\mathrm{a}}$ & 90 & 120 \\
\hline Neoglucobrassicin (9) & 10 & n.d. \\
\hline
\end{tabular}

dominant in the leaves [11]. In summary, our findings show organ-specific differences in glucosinolates. In combination with our previously reported results [11] these findings support the molecular taxonomy [12] showing that Isatis tinctoria and Isatis indigotica should be considered as separate species. From a practical viewpoint, seed material of Isatis species can be easily differentiated on the basis of characteristic glucosinolate pattern.

\section{Materials and Methods}

$\nabla$

Seeds of defined strains of Isatis tinctoria ("Thüringer Waid", "Jenaer Waid", "Kieler Waid", "French Woad" and "Swiss Woad") were obtained from the Agricultural Research Station of Thuringia (TLL), Dornburg, Germany. Isatis indigotica seeds were purchased from Sand Mountain Herbs ("Isatis indigotica USA") and from the Shanghai Institute of Materia Medica, Shanghai, China ("Isatis indigotica Shanghai"). Voucher specimens are kept at the Institute of Pharmaceutical Biology, University of Basel under accession numbers 153 PG 1 (Thüringer Waid), 153 PG 4 (Swiss woad), 153 PG 5 (French woad), 153 PG 9 (Kieler Waid), 153 PG 10 (Jenaer Waid), 153 PG 20 (Isatis indigotica USA) and 163 PG 21 (Isatis indigotica Shanghai).

Glucosinolate analysis was carried out according to a published protocol [16] with small modifications in the HPLC gradient. The mobile phase consisted of an aqueous solution of $10 \mathrm{mM}$ ammonium formate (adjusted to $\mathrm{pH} 6.4$ with formic acid; eluent A) and acetonitrile (eluent B). The gradient of B was as follows: from $1 \%$ to $3 \%$ in $7 \mathrm{~min}, 3 \%$ to $15 \%$ ( $5 \mathrm{~min}$ ), $15 \%$ to $17 \%$ ( $3 \mathrm{~min}$ ), held at $17 \%$ for $2 \mathrm{~min}, 17 \%$ to $19 \%$ ( $4 \mathrm{~min}$ ), held at $19 \%$ for $3 \mathrm{~min}$, $19 \%$ to $24 \%$ ( $6 \mathrm{~min})$. Flow rate was $1.0 \mathrm{~mL} / \mathrm{min}$. A split ratio of $1: 4$ was used with the ESI interface. Separations were carried out on an Aqua C18 125 A column $(5 \mu \mathrm{m}, 250 \times 4.5$ mm I.D.; Phenomenex $)$ equipped with a guard column $(4.0 \times 3.0 \mathrm{~mm}$ I.D. $)$ at $20.0^{\circ} \mathrm{C}$. The sample injection volume was $20 \mu \mathrm{L}$. LC-TOF-MS in negative mode was used to confirm the molecular formula of glucosinolates (see [16]).

For the detection of the fragment ion $\mathrm{m} / \mathrm{z}=97\left(\left[\mathrm{SO}_{4} \mathrm{H}\right]^{-}\right)$mass spectrometric conditions of the Esquire 3000 plus ion trap MS were optimized as follows: ion charge control: (ICC 30000), scan speed: $13000 \mathrm{~m} / \mathrm{z} / \mathrm{s}$, gauss filter width: $0.2 \mathrm{~m} / \mathrm{z}$, nitrogen as drying gas (10 L/min) and nebulizing gas (30 psi), nebulizer temperature: $300^{\circ} \mathrm{C}$, capillary voltage: $4107 \mathrm{~V}$, endplate offset: -500 $\mathrm{V}$, skimmer voltage: $-87.5 \mathrm{~V}$ and trap drive: 28.4 . Spectra were recorded in the range of 70 to $650 \mathrm{~m} / \mathrm{z}$.

$\mathrm{MS}^{\mathrm{n}}$ experiments were performed on the glucosinolate $[\mathrm{M}-\mathrm{H}]^{-}$ ions using helium as collision gas. The isolation width was set to $4.0 \mathrm{~m} / \mathrm{z}$ and the fragmentation amplitude was set to $1.00 \mathrm{~V}$ in the 'smart fragmentation' mode. ESI source voltages were as follows: capillary voltage at $4500 \mathrm{~V}$, endplate offset at $-500 \mathrm{~V}$, capillary exit offset at $-115 \mathrm{~V}$, skimmer voltage at $-40.0 \mathrm{~V}$ and trap drive at 53.4. The scan range for mass spectra was $80 \mathrm{~m} / \mathrm{z}$ to 800 $m / z$.

\section{Supporting information}

EIC spectra of glucosinolates from Isatis seeds and concentration of glucosinolates in Isatis seeds in comparison to published data of Isatis leaf material and seeds are available as Supporting Information.

\section{Acknowledgements \\ $\nabla$}

We thank Dr. A. Vetter and A. Biertümpfel, Thüringische Landesanstalt für Landwirtschaft (TLL), Jena and Dornburg and Prof. Y. Ye, Shanghai Institute of Materia Medica, Shanghai, China for the provision of woad samples.

\section{References}

1 Hamburger M. Isatis tinctoria - from the rediscovery of an ancient medicinal plant towards a novel anti-inflammatory phytopharmaceutical. Phytochem Rev 2002; 1: $333-44$

2 Danz H, Stoyanova S, Wippich P, Brattström A, Hamburger M. Identification and isolation of the cyclooxygenase-2 inhibitory principle in Isatis tinctoria. Planta Med 2001; 67: 411-6

3 Danz H, Stoyanova S, Thomet OAR, Simon H-U, Dannhardt G, Ulbrich H et al. Inhibitory activity of tryptanthrin on prostaglandin and leukotriene synthesis. Planta Med 2002; 68: 875-80

4 Ishihara T, Kohno K, Ushio S, Iwaki K, Ikeda M, Kurimoto M. Tryptanthrin inhibits nitric oxide and prostaglandin E2 synthesis by murine macrophages. Eur J Pharmacol 2000; 407: 97-204

5 Recio MC, Cerda-Nicolas M, Potterat O, Hamburger M, Rios J-L. Anti-inflammatory and antiallergic activity in vivo of lipophilic Isatis tinctoria extracts and tryptanthrin. Planta Med 2006; 72: 539-46

6 Recio MC, Cerda-Nicolas M, Hamburger M, Rios J-L. Anti-arthritic activity of a lipophilic woad (Isatis tinctoria) extract. Planta Med 2006; 72: $715-20$

7 Oberthür C, Schneider B, Graf H, Hamburger M. The elusive indigo precursors in woad (Isatis tinctoria L.) - Identification of the major indigo precursor, isatan $\mathrm{A}$, and a structure revision of isatan $\mathrm{B}$. Chem Biodiv 2004; $1: 174-82$

8 Heinemann C, Schliemann-Willers S, Oberthür C, Hamburger M, Elsner $P$. Prevention of experimentally induced irritant contact dermatitis by extracts of Isatis tinctoria compared to pure tryptanthrin and its impact on UVB-induced erythema. Planta Med 2004; 70: 385-90

9 Oberthür C, Graf H, Hamburger M. The content of indigo precursors in Isatis tinctoria leaves - a comparative study of selected accessions and post-harvest treatments. Phytochemistry 2004; 65: 3261 -8 
10 Oberthür C, Hamburger M. Tryptanthrin content in Isatis tinctoria leaves - a comparative study of selected strains and post-harvest treatments. Planta Med 2004; 70: $642-5$

11 Mohn T, Suter K, Hamburger M. Seasonal changes and effect of harvest on glucosinoates in Isatis leaves. Planta Med 2008; 74: $582-7$

12 Gilbert KG, Garton S, Karam MA, Arnold GM, Karp A, Edwards KJ et al. A high degree of genetic diversity is revealed in Isatis spp. (dyer's woad) by amplified fragment length polymorphism (AFLP). Theor Appl Genet $2002 ; 104: 1150-6$

13 Elliott MC, Stowe BB. Distribution and variation of indole glucosinolates in woad (Isatis tinctoria). Plant Physiol 1971; 48: 498-503

14 Frechard A, Fabre N, Péan C, Montaut S, Fauvel M-T, Rollin P et al. Novel indole-type glucosinolates from woad (Isatis tinctoria L.). Tetrahedron Lett 2001; 42: 9015-7

15 Lockwood GB, Belkhiri A. Glucosinolate spectrum of some Algerian Cruciferae. Plant Syst Evol 1991; 176: 11 - 20

16 Mohn T, Cutting B, Ernst B, Hamburger M. Extraction and analysis of intact glucosinolates - a validated pressurized liquid extraction/liquid chromatography-mass spectrometry protocol for Isatis tinctoria, and qualitative analysis of other cruciferous plants. J Chromatogr A 2007; 1166: $142-51$

17 Fabre N, Poinsot V, Debrauwer L, Vigor C, Tulliez J, Fouraste I et al. Characterisation of glucosinolates using electrospray ion trap and electrospray quadrupole time-of-flight mass spectrometry. Phytochem Anal 2007; 18: 306-19

18 Mellon FA, Bennett RN, Holst B, Williamson G. Intact glucosinolate analysis in plant extracts by programmed cone voltage electrospray $\mathrm{LC} /$ MS: performance and comparison with LC/MS/MS methods. Anal Biochem 2002; 306: 83-91

19 Song L, Morrison JJ, Botting NP, Thornalley PJ. Analysis of glucosinolates, isothiocyanates, and amine degradation products in vegetable extracts and blood plasma by LC-MS/MS. Anal Biochem 2005; 347: $234-43$

20 Tian Q Rosselot RA, Schwartz SJ. Quantitative determination of intact glucosinolates in broccoli, broccoli sprouts, Brussels sprouts, and cauliflower by high-performance liquid chromatography-electrspray ionization-tandem mass spectrometry. Anal Biochem 2005; 343: 93 -9

received March 21, 2008

revised April 17, 2008

accepted April 20, 2008

Bibliography

DOI $10.1055 / \mathrm{s}-2008-1074554$

Planta Med 2008; 74: 885-888

(c) Georg Thieme Verlag KG Stuttgart · New York

Published online June 6, 2008

ISSN 0032-0943

\section{Correspondence}

\section{Prof. Dr. Matthias Hamburger}

Institute of Pharmaceutical Biology

Department of Pharmaceutical Sciences

University of Basel

Klingelbergstrasse 50

4056 Basel

Switzerland

Phone: $+41 / 61 / 267 / 1425$

Fax: $+41 / 61 / 267 / 1474$

matthias.hamburger@unibas.ch 


\section{Supporting Information}

\section{Glucosinolate pattern in Isatis tinctoria and I. indigotica}

\section{seeds}

Tobias Mohn and Matthias Hamburger*

Institute of Pharmaceutical Biology, Department of Pharmaceutical Sciences, University of Basel, Klingelbergstrasse 50, CH-4056 Basel, Switzerland.

*To whom correspondence should be addressed: Prof. Dr. Matthias Hamburger, Institute of Pharmaceutical Biology, Department of Pharmaceutical Sciences, University of Basel,

Klingelbergstrasse 50, CH-4056 Basel, Switzerland.

Fax: $+41-612671474$

Email: matthias.hamburger@unibas.ch

Tel.: +41-612671425 


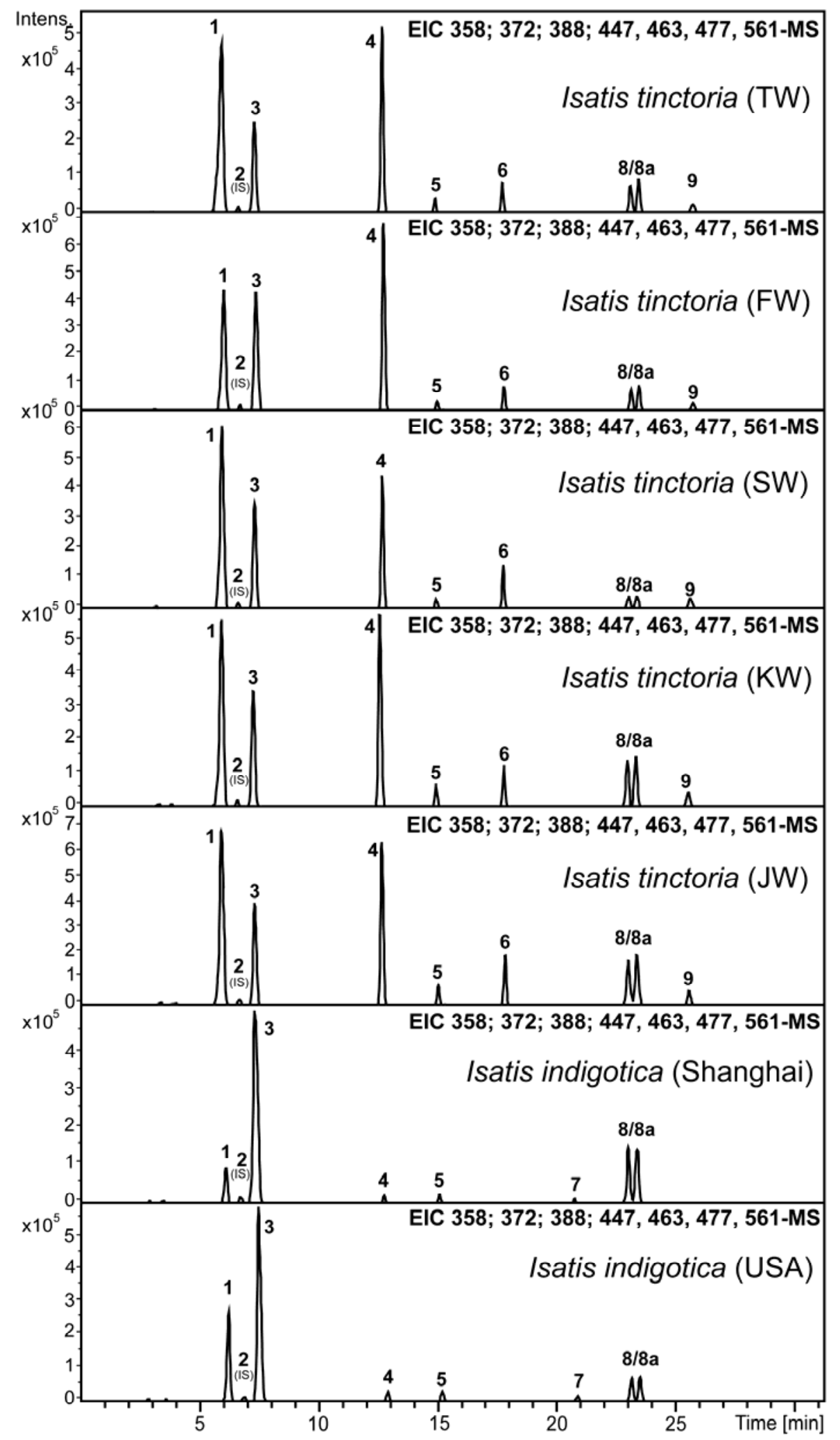

Figure 1. Glucosinolates in Isatis seeds. Extracted ion chromatograms (EIC) of identified glucosinolates of the Isatis tinctoria accessions "Thüringer Waid" (TW), "French Woad" (FW), "Swiss Woad" (SW), "Kieler Waid" (KW), "Jenaer Waid" (JW) and of "Isatis indigotica "Shanghai" and "Isatis indigotica USA" are shown. Sinigrin (2) was used as internal standard (IS). 
Table 1. Concentration of glucosinolates in Isatis seeds in comparison to published data of Isatis leaf material and seeds

\section{Leaves}

Data from Mohn et al. [16] (amount of glucosinolates calculated in $\mathrm{mg} / 100 \mathrm{~g}$ dry weight) Isatis tinctoria ("Thüringer Waid")

\begin{tabular}{|l|cc|}
\hline \multicolumn{2}{|c|}{ amount in } \\
glucosinolate & \multicolumn{2}{|c|}{$\mathrm{mg} / 100^{\text {g dw }}$} \\
min $^{\mathrm{a}}$ & max $^{\mathrm{a}}$ \\
\hline Epiprogoitrin (1) & 0.574 & 21.8 \\
Progoitrin (3) & 0.374 & 28.3 \\
& & \\
Gluconapin (4) & n.d. & 0.5 \\
Sulfoglucobrassicin (10) & 553.9 & 4482.6 \\
4-Hydroxyglucobrassicin (5) & n.d. & n.d. \\
Glucobrassicin (6) & 157.3 & 401.7 \\
4-Methoxyglucobrassicin (7) & n.d. & n.d. \\
Glucoisatisin (8/8a) & n.d. & n.d. \\
Neoglucobrassicin (9) & n.d. & 2.7 \\
\hline
\end{tabular}

Isatis indigotica
\begin{tabular}{|l|cc|}
\hline \multicolumn{2}{|c|}{ amount in } \\
glucosinolate & \multicolumn{2}{|c|}{$\begin{array}{cc}\mathrm{mg}^{\mathrm{a}} / 100 \mathrm{~g} \mathrm{dw} \\
\text { max }^{\mathrm{a}}\end{array}$} \\
\hline Epiprogoitrin (1) & 11.9 & 45.3 \\
Progoitrin (3) & 194.5 & 546.6 \\
& & \\
Gluconapin (4) & 0.3 & 16.7 \\
Sulfoglucobrassicin (10) & n.d. & n.d. \\
4-Hydroxyglucobrassicin (5) & 213.8 & 1762.7 \\
Glucobrassicin (6) & n.d. & n.d. \\
4-Methoxyglucobrassicin (7) & n.d. & n.d. \\
Glucoisatisin (8/8a) & n.d. & n.d. \\
Neoglucobrassicin (9) & n.d. & n.d. \\
\hline
\end{tabular}

\section{Data from Elliott and Stowe [13]} Isatis tinctoria

\begin{tabular}{|l|cc|}
\hline & \multicolumn{2}{|c|}{$\begin{array}{l}\text { amount in mg /100 g dw } \\
\text { Light } \\
\text { grown }\end{array} \quad$ Etiolated } \\
glucosinolate & 50.2 & 11 \\
shoots & shoots \\
\hline Sulfoglucobrassicin (10) & n.d. & n.d. \\
4-Hydroxyglucobrassicin (5) & 175.6 & 160 \\
Glucobrassicin (6) & 3.4 & 132 \\
Neoglucobrassicin (9) & \multicolumn{2}{|}{} \\
\hline
\end{tabular}

\section{Seeds}

\section{Isatis tinctoria ("Thüringer Waid")}

\begin{tabular}{|l|c|}
\hline & $\begin{array}{c}\text { amount }^{\text {b }} \\
\text { in }^{\text {mg / }} \\
100 \mathrm{~g} \\
\mathrm{dw}\end{array}$ \\
glucosinolate & 130 \\
Epiprogoitrin (1) & 90 \\
Progoitrin (3) & 55 \\
Gluconapin (4) & $\mathrm{n} . \mathrm{d}$. \\
Sulfoglucobrassicin (10) & 15 \\
4-Hydroxyglucobrassicin (5) & 45 \\
Glucobrassicin (6) & $\mathrm{n} . \mathrm{d}$. \\
4-Methoxyglucobrassicin (7) & 90 \\
Glucoisatisin (8/8a) & \\
(both isomers together) & 10 \\
Neoglucobrassicin (9) & \\
\hline
\end{tabular}

n.d. $=$ not detected

${ }^{a}$ amount glucosinolates depending on seasonal variation

${ }^{\mathrm{b}}$ values estimated

\begin{tabular}{|l|c|} 
Isatis indigotica (Shanghai) \\
\begin{tabular}{|l|c|}
\hline \multicolumn{2}{|c|}{$\begin{array}{c}\text { amount } \\
\text { in } \mathbf{~ m g ~ / ~} \\
100 \mathrm{~g} \\
\mathrm{dw}\end{array}$} \\
glucosinolate & 50 \\
Epiprogoitrin (1) & 140 \\
Progoitrin (3) & 10 \\
Gluconapin (4) & n.d. \\
Sulfoglucobrassicin (10) & 10 \\
4-Hydroxyglucobrassicin (5) & n.d. \\
Glucobrassicin (6) & traces \\
4-Methoxyglucobrassicin (7) & 120 \\
Glucoisatisin (8/8a) & \\
(both isomers together) & n.d. \\
Neoglucobrassicin (9)
\end{tabular}
\end{tabular}

Data from Elliott and Stowe [13] Isatis tinctoria

\begin{tabular}{|l|c|}
\hline glucosinolate & $\begin{array}{c}\text { amount in } \\
\mathrm{mg} / 100 \mathrm{~g} \\
\mathrm{dw}\end{array}$ \\
\hline Sulfoglucobrassicin (10) & n.d. \\
4-Hydroxyglucobrassicin (5) & n.d. \\
Glucobrassicin (6) & 230 \\
Neoglucobrassicin (9) & n.d. \\
\hline
\end{tabular}


4. CONCLUSION AND OUTLOOK 
The future aim is to establish a new phytomedicinal product based on a lipophilic woad extract as a "New Herbal Entity" (NHE = herbal remedy without traditional use). As for the vast majority of phytomedicines, the known active compounds in woad amount only to a small proportion of the total extract, while the composition of the extract matrix remains unclear. A systematic investigation of the metabolite profile of Isatis tinctoria leaf extracts was therefore carried out using a combination of HPLC-based MS and NMR profiling techniques. Approximately $90 \%$ of the pharmacologically active dichloromethane extract could be assigned to particular compounds or compound classes (by taking the relative peak areas of the ELSD profile as a measure). This is comparable or better than the state of knowledge for well-characterised special extracts, such as EGb 761 from Gingko biloba L. and ZE 331 from Petasites hybridus L. which are active ingredients in well-known phytopharmaceuticals. The applied analytical methods enable a profiling of Isatis extracts in a holistic manner and will provide a means of standardisation and quality control of Isatis based on its entire composition. To our knowledge, this was the first time in natural product analysis that such a broad range of detectors/detection modes were used in parallel. It enabled the detection of a structurally highly diverse spectrum of metabolites. Our approach is of general interest for any profiling/metabolomics study.

The sourcing of homogenous raw material represents another challenge in the development of a new phytomedicine. Our investigations on five different $I$. tinctoria strains revealed some differences in the secondary metabolite patterns due to a relative high degree of genetic diversity. With the used profiling strategies, it will be possible to select the best suitable Isatis variety and to standardise the plant cultivation process in order to develop an active herbal preparation that can be produced in an industrial scale.

It is still unclear which precursor molecules are involved in the formation of tryptanthrin during harvest and post-harvest treatment. Clear evidences for a contribution of indole 
glucosinolates are still missing so far. Isotope labelling of the indole unit of putative precursors, and the subsequent identification of the labelled indole units in tryptanthrin by NMR would provide direct evidence. However, this approach would be costly and time-consuming. Continuing experiments for the search of other possible candidates as precursor molecules should also be carried out. Whether previously identified precursors of indigo like isatan $A$ and $B$ are involved in the formation of tryptanthrin and other indole alkaloids in woad should be investigated. Knowledge on the formation of tryptanthrin would facilitate the optimisation of cultivation and post-harvest conditions.

Besides the cultivation aspects, more investigations are needed to develop a woad based phytomedicine. The mode of action of the active principles is known only in part. Previous studies showed that tryptanthrin inhibits cycloxygenase-2 (COX-2) and lipoxygenase-5 (5-LOX) but the binding sites are still unknown. Studies analysing the interaction between the involved enzymes and tryptanthrin (e.g. analysed by SPR) would be suitable to reveal the binding sites. Further experiments are also needed to understand the mode of action of (E)-3-(3',5'-dimethoxy-4'-hydroxy-benzylidene)-2indolinone on a molecular level.

Moreover, pharmacological synergies, through compounds acting on different targets involved in inflammation, seem to occur in woad. However, experimental evidence is lacking and needs to be provided for Isatis. Such findings would be of interest for phytomedicines in general.

Finally, the bioavailability of active substances in a standardised woad extract has to be investigated, and toxicological studies in animals need to be carried out before legal authorities would allow first clinical efficacy studies. 


\section{CURRICULUM VITAE}

Name

Date and place of birth

Civil status

Nationality
Tobias Mohn

October $9^{\text {th }} 1979$; IImenau, Germany

single

German

\section{Education}

$04.2005-02.2009$

PhD studies in the group of Prof. Dr. M. Hamburger at the Institute of Pharmaceutical Biology, University of Basel, Switzerland; Research project: 'A comprehensive metabolite profiling of Isatis tinctoria leaf extracts'

11. 2004

Degree as a pharmacist 'Approbation als Apotheker'

$10.1999-10.2003$

Studies in pharmacy, University of Jena, Germany

$10.1992-10.1998$

Grammar school, Bad Blankenburg, Germany

$10.1990-10.1992$

Secondary school, Königsee, Germany

$09.1986-09.1990$

Primary school, Königsee, Germany

\section{Work Experiences}

10. $2004-03.2005$

Employment as a local pharmacist, Markt-Apotheke Rudolstadt, Germany

$05.2004-10.2004$

Preregistration training in a local pharmacy, Markt-Apotheke Rudolstadt, Germany

$11.2003-04.2004$

Preregistration training in a pharmaceutical company, Merck KGaA, Darmstadt, Germany Department of Pharmaceutical Analysis / Quality Control working area: HPLC method development and validation in GMP environment 


\section{Publications, Short lectures and Awards}

\section{Publications:}

1. Basalo C, Mohn T, Hamburger M. Are extraction methods on quantitative assays of pharmacopoiea monographs exhaustive? A comparison with pressurized liquid extraction. Planta Med 2006; 72:1157-62.

2. Mohn T, Potterat O, Hamburger M. Quantification of active principles and pigments in leaf extracts of Isatis tinctoria by HPLC/UV/MS. Planta Med 2007; 73:151-6.

3. Mohn T, Cutting B, Ernst B, Hamburger M. Extraction and analysis of intact glucosinolates - A validated pressurized liquid extraction/liquid chromatography - mass spectrometry protocol for Isatis tinctoria, and qualitative analysis of other cruciferous plants. J Chromatogr A 2007; 1166:142-51.

4. Mohn T, Suter K, Hamburger M. Seasonal Changes and effect of harvest on glucosinolates in Isatis leaves. Planta Med 2008; 74:582-7.

5. Mohn T, Hamburger M. Glucosinolate pattern in Isatis tinctoria and I. indigotica seeds. Planta Med 2008; 74:885-8.

6. Plitzko I, Mohn T, Sedlacek N, Hamburger M. Composition of Indigo naturalis. Planta Med 2009, accepted for publication.

7. Mohn T, Plitzko I, Hamburger M. A comprehensive metabolite profiling of Isatis tinctoria leaf extracts. Phytochemistry, submitted for publication.

\section{Short lectures:}

- Mohn T, Rüster U, Hamburger M. Extraction and analysis of non-derivatized glucosinolates in plant extracts - a validated PLE/LC-MS protocol. 55th International congress and annual meeting of the Society of Medicinal Plant Research, Graz, Austria, September 2-6, 2007.

- Mohn T, Plitzko I, Hamburger M. A comprehensive metabolite profiling of Isatis tinctoria leaf extracts. International Conference on LC-NMR and related techniques: Challenges in biological systems. Jena, Germany, August 27 - 29, 2008.

\section{Awards:}

09.2007: Winner of the 'young researcher award' of the International Society of Medicinal Plant Research. 